Feasibility Study of Supercritical Light Water Cooled Reactors for Electric Power Production

Progress Report for Work Through September 2003 $2^{\text {nd }}$ Annual Report and $8^{\text {th }}$ Quarterly Report

Philip MacDonald

Dr. Jacopo Buongiorno

Cliff Davis

Dr. Robert Witt

September 2003

Idaho National Engineering and Environmental Laboratory Bechtel BWXT Idaho, LLC 


\title{
Feasibility Study of Supercritical Light Water Cooled Reactors for Electric Power Production
}

\author{
Nuclear Energy Research Initiative Project 2001-001 \\ Westinghouse Electric Co. Award Number: DE-FG07-02SF22533 \\ Progress Report for Work Through September 2003 \\ $2^{\text {nd }}$ Annual Report and 8th Quarterly Report
}

Principal Investigators: Philip MacDonald, Dr. Jacopo Buongiorno, Cliff Davis, and Dr. Robert Witt

Telephone: 208-526-9634

Fax: 208-526-2930

Email: pem@inel.gov

Collaborating Organizations:

Massachusetts Institute of Technology

Principal Investigators: Prof. Ron Latanision and Dr. Bryce Mitton

University of Michigan

Principal Investigator: Prof. Gary Was, J. McKinley, and S. Teysseyre

Westinghouse Electric Company

Principal Investigators: Dr. Luca Oriani, Dr. Vefa Kucukboyaci, Hans Garkish, Lawrence Conway, and John Kielb 


\section{Executive Summary}

The supercritical water-cooled reactor (SCWR) is one of the six reactor technologies selected for research and development under the Generation-IV program. SCWRs are promising advanced nuclear systems because of their high thermal efficiency (i.e., about $45 \%$ vs. about $33 \%$ efficiency for current Light Water Reactors, LWRs) and considerable plant simplification. SCWRs are basically LWRs operating at higher pressure and temperatures with a direct once-through cycle. Operation above the critical pressure eliminates coolant boiling, so the coolant remains single-phase throughout the system. Thus the need for recirculation and jet pumps, a pressurizer, steam generators, steam separators and dryers is eliminated. The main mission of the SCWR is generation of low-cost electricity. It is built upon two proven technologies, LWRs, which are the most commonly deployed power generating reactors in the world, and supercritical fossil-fired boilers, a large number of which is also in use around the world.

The reference SCWR design for the U.S. program is a direct cycle system operating at $25.0 \mathrm{MPa}$ with core inlet and outlet temperatures of 280 and $500{ }^{\circ} \mathrm{C}$, respectively. The coolant density decreases from about $760 \mathrm{~kg} / \mathrm{m}^{3}$ at the core inlet to about $90 \mathrm{~kg} / \mathrm{m}^{3}$ at the core outlet. The inlet flow splits with about $10 \%$ of the inlet flow going down the space between the core barrel and the reactor pressure vessel (the downcomer) and about $90 \%$ of the inlet flow going to the plenum at the top of the rector pressure vessel to then flow downward through the core in special water rods to the inlet plenum. Here it mixes with the feedwater from the downcomer and flows upward to remove the heat in the fuel channels. This strategy is employed to provide good moderation at the top of the core. The coolant is heated to about $500{ }^{\circ} \mathrm{C}$ and delivered to the turbine.

The purpose of this NERI project is to assess the reference U.S. SCWR design and explore alternatives to determine feasibility. The project is organized into three tasks.

- $\quad$ Task 1. Fuel-cycle Neutronic Analysis and Reactor Core Design.

- Task 2. Fuel Cladding and Structural Material Corrosion and Stress Corrosion Cracking.

- Task 3. Plant Engineering and Reactor Safety Analysis.

\section{Task 1. Fuel-cycle Neutronic Analysis and Reactor Core Design.}

An alternative SCWR design based on vertical power channels and small hexagonal fuel assemblies was assessed. Sufficient neutron moderation is provided by the feedwater flowing downward in the gap between the channels. The control rods are inserted through the lower head of the reactor pressure vessel. Compared with other approaches like water rods, solid moderators or heavy-water, this design has a higher power density and affords some advantages in the area of fuel assembly design and ease of refueling. Based on a simplified thermal-hydraulic and neutronic analysis, it appears that this approach is technically feasible to the extent that issues common to all SCWR designs (e.g., development of in-core materials, demonstration of safety and stability) can be resolved. The estimated fuel-cycle cost is comparable with that of the PWR; the temperature and power distributions are acceptable; the Doppler and coolant reactivity feedbacks are both negative and within LWR range.

Steady-state analyses were performed with the RELAP5/3D computer code for SCWR designs with water rods and hexagonal power channels. The steady-state analyses showed that buoyancy significantly affected the heat transfer rate from the fuel assemblies to the moderator. For example, buoyancy increased the average heat transfer coefficient on the inside of the water rods by a factor of 2.2 in the original design that directed $30 \%$ of the total feedwater flow to the water rods. Consequently, the current design directs $90 \%$ of the total feedwater flow towards the water rods to suppress the heat transfer 
enhancement due to buoyancy. Even with the current design, buoyancy increased the average heat transfer coefficient by more than $20 \%$ and thus must be accounted for.

The steady-state analysis showed that both designs had sufficient moderation to achieve acceptable fuel cycle costs. The steady-state analyses also showed that somewhat lower cladding temperatures could be obtained during normal operation with the power channel design. These lower cladding temperatures were a result of a higher mass flux through the assembly, which increased the heat transfer coefficient, and the zirconium-oxide insulation, which reduced the fluid temperature in the assembly. The analysis also indicates that, although insulation is not necessary for the design with water rod boxes to achieve acceptable fuel cycle costs, insulation is necessary to meet the steady-state thermal limit.

\section{Task 2. Fuel Cladding and Structural Material Corrosion and Stress Corrosion Cracking.}

The work conducted in Year 2 of the project at the University of Michigan provides information on the deformation and stress corrosion cracking behavior of $304 \mathrm{~L}$ and $316 \mathrm{~L}$ stainless steels in flowing argon at $500{ }^{\circ} \mathrm{C}$, and in deaerated supercritical water at $500{ }^{\circ} \mathrm{C}$. Data on nickel-based Alloy 625 in $500{ }^{\circ} \mathrm{C}$ deaerated supercritical water and information on oxide layer growth on all the alloys in both argon and water are also provided. The stress corrosion cracking results of last year's experiment on 304L in nondeaerated supercritical water are compared with the 304L sample tested in deaerated SCW.

The Massachusetts Institute of Technology (MIT) conducted two corrosion tube experiments during Year 2 , one with 316L stainless steel and one with Alloy 625. During these experiments, a tube of the alloy to be tested is used as the autoclave, and micro-thermocouples are attached externally along the length of the vessel. Water at an elevated temperature and pressure is pumped into one end and permitted to cool as it traverses the tube. The highest temperature achieved was in excess of $395^{\circ} \mathrm{C}$.

The results from the Year 2 testing at Michigan and MIT show that:

- The stainless steel alloys 304L and 316L are susceptible to intergranular stress corrosion cracking in $500{ }^{\circ} \mathrm{C}$ deaerated water. The Alloy $304 \mathrm{~L}$ sample exhibited a higher crack density than did the $316 \mathrm{~L}$ sample. Alloy 304L stress corrosion cracking is more severe in non-deaerated water than in deaerated water.

- The oxide growth on the 304L and 316L samples tested in deaerated supercritical water were similar in composition. The oxide on the 316L sample was slightly thinner than the oxide on the 304L sample. The oxide thickness on the 304L sample tested in non-deaerated water was significantly greater than the oxide thickness of the 304L sample tested in deaerated water.

- The nickel-based Alloy 625 is susceptible to stress corrosion cracking in deaerated supercritical water. Its yield stress and maximum stress is higher than those for the stainless steel alloys, but the intergranular cracking is more extensive.

- Unstressed Alloy 625 displays significant pitting when tested in $500{ }^{\circ} \mathrm{C}$ deaerated supercritical water.

\section{Task 3. Plant Engineering and Reactor Safety Analysis}

The VIPRE-W code was modified for supercritical water applications, a VIPRE-W model of the SCWR core was built, and preliminary sub-channel analyses to investigate the thermal-hydraulic behavior of the SCWR core were performed. The results of the VIPRE-W calculations indicate that multiple enrichments in the fuel assemblies that result in relatively flat power distributions within each fuel assembly, an optimized assembly geometry for better flow distribution within the fuel assemblies, and orificing to carefully control the coolant flow to each assembly are essential to lower the hot channel temperatures. 
The effort to minimize local peaking factors in the hot assembly will lead to a complex assembly design that will have to rely on the BWR assembly design experience.

Fuel rod design criteria that will assure satisfactory performance in a SCWR were developed. These criteria reflect the acceptance criteria for fuel designs established in the Federal regulations and the NRC Standard Review Plan. Also, the required fuel rod design data for an example material, MA956, is presented. The FRAPCON-3 computer code was used to perform a preliminary calculation of the thermal and fission gas release performance of SCWR fuel rods from beginning of life to end of life (1350 days and rod average burnup of $77.6 \mathrm{MWd} / \mathrm{kgU}$ ). The fuel rod design had a relatively large gas plenum volume to better accommodate released fission gases. Nevertheless, the relatively high coolant temperatures in a SCWR result in large amounts of fission gas release and relatively high fuel rod internal pressures. The design of SCWR fuel rods, and the power history imposed on the fuel rods, need to take into account the effect of higher coolant temperatures on fission gas release.

Parametric calculations were performed with the RELAP5/3D computer code to characterize the transient response of three SCWR designs, so that the required response times and capacities of various safety systems could be determined. The designs used either solid or water moderator. Moderation by water was achieved with either square water rods or hexagonal power channels. The calculations were performed to investigate the relative safety characteristics of the designs with water rods or power channels. Transients initiated by loss of feedwater, turbine trip, reactivity insertion, and a step decrease in main feedwater temperature were simulated. Loss-of-coolant accidents (LOCAs) were also simulated.

The parametric calculations showed that the design with solid moderator rods could tolerate a $50 \%$ instantaneous reduction in feedwater flow without a reactor scram and still meet a transient temperature limit of $840{ }^{\circ} \mathrm{C}$. Transients involving a total loss of feedwater pose a more serious challenge to the reactor. The calculations indicated that acceptable temperature results could be obtained with a 5-s main feedwater flow coast down, a reactor scram, and an auxiliary feedwater flow rate that is $15 \%$ or more of the initial feedwater flow. The auxiliary feedwater flow would have to be generated within $4.25 \mathrm{~s}$ of the start of the event to be consistent with the analysis. The rapid initiation of auxiliary feedwater will likely pose a significant challenge for the design. Additional calculations showed that a fast-opening, $100 \%$ capacity turbine bypass system could significantly reduce the peak cladding temperature, thus allowing more time to initiate the auxiliary feedwater.

The parametric calculations also showed that the SCWR could meet reactor vessel pressure limits following a turbine trip provided that the safety relief valve capacity at normal operating conditions is $90 \%$ or more of the rated steam flow. This safety relief valve capacity is well within typical BWR ranges. The power increase following a turbine trip was much smaller than in a comparable BWR. The parametric calculations also showed that the SCWR could easily tolerate reactivity insertion rates between 5 and $100 \mathrm{pcm} / \mathrm{s}$ provided that the reactor was scrammed at $118 \%$ neutron power. The peak cladding temperatures were less than $700{ }^{\circ} \mathrm{C}$ for these transients.

Transient analyses were also performed for thermal-spectrum SCWR designs with water rods and hexagonal power channels. The transients were initiated by upsets in the main feedwater system, including overheating (loss of main feedwater flow) and overcooling (decrease in main feedwater temperature) events. Because insulation of the water rod boxes or power channels is an important consideration, sensitivity calculations were also performed with a 1-mm thick layer of zirconium oxide on the water rod wall. The base designs (water rods without insulation, power channels with $0.5 \mathrm{~mm}$ insulation) respond similarly during the loss of main feedwater events. The effect of insulation is to reduce maximum steady-state cladding temperature by reducing the fluid temperature of the coolant. However, the insulation retards the flow of heat from the fuel channel to the water rods during an 
overheating transient, which keeps more of the heat inside the fuel channel, delays the moderator reactivity effect, and thus results in a larger increase in cladding temperature. Consequently, insulation actually increases the peak cladding temperature during the overheating transients studied. (As discussed previously, insulation is required to meet the steady-state temperature limit for the design with water rods.) The peak cladding temperatures are lower in the design with power channels than in the design with insulated water rods for all three of the transients evaluated. Thus, the overall response to transients initiated by main feedwater upsets is better in the design with power channels.

The response of the two designs during LOCAs was evaluated by determining the time that the maximum cladding temperature reached $1204{ }^{\circ} \mathrm{C}$, which corresponds to the accident limit for current LWRs with Zircaloy cladding. The accident limit was reached more than $300 \mathrm{~s}$ after the start of the large steam line break and the small feedwater line break. The response of the design with water rods was better for these LOCAs because the accident limit was reached at least $80 \mathrm{~s}$ later, allowing more time for the safety systems to actuate and mitigate the transient. The larger reactor vessel in this design slowed the depressurization rate and delayed the onset of the nearly adiabatic heatup. The heatup rate was also slower in this design because of its larger fuel rods. The response of the design with power channels was better for the LOCA initiated by a large feedwater line break. In this transient, the heatup was primarily caused by the re-distribution of the initial stored energy in the fuel rod, which was lower in the design with power channels because of the insulation and the higher core mass flux during steady-state operation.

Relatively long times are available for safety systems to mitigate the large steam line break and the small feedwater break. Although more time is available for the design with water rods, both designs are considered acceptable for these transients. The large feedwater line break is the most limiting transient because the temperature limit is reached much earlier, at $26 \mathrm{~s}$ for the design with water rods and at $57 \mathrm{~s}$ for the design with power channels. Since the design with power channels has more time available during the most limiting transient, the overall response to LOCAs is judged better for the design with power channels. Designing safety systems to protect the core during a large feedwater line break will be challenging because of the higher operating temperature of the SCWR and the reduced margin to the temperature limit. However, sufficient time appears available to develop a reasonable safety system design.

The calculated results for the SCWR are sensitive to the choice of heat transfer correlation. Furthermore, the databases of the existing correlations do not cover a sufficiently wide range of thermal-hydraulic conditions to fully support analysis of the reactor at off-normal conditions and during transients. Heat transfer experiments that are prototypical with respect to thermal-hydraulic conditions and geometry should be performed to support analysis of the reactor.

A study was performed to establish the feasibility and general layout of the reactor vessel, focusing on identifying issues associated with operating the reactor with an outlet fluid temperature of $500{ }^{\circ} \mathrm{C}(932$ ${ }^{\circ} \mathrm{F}$ ) and at elevated pressures as compared to current PWRs. The preliminary SCWR vessel design has remained similar to a typical large PWR vessel in many respects, and has used current PWR materials for the pressure vessel boundary. The use of standard PWR vessel design, manufacturing techniques, and materials should prove to be a major economic advantage for the SCWR compared with other Generation IV reactor concepts; the later will require the use of advanced alloys operating at much higher temperatures. The following vessel wall thicknesses were established using minimum thickness calculations based on the ASME Code

- The vessel shell wall thickness is $0.46 \mathrm{~m}$ (18.0 inches).

- The vessel upper nozzle and closure flange ring-forging wall thickness is $0.63 \mathrm{~m}$ (24.75 inches). 
- The vessel lower head wall thickness is $0.30 \mathrm{~m}$ (12.0 inches)

- The vessel upper head thickness is $0.30 \mathrm{~m}$ (12.0 inches).

Finite element analyses have been performed for this preliminary vessel design at both Westinghouse and INEEL. These analyses indicate the vessel is able to meet ASME Code specifications under design pressure. In addition, INEEL has been exploring alternatives to the preliminary design to reduce both peak stress and vessel thickness. INEEL has also started to look at alternative approaches to the outlet nozzle thermal sleeve. Although we have not yet achieved a satisfactory design for the thermal sleeve, it appears that multiple isolation features will be required to isolate the bulk reactor vessel from the hot leg temperature $\left(500^{\circ} \mathrm{C}\right)$.

Finally, the reactor internals design work was initiated this year and it was concluded that

- The reactor vessel internals can be designed so that the fluid in contact with the vessel walls is within current PWR operating temperatures.

- It is feasible to incorporate water rods in the fuel assembly and supply these rods with the inlet coolant.

- The SCWR reactor internals and vessel designs need to incorporate special design features to prevent excessive thermal stresses in the structures exposed to both the hot and cold fluid temperatures.

The detailed results of this work will be presented in the Year 3 Annual Report. 


\section{Table of Contents}

EXECUTIVE SUMMARY ............................................................................................................................II

TABLE OF CONTENTS ............................................................................................................... VII

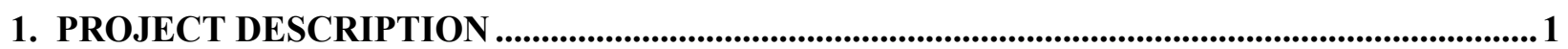

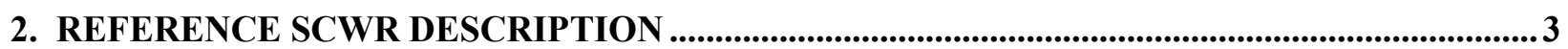

2.1. REFERENCE DESIGN POWER AND COOLANT CONDITIONS …....................................................... 3

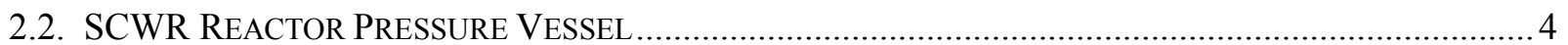

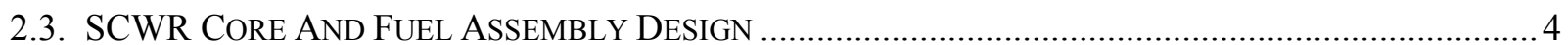

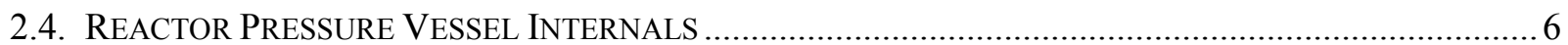

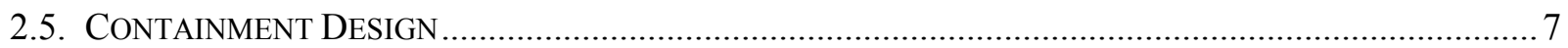

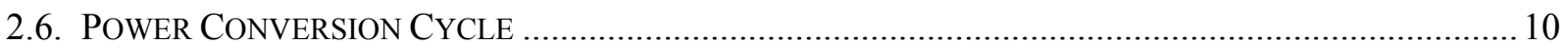

\section{TASK 1 RESULTS: FUEL-CYCLE NEUTRONIC ANALYSIS AND REACTOR CORE}

DESIGN ............................................................................................................................... 13

3.1. An Alternative SCWR Design BASEd on VERTiCAl POWER CHANNELS AND HeXAgOnAL

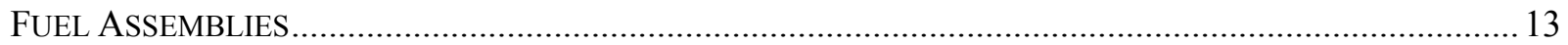

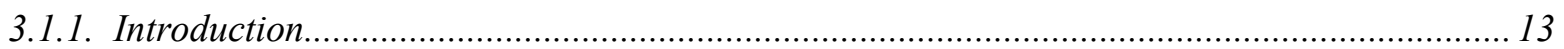

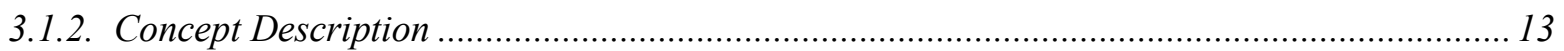

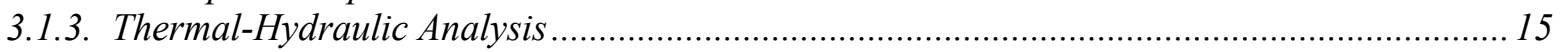

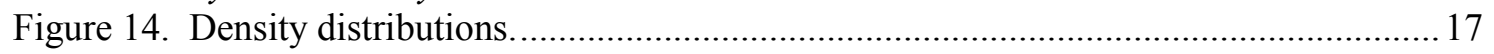

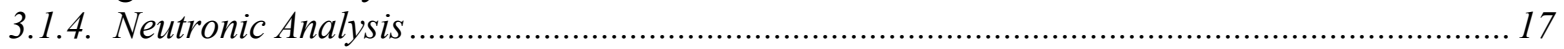

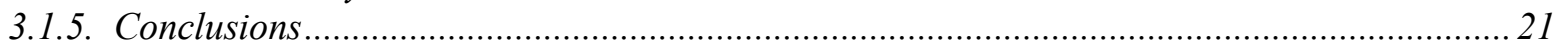

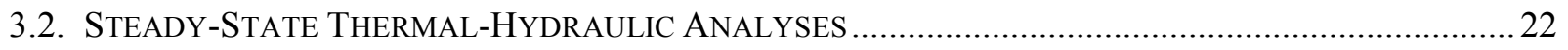

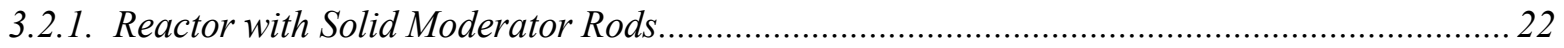

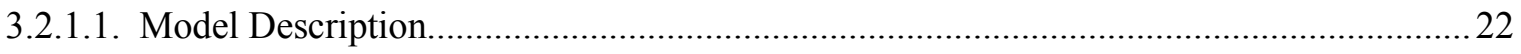

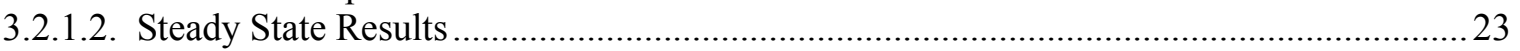

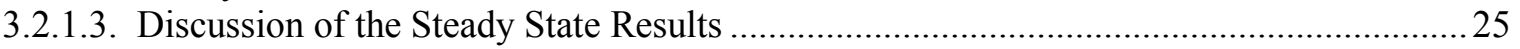

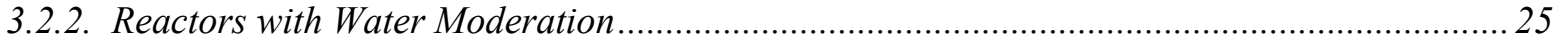

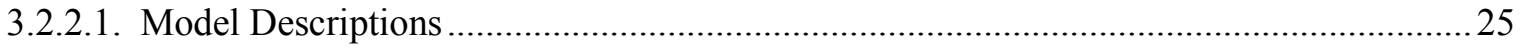

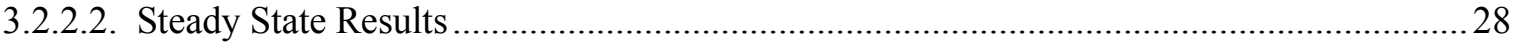

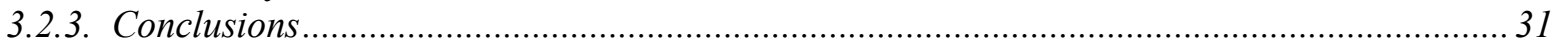

4. TASK 2 RESULTS: CORROSION AND STRESS CORROSION CRACKING STUDIES ........33

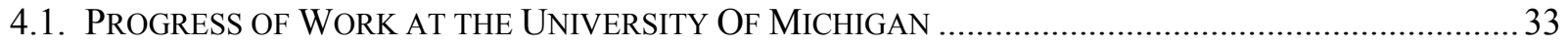

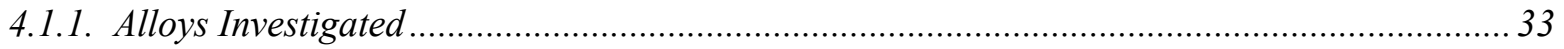

4.1.2. Mechanical Behavior of Austenitic Alloys in Argon ........................................................ 33

4.1.3. Stress Corrosion Cracking Behavior of Austenitic Alloys in Deaerated Supercritical Water. 37

4.1.4. Corrosion Behavior of Austenitic Alloys in Supercritical Water......................................... 40

4.1.4.1. Results of the Analysis of the Oxide Formed During Stress Corrosion Cracking

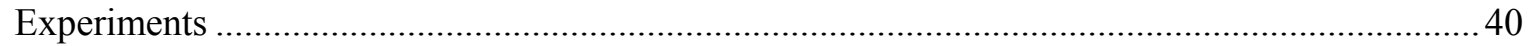

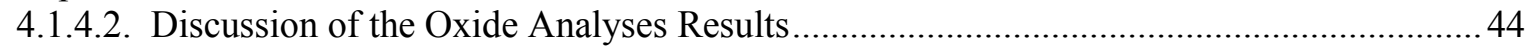

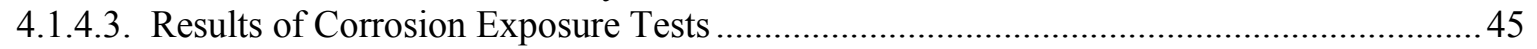

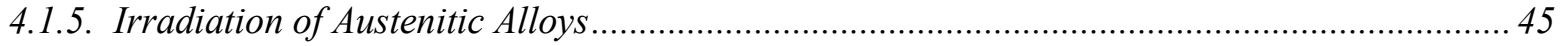

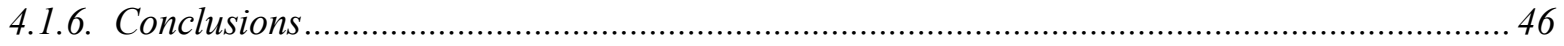

4.2. PROGRESS ON TASK 2 AT THE MASSACHUSETtS InSTITUTE OF TECHNOLOGY.............................46

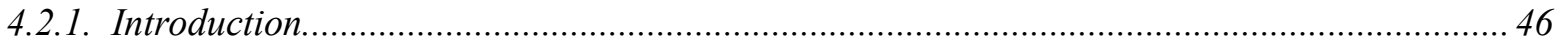




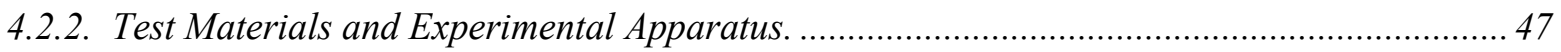

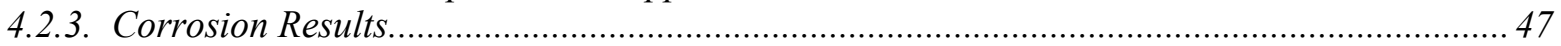

5. TASK 3 RESULTS: PLANT ENGINEERING AND REACTOR SAFETY ANALYSIS ...........51

5.1. VIPRE-W MODELING OF THE SUPERCRITICAL WATER REACTOR............................................... 51

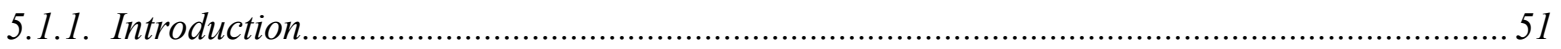

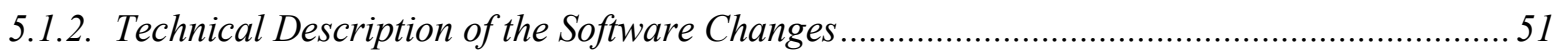

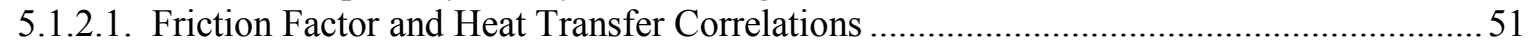

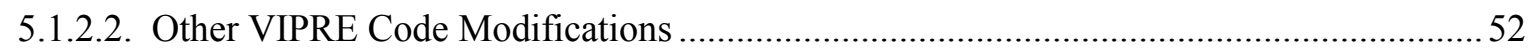

5.1.3. Supercritical Water Reactor Sub-Channel Analysis ....................................................... 52

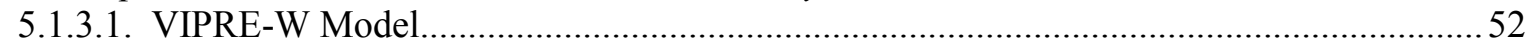

5.1.3.2. Thermal-Hydraulic Profiles in the Hot and Cold Channels for Different Radial Power

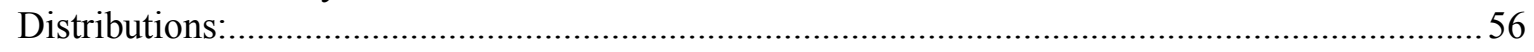

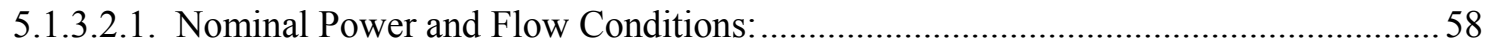

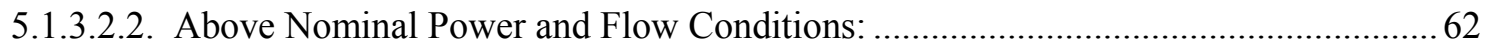

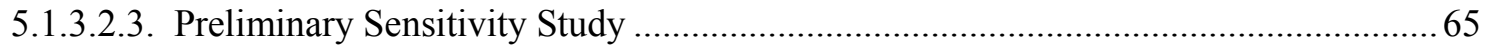

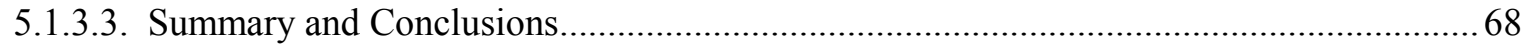

5.2. SuPERCRITICAL WATER COOLED REACTOR FuEL Rod DESIGN REQUIREMENTS .......................69

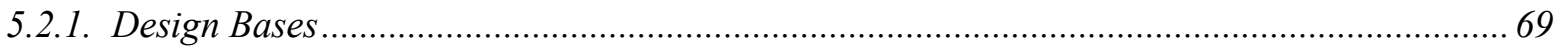

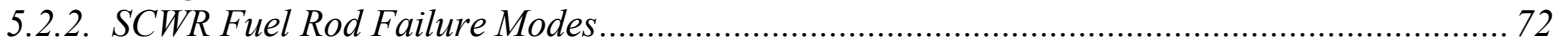

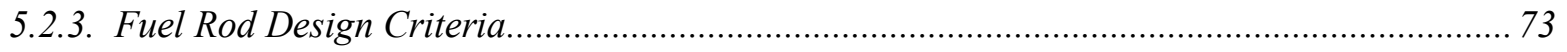

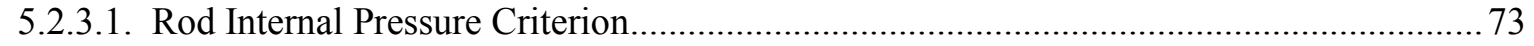

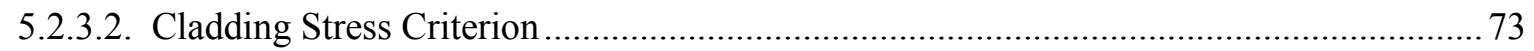

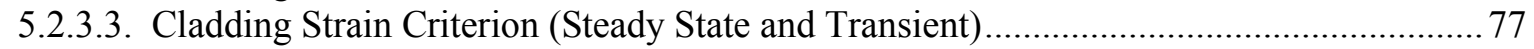

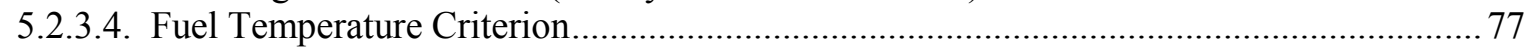

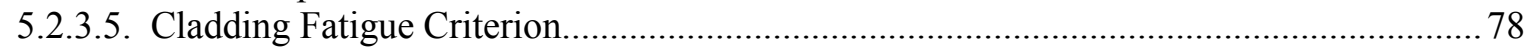

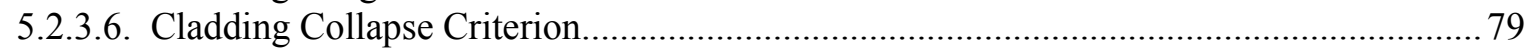

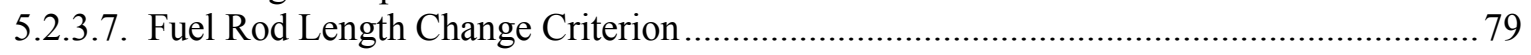

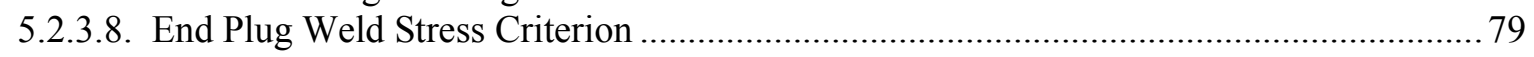

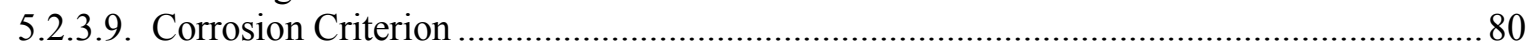

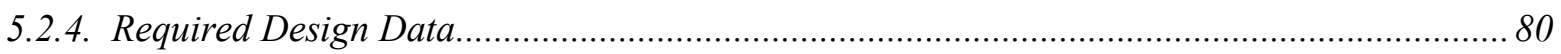

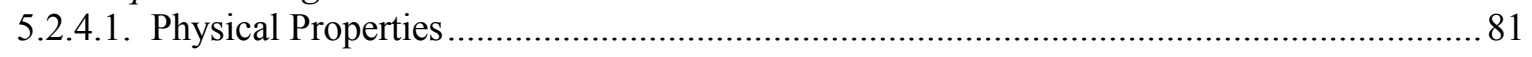

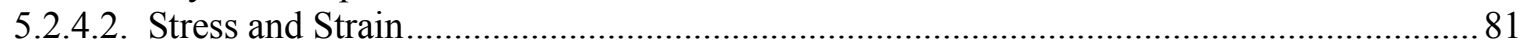

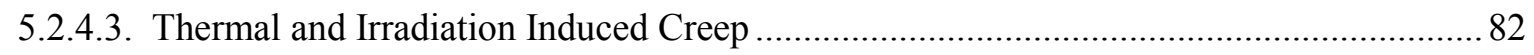

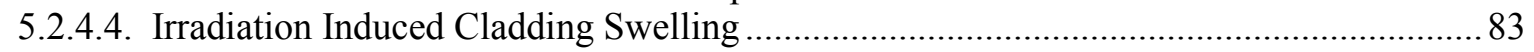

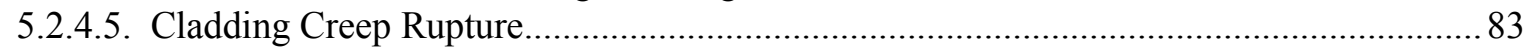

5.2.4.6. Stress Corrosion Induced and Irradiation Assisted Stress Corrosion Cracking ................84

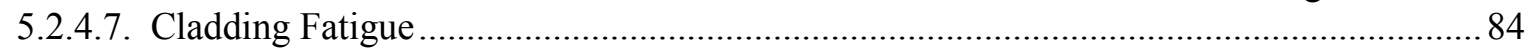

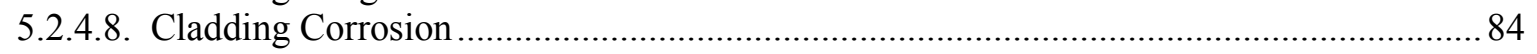

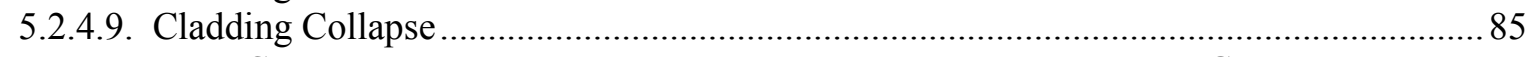

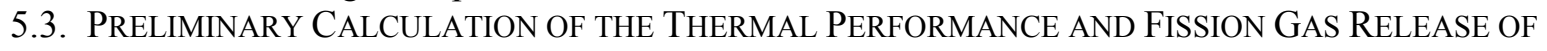

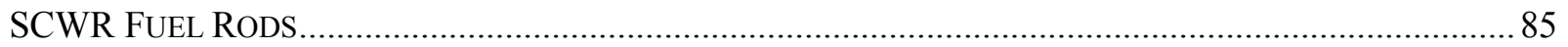

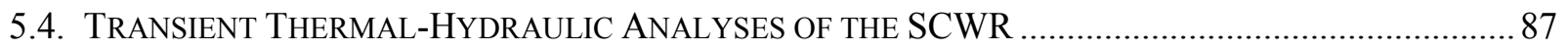

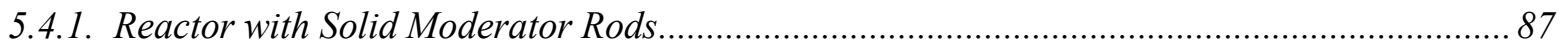

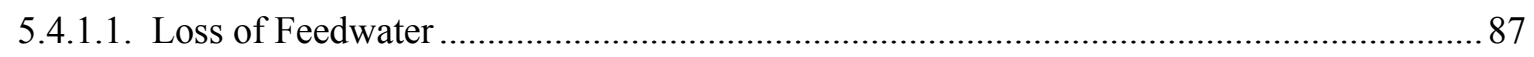

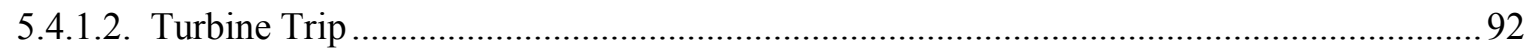

5.4.1.3. Reactivity Insertion Accidents ......................................................................... 93

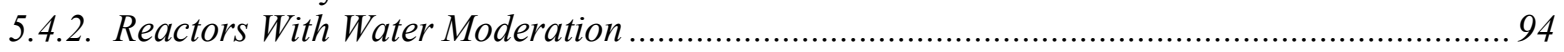

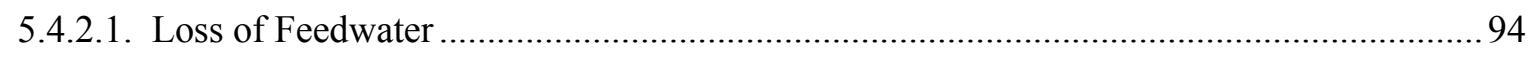

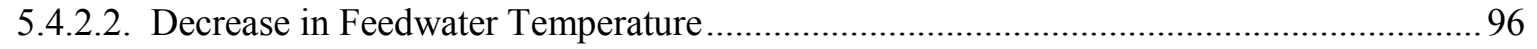

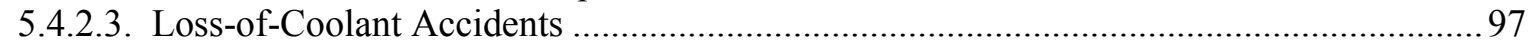




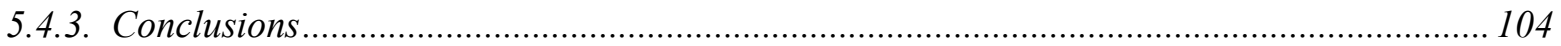

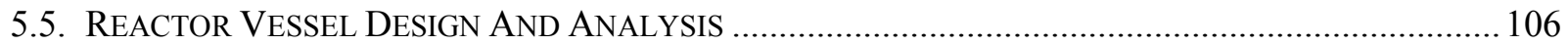

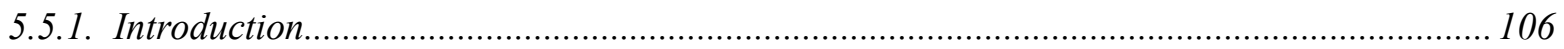

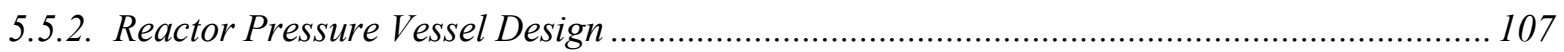

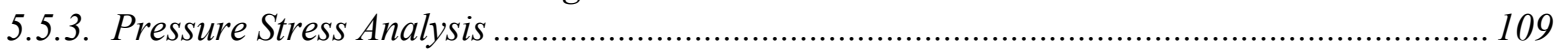

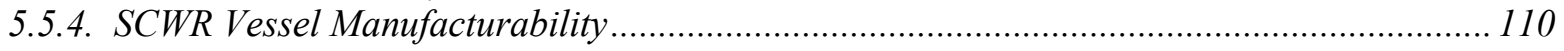

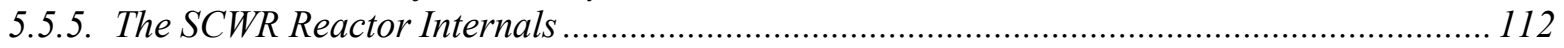

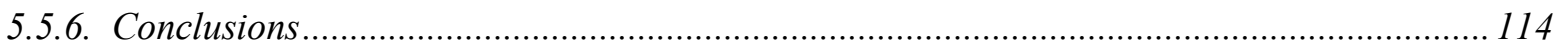

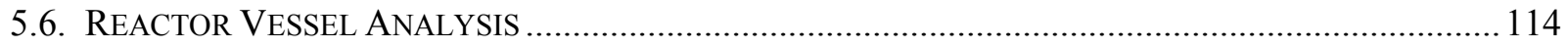

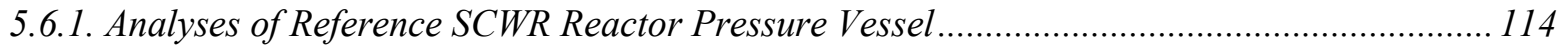

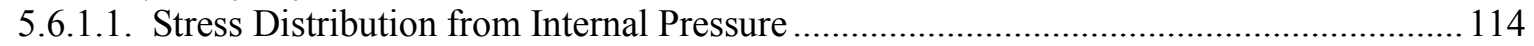

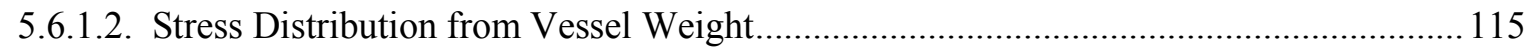

5.6.1.3. Stress Distribution from Steady-State Vessel Temperature Profile................................ 116

5.6.1.4. Conclusions from Steady Temperature/Stress Analysis of Preliminary SCWR Reactor

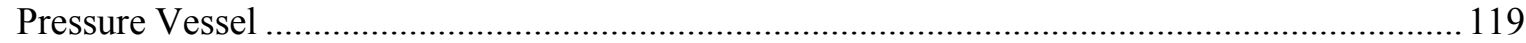

5.6.2. Modifications of Reference SCWR Reactor Pressure Vessel - An Examination of Inlet and

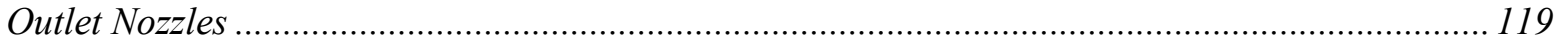

5.6.2.1. Finite Element Models of Reference and Alternative Inlet Nozzles............................. 121

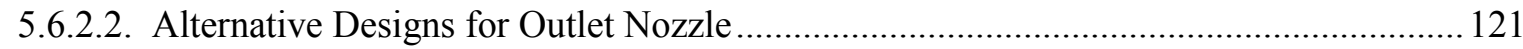

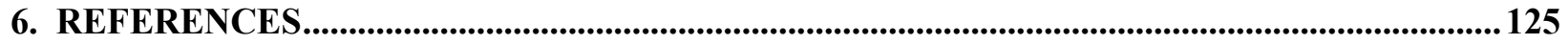

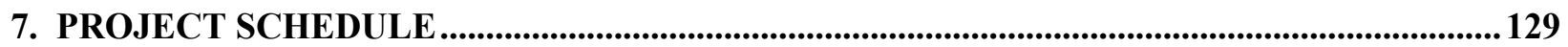

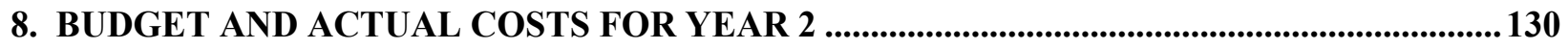

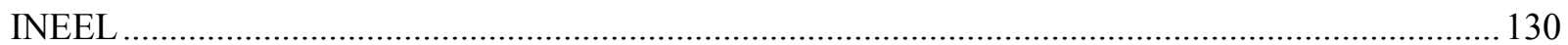

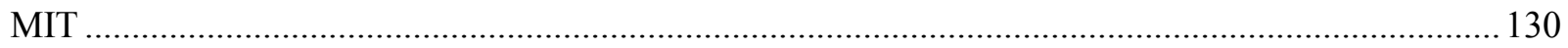

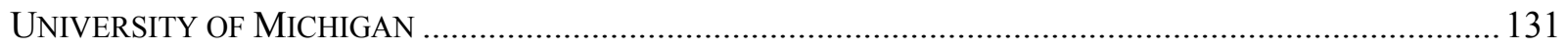

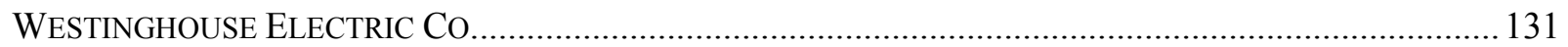

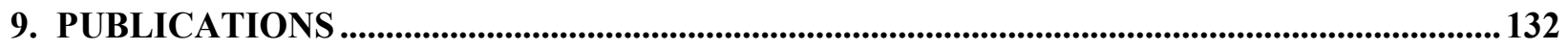

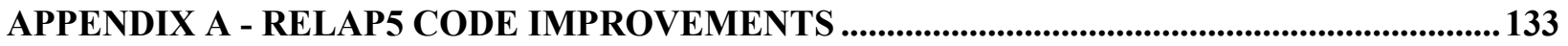




\section{Project Description}

The use of light water at supercritical pressures as the coolant in a nuclear reactor offers the potential for considerable plant simplification and consequent capital and O\&M cost reduction compared with current light water reactor (LWR) designs. Also, given the thermodynamic conditions of the coolant at the core outlet (i.e. temperature and pressure beyond the water critical point), very high thermal efficiencies of the power conversion cycle are possible (i.e. up to about 45\%). Because no change of phase occurs in the core, the need for steam separators and dryers as well as for boiling water reactor (BWR)-type recirculation pumps is eliminated, which, for a given reactor power, results in a substantially shorter and somewhat smaller diameter reactor vessel and smaller containment building than the current BWRs. Furthermore, in a direct cycle steam generators are not needed.

If no additional moderator is added to the fuel rod lattice, it is possible to attain fast neutron energy spectrum conditions in a supercritical water-cooled reactor (SCWR). This type of core can make use of either fertile or fertile-free fuel and retain a hard spectrum to effectively burn plutonium and minor actinides from LWR spent fuel while efficiently generating electricity. One can also add moderation and design a thermal spectrum SCWR. The Generation IV Roadmap effort has identified the thermal spectrum SCWR (followed by the fast spectrum SCWR) as one of the advanced concepts that should be developed for future use. Therefore, the work in this NERI project has been addressing both types of SCWRs.

The project is organized into three tasks.

Task 1. Fuel-cycle Neutronic Analysis and Reactor Core Design (INEEL). For the fastspectrum SCWR, metallic and oxide fertile fuels were investigated during Year 1 to evaluate the void and Doppler reactivity coefficients, actinide burn rate, and reactivity swing throughout the irradiation cycle (these results were reported in the $1^{\text {st }}$ Quarterly). For the thermal-spectrum SCWR, a variety of fuel and moderator types and core arrangements were also assessed during Years 1 and 2. The detailed results from the solid moderator studies are presented in the $3^{\text {rd }}$ Quarterly and $1^{\text {st }}$ Annual Reports. Results from our analyses of a thermal-spectrum SCWR design with water rod boxes and from our analyses of an alternative design based on vertical power channels, hexagonal fuel assemblies, and water moderation between the fuel assemblies are presented in this report.

Task 2. Fuel Cladding and Structural Material Corrosion and Stress Corrosion Cracking (University of Michigan and MIT). The existing data base on the corrosion and stresscorrosion cracking of austenitic stainless steel and nickel-based alloys in supercritical water is very sparse. Therefore, the focus of this work has been corrosion and stress corrosion cracking testing of candidate fuel cladding and structural materials. MIT used an existing supercriticalwater loop during Year 1 to conduct corrosion experiments on a first set of candidate alloys in flowing supercritical water. This work continued in Year 2 and the results from the Year 2 work are provided in this report. A high temperature autoclave containing a constant rate mechanical test device was built and tested in Year 1 and operated in Year 2 at the University of Michigan. The resulting stress corrosion cracking data is also being used to identify promising materials and develop appropriate corrosion and stress corrosion cracking correlations.

Task 3. Plant Engineering and Reactor Safety Analysis (Westinghouse and INEEL). The optimal configuration of the power conversion cycle was identified in Year 1. Particular emphasis was given to the applicability of current supercritical fossil-fired plant technology and 
experience to a direct-cycle nuclear system. Also during Year 1 preliminary core design criteria were developed, a critical review of the supercritical water heat transfer correlations was completed, preliminary hot channel factors were identified, approximate temperature and density profiles in the average and hot channels were calculated, and improvements were made in the RELAP5 and VIPRE computer codes. During Year 2, an assessment of the water rod density and moderation effectiveness and a more detailed steady-state sub-channel analysis of the reactor core were undertaken with the goal of establishing power limits and safety margins under normal operating conditions. Also, the response of the plant to accident situations and anticipated transients without scram was assessed for the solid moderator, water rod, and power channelhexagonal fuel assembly core designs. In particular the following transients and accidents were analyzed: loss-of-feedwater, turbine trip, reactivity insertion, decrease in feedwater temperature, and loss-of-coolant accidents (LOCAs). As part of this analysis, a suitable containment design was explored to mitigate the consequences of LOCAs and severe accidents. Also, work started on the reactor pressure vessel and reactor pressure vessel internals mechanical designs (the pressure vessel design work is discussed in this report, the internals design work will be reported in Year 3).

The work on this NERI project has been closely coordinated with the work on the Generation IV SCWR project. The results from both projects have resulted in the identification of a reference U.S. SCWR design, which is described in Section 2 of this report to help the reader put the following analyses in perspective. The candidate materials to be used in the SCWR are described in a document by Buongiorno et al. [2003]. The remainder of this report presents our detailed assessments of various components of this reference plant.

Section 3 presents the results of our Task 1 work including the results of our analyses of an alternative thermal spectrum core design based on vertical power channels and hexagonal fuel assemblies. Also included in Section 3 are the results of our steady-state thermal-hydraulic analyses of the SCWR core design with solid moderator rods and the SCWR core designs with either water rod boxes or vertical power channels and hexagonal fuel assemblies. Section 4 presents the results of our Task 2 materials studies including the results of recent corrosion tests at the University of Michigan and MIT and the results of our stress corrosion cracking tests at Michigan of three different alloys. Section 5 presents our Task 3 work on the plant design, including

- The results of detailed subchannel analyses with the VIPRE-W computer code.

- Information on SCWR fuel design criteria and the results of our preliminary fuel design analyses.

- The results of our plant safety analysis including assessments of loss-of-feedwater, turbine trip, reactivity insertion, decrease in feedwater temperature, and loss-of-coolant transients.

- Our reactor pressure vessel design and the results of our stress analysis of the reactor pressure vessel. 


\section{Reference SCWR Description}

\subsection{Reference Design Power and Coolant Conditions}

As mentioned in the project description, we have chosen to focus on a direct cycle plant design. Highpressure $(25.0 \mathrm{MPa})$ coolant enters the vessel at $280{ }^{\circ} \mathrm{C}$. The inlet flow splits with about $10 \%$ of the inlet flow going down the space between the core barrel and the reactor pressure vessel (the down-comer) and about $90 \%$ of the inlet flow going to the plenum at the top of the rector pressure vessel to then flow downward through the core in special water rods to the inlet plenum. This strategy is employed to provide good moderation at the top of the core. The coolant is heated to about $500{ }^{\circ} \mathrm{C}$ and delivered to a power conversion cycle similar to that used in supercritical fossil-fired plants: high- intermediate- and low-pressure turbines are employed with two re-heaters. The single most significant factor in going from the current pressurized water reactor (PWR) and BWR designs to the SCWR is the associated increase in outlet coolant temperature from 300 to $500{ }^{\circ} \mathrm{C}$.

The reference power, efficiency, pressure, and coolant flow rate and temperatures are listed in Table I. Figure 1 is a sketch of the reactor pressure vessel and internals showing the coolant flow paths.

Table I. U.S. GenerationIV SCWR reference design power and coolant conditions.

\begin{tabular}{|l|l|}
\hline Parameter & Value \\
\hline $\begin{array}{l}\text { Thermal } \\
\text { power }\end{array}$ & $3575 \mathrm{MWt}$ \\
\hline $\begin{array}{l}\text { Net electric } \\
\text { power }\end{array}$ & $\begin{array}{l}1600 \\
\mathrm{MWe}\end{array}$ \\
\hline $\begin{array}{l}\text { Net thermal } \\
\text { efficiency }\end{array}$ & $44.8 \%$ \\
\hline $\begin{array}{l}\text { Operating } \\
\text { pressure }\end{array}$ & $25 \mathrm{MPa}$ \\
\hline $\begin{array}{l}\text { Reactor inlet } \\
\text { temperature }\end{array}$ & $280^{\circ} \mathrm{C}$ \\
\hline $\begin{array}{l}\text { Reactor } \\
\text { outlet } \\
\text { temperature }\end{array}$ & $500^{\circ} \mathrm{C}$ \\
\hline $\begin{array}{l}\text { Reactor flow } \\
\text { rate }\end{array}$ & $1843 \mathrm{~kg} / \mathrm{s}$ \\
\hline Plant lifetime & 60 years \\
\hline
\end{tabular}

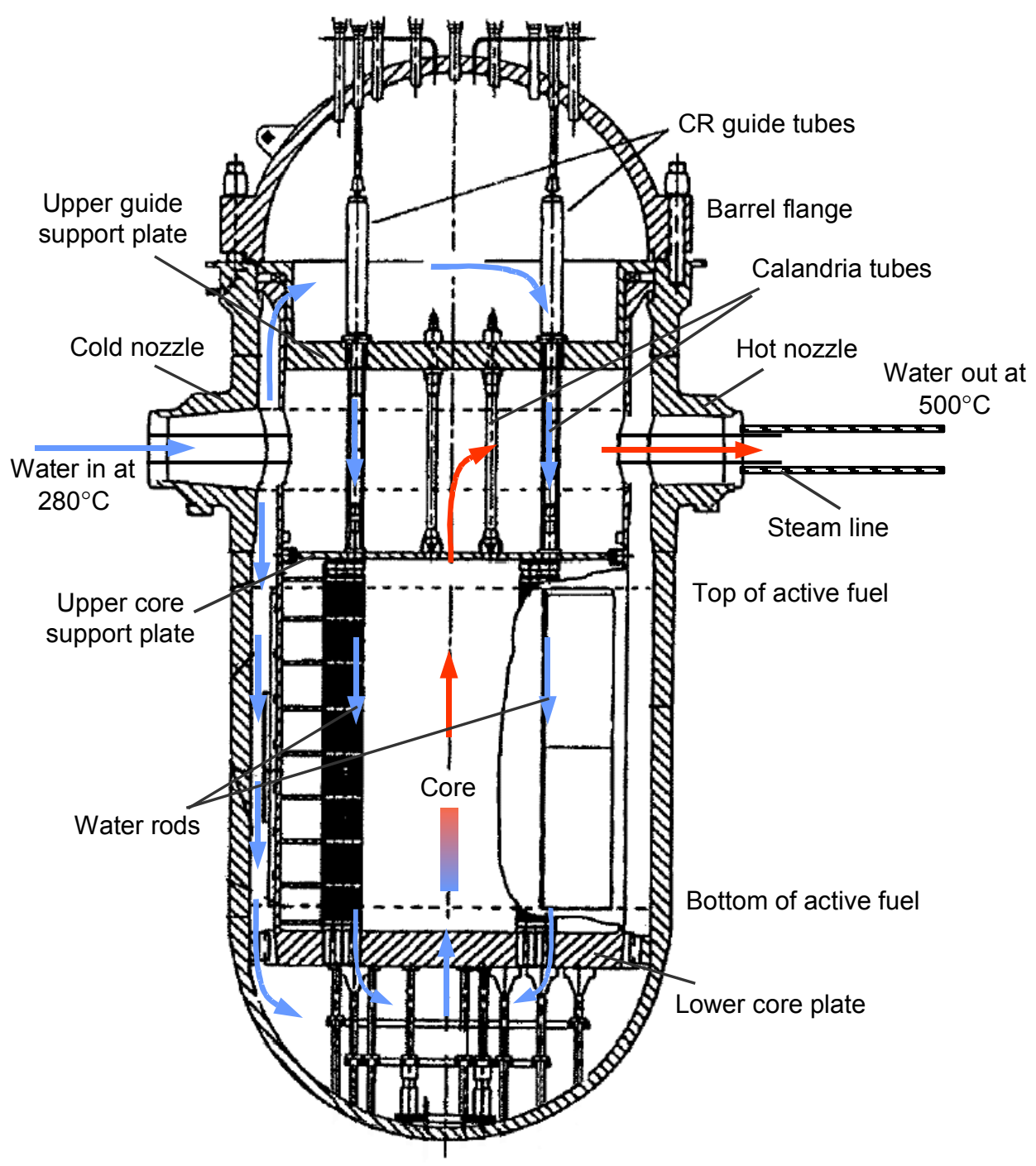

Figure 1. The SCWR reactor pressure vessel and internals. 


\subsection{SCWR Reactor Pressure Vessel}

A three-dimensional cad-cam representation of the current vessel design is shown in Figure 2. The key vessel dimensions are listed in Table II. This vessel design is similar to a typical large-size PWR vessel design with no major penetrations through the lower head. However the thickness is significantly larger due to the higher operating pressure. The vessel appears to be within the current manufacturing capability in Japan and possibly elsewhere. The hot nozzles will be protected with insulation and/or thermal sleeves against the full outlet temperature. However, they may operate at temperatures somewhat above $280{ }^{\circ} \mathrm{C}$. The rest of the vessel will be exposed to $280{ }^{\circ} \mathrm{C}$ inlet coolant on the inside surfaces. Also, the inside surfaces will be clad with stainless steel, probably Type 308 stainless steel.

Table II. Reference reactor pressure vessel design for the U.S. Generation-IV SCWR.

\begin{tabular}{|l|l|}
\hline Parameter & Value \\
\hline Height & $12.4 \mathrm{~m}$ \\
\hline Material & $\begin{array}{l}\text { SA-533 or SA-508 } \\
\text { Grade 3, Class 1 }\end{array}$ \\
\hline Design pressure & $\begin{array}{l}27.5 \mathrm{MPa}(110 \% \text { of } \\
\text { nominal pressure })\end{array}$ \\
\hline Operating temperature & $280^{\circ} \mathrm{C}$ \\
\hline $\begin{array}{l}\text { Number of cold/hot } \\
\text { nozzles }\end{array}$ & $2 / 2$ \\
\hline Inside diameter of shell & $5.322 \mathrm{~m}(209.5 \mathrm{in})$. \\
\hline Thickness of shell & $0.457 \mathrm{~m}(18$ in) \\
\hline $\begin{array}{l}\text { Thickness of the shell in } \\
\text { the nozzle region }\end{array}$ & $0.629 \mathrm{~m}(24.75$ in. $)$ \\
\hline Inside diameter of head & $5.352 \mathrm{~m}(210 \mathrm{in})$ \\
\hline Thickness of head & $0.305 \mathrm{~m}(12 \mathrm{in})$ \\
\hline Vessel weight & $\begin{array}{l}780 \mathrm{mt}(1.7 \mathrm{million} \\
\text { lbs })\end{array}$ \\
\hline Peak fast fluence, $>1 \mathrm{MeV}$ & $<5 \times 10^{19} \mathrm{n} / \mathrm{cm}^{2}$ \\
\hline
\end{tabular}

\subsection{SCWR Core And Fuel Assembly Design}

The reference SCWR core design is shown in Figure 3. The relevant dimensions are listed in Table III. The core will have 145 assemblies with an equivalent diameter of about 3.9 meters. The core barrel will have inside and outside diameters of about 4.3 and 4.4 meters, respectively. The average power density will be about $70 \mathrm{~kW} / \mathrm{L}$ with a total target power peaking factor of about 2.0. The core pressure drop will be around 0.15 $\mathrm{MPa}$ (comparable with typical LWR pressure drops) and

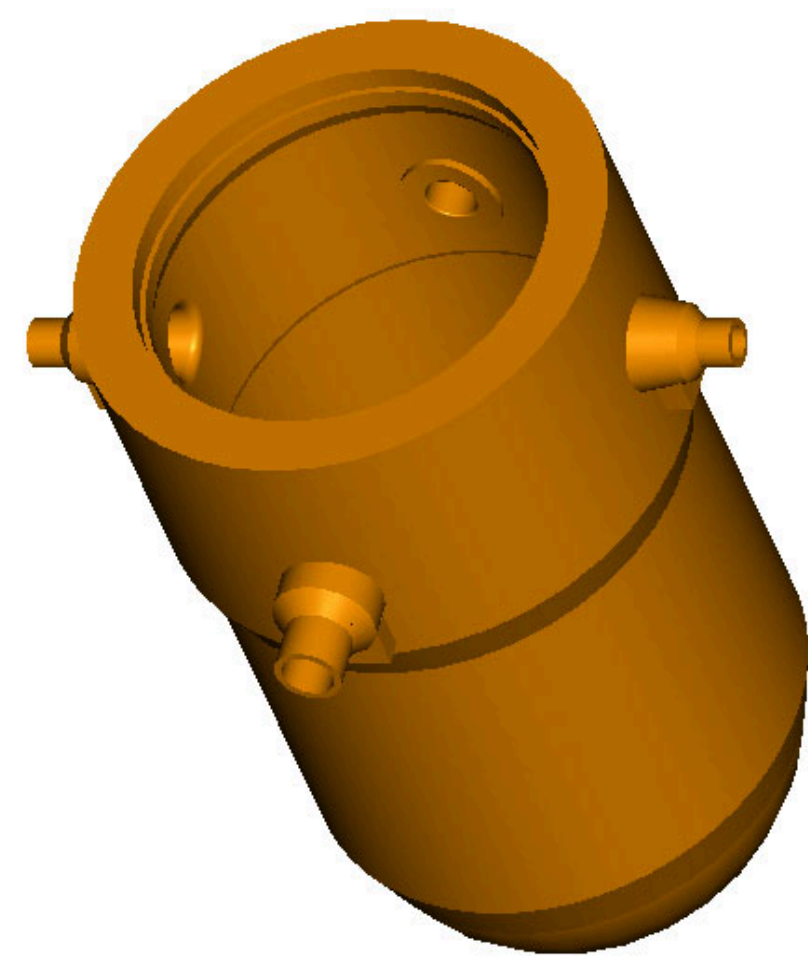

Figure 2. Three-dimensional cad-com representation of the current SCWR pressure vessel design.

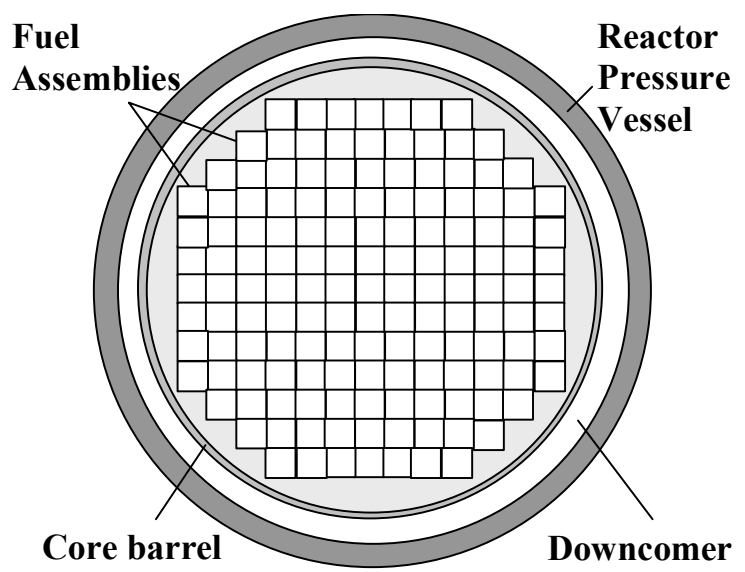

Figure 3. Sketch of the reference SCWR core. 
inlet orifices will be used to adjust the flow to each assembly based on its expected power. As mentioned above, about $90 \%$ of the inlet flow will be passed through the water rods with a flow rate in the water rods of about $1660 \mathrm{~kg} / \mathrm{s}$.

Table III. Reference reactor core design for the U.S. Generation-IV SCWR.

\begin{tabular}{|l|l|}
\hline Parameter & Value \\
\hline Number of fuel assemblies & 145 \\
\hline Equivalent diameter & $3.93 \mathrm{~m}$ \\
\hline Core barrel inside and outside diameter & $4.3 / 4.5 \mathrm{~m}$ \\
\hline Axial/Radial/Local/Total Peaking Factor & $1.4 / 1.3 / 1.1 / 2.0$ (best estimate) \\
& $1.4 / 1.4 / 1.2 / 2.35$ (safety analysis) \\
\hline Average power density & $69.4 \mathrm{~kW} / \mathrm{L}$ \\
\hline Average linear power & $19.2 \mathrm{~kW} / \mathrm{m}$ \\
\hline Peak linear power at steady-state conditions & $39 \mathrm{~kW} / \mathrm{m}$ \\
\hline Core pressure drop & $0.15 \mathrm{MPa}$ \\
\hline Water rod flow & $1660 \mathrm{~kg} / \mathrm{s}(90 \%$ of nominal flow rate) \\
\hline
\end{tabular}

The reference SCWR fuel assembly design is shown in Figure 4 and the relevant dimensions are listed in Table IV. Our analyses have shown that it may be necessary to insulate the water moderator boxes to retain a sufficient moderator density. Figure 5 is a $1 / 8$ size scaled drawing of a SCWR fuel assembly with Zircaloy water boxes with $1 \mathrm{~mm}$ of yttrium-stabilized zirconium oxide on the outside of the water boxes (i.e. on the hot coolant side of the water boxes). Figure 4 shows typical Westinghouse PWR size control rods inside 16 water moderator boxes (not shown are the Zircaloy control rod guide tubes). However, our control rod worth calculations are not complete and it may be desirable change the number and/or size of the control elements, or it may be desirable to change the locations of the control elements. Also, it is assumed that there will be one instrumentation tube in each assembly at the center fuel rod location, but maybe more will be needed. Also, a number of the dimensions are tentative including the fuel bundle wall thickness and the inter-assembly gap size and the fuel pin spacer have yet to be designed. In fact, we may need to use wire wrap spacers because of the tight dimensions between the fuel rods. However, we need to determine whether hot spots will occur under the wires in a supercritical water environment.

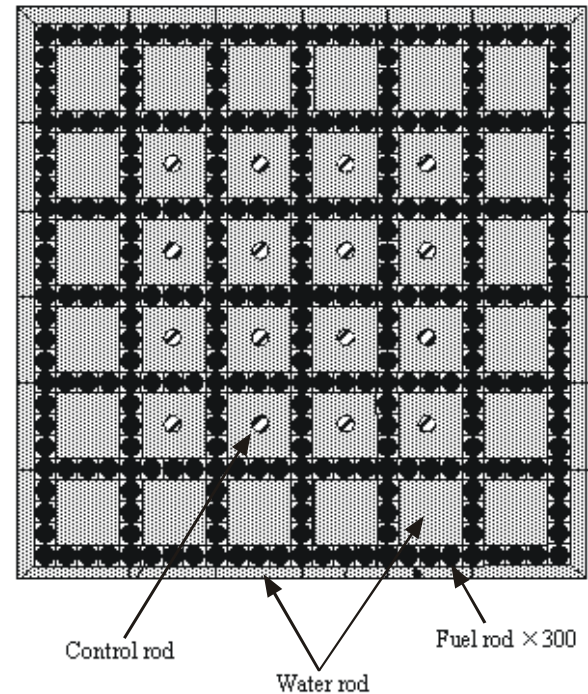

Figure 4. The SCWR fuel assembly with metal water rod boxes.

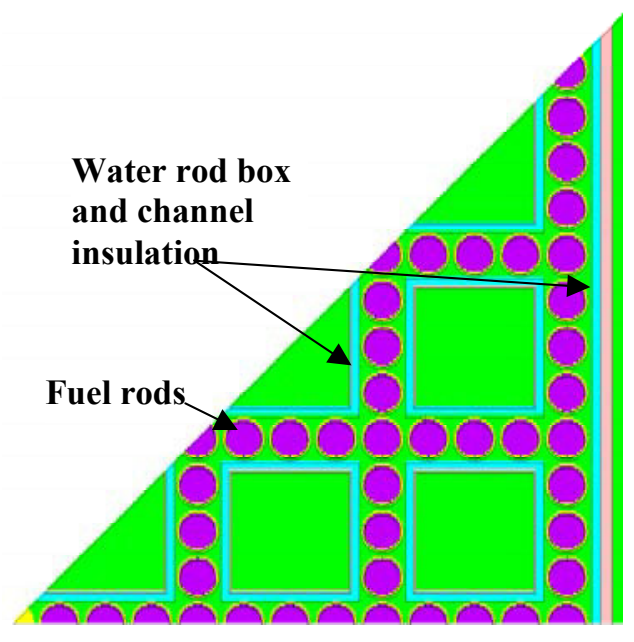

Figure 5. The SCWR fuel assembly with zirconium oxide insulated water rod boxes. 
Table IV. Reference fuel assembly design for the U.S. Generation-IV SCWR.

\begin{tabular}{|l|l|}
\hline Parameter & Value \\
\hline Fuel pin lattice & Square 25x25 array \\
\hline Number of fuel pins per assembly & 300 \\
\hline Number of water rods per assembly & 36 \\
\hline Water rod side & $33.6 \mathrm{~mm}$ \\
\hline Water rod wall thickness & $0.4 \mathrm{~mm}$ (plus insulation if needed) \\
\hline Water rod wall materials & TBD \\
\hline Number of instrumentation rods per assembly & 1 \\
\hline Number of control rod fingers per assembly & 16 \\
\hline Control rod material & $\mathrm{B}_{4} \mathrm{C}$ for scram, Ag-In-Cd for control \\
\hline Number of spacer grids & 14 (preliminary estimate) \\
\hline Assembly wall thickness & $3 \mathrm{~mm}$ (plus insulation if needed) \\
\hline Assembly wall material & TBD \\
\hline Assembly side & $286 \mathrm{~mm}$ \\
\hline Inter-assembly gap & $2 \mathrm{~mm}$ \\
\hline Assembly pitch & $288 \mathrm{~mm}$ \\
\hline
\end{tabular}

The reference fuel pin dimensions are listed in Table V. With the exception of the plenum length and fill pressure, the fuel pin dimensions are typical of 17 by 17 PWR fuel assembly pins. However, the fuel pin pitch is considerably smaller than the pitch used in LWRs. The U-235 enrichment, the $\mathrm{Gd}_{2} \mathrm{O}_{3}$ loading and fuel burnup are typical of the values used in high burnup LWR fuel.

Table V. Reference fuel pin design for the U.S. Generation-IV SCWR.

\begin{tabular}{|l|l|}
\hline Parameter & Value \\
\hline Fuel pin outside diameter & $10.2 \mathrm{~mm}$ \\
\hline Fuel pin pitch & $11.2 \mathrm{~mm}$ \\
\hline Cladding thickness & $0.63 \mathrm{~mm}$ \\
\hline Cladding materials & $\mathrm{TBD}$ \\
\hline Fuel pellet outside diameter & $8.78 \mathrm{~mm}$ \\
\hline Fuel composition & $\mathrm{UO}_{2}, 95 \%$ TD \\
\hline Fuel enrichment & $5 \%$ wt. average \\
\hline Target average burnup at discharge & 45,000 MWD/t or higher \\
\hline Burnable poisons & $\mathrm{Gd}_{2} \mathrm{O}_{3}$ (Distribution TBD) \\
\hline Heated length & $4.27 \mathrm{~m}$ \\
\hline Fission gas plenum length & $0.6 \mathrm{~m}$ \\
\hline Total fuel pin height & $4.87 \mathrm{~m}$ \\
\hline $\begin{array}{l}\text { Fill gas pressure at room } \\
\text { temperature }\end{array}$ & $6.0 \mathrm{MPa}$ \\
\hline
\end{tabular}

\subsection{Reactor Pressure Vessel Internals}

The important reactor pressure vessel internals include the lower core support plate, the core former, the core barrel, the upper core support plate, the calandria tubes located immediately above the upper core support plate, the upper guide support plate, the hot nozzle thermal sleeve or insulation, and the control rod guide tubes. The location and approximate shape of most of these components is shown in Figure 1. All the reactor pressure vessel internals components will be designed for periodic replacement so that high fluence ( $>20 \mathrm{dpa}$ ) loadings will not need to be considered. 
Some of these components, including the lower core support plate and the control rod guide tubes in the upper head, will be subjected to normal PWR coolant temperature conditions and will be similar to the components typically used in PWRs. However, a number of the reactor pressure vessel internals, including the core barrel (or possibly the core former, depending on the design details), the upper guide support plate, the calandria tubes, and the reactor pressure vessel hot nozzle sleeve, will be in contact with the inlet temperature at $280{ }^{\circ} \mathrm{C}$ on one side and the hot outlet coolant at a temperature of $500{ }^{\circ} \mathrm{C}$ on the other side. Our preliminary stress analyses indicate that we will not be able to use metal wall designs that are similar to those currently used in LWRs for those components. Such a high temperature drop across those walls will cause the thermal stresses and deformations to be too large and/or cause too much heat to be transferred across the walls. For example, a simplified thermal stress analysis of the upper guide support plate was performed using a temperature difference of $220{ }^{\circ} \mathrm{C}$ $\left(396{ }^{\circ} \mathrm{F}\right)$ and the Pro/Mechanica software. The result was that much of the structure will exceed the $3 \mathrm{Sm}$ Primary + Secondary stress limit of Subsection NG of the ASME code as shown in Figure 6. Resolution of these issues may require new design features including special materials, insulation layers, and/or use of an insulating layer between double walls.

Some other reactor pressure vessel internals components, such as the upper core support plate, will be exposed to the outlet coolant at a temperature of about $500{ }^{\circ} \mathrm{C}$ on all sides.

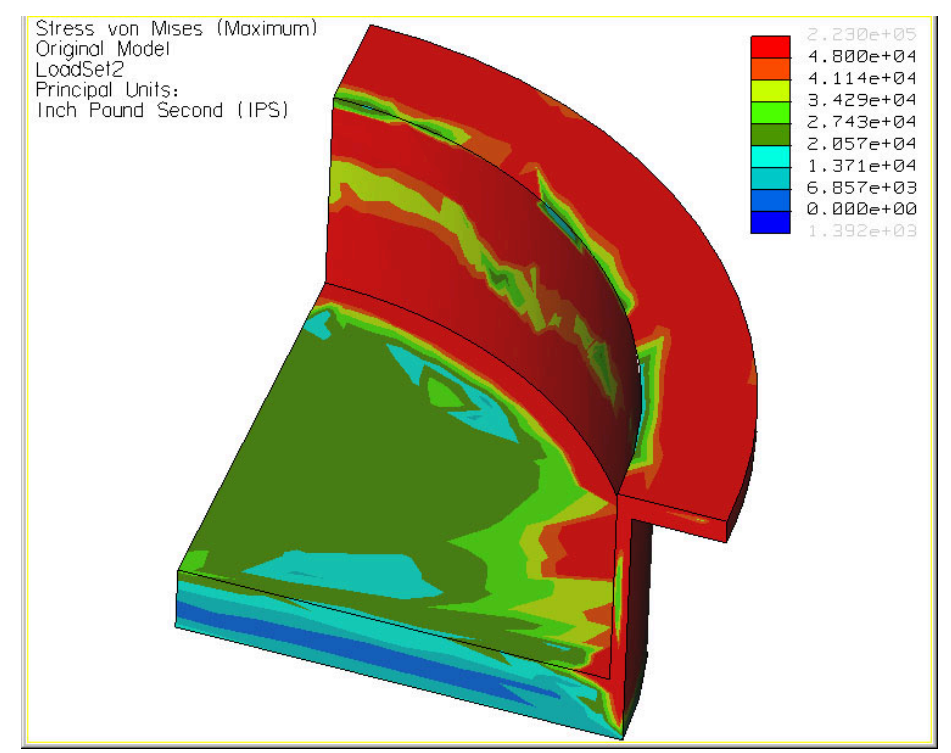

Figure 6. Results of the preliminary thermal stress analysis of the upper guide support plate.

The size and shape of most of the reactor pressure vessel internals discussed above should be similar to comparable components in a large Westinghouse designed PWR. However, it should be noted that the design of the calandria tubes that guide the flow of the moderator water through the hot region above the core and guide the control rods is not complete. We need to minimize the heat transfer surface area; one way to do that is to combine the outside water moderator boxes into one channel in the region above the core.

\subsection{Containment Design}

The SCWR containment will be a pressure-suppression type containment with a condensation pool, essentially the same design as modern BWRs [Jonsson 2003]. The key containment parameters are listed in Table VI. A 3-dimensional isometric sketch of the SCWR containment is shown in Figure 7 and an axial view with dimensions is shown in Figure 8 . The dry and wet well volumes were calculated to limit the pressure build-up to typical BWR levels following a LOCA or a severe accident with core melting (hydrogen generation from cladding oxidation is considered). Also, the concrete floors were designed to withstand such loads. The condensation pool water inventory provides ample margin for residual heat removal and meets the requirement that active safety systems are not needed during the first 12 hours following an initiating event resulting in a severe accident. The blow-down pipes or vents are placed in the outer cylindrical walls due to lack of space in the inner cylindrical walls. 
Compared to the advanced BWR containment designs, the SCWR containment drywell can be reduced because:

- The SCWR has only 2 steam and feedwater lines.

- The SCWR has a smaller diameter pressure vessel.

- The control rods enter the reactor pressure vessel from the top. Also, there are fewer control rod drive installations and fewer areas for transportation of equipment. Also, installations for control rod drive maintenance are not needed below the pressure vessel.

- There are no internal recirculation pumps.

On the other hand, the SCWR containment drywell volume is increased because of the high temperature fluid to the turbine, since additional cooling and thermal expansion space are needed. Also, the concrete must accommodate higher temperatures during an accident. Furthermore the SCWR containment is lower because the pressure vessel is lower. However, this will tend to increase the diameter of the containment and will also lead to less space for connections and floorings. When all these effects are included, the SCWR containment is somewhat smaller than that of an advanced BWR of similar thermal power, and thus significantly smaller on a per unit electric power basis.

Because the potential for core damage in a SCWR is similar to traditional LWRs, enhanced safety is only possible if the offsite consequences of a core damage accident are negligible. The European Utility Requirements statements regarding severe accidents and mitigation of their effects were adopted: "Core debris cooling. This can be achieved via a solidly founded technical demonstration for either in-vessel debris cooling or ex-vessel debris cooling"
Table VI. SCWR containment parameters.

\begin{tabular}{|l|l|}
\hline Parameter & Value \\
\hline Dry well volume & $5000 \mathrm{~m}^{3}$ \\
\hline Wet well gas volume & $3300 \mathrm{~m}^{3}$ \\
\hline Wet well condensation pool volume & $5640 \mathrm{~m}^{3}$ \\
\hline Blow-down area & $\begin{array}{l}18 \mathrm{~m}^{2} \\
(\sim 60 \\
\text { vents) }\end{array}$ \\
\hline Dry well maximum pressure & $510 \mathrm{kPa}$ \\
\hline Wet well maximum pressure & $470 \mathrm{kPa}$ \\
\hline $\begin{array}{l}\text { Dry to wet well maximum pressure } \\
\text { difference }\end{array}$ & $300 \mathrm{kPa}$ \\
\hline Dry well temperature local (short time) & $500^{\circ} \mathrm{C}$ \\
\hline Dry well temperature global (short time) & $350^{\circ} \mathrm{C}$ \\
\hline Dry well temperature global (long time) & $150^{\circ} \mathrm{C}$ \\
\hline Wet well gas temperature & $100^{\circ} \mathrm{C}$ \\
\hline Condensation pool temperature & $<100^{\circ} \mathrm{C}$ \\
\hline
\end{tabular}

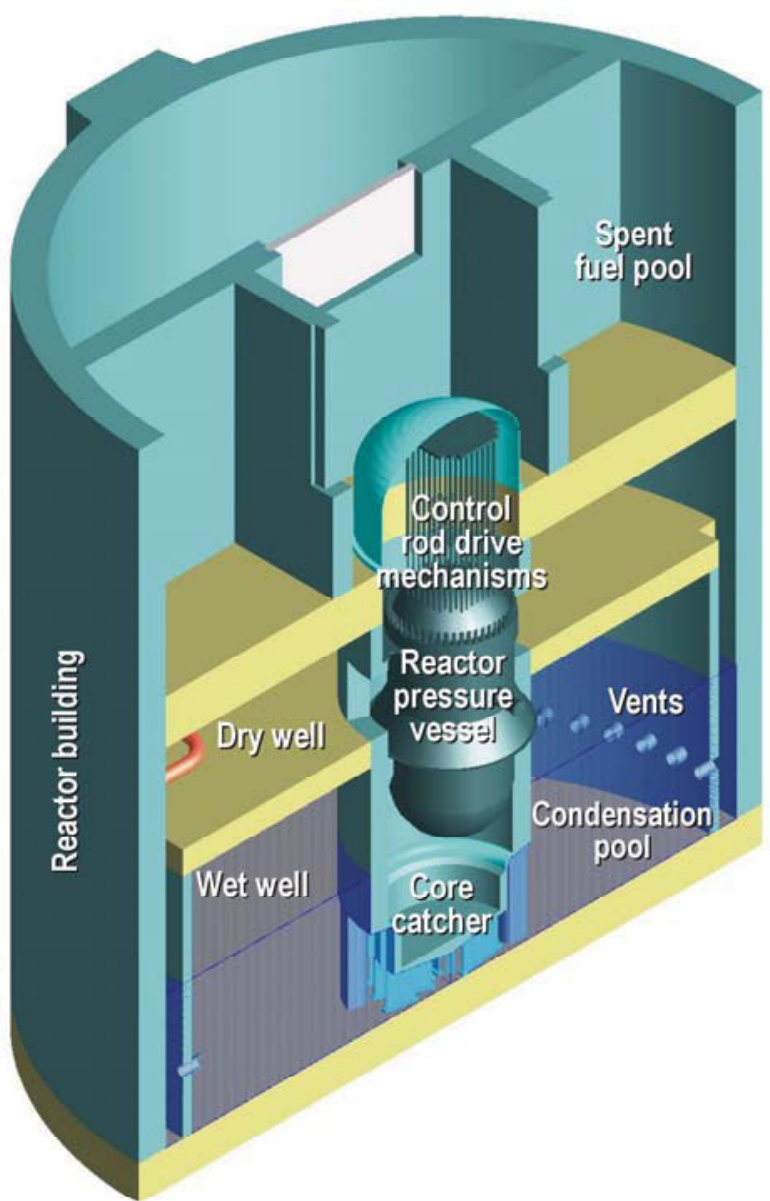

Figure 7. SCWR pressure suppression pool type containment. 
[European Utility Requirements 2001]. Therefore, the current SCWR design includes a core catcher under the reactor pressure vessel, thus achieving ex-vessel retention. However, based on the power rating and the size of the SCWR vessel, an alternative solution featuring in-vessel core debris cooling should also be possible. As already mentioned, the condensation pool is sized to provide a sufficient heat sink for decay heat in case of severe accident. This approach leads to a larger containment size, but simplifies the design of safety and mitigation systems. Other alternatives should be possible to provide the same grace period following a severe accident, e.g., a passive containment cooling system. It is difficult to judge the best solution at this point of the design, and it was, therefore, decided to proceed with this reference solution. Further reductions of the containment volume will be explored in FY-04.

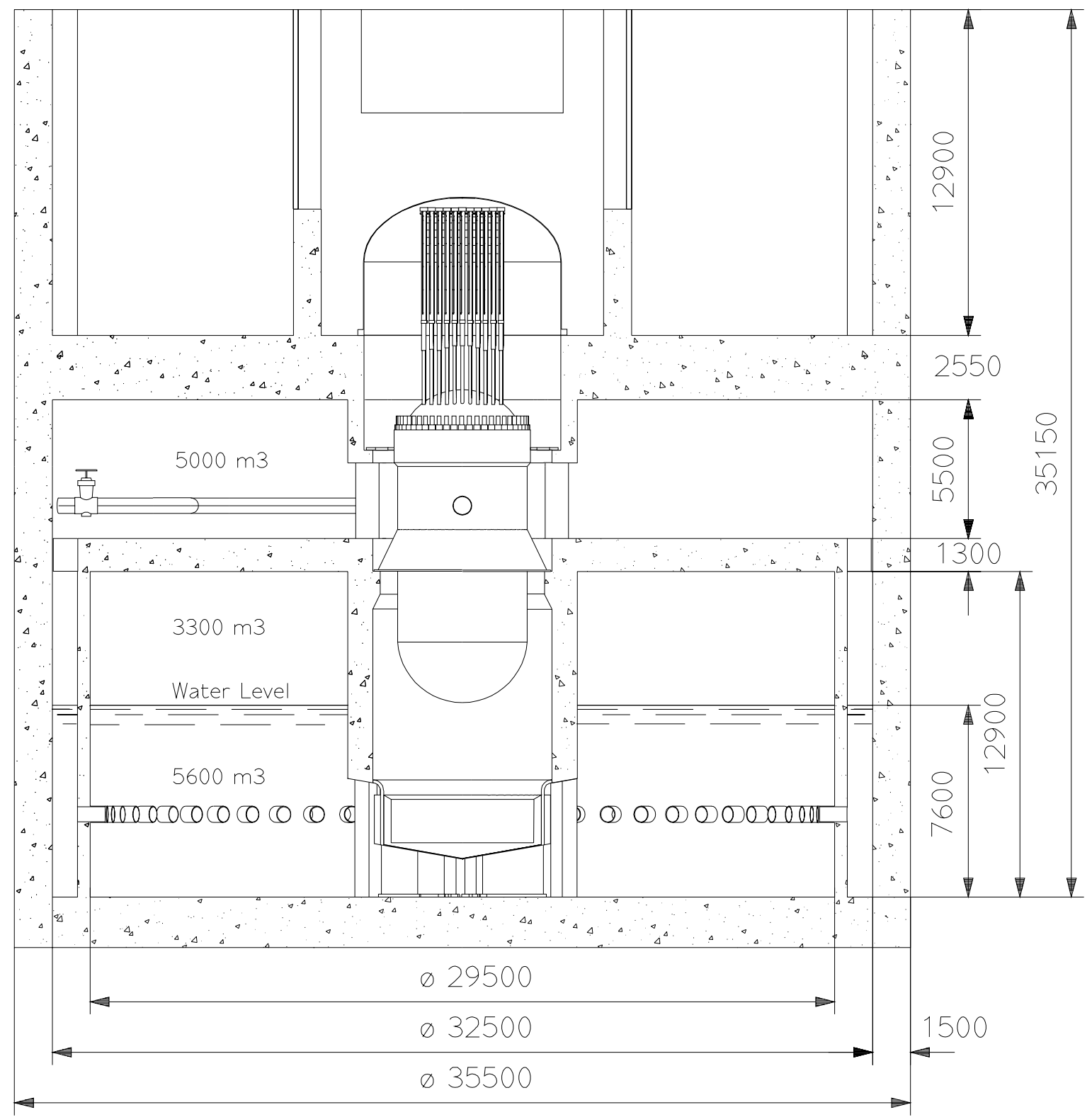

Figure 8. SCWR pressure suppression containment building. 


\subsection{Power Conversion Cycle}

The reference SCWR system will have a power conversion cycle that is very similar to a supercritical coal-fired plant, with the boiler replaced by the nuclear reactor. As part of the U.S. Gen-IV SCWR R\&D program, Burns \& Roe Enterprises Inc. has performed a conceptual study of the power conversion cycle for the SCWR to identify an optimal configuration that will maximize the thermal efficiency and minimize the capital cost [Burns \& Roe 2003]. Particular attention was given to ensure that all components are either commercially available or within current design capabilities. A schematic of the SCWR power conversion cycle is shown in Figure 9; the operating conditions are reported in Table VII and the turbine expansion is shown in Figure 10.

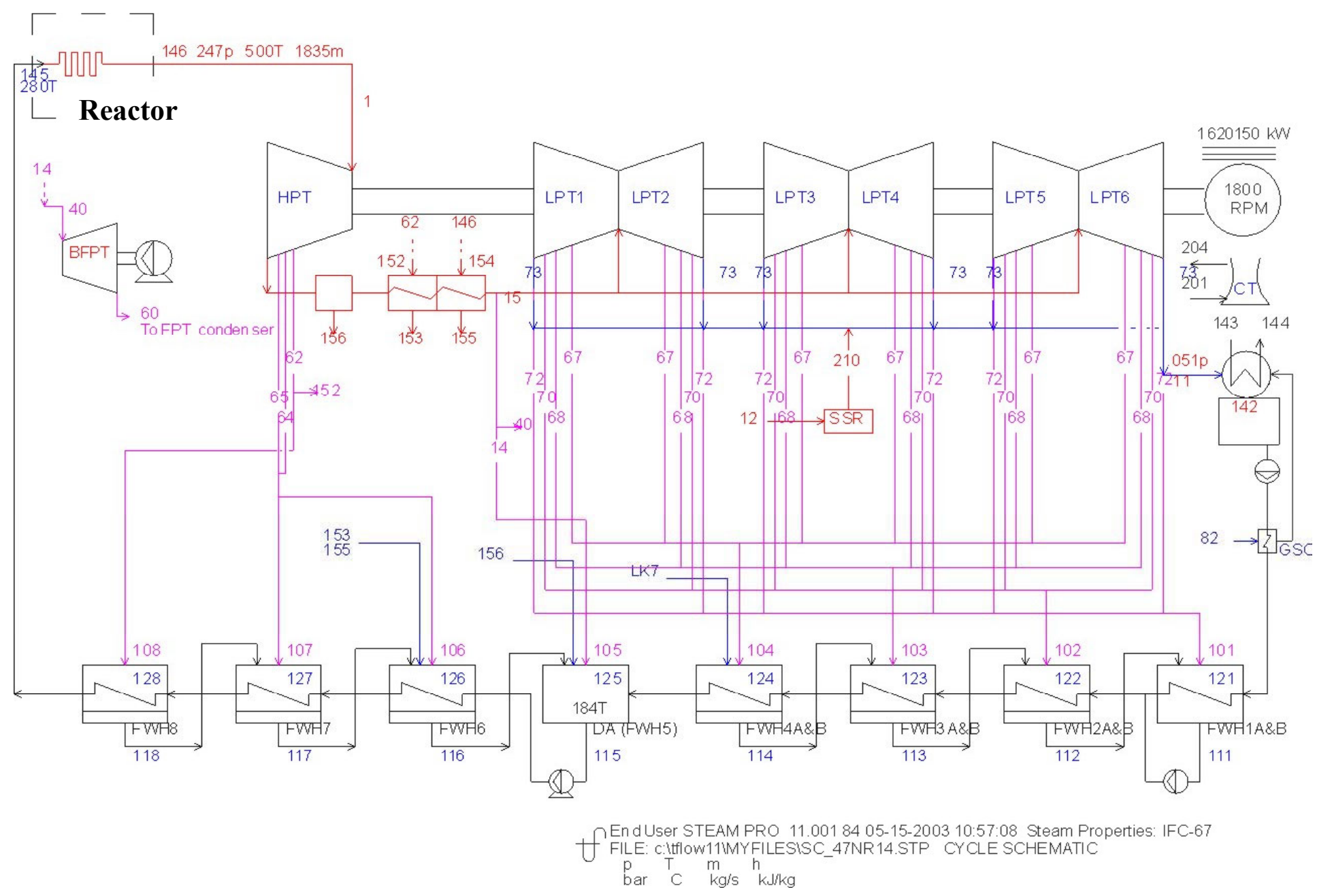

Figure 9. Schematic of the SCWR power conversion cycle (HPT $=$ high pressure turbine, $\mathrm{LPT}=$ low pressure turbine, $\mathrm{FWH}=$ feedwater heater).

The cycle is based on a large single-shaft turbine with one high-pressure/intermediate-pressure unit and three low-pressure units operating at reduced speed $(1800 \mathrm{rpm})$. The reduced speed is needed to prevent excessive steam speeds and high stresses in the 52" blade stages of the low-pressure units. The steam parameters at the high-pressure/intermediate-pressure unit inlet are $494{ }^{\circ} \mathrm{C}$ and $23.4 \mathrm{MPa}$, well within current capabilities of fossil plants. Similarly to traditional LWR cycles, a moisture separator-reheater 
(MSR) module is located between the high-pressure/intermediate-pressure and the low-pressure turbines, and reheating is achieved with the steam. Heat rejection occurs in traditional natural-draft cooling towers. Eight feedwater heaters raise the condensate temperature to the reactor inlet level of $280{ }^{\circ} \mathrm{C}$. The main feedwater pumps are turbine-driven and operate at about $190{ }^{\circ} \mathrm{C}$. There are two steam lines with outside diameters of $0.470 \mathrm{~m}$ (18.5 in.) and inside diameters of 0.368 (14.5 in.). The material identified by Burns and Roe for these lines is Alloy P92 (9Cr-2W).

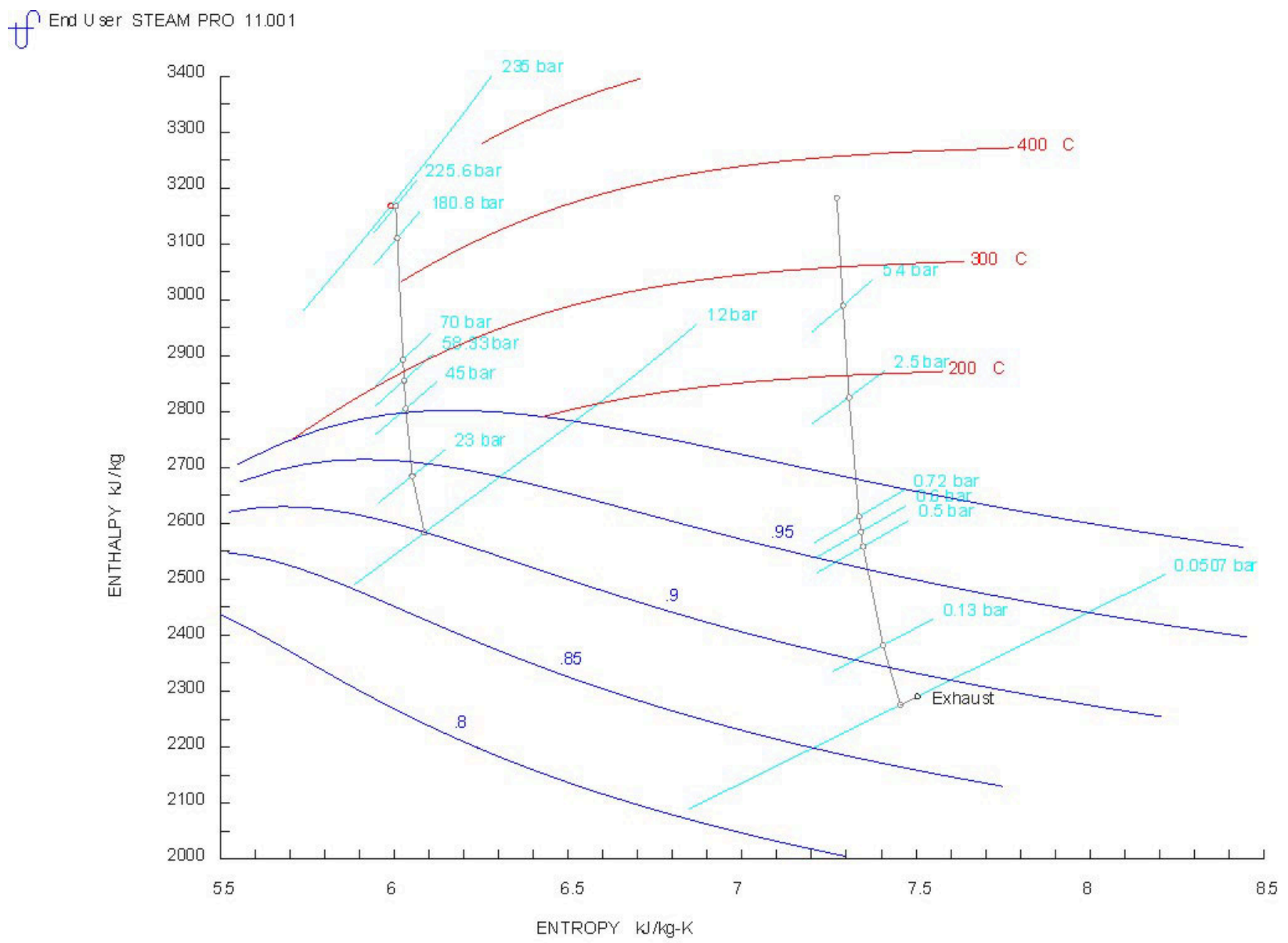

84 05-20-2003 14:00:45 C:Itflow11MMYFILESISC_47NR14.STP

Figure 10. Enthalpy versus entropy at various steam/water fractions and pressures for the SCWR turbine expansion and reheating.

The cycle shown in Figure 9 and Table VII achieves a net thermal efficiency (net power to grid / fission power) of $44.8 \%$, which accounts for all losses and the plant self-consumption (excluding the nuclear island). 
Table VII. List of pressures, temperatures, mass flow, and enthalpy at the numbered locations of Figure 9.

\begin{tabular}{|c|c|c|c|c|}
\hline Stream & p [bar] & $\mathrm{T}[\mathrm{C}]$ & $\mathrm{T}[\mathrm{kg} / \mathrm{s}]$ & $\mathrm{h}[\mathrm{kJ} / \mathrm{kg}]$ \\
\hline 1 Throttle or initial condition outside ST & 235 & 494 & 1722.47 & 3167.3 \\
\hline 6 PIPT ahead of intercept valve & 12 & 188 & 1130.63 & 2773.7 \\
\hline 11 Condenser (LPT exhaust & 0.05 & 33.1 & 782.36 & 2290.3 \\
\hline 12 SSR Inlet & 1.24 & 105.8 & 0.94 & 2616.5 \\
\hline 14 After 2nd RH & 12 & 363 & 149.69 & 3182.2 \\
\hline 15 LPT Crossover & 12 & 363 & 982.07 & 3182.2 \\
\hline 40 Inlet stream of FPT & 11.43 & 361.4 & 96.15 & 3179.9 \\
\hline 60 Extr1 (or exh if only 1 group) of FPT & 0.07 & 38.7 & 96.15 & 2410.4 \\
\hline 62 Add / extr of ST group 2 & 70 & 313.3 & 265.4 & 2893 \\
\hline 64 Add / extr of ST group 4 & 45 & 259.4 & 127.38 & 2805.3 \\
\hline 65 Add / extr of ST group 5 & 23 & 219.6 & 75.74 & 2684.8 \\
\hline 67 Add / extr of ST group 7 & 5.4 & 264.2 & 13.39 & 2989.3 \\
\hline 68 Add / extr of ST group 8 & 2.5 & 179.2 & 6.82 & 2825.1 \\
\hline 70 Add / extr of ST group 10 & 0.6 & 86 & 9.84 & 2585.1 \\
\hline 72 Add / extr of ST group 12 & 0.13 & 51.1 & 3.33 & 2382.1 \\
\hline 73 Add / extr of ST group 13 & 0.05 & 33.1 & 130.3 & 2290.3 \\
\hline 82 Stream to GSC 0.83 & 0.83 & N/A & 0.38 & 2616.5 \\
\hline 101 Heating steam at FWH1 & 0.12 & 49.5 & 19.96 & 2379.8 \\
\hline 102 Heating steam at FWH2 & 0.58 & 85 & 59.06 & 2582.7 \\
\hline 103 Heating steam at FWH3 & 2.4 & 177.8 & 40.94 & 2822.8 \\
\hline 104 Heating steam at FWH4 & 5.18 & 262.8 & 80.32 & 2987 \\
\hline 105 Heating steam at FWH5 & 11.08 & 361.1 & 53.54 & 3179.9 \\
\hline 106 Heating steam at FWH6 & 22.05 & 217.4 & 75.74 & 2682.4 \\
\hline 107 Heating steam at FWH7 & 42.17 & 254.5 & 127.38 & 2803 \\
\hline 108 Heating steam at FWH8 & 67.11 & 309.6 & 157.45 & 2890.7 \\
\hline 111 Drain liquid at FWH1 & 0.12 & 49.5 & 200.94 & 207.3 \\
\hline 112 Drain liquid at $\mathrm{FWH} 2$ & 0.58 & 52.9 & 180.99 & 221.5 \\
\hline 113 Drain liquid at $\mathrm{FWH} 3$ & 2.4 & 87.8 & 121.93 & 367.7 \\
\hline 114 Drain liquid at FWH4 & 5.18 & 112 & 80.99 & 470.2 \\
\hline 115 Drain liquid at FWH5 & 11.08 & 184.4 & 1842.92 & 782.5 \\
\hline 116 Drain liquid at FWH6 & 22.05 & 195.6 & 588.98 & 832.7 \\
\hline 117 Drain liquid at $\mathrm{FWH} 7$ & 42.17 & 220 & 513.24 & 944 \\
\hline 118 Drain liquid at FWH8 & 67.11 & 256.3 & 385.86 & 1116.4 \\
\hline 121 Feedwater into FWH1 & 19.42 & 34.2 & 878.88 & 145 \\
\hline 122 Feedwater into FWH2 & 17.81 & 47.3 & 1079.83 & 199.6 \\
\hline 123 Feedwater into FWH3 & 15.55 & 82.2 & 1079.83 & 345.2 \\
\hline 124 Feedwater into FWH4 & 14.69 & 106.1 & 1079.83 & 446 \\
\hline 125 Feedwater into FWH5 & 11.08 & 150.5 & 1079.83 & 634.5 \\
\hline 126 Feedwater into FWH6 & 253.69 & 190 & 1842.92 & 819.2 \\
\hline 127 Feedwater into FWH7 & 253.13 & 214.4 & 1842.92 & 926.2 \\
\hline 128 Feedwater into FWH8 & 252.53 & 250.7 & 1842.92 & 1090.8 \\
\hline 142 Feed water leaving condenser & 0.35 & 33.1 & 782.74 & 138.8 \\
\hline 143 Cooling water into condenser & 3.74 & 17.7 & 30275.3 & 74.5 \\
\hline 144 Cooling water leaving condenser & 2.51 & 31 & 30275.3 & 130.1 \\
\hline 145 Feed water into reactor & 252.01 & 280 & 1842.92 & 1230 \\
\hline 146 Steam leaving reactor & 246.75 & 499.7 & 1842.92 & 3169.6 \\
\hline 152 Heating steam of 1 st $\mathrm{RH}$ & 70 & 313.3 & 107.95 & 2893 \\
\hline 153 Drain of 1 st $\mathrm{RH}$ & N/A & $\mathrm{N} / \mathrm{A}$ & 107.95 & 825.7 \\
\hline 154 Heating steam of $2 \mathrm{nd} \mathrm{RH}$ & 246.75 & 499.7 & 120.46 & 3169.6 \\
\hline 155 Drain of $2 \mathrm{nd} \mathrm{RH}$ & N/A & $\mathrm{N} / \mathrm{A}$ & 120.46 & 1188.2 \\
\hline 156 Moisture separator drain & N/A & N/A & 120.57 & 798.4 \\
\hline 201 Cooling tower inlet air & N/A & 20 & 32549.72 & $\mathrm{~N} / \mathrm{A}$ \\
\hline 204 Cooling tower exit air & $\mathrm{N} / \mathrm{A}$ & 27.2 & 33201.16 & $\mathrm{~N} / \mathrm{A}$ \\
\hline 210 SSR to condenser & 1.24 & 105.8 & 0.94 & 2616.5 \\
\hline Valve Stem leak 1 => LPcrs & $\mathrm{N} / \mathrm{A}$ & $\mathrm{N} / \mathrm{A}$ & 1.13 & 3167.3 \\
\hline Valve Stem leak 2 => SSR & N/A & $\mathrm{N} / \mathrm{A}$ & 0.05 & 3167.3 \\
\hline HPT LP leak 1 => FWH4 & $\mathrm{N} / \mathrm{A}$ & $\mathrm{N} / \mathrm{A}$ & 0.67 & 2583.4 \\
\hline HPT LP leak 2 => SSR & $\mathrm{N} / \mathrm{A}$ & $\mathrm{N} / \mathrm{A}$ & 0.89 & 2583.4 \\
\hline
\end{tabular}




\section{Task 1 Results: Fuel-Cycle Neutronic Analysis and Reactor Core Design}

\subsection{An Alternative SCWR Design Based on Vertical Power Channels and Hexagonal Fuel Assemblies (Jacopo Buongiorno, INEEL)}

\subsubsection{Introduction}

It is well known that supercritical-water cooled reactors (SCWRs) require a dedicated moderator to realize a thermal-spectrum core because of their relatively low coolant density. Several approaches are being investigated in Japan, Europe, the U.S. and Canada, including the use of water rods [Oka and Koshizuka 2000, Cheng and Schulenberg 2000], solid-moderator rods [Buongiorno and MacDonald 2003a and 2003b], or low-temperature heavy water in a separate moderator tank [Bushby et al. 2000, Spinks et al. 2002]. The mechanical design of the fuel assembly with water rods is fairly complicated. On the other hand, solid moderators simplify the vessel internals, but do not have a favorable neutron economy, while the use of heavy water requires the development of a very high-temperature highpressure tube design. Therefore, we have explored an alternative design based on vertical power channels and hexagonal fuel assemblies, which may counter the shortcomings of the aforementioned approaches. This design is effectively a much-simplified version of the 1950s' Westinghouse SCR concept described by Oka [2000], and Marchaterre and Petrick [1960].

\subsubsection{Concept Description}

The overall parameters of this new design are similar to the traditional water-rod SCWR design, i.e., the fuel is low-enriched uranium oxide, the operating pressure is $25 \mathrm{MPa}$, the inlet and outlet temperatures are 280 and $500{ }^{\circ} \mathrm{C}$, respectively. A schematic view of the vessel and vessel internals is shown in Figure 11. The vertical power channels contain the fuel assemblies. As it flows downward in the interpower-channel gap, the feedwater acts as the neutron moderator. The moderator reverses flow direction in the cold plenum and flows upward in the fuel assemblies as coolant. The coolant collects in the hot plenum from where it is directed to the turbine. The unheated region above the active core provides uniform feedwater flow distribution (hence uniform moderation) throughout the core underneath. Cooling of the upper head and cylindrical shell of the reactor pressure vessel (RPV) is achieved by means of the small feedwater bypasses (e.g.,

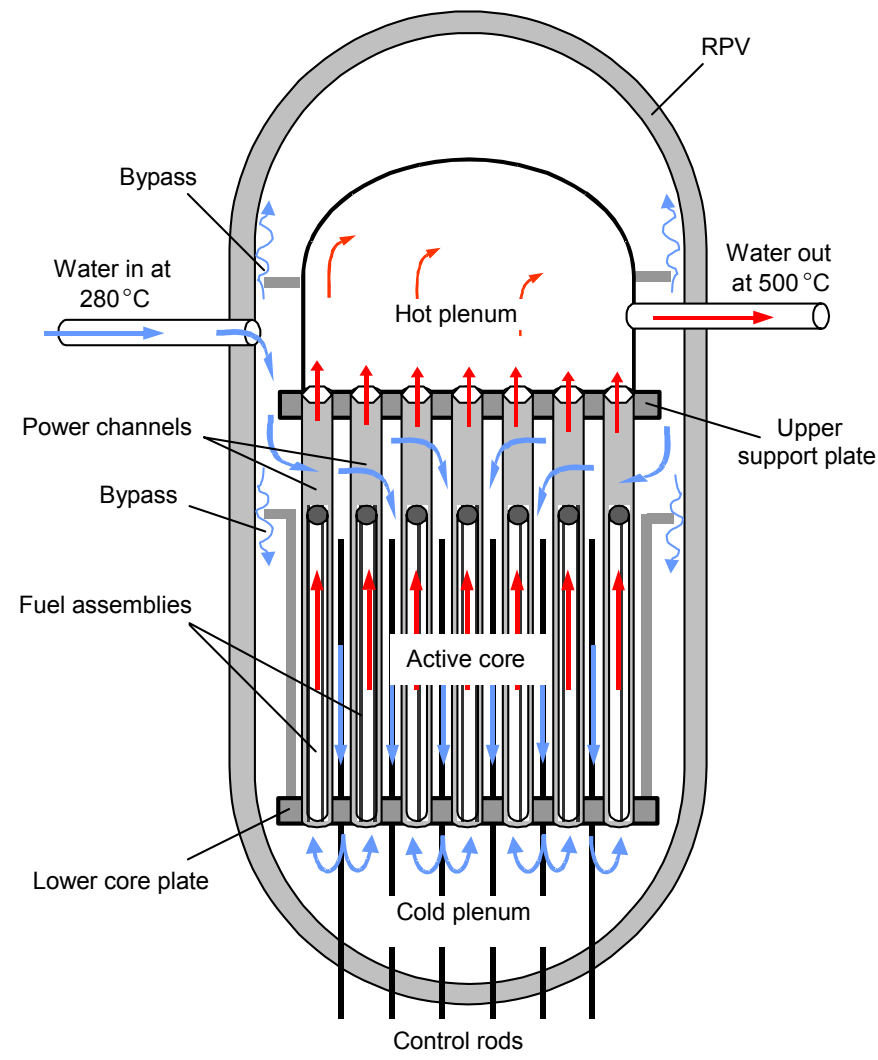

Figure 11. SCWR with power channels. 
$1 \%$ of the nominal flow each) shown in Figure 11. A cross section of the core unit cell with the power channels and the fuel assemblies is shown in Figure 12. The fuel assemblies are of the hexagonal type with 19 fuel pins. In the reference configuration the fuel pins are separated by wire-wrap spacers, but also grid spacers could be utilized since the pin-topin gap is sufficiently wide. The reference fuel-cladding material is an Oxide Dispersion Strengthened (ODS) ferritic steel, designated Incoloy MA956. ODS ferritic alloys have been shown to possess excellent mechanical, corrosion and irradiation properties [Harper 2002, Bottcher et al. 2002, Ukai et al. 1998]. Alloy MA956 in particular is commercially available in the U.S. [Special Metals 2003], and its properties are well known [Klopp 1992]. However, the performance of MA956 in the coolant chemistry of the SCWR is very uncertain at this time, so the use of this alloy should be considered only as a working assumption.

The upper support plate provides a seal to minimize feedwater leakage into the hot plenum. To minimize parasitic neutron

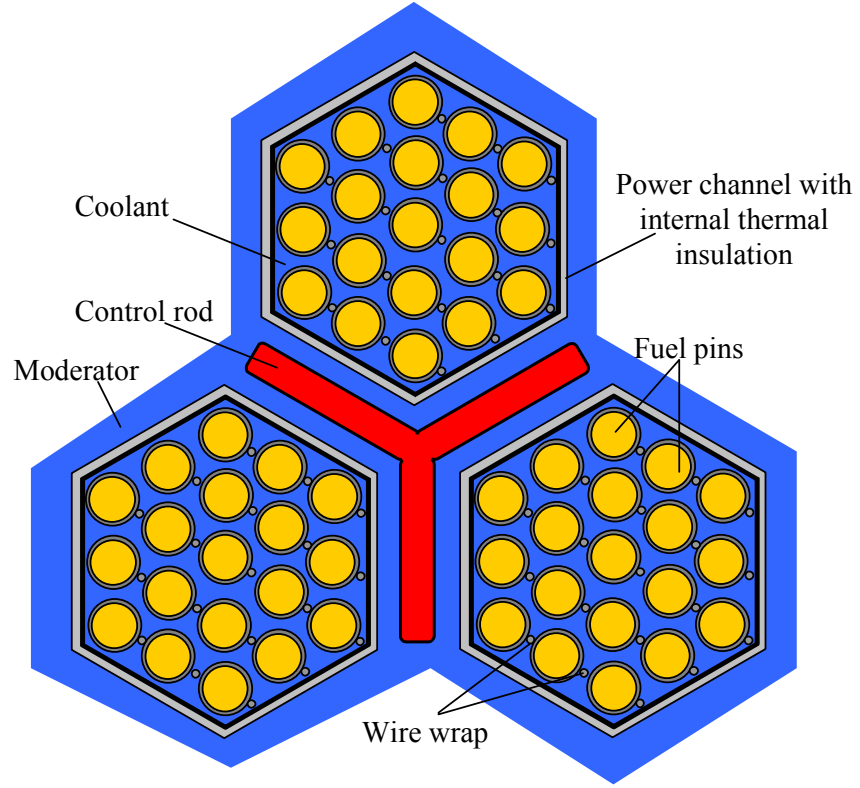

Figure 12. Geometry of the core unit cell. captures in the structures, the power channels are made of $\mathrm{Zr}-2.5 \mathrm{Nb}$ alloy, which has been extensively and successfully used for CANDU reactor pressure tubes. However, unlike in CANDU reactors, thermal and irradiation creep effects should be negligible here because the power channels do not perform a pressure-bearing function. Therefore, their thickness can be kept low. The inner surface of the power channels is coated with a thermal insulator to prevent corrosion by the high-temperature coolant. The outer surface of the power channels needs no specific protection because it is exposed to relatively low temperature water (i.e., 280-338 ${ }^{\circ} \mathrm{C}$ ), for which the $\mathrm{Zr}-2.5 \mathrm{Nb}$ alloy has adequate corrosion resistance and strength [Bushby et al. 2000]. Several materials could be used for the thermal insulation. For example, AECL is developing a $\mathrm{ZrO}_{2}$-based insulating material for operation of their CANTHERM pressure tube in supercritical water. The control rods are inserted through the vessel bottom head, and are located between the power channels. The control rods are of the BWR type except that they have only three blades with $120^{\circ}$ spacing. The total number of control rods has not been selected yet, but it is expected that not all power-channel intersections will have a control rod.

The advantages of this system are as follows

1) The mechanical design of the fuel assembly is simple with no water rods and external ducting. A wire wrap can be used as spacer for the fuel pins.

2) The amount of vessel internals above the core is minimal, which should simplify refueling operation.

3) A favorable neutron economy is achievable due to the use of the zirconium-based alloy for the power channels.

4) A higher power density is achievable compared to the SCWR design with water rods.

However, this approach presents also some specific challenges. The most significant ones are listed below. 
1) The local peaking in the fuel assembly is high due to the distance of the inner fuel rods from the moderator in the inter-power-channel gap. This requires a significant radial variation of the enrichment within the fuel assembly.

2) As it flows downward between the power channels, the moderator temperature rises roughly 58 ${ }^{\circ} \mathrm{C}$. Therefore the reactor pressure vessel lower head operates at higher temperature than the rest of the vessel, which is not desirable.

3) A durable insulation material for the power channels needs to be selected/developed.

In the following sections the results of simplified thermal-hydraulic and neutronic analyses are presented to illustrate the characteristics of this novel design.

\subsubsection{Thermal-Hydraulic Analysis}

The design parameters for the SCWR with power channels are reported in Table VIII. Note that the fuel pin dimensions are similar to those of the PWR fuel design. The pin-to-pin and pin-to-power-channel gaps are $1 \mathrm{~mm}$ each, sufficient to accommodate the wire-wrap spacer. The average linear power was selected to prevent fuel centerline melting during a $118 \%$ transient overpower (same criterion as the PWR) with a total (radial + axial + local) peaking factor in the core of 2.1 and a cladding peak temperature of $840{ }^{\circ} \mathrm{C}$ (the thermal limit for Condition II events). The average power density with this selection of the parameters is about $90 \mathrm{~kW} / \mathrm{L}$, comparable to the PWR and much higher than more traditional water-rod SCWR designs (i.e., $55-75 \mathrm{~kW} / \mathrm{L}$ ). Therefore, it is expected that for a given vessel size, this design will allow for $>20 \%$ higher power output, an important economic advantage.

Table VIII. Reference parameters for the SCWR design with power channels.

\begin{tabular}{|c|c|}
\hline Parameter & Value \\
\hline Fuel & $\mathrm{UO}_{2}, 10.42 \mathrm{~g} / \mathrm{cm}^{3}$ (95\% TD) \\
\hline Fuel Pellet outside diameter & $8.2 \mathrm{~mm}$ \\
\hline Fuel Pin outside diameter & $9.5 \mathrm{~mm}$ \\
\hline Cladding Thickness & $0.57 \mathrm{~mm}$ \\
\hline Cladding Material / Composition / Density & MA956, Fe-21.5Cr-5.75Al-0.6Ti-0.7Y ${ }_{2} \mathrm{O}_{3}, 7.25 \mathrm{~g} / \mathrm{cm}^{3}$ \\
\hline Fuel Pin Pitch & $10.5 \mathrm{~mm}$ \\
\hline Pitch-to-Diameter Ratio & 1.105 \\
\hline Wire-Wrap Axial Pitch & $190 \mathrm{~mm}$ \\
\hline Power Channel Materials / Density & $\begin{array}{l}\mathrm{Zr}-2.5 \mathrm{Nb}\left(6.5 \mathrm{~g} / \mathrm{cm}^{3}\right), \quad \mathrm{ZrO}_{2}\left(4.7 \mathrm{~g} / \mathrm{cm}^{3}\right) \text { internal } \\
\text { insulation }\end{array}$ \\
\hline Power Channel Width & $51.9 \mathrm{~mm}$ (flat to flat) \\
\hline Power Channel Thickness & $1.5 \mathrm{~mm}(\mathrm{Zr}-2.5 \mathrm{Nb})+0.5 \mathrm{~mm}\left(\mathrm{ZrO}_{2}\right)$ \\
\hline Inter-Power-Channel Gap & $16 \mathrm{~mm}$ \\
\hline Fuel Assembly Hydraulic Diameter & $3.5 \mathrm{~mm}$ \\
\hline Fuel Assembly Flow Area & $638 \mathrm{~mm}^{2}$ \\
\hline Active Fuel Length & $4.27 \mathrm{~m} \mathrm{(14 \textrm {ft } )}$ \\
\hline Power Channel Length & $5.55 \mathrm{~m}$ \\
\hline Core Inlet / Outlet Temperature & $280 / 500^{\circ} \mathrm{C}$ \\
\hline Operating Pressure & $25 \mathrm{MPa}$ \\
\hline Average Linear Power & $19 \mathrm{~kW} / \mathrm{m}$ \\
\hline Average Fuel Pin Power & $81.1 \mathrm{~kW}$ \\
\hline Average Power Density & $90.5 \mathrm{~kW} / \mathrm{L}$ \\
\hline
\end{tabular}

TD=Theoretical Density 
The moderator/coolant temperature and density profiles in the core were calculated by means of the following equations, which account for the heat transfer between the coolant and the moderator across the power channels

$$
\left\{\begin{array}{l}
\mathrm{m} \frac{\mathrm{dh}_{\mathrm{m}}}{\mathrm{dz}}=\gamma \mathrm{Nq}+6 \mathrm{Sq}^{\prime \prime} \\
-\mathrm{m} \frac{\mathrm{dh}}{\mathrm{dz}}=(1-\gamma) \mathrm{Nq}^{\prime}-6 \mathrm{Sq}^{\prime \prime}
\end{array}\right.
$$

where $\mathrm{m}$ is the moderator/coolant mass flow rate associated with a fuel assembly, $h_{m}$ and $h_{c}$ are the moderator and coolant enthalpies, respectively, $\mathrm{z}$ is the axial coordinate $(\mathrm{z}=0$ at the top of the power channels), $\gamma=0.025$ is the fraction of fission heat directly deposited in the moderator, $N=19$ is the number of fuel pins in the fuel assembly, $\mathrm{q}^{\prime}$ is the linear power per fuel $\operatorname{pin}^{1}, \mathrm{~S}$ is the power channel side length, and q" is the heat flux at the power channel wall. Equations (1) and (2) are solved with the following boundary conditions:

$$
\begin{array}{ll}
\left.\mathrm{T}_{\mathrm{m}}\right|_{\mathrm{z}=0}=280^{\circ} \mathrm{C} & \text { (inlet condition) } \\
\mathrm{T}_{\mathrm{c}} \mathrm{z}_{\mathrm{z}}=500^{\circ} \mathrm{C} & \text { (outlet condition) } \\
\mathrm{T}_{\mathrm{c}}-\mathrm{T}_{\mathrm{m}}=\mathrm{q}^{\prime \prime} / \mathrm{H}_{\mathrm{w}} & \text { (coolant-moderator heat transfer) }
\end{array}
$$

where $\mathrm{H}_{\mathrm{w}}$ is the heat transfer resistance between the coolant and the moderator

$$
1 / \mathrm{H}_{\mathrm{w}}=1 / \mathrm{H}_{\mathrm{c}}+\mathrm{t}_{\mathrm{ZN}} / \mathrm{k}_{\mathrm{ZN}}+\mathrm{t}_{\mathrm{Z}} / \mathrm{k}_{\mathrm{Z}}+1 / \mathrm{H}_{\mathrm{m}}
$$

In Equation (6) $\mathrm{H}_{\mathrm{c}}$ and $\mathrm{H}_{\mathrm{m}}$ are the heat transfer coefficients ${ }^{2}$ for the coolant and moderator, respectively; $\mathrm{t}$ and $\mathrm{k}$ are thickness and thermal conductivity, respectively, while the subscripts " $\mathrm{ZN}$ " and " $\mathrm{Z}$ " stand for $\mathrm{Zr}-2.5 \mathrm{Nb}$ and $\mathrm{ZrO}_{2}$, respectively ${ }^{3}$. In addition to Equations (1) through (6) the fuel-cladding temperature, $\mathrm{T}_{\text {clad, }}$, can be calculated as follows

$$
\mathrm{T}_{\text {clad }}=\mathrm{T}_{\mathrm{c}}+\frac{\mathrm{q}^{\prime}}{\pi \mathrm{dH}_{\mathrm{c}}^{\prime}}
$$

where $\mathrm{d}$ is the fuel pin outside diameter and $\mathrm{H}_{\mathrm{c}}^{\prime}$ is the heat transfer coefficient at the cladding surface. Further, the total pressure drop in the core, $\Delta \mathrm{P}_{\text {core }}$, can be calculated as follows

$$
\Delta \mathrm{P}_{\text {core }}=\sum_{\mathrm{j}}\left(\mathrm{K}_{\mathrm{j}}+\mathrm{f}_{\mathrm{j}} \frac{\mathrm{L}_{\mathrm{j}}}{\mathrm{d}_{\mathrm{j}}}\right) \frac{\rho_{\mathrm{j}} \mathrm{V}_{\mathrm{j}}^{2}}{2}
$$

where $K_{j}, f_{j}, L_{j}, d_{j}, \rho_{j}$ and $V_{j}$ are the form loss coefficient, friction coefficient, length, hydraulic diameter, water density and velocity in the $\mathrm{j}^{\text {th }}$ section of the core. The form loss coefficient was assumed to be 0.5 and 1.0 for entrance from the cold and exit to the hot plenum, respectively. The friction coefficient in the fuel assembly was calculated with the Cheng and Todreas correlation for hexagonal rod bundles with wire-wrap spacers [15]. Equation (8) yields a total pressure drop of $0.16 \mathrm{MPa}$ for the SCWR core, which is comparable to that of a LWR, and thus acceptable. Note that the moderator pressure drop is negligibly

\footnotetext{
${ }^{1}$ Obviously $\mathrm{q}^{\prime}=0$ above the active fuel region.

${ }^{2}$ Calculated with the Oka-Koshizuka correlation [2000].

${ }^{3}$ Values of $\mathrm{k}_{\mathrm{ZN}}$ and $\mathrm{k}_{\mathrm{Z}}$ are 24 and $2 \mathrm{~W} / \mathrm{m} \cdot \mathrm{K}$, respectively.
} 
small $(<1 \%)$ compared with the coolant pressure drop, i.e., most of the pressure drop occurs within the fuel assemblies, not in the inter-power-channel gap.

The above algorithm was implemented with the MATLAB program and the results are illustrated in Figures 13 and 14 for the average fuel assembly (again, note that $z=0$ at the top of the power channels and $\mathrm{Z}=5.55 \mathrm{~m}$ at bottom of the active core). It can be seen that the fuel cladding temperature remains within reasonable limits $\left(\sim 550{ }^{\circ} \mathrm{C}\right)$. Also, the thermal insulation is effective in maintaining the $\mathrm{Zr}-2.5 \mathrm{Nb}$ (marked "power channel" in Figure 13) as well as the moderator at relatively low temperature. The moderator temperature rise is only $58{ }^{\circ} \mathrm{C}$, and its density remains fairly constant, as shown in Figure 14. Figure 14 also shows the average water density in the core, calculated as the area-weighed sum of the moderator and coolant densities.

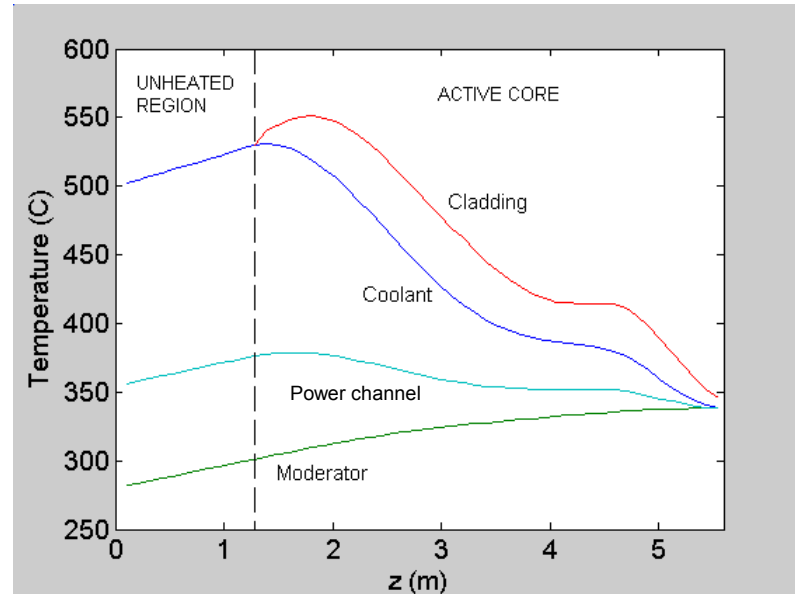

Figure 13. Temperature distributions.

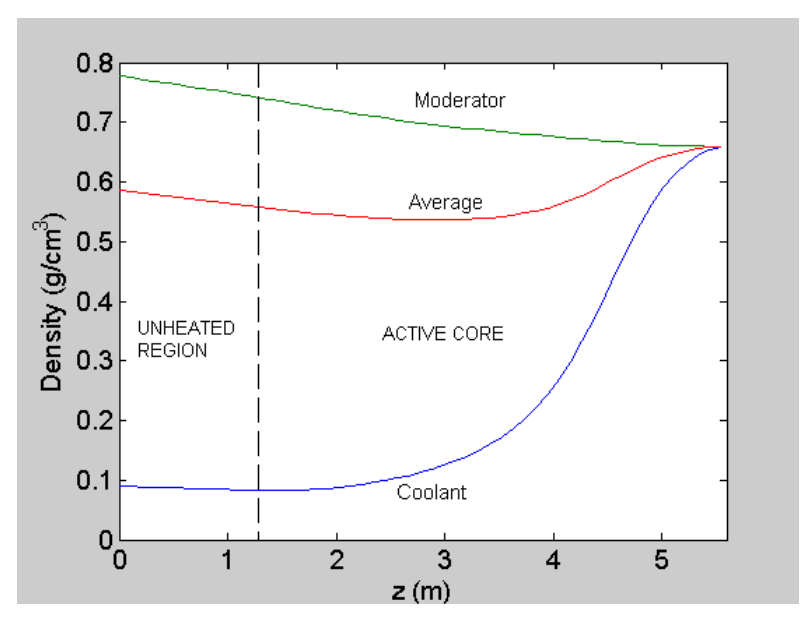

Figure 14. Density distributions.

The effect of the axial power profile in the core is captured in Equation (1) by the axial variation of q'. Because in a thermal-spectrum SCWR core the neutronics and thermal-hydraulics are coupled, the actual axial profile was calculated iterating the thermal-hydraulic model in this section with the neutronic model of the fuel-assembly discussed below in Section 3.1.4 until convergence was achieved. The "equilibrium" axial power profile is shown in Figure 23 below.

\subsubsection{Neutronic Analysis}

To analyze the neutronic performance of the SCWR design with power channels, a unit cell model for the core was developed with the Monte Carlo code MCNP-4B. The geometry is shown in Figure 15 and is equivalent to that of Figure 12, since it represents $1 / 12$ of a fuel assembly with the associated power channel and moderator regions. The control rod is not considered. The dimensions are those of Table VIII. The cell is reflected from both the radial and axial directions and the coolant and moderator densities are 0.261 and $0.690 \mathrm{~g} / \mathrm{cm}^{3}$, respectively, calculated as the average of the coolant and moderator density axial profiles in the active core (from Figure 14). For comparison purposes the unit core cell of a typical PWR with Zircaloy-4 cladding $(\mathrm{Zr}-1.5 \mathrm{Sn}-0.2 \mathrm{Fe}-0.15 \mathrm{Cr}$, wt $\%)$ and $\mathrm{UO}_{2}$ fuel was also modeled (Figure 15). The PWR fuel pin geometry (i.e., cladding outside diameter and thickness, fuel pellet outside diameter, etc.) is the same as for the SCWR, but with a simple square lattice, a typical PWR pitchto-diameter ratio of 1.33 , an average coolant density of $0.712 \mathrm{~g} / \mathrm{cm}^{3}$, and obviously without the power channels. 


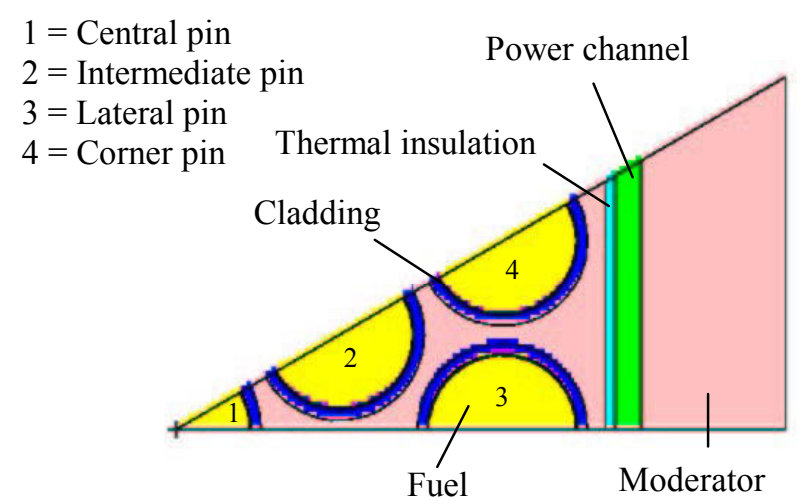

(SCWR)

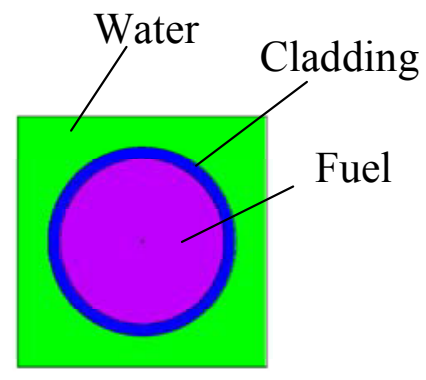

(PWR)

Figure 15. Geometry for the MCNP neutronic model

The acceptability of the SCWR core design with power channels will depend, among other factors, on its fuel-cycle cost compared with that of current LWRs. Therefore, we elect to use the fuel-cycle cost as a measure of the neutronic performance of this design. The following relation holds for the specific fuelcycle cost (\$/MWh), c:

$$
\mathrm{c} \propto \frac{\mathrm{SWU}}{\eta \cdot\left(\mathrm{k}_{\infty}-1\right)_{\mathrm{BOL}}}
$$

where SWU is the separative work units needed to obtain a certain enrichment ${ }^{4}$, and $\eta$ is the reactor thermal efficiency (i.e., $43.5 \%$ for the SCWR and 35\% for the PWR). In Equation (9) an assumption is made that the discharge burnup is directly proportional to the beginning-of-life excess reactivity, $\mathrm{k}_{\infty}-1$. This assumption is accurate when one compares systems with similar spectrum (e.g., thermal with thermal) and fuel form (e.g., uranium oxide with uranium oxide), because the reactivity-versus burnup curve has a more-or-less fixed slope. Beginning-of-life reactivity calculations were performed with the MCNP model for the SCWR and PWR core unit cells for different values of the U-235 enrichment. The ENDF-B/VI cross-section libraries at $607{ }^{\circ} \mathrm{C}$ were used for the fuel (U-235 and U-238), while roomtemperature libraries were used for all other materials. The number of neutron histories followed was $4 \times 10^{5}$ for each run.

The results of the calculations are reported in Figures 16 and 17. It can be seen that, for a given enrichment, the beginning-of-life excess reactivity, hence the discharge burnup, is higher for the PWR. However, when one takes into account the thermal efficiency, the fuel-cycle cost for the SCWR appears to be comparable with that of the PWR. We select 5 at $\%$ as a reasonable value for the enrichment of the SCWR design with power channels. Note that in reality the selection of the fuel enrichment for a commercial reactor also involves considerations of other effects such as optimal refueling frequency, capacity factor, etc, which are beyond the scope of this study.

\footnotetext{
${ }^{4}$ A U-235 content of 0.3 at $\%$ is assumed for the tails.
} 


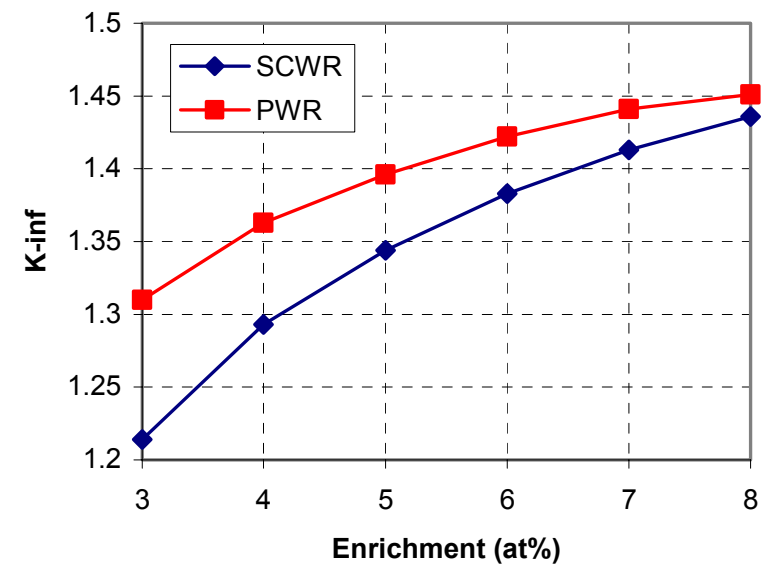

Figure 16. BOL multiplication factor.

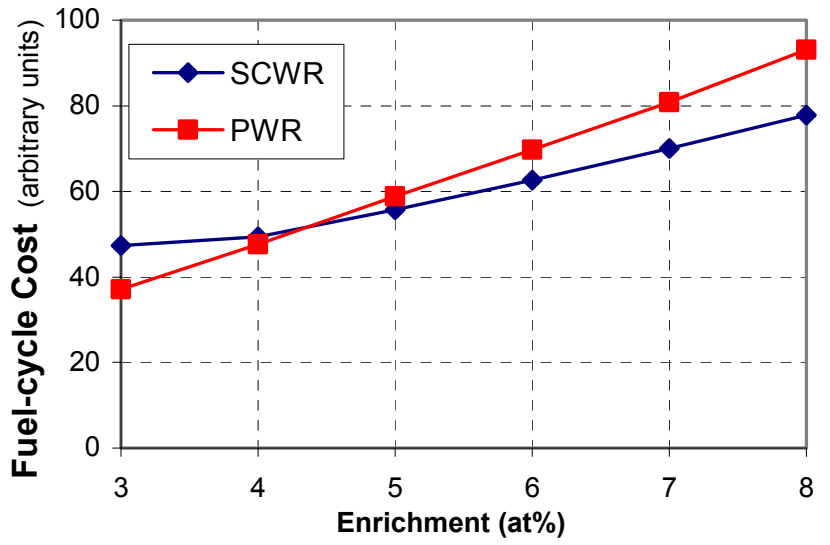

Figure 17. Fuel-cycle cost.

The average neutron spectrum in the fuel of the SCWR with power channels is shown in Figure 18 along with the PWR spectrum. The SCWR is as well-moderated as the PWR, and their respective spectra are practically identical. This is not unexpected since the hydrogen-to-heavy-metal ratio in the core is about the same for the two systems, i.e., 3.84 for the SCWR vs. 3.41 for the PWR. The thermal region of the neutron spectrum in the different fuel pins of the SCWR fuel assembly is shown in Figure 19. Because most moderation is provided by the high-density water in the inter-power-channel gap, the corner and lateral fuel pins are better moderated than the intermediate and central pins, which results in a high local peaking.

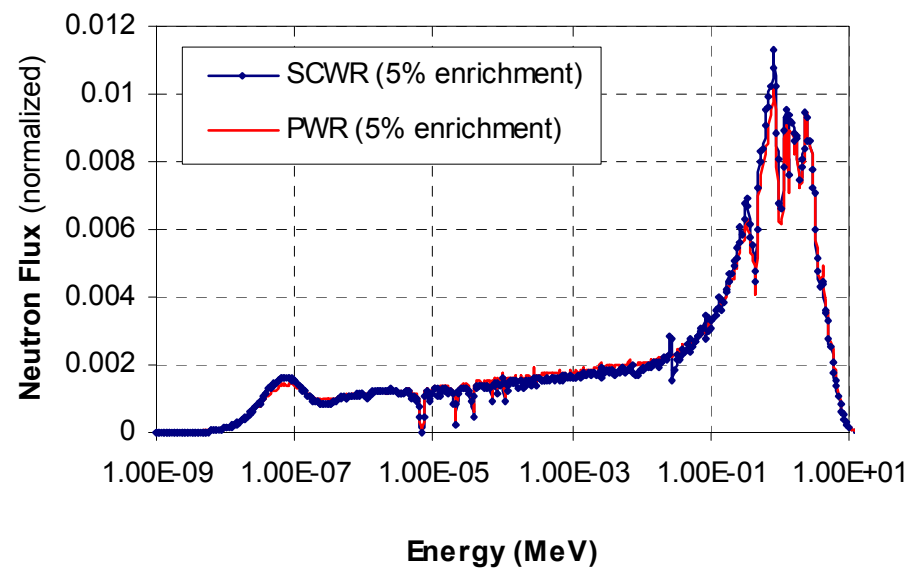

Figure 18. Neutron spectrum for the SCWR and PWR.

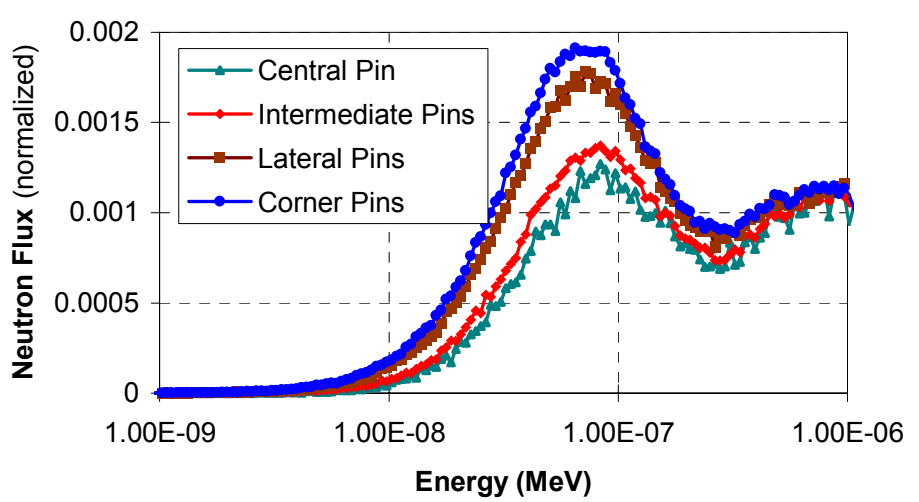

Figure 19. Thermal region of the SCWR spectrum.

The Doppler reactivity coefficient, $\alpha_{\mathrm{D}}$, was evaluated by recalculating the multiplication factor for the SCWR cell with the fuel at room temperature, $20^{\circ} \mathrm{C}$, and by means of the following equation

$$
\alpha_{\mathrm{D}} \approx \frac{\rho\left(\mathrm{T}_{2}\right)-\rho\left(\mathrm{T}_{1}\right)}{\mathrm{T}_{2}-\mathrm{T}_{1}} \approx-2.0 \mathrm{pcm} /{ }^{\circ} \mathrm{C}
$$

where $\rho=\left(k_{\infty}-1\right) / k_{\infty}$ is the neutron reactivity, $T_{2}=607{ }^{\circ} \mathrm{C}$ and $T_{1}=20{ }^{\circ} \mathrm{C}$. This value falls within the typical range for LWRs (i.e., from -4 to $-1 \mathrm{pcm} /{ }^{\circ} \mathrm{C}$, [Duderstadt and Hamilton 1976]), and thus is deemed 
acceptable. For the sake of comparison, the PWR Doppler feedback calculated with the same methodology is $-2.6 \mathrm{pcm} /{ }^{\circ} \mathrm{C}$.

The void reactivity coefficient was evaluated by systematically varying the average water density in the unit core cell. The results are shown in Figure 20 . The 0 and $1 \mathrm{~g} / \mathrm{cm}^{3}$ points correspond to complete voiding and cold zero-power conditions, respectively. The nominal hot full-power conditions are also marked in Figure 20. It can be seen that the SCWR with power channels retains the negative void reactivity feedback typical of the LWRs. The reactivity-vs.-density curve is sufficiently linear about the nominal conditions so that a constant void coefficient can be defined, and is estimated by the least-mean-squares method to be $11.3 \mathrm{pcm} /\left(\mathrm{kg} / \mathrm{m}^{3}\right)$. For the sake of comparison, the PWR void coefficient was also estimated from the PWR curve in Figure 20 and found to be $17.1 \mathrm{pcm} /\left(\mathrm{kg} / \mathrm{m}^{3}\right)$.

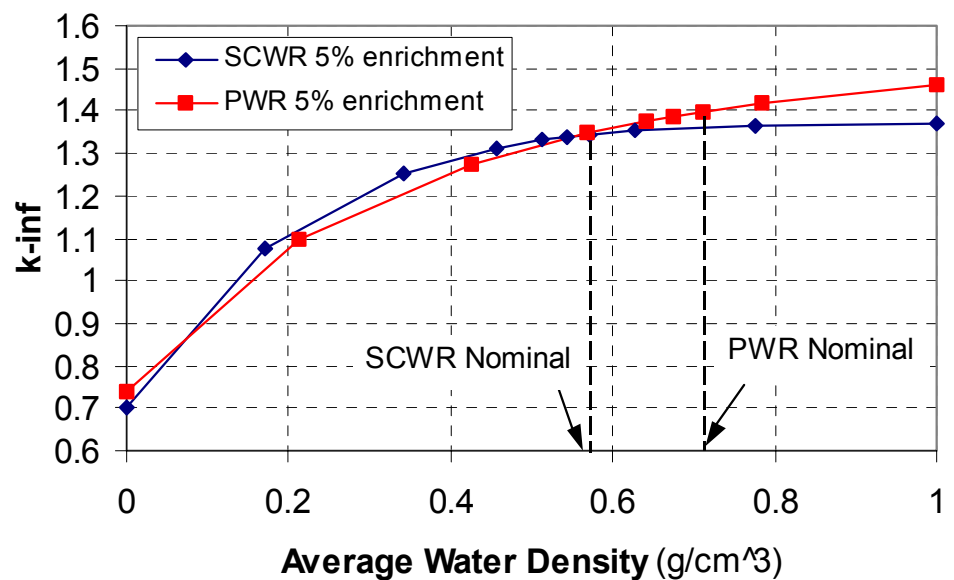

Figure 20. Void reactivity feedback curve.

The BOL local peaking for the SCWR with uniform enrichment is high and is shown in Figure 21. However, the peaking can be reduced by varying the enrichment from pin to pin. For example, a fuel assembly with the modified enrichment values shown in Figure 21 has a local peaking of only about $1 \%$. Note that the average enrichment has been maintained at 5 at $\%$ so that the fuel-cycle cost does not change significantly, i.e., the average SWU is 7.127 for the uniform 5 at $\%$ enrichment vs. 7.236 for the modified enrichment values. Also, the use of burnable-poison concentration variation from pin to pin, which is common practice in BWRs, would help lower the local peaking, but at the moment this approach has not been explored.

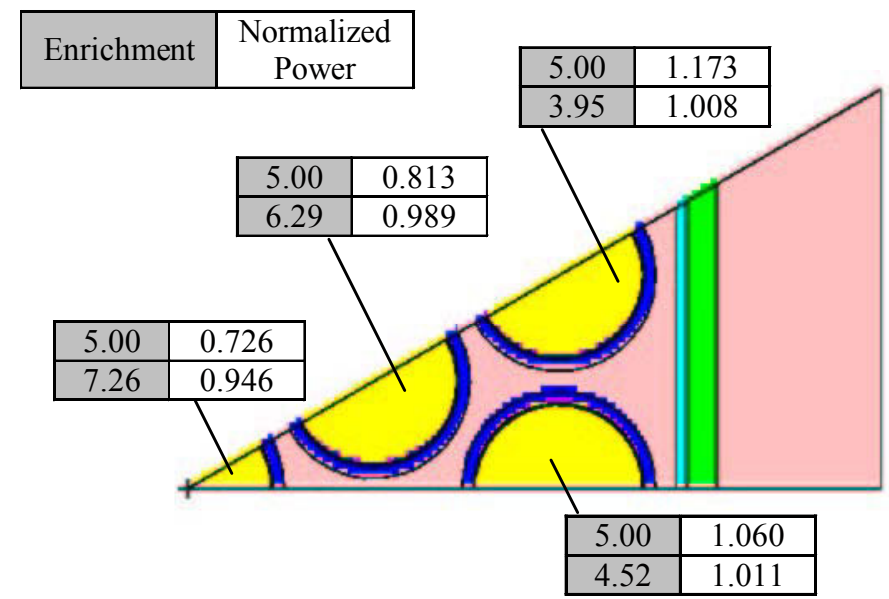

Figure 21. BOL local peaking in the SCWR fuel assembly.

The power gradient within the individual pins was also assessed and is shown in Figure 22. As expected, relatively large gradients exist in the lateral and corner pins, which are close to the inter-power-channel gap. Because of the potential for fuel-pin bowing and local heat-flux peaks, this issue will require special 
attention if further development of this concept will be pursued. However, note that similar power gradients exist also in the peripheral pins of CANDU reactor fuel bundles with little consequences.

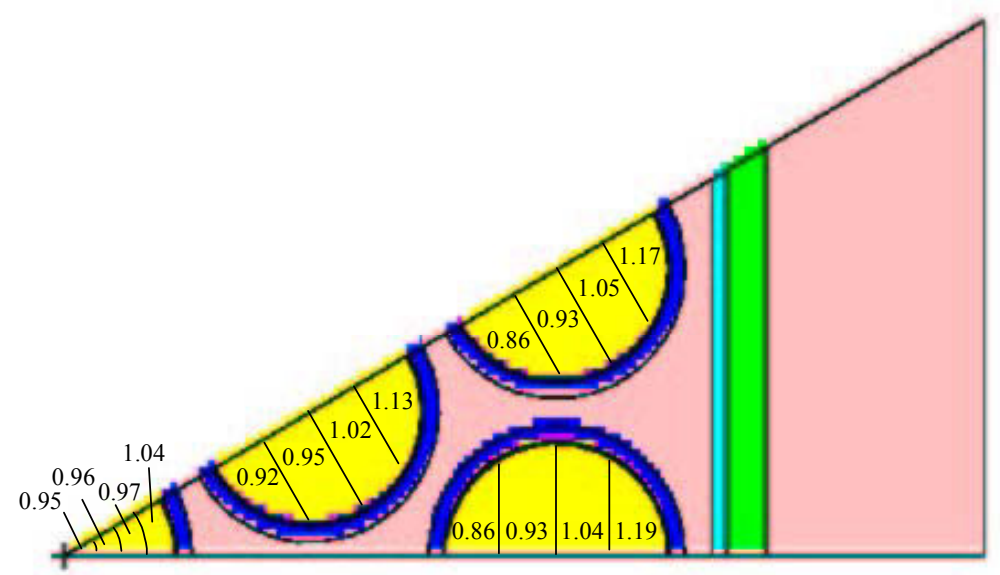

Figure 22. Power distribution within the individual pins (normalized to the pin power).

The axial peaking was calculated by iteration of the thermal-hydraulic model discussed in Section 3.1.3 above with the MCNP model, but modified to allow for axial variation of the coolant and moderator densities as well as for axial neutron leakage. The number of coolant and moderator axial cells is forty in the core, plus one above the active core. The upper and lower core plates are modeled as 3-cm thick plates made of MA956. The cold and hot plena are modeled as semi-infinite regions with water densities equal to 0.659 and $0.090 \mathrm{~g} / \mathrm{cm}^{3}$, respectively. The number of neutron histories followed was $4 \times 10^{6}$ for each run. (Ad hoc calculations verified the consistency of the cell and full-length models as far as fuelcycle cost, neutron spectrum, reactivity coefficients, and local peaking are concerned.) The axial power profile is shown in Figure 23. The power peak is located in the bottom half of the core, consistent with the average water density profile of Figure 14. The axial peaking is 1.42 . Note that this relatively low peaking is achieved without axial variation of the enrichment. This is again due to the average water density axial profile exhibiting a minimum roughly at the core mid-plane (Figure 14), which counters the effect of the neutron leakage, thus helping to flatten the axial power profile. The use of axial enrichment variations and part-length control rods, which is common practice in LWRs, would enable achievement of an even lower axial peaking, e.g., 1.2 .

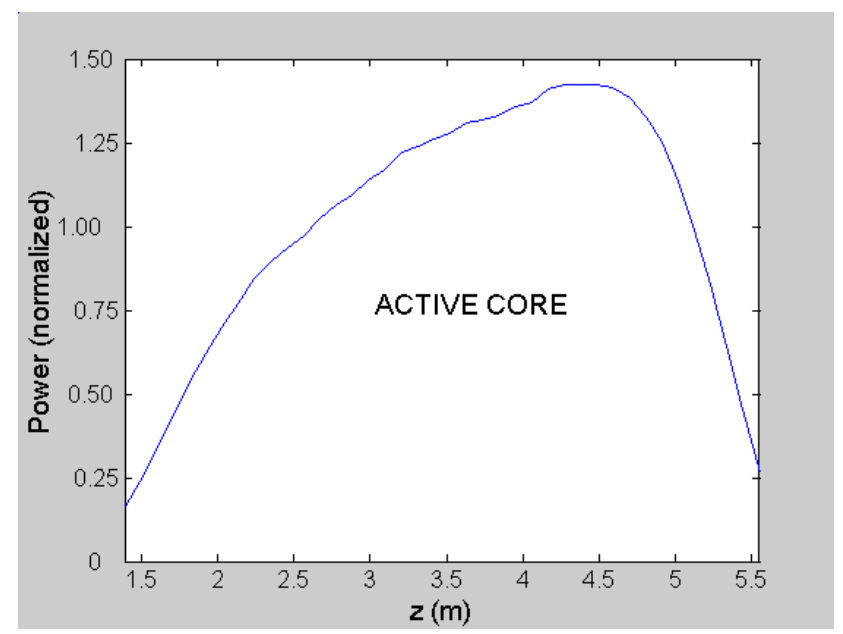

Figure 23. BOL axial power profile in the core.

\subsubsection{Conclusions}

An alternative SCWR design based on vertical power channels and small hexagonal fuel assemblies has been assessed. Compared with other approaches like water rods, solid moderators or heavy-water, this design affords some advantages in the area of fuel assembly design and ease of refueling. Based on a simplified thermal-hydraulic and neutronic analysis, it appears that this approach is technically feasible to the extent that issues common to all SCWR designs (e.g., development of in-core materials, demonstration of safety and stability) can be resolved. The estimated fuel-cycle cost is comparable with 
that of the PWR; the temperature and power distributions are acceptable; the Doppler and coolant reactivity feedbacks are both negative and within LWR range.

\subsection{Steady-State Thermal-Hydraulic Analyses (Cliff Davis, INEEL)}

Thermal-hydraulic analyses were performed for three different reactor designs during Year 2 of this NERI project. The first design utilized solid moderator rods containing zirconium hydride. The neutronic and mechanical design of this reactor concept was discussed in detail in the $3^{\text {rd }}$ Quarterly and $1^{\text {st }}$ Annual Report for this project [MacDonald et al. 2002a and 2002b] and in papers presented at ICONE 11 [Buongiorno and MacDonald 2003a and 2003b]. The second design utilized square fuel bundles with downward flow of water through water rods to achieve neutron moderation. This design is based on the reference Generation IV design described in Section 2 of this report. The third design used hexagonal power channels with downward flow of water between the channels to achieve neutron moderation and is described in Section 3.1 above. The purpose of these analyses was to assess the steady-state performance of this reactor concept and to perform simple parametric calculations to characterize the transient response of the reactor so that the time available for various safety systems to respond and capacity requirements could be determined. The steady-state results are presented in this section (Task 1 results) and the transient results are presented in Section 5 (Task 3 results). The models used for both the steady state and transient calculations are presented in this section.

The RELAP5 computer code [INEEL 2002] was used for these analyses. The code was originally developed for thermal-hydraulic analysis of LWRs and related experimental systems during loss-of-coolant accidents and operational transients. Additional correlations have been added to the code for the analysis of supercritical water reactors. These additions include the correlations of Bishop et al. [1964], Koshizuka-Oka [2000], and Jackson [2002] for forced convection heat transfer to supercritical water; the correlation of Jackson [1979] for representing the effects of mixed convection heat transfer; and the correlation of Petrov and Popov [1988] for determining the effect of wall temperature on the friction factor at supercritical conditions. Appendix A presents a more detailed discussion of the changes made to the RELAP5 computer code to support these analyses.

\subsubsection{Reactor with Solid Moderator Rods}

\subsubsection{Model Description}

A RELAP5 model of the SCWR with solid moderator rods is illustrated in Figure 24. The model represents the reactor vessel including the downcomer (Component 300), lower plenum (Components 310 and 315), core (Components 325, 330, and 335), upper plenum (Component 360), and upper head (Component 370). The core is modeled with three parallel channels, one

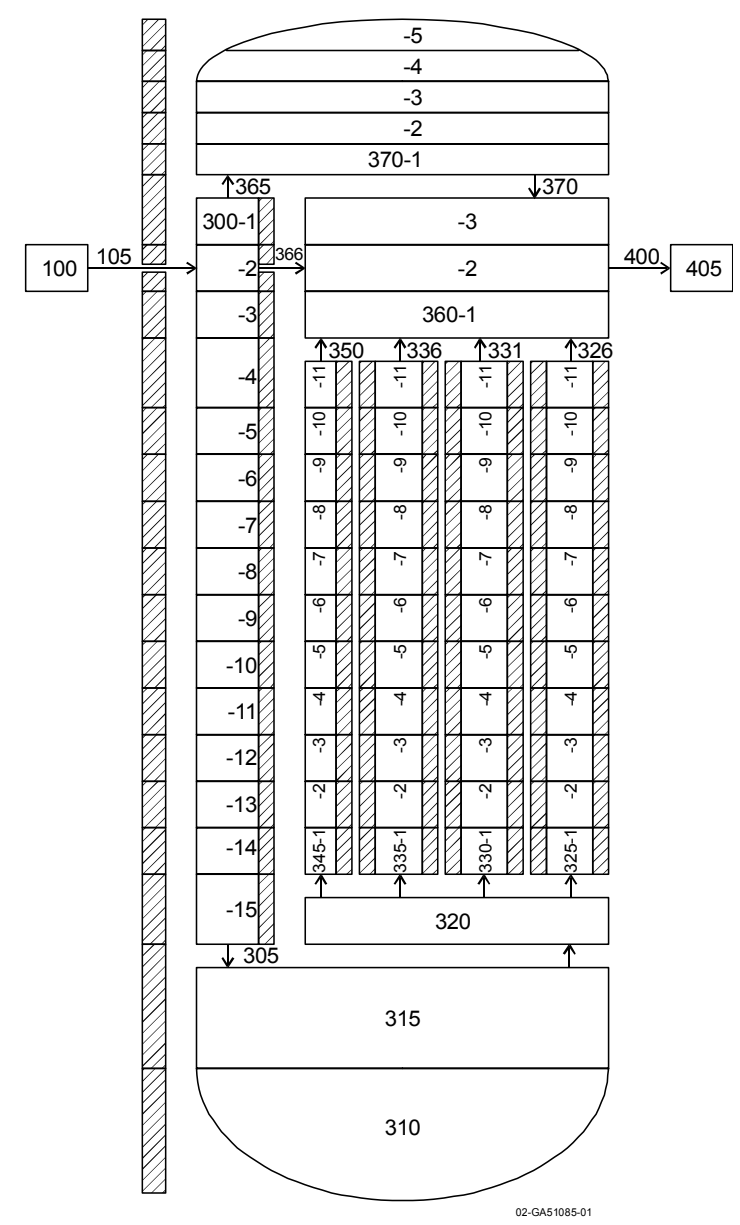

Figure 24. RELAP5 model of the SCWR with solid moderator rods. 
(Component 325) representing a high-powered fuel bundle, one (Component 330) representing 155 average-powered fuel bundles, and one (Component 335) representing a low-powered fuel bundle. The heated length is divided equally into ten axial control volumes. Heat structures are used to represent fuel rods and moderator rods in each core channel, as well as the reactor vessel wall and core barrel. A separate heat structure is used to model four hot rods in the high-powered fuel bundle.

Orifices are simulated at the bottom of each core channel to achieve a uniform power-to-flow ratio across the core. Three core bypass paths are simulated. Component 345 simulates the gaps between assemblies and between the outer assemblies and the core barrel. Junction 365 represents the cooling flow from the downcomer to the upper head. Component 366 represents leakage from the downcomer to the upper plenum around the hot leg nozzle. Form loss coefficients in the bypass flow paths were adjusted to obtain the desired flow rates at normal operating conditions. Boundary conditions are used to represent the feedwater (Junction 105) and main steam (Component 405) systems. The geometry of the reactor is summarized in Table IX.

The local peaking factor of the hot rods is 1.108 based on Figure 6 of MacDonald et al. [2002b]. The axial power profile is based on the two-zone enrichment curve shown in Figure 3 of MacDonald et al. [2002b] and has a peak value of 1.41. The radial peaking factors of the highpowered and low-powered fuel bundles are assumed to be 1.30 and 0.70 , respectively. The moderator boxes receive $2.6 \%$ of the total core power [MacDonald et al. 2002a]. The fuel rods contain uranium dioxide clad with Alloy 718 . The moderator rods contain zirconium hydride $\left(\mathrm{ZrH}_{1.6}\right)$.

Transient reactor power is calculated using a bestestimate point kinetics model. The model uses representative pressurized water reactor (PWR) values for the kinetics, decay heat, and scram parameters. The reactivity feedback model is used

Table IX. Geometry of the RELAP5 model of the SCWR with solid moderator rods.

\begin{tabular}{|l|c|}
\hline Parameter & Value \\
\hline Core: & \\
\hline Number of fuel assemblies & 157 \\
\hline Assembly inner width, mm & 218 \\
\hline Number of fuel pins per assembly & 217 \\
\hline Fuel outer diameter, mm & 8.19 \\
\hline Cladding inner diameter, mm & 8.36 \\
\hline Cladding outer diameter, mm & 9.50 \\
\hline Fuel rod pitch-to-diameter ratio & 1.21 \\
\hline Heated length, $\mathrm{m}$ & 4.27 \\
\hline Moderator rods: & \\
\hline Number of water rods per assembly & 36 \\
\hline Water rod outer width, mm & 23.0 \\
\hline Vessel: & \\
\hline Height, m & 12.37 \\
\hline Inner diameter, $\mathrm{m}$ & 4.41 \\
\hline Outer diameter, $\mathrm{m}$ & 5.13 \\
\hline Core barrel: & \\
\hline Inner diameter, $\mathrm{m}$ & 3.80 \\
\hline Outer diameter, $\mathrm{m}$ & 3.90 \\
\hline
\end{tabular}
to simulate the effects of changes in the fuel temperature and coolant density. The Doppler and density feedback coefficients are $-2.3 \mathrm{pcm} / \mathrm{K}(-$ $\left.3.23 \times 10^{-3} \$ / \mathrm{K}\right)$ and $2.3 \mathrm{pcm} /\left(\mathrm{kg} / \mathrm{m}^{3}\right)\left[+3.23 \times 10^{-3} \$ /\left(\mathrm{kg} / \mathrm{m}^{3}\right)\right]$, respectively, based on the calculations described in Section 1.3 of MacDonald et al. [2002b] and Figure 9 of MacDonald et al. [2002a]. The feedback associated with changes in the temperature of the zirconium-hydride moderator is neglected. Power-squared averaging is used to determine the weighting factors in the feedback model. For cases with reactor scram, the control rods begin moving $0.8 \mathrm{~s}$ after the scram signal is generated, and are fully inserted $2.5 \mathrm{~s}$ later. The total control rod worth is about $11 \$$.

\subsubsection{Steady State Results}

A RELAP5 calculation was performed to determine the steady-state thermal-hydraulic conditions at normal operating power. These normal operating conditions are summarized in Table $\mathrm{X}$. The values are consistent with the desired initial conditions described in Table 3 of MacDonald et al. [2002b]. As mentioned previously, orifices were simulated at the inlet of each core channel to achieve the same power-to-flow ratio, which results in a uniform fluid temperature at the outlet of each channel. The 
orifice size was set to achieve a core pressure drop of $0.150 \mathrm{MPa}$, which is similar to that in most operating LWRs. The simulated orifice at the bottom of the high-powered channel had a diameter near $4.8 \mathrm{~cm}$. The pressure loss due to the orifice exceeded the losses due to the grid spacers and wall friction. The pressure drop across the core was only about $0.080 \mathrm{MPa}$ in preliminary calculations in which the high-powered channel did not contain an inlet orifice. However, preliminary calculations of loss-of-feedwater events without the orifice resulted in flow oscillations in the high-powered channel. These oscillations disappeared when the pressure drop across the core was increased to $0.150 \mathrm{MPa}$.

The RELAP5 model was used to perform a series of steady-state calculations in which the feedwater flow and core power were varied so that their ratio remained constant. Figure 25 presents the results of these calculations in the form of maximum core cladding temperature as a function of normalized power. A normalized power of 1.0 corresponds to Table X. Calculated initial conditions for the SCWR with solid moderator rods at rated power.

\begin{tabular}{|l|c|}
\hline Parameter & Value \\
\hline Core power, MWt & 2700 \\
\hline Pressure, $\mathrm{MPa}$ & 25.0 \\
\hline Feedwater temperature, ${ }^{\circ} \mathrm{C}$ & 280 \\
\hline${\text { Vessel outlet temperature, }{ }^{\circ} \mathrm{C}}^{\circ}$ & 450 \\
\hline Core outlet temperature, ${ }^{\circ} \mathrm{C}$ & 474 \\
\hline Peak cladding temperature, ${ }^{\circ} \mathrm{C}$ & 572 \\
\hline Feedwater flow, $\mathrm{kg} / \mathrm{s}$ & 1567.9 \\
\hline Core flow rate, $\mathrm{kg} / \mathrm{s}$ & 1473.7 \\
\hline Core differential pressure, $\mathrm{MPa}$ & 0.150 \\
\hline Bypass flow rates & \\
\hline Core bypass, \% & 4.0 \\
\hline Outlet nozzle leakage, $\%$ & 1.0 \\
\hline Upper head cooling, $\%$ & 1.0 \\
\hline Linear heat generation rate, $\mathrm{kW} / \mathrm{m}$ & 18.1 \\
\hline
\end{tabular}
the normal operating conditions presented in Table $\mathrm{X}$. Lower normalized values correspond to operation at reduced power and flow. Because the power-toflow ratio was held constant, the fluid temperature distribution in the core was roughly the same for each calculation, differing only because the fraction of core bypass varied with flow.

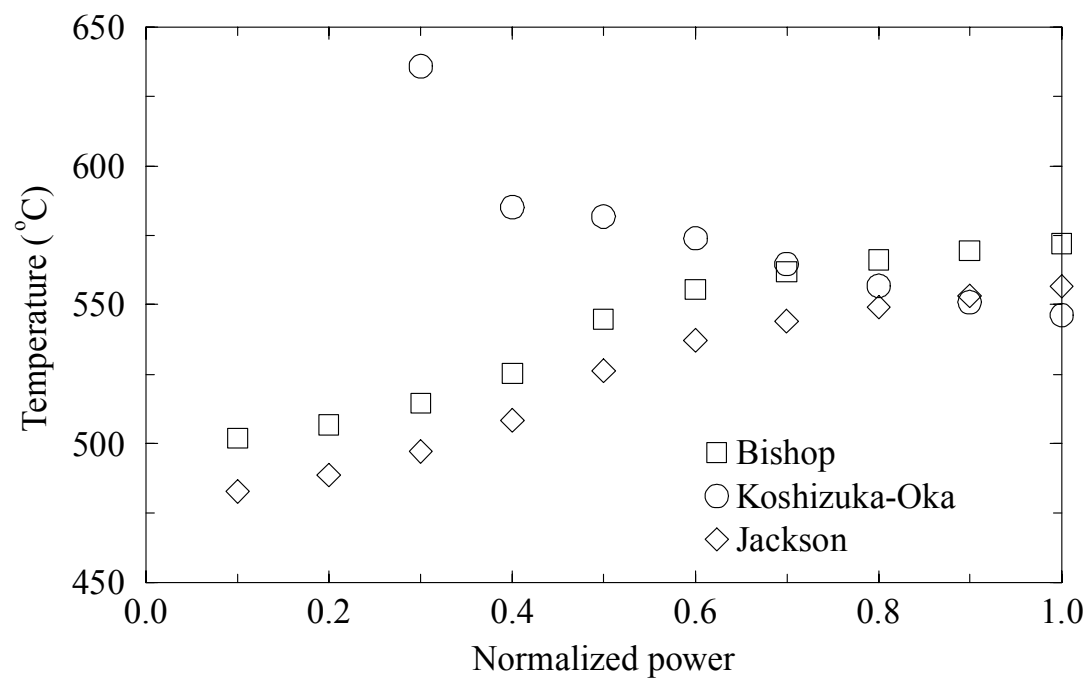

Figure 25. Maximum cladding temperature as a function of normalized power, with the power-toflow ratio held constant.

Figure 25 shows that the maximum cladding temperatures obtained with the Bishop, Koshizuka-Oka, and Jackson correlations were similar at a normalized power of 1.0. The Bishop and Jackson correlations predicted similar trends with respect to power, but the maximum cladding temperatures were consistently higher with the Bishop correlation. However, the Koshizuka-Oka correlation predicted completely different trends with respect to power. The Bishop and Jackson correlations predicted that the maximum cladding temperature increased with power, while the Koshizuka-Oka correlation predicted that it 
decreased with power. The location of the maximum cladding temperature also varied between correlations. The maximum occurred in the eighth (out of ten) heated control volumes with the Bishop correlation, in the eighth or ninth heated control volume with the Jackson correlation, but varied between the fourth and sixth control volumes with the Koshizuka-Oka correlation.

\subsubsection{Discussion of the Steady State Results}

The calculated conditions in the SCWR core shown in Figure 25 required that all the correlations be extrapolated from their respective databases. For example, the calculated heat and mass fluxes dropped below the lower limits of the Bishop correlation near normalized values of 0.4 and 0.7 , respectively. The mass flux dropped below the lower limit of the Jackson correlation near a normalized value of 0.7 . The Koshizuka-Oka correlation required a larger extrapolation as the mass flux during normal operation was $10 \%$ below the lower limit of the correlation. The results shown in Figure 25 demonstrate the dangers of extrapolating correlations beyond their database. The results also demonstrate the importance of obtaining heat transfer data that cover the range of interest for the SCWR.

Heat transfer data should also be taken that cover the transitions between the forced convection, natural convection, and laminar heat transfer regimes as these transitions may be encountered during loss-of-flow transients. RELAP5 normally calculates the heat transfer coefficient as the maximum of forced convection, natural convection, and laminar correlations. A mixed convection correlation has also been added as shown in Equation (A11) in Appendix A. However, the natural convection and mixed convection contributions were suppressed for these calculations to demonstrate the difference between the three forced convection correlations. The heat transfer coefficient from the code's natural convection correlation exceeded that from the Koshizuka-Oka correlation, particularly at low flow rates.

\subsubsection{Reactors with Water Moderation}

Two different reactor designs that use water to achieve neutron moderation were studied. The first design used square fuel assemblies and water rods and is illustrated in Figures 1 and 4 in Section 2 above. The second design used hexagonal power channels and is illustrated in Figures 11 and 12 in Section 3.1 above. The primary purpose of this analysis was to assess the steady-state performance of these two designs and to compare their safety characteristics following various transients. Again, the models and the steady-state results are discussed in this section (Task 1 results) and the transient results are discussed in Section 5 (Task 3 results).

Note that the design with water rods modeled here is based on a preliminary, smaller version of the reference design described in Table I and Section 2. The operating conditions of the two designs are similar, but the number of fuel assemblies, core power, reactor vessel, and total feedwater flow rate are smaller in this preliminary design. For example, the total reactor core power in the preliminary design is about $15 \%$ less than in the current reference design. The differences between the current and preliminary designs should have no impact on the relative safety characteristics of designs with water rods and power channels, which is the primary purpose of the analysis described here.

\subsubsection{Model Descriptions}

The RELAP5 model of the SCWR design with water rods is illustrated in Figure 26. The model is similar to that shown previously in Figure 24 except that it includes water rods and simulates two feedwater lines and two steam lines. The feedwater enters the downcomer, where most of it is directed upwards into the upper head. The liquid then flows downwards through the water rods where it acts as moderator. The moderator mixes with the flow from the downcomer in the lower plenum and then enters the fuel 
assemblies and acts as coolant. The water rods are represented with three parallel channels (Components 375, 380, and 385) corresponding to the high-powered, averagepowered, and low-powered assemblies. The heated length is divided equally into ten axial control volumes. Heat structures are used to represent fuel rods, water rods, and assembly walls in each core channel, as well as the reactor vessel and core barrel. A separate heat structure is used to model four hot rods in the high-powered fuel bundle. The fuel rod gas plenum is located below the bottom of the heated length to minimize the heat transfer from the fuel assemblies to the water rods. The uppermost two levels of the water rod walls, which are above the top of the active fuel, are heavily insulated to minimize the heat transfer.

The RELAP5 model of the SCWR design with hexagonal power channels is illustrated in Figure 27. In this design, the feedwater enters the vessel in a region outside of the power channels (Component 320). Most of the feedwater flows downward through the gaps between the power channels where it acts as a moderator. The moderator then mixes with the flow from the downcomer in the lower plenum and enters the bottom of the fuel assemblies and acts as coolant. The model is similar to that shown previously in Figure 26 except that a single region (Component 380 ) is used to represent the moderator in the gaps between the power channels. Heat structures are used to represent fuel rods and the walls between the power channel and the moderator. The inside surface of the power channel wall is insulated with $0.5 \mathrm{~mm}$ of zirconium oxide to reduce the heat transfer from the power channel to the moderator. A separate heat structure is used to model the hottest rod in the high-powered fuel bundle. The fuel rod gas plenum is located below the bottom of the heated length to minimize the heat transfer from the power channels to the moderator.

The models used the Jackson forced convection heat transfer correlation (Equation A7 in Appendix A) for the fuel rods and both walls of the water rods or the hexagonal power

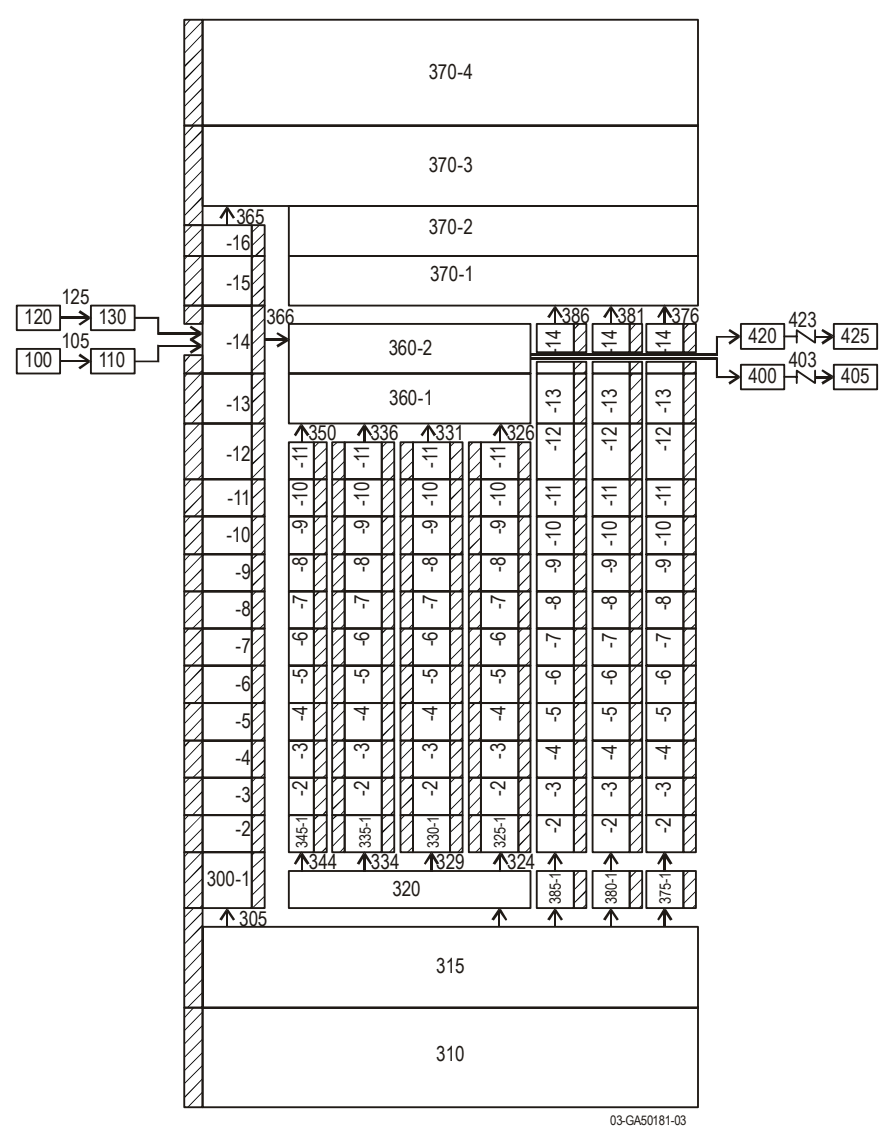

Figure 26. RELAP5 model of the SCWR design with water rods.

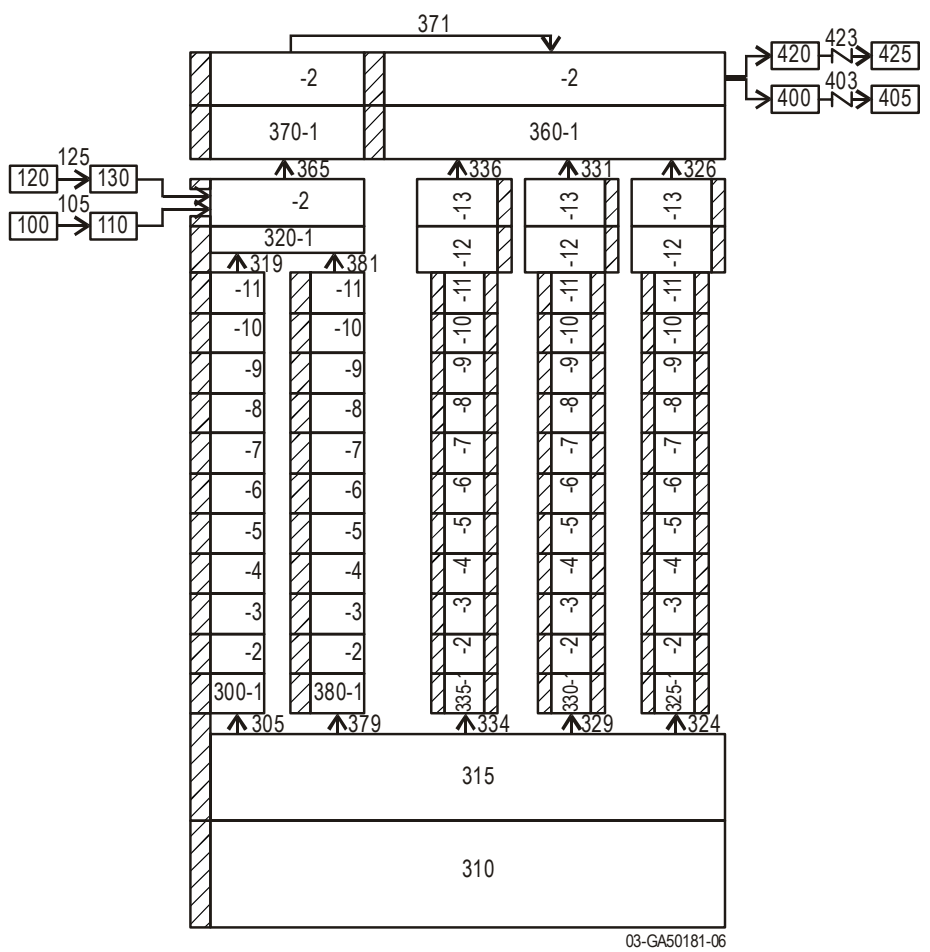

Figure 27. RELAP5 model of the SCWR design with hexagonal power channels. 
channels. Buoyancy effects were calculated using Equation (A11) in Appendix A. Heat transfer coefficients for the other surfaces, such as the core barrel and reactor vessel, were calculated using the Bishop correlation (Equation A2 in Appendix A). Since the buoyancy effects were calculated using Equation (A11) for the most important heat structures, the heat transfer coefficient was calculated as the maximum of the values from the forced convection and laminar correlations. The friction factor was calculated using the heated wall effect shown in Equation (A14) in Appendix A.

The geometry of each reactor design is summarized in Table XI. In the first design, the moderator flows downwards through 36 water rods that are located within each assembly. Each water rod has a square cross-section, with an outer width of $32.6 \mathrm{~mm}$. The water rod wall is $0.4-\mathrm{mm}$ thick and is not insulated. In the second design, the moderator flows downwards through a 16-mm gap between adjacent assemblies. The hexagonal assembly wall is $2 \mathrm{~mm}$ thick including a $0.5-\mathrm{mm}$ layer of zirconium oxide on the interior surface to insulate the moderator from the coolant.

Table XI. Description of the RELAP5 models of the SCWR with water moderation.

\begin{tabular}{|c|c|c|}
\hline \multirow[t]{2}{*}{ Parameter } & \multicolumn{2}{|c|}{ Value } \\
\hline & $\begin{array}{c}\text { Design with water } \\
\text { rods }\end{array}$ & $\begin{array}{l}\text { Design with power } \\
\text { channels }\end{array}$ \\
\hline \multicolumn{3}{|l|}{ Fuel Assembly: } \\
\hline Number of fuel assemblies & 121 & 1951 \\
\hline Assembly outer width, $\mathrm{mm}$ & 287 & 51.9 \\
\hline Assembly wall thickness, $\mathrm{mm}$ & 3.0 & 2.0 \\
\hline Number of fuel pins per assembly & 300 & 19 \\
\hline Fuel outer diameter, $\mathrm{mm}$ & 8.78 & 8.20 \\
\hline Cladding inner diameter, $\mathrm{mm}$ & 8.94 & 8.36 \\
\hline Cladding outer diameter, $\mathrm{mm}$ & 10.2 & 9.50 \\
\hline Fuel rod pitch-to-diameter ratio & 1.098 & 1.105 \\
\hline Heated length, $m$ & 4.27 & 4.27 \\
\hline Fission gas plenum length, $\mathrm{m}$ & 0.39 & 0.39 \\
\hline Coolant flow area, $\mathrm{m}^{2} /$ assembly & 0.0161 & 0.000640 \\
\hline Hydraulic diameter, $m$ & 0.00417 & 0.00349 \\
\hline \multicolumn{3}{|l|}{ Moderator: } \\
\hline Flow area, $\mathrm{m}^{2}$ /assembly & 0.0364 & 0.00166 \\
\hline Hydraulic diameter, $m$ & 0.0318 & 0.0369 \\
\hline Flow length, $\mathrm{m}$ & 6.15 & 5.94 \\
\hline \multicolumn{3}{|l|}{ Vessel: } \\
\hline Height, $\mathrm{m}$ & 12.4 & 12.6 \\
\hline Inner diameter, m & 4.60 & 3.70 \\
\hline Outer diameter, $\mathrm{m}$ & 5.34 & 4.44 \\
\hline \multicolumn{3}{|l|}{ Core barrel: } \\
\hline Inner diameter, $\mathrm{m}$ & 4.10 & 3.20 \\
\hline Outer diameter, $\mathrm{m}$ & 4.20 & 3.30 \\
\hline \multicolumn{3}{|l|}{ Miscellaneous: } \\
\hline Elevation of the bottom of the active fuel, $m$ & 3.2 & 5.2 \\
\hline Fluid volume, $\mathrm{m}^{3}$ & 144 & 103 \\
\hline Feed/steam line inner diameter, $m$ & 0.368 & 0.368 \\
\hline
\end{tabular}

Table XI shows that the fuel rods are slightly thinner in the design with power channels. Each power channel is much smaller than a corresponding assembly in the design with water rods, but there are many more power channels. The design with power channels is more compact, resulting in a significantly 
smaller reactor vessel. The bottom of the active fuel is $2.0 \mathrm{~m}$ higher in the design with power channels to accommodate bottom-entry control rods.

The power distribution is similar in both models. The radial peaking factors of the high-powered and low-powered fuel bundles are assumed to be 1.40 and 0.60 , respectively. The local peaking factor of the hot rods is 1.2. These radial and local peaking factors are higher than assumed previously in the analysis of the design with solid moderator, thus are intended to be bounding values. The axial power profile is based on the two-zone enrichment curve shown in Figure 3 of MacDonald et al. (2002b) and has a peak value of 1.41 . The models assume that $2.6 \%$ of the power appears as direct moderator heating, with $80 \%$ deposited in the water rods or moderator and the remainder deposited in the coolant channel. The fuel rods contain uranium dioxide clad with ODS ferritic steel MA956 and a 0.08-mm gas gap.

Transient reactor power is calculated using a best-estimate point kinetics model. The model uses representative PWR values for the kinetics, decay heat, and scram parameters. The reactivity feedback model is used to simulate the effects of changes in the fuel temperature and fluid density. The Doppler and density feedback coefficients are $-2.5 \mathrm{pcm} / \mathrm{K}\left(-3.5 \times 10^{-3} \$ / \mathrm{K}\right)$ and $14.3 \mathrm{pcm} /\left(\mathrm{kg} / \mathrm{m}^{3}\right)\left[2.05 \times 10^{-2}\right.$ $\left.\$ /\left(\mathrm{kg} / \mathrm{m}^{3}\right)\right]$, respectively, for the design with water rods. The Doppler and density feedback coefficients are $-2.2 \mathrm{pcm} / \mathrm{K}\left(-3.1 \times 10^{-3} \$ / \mathrm{K}\right)$ and $12.1 \mathrm{pcm} /\left(\mathrm{kg} / \mathrm{m}^{3}\right),\left[1.7 \times 10^{-2} \$ /\left(\mathrm{kg} / \mathrm{m}^{3}\right)\right]$, respectively, for the design with power channels. Power-squared averaging is used to determine the weighting factors for the Doppler feedback. The weighting factors for the density feedback are based on linear weighting of the power deposited in the fluid due to direct heating. For cases with reactor scram, the control rods begin moving $0.8 \mathrm{~s}$ after the scram signal is generated, and are fully inserted $2.5 \mathrm{~s}$ later. The total control rod worth is about $11 \$$.

Orifices are simulated at the bottom of each core channel to achieve a uniform power-to-flow ratio across the core. Although the flow through each coolant channel is consistent with the radial peaking factor, heat transfer to the water rod results in fluid temperature variations between the high-powered, averagepowered, and low-powered assemblies. The resulting variations in heat transfer to the water rods are sufficient to cause large variations in water rod flow per assembly. For example, in preliminary calculations the flow through the water rods in the hot assembly was up rather than down. Orifices are placed at the top of the water rods to help balance the flow between water rods. The equivalent orifice area is about $8 \%$ of that of the flow area of the water rods. The resulting variation in water rod flow per assembly is $+/-4 \%$, with the water rods in the high-powered assembly receiving less than the average flow and water rods in the low-powered assembly receiving more than the average flow.

\subsubsection{Steady State Results}

Table XII shows the calculated steady-state thermal-hydraulic conditions at normal operating power. The axial profiles of temperature and density in the average-powered channel are presented in Figures 28 through 31 for the two designs. The profiles are presented as a function of normalized length, where zero and unity correspond to the bottom and top of the active fuel, respectively.

The boundary conditions of core power, feedwater flow and temperature, and steam line pressure are identical for both models. Most of the flow is directed towards the water rods or towards the moderator in the design with power channels. The fraction of flow that bypasses the core varies somewhat because of differences in design. The model of the design with water rods assumes that $5 \%$ of the MFW flow bypasses the core, $4 \%$ through the core barrel-baffle region and inter-assembly gaps (Component 345 ) and $1 \%$ around the outlet nozzle (Component 366). The model of the design with power channels assumes that $2 \%$ of the MFW flow bypasses the core through Junction 371 . This bypass accounts for cooling flow to the upper head (1\%) and leakage around the outlet nozzle (1\%). Losses through the interassembly gaps and barrel-baffle region are not applicable to this design. The downcomer receives $3 \%$ of 
the total MFW flow, but this flow mixes with the moderator flow in the lower plenum and does not bypass the core. In both models, the various flow splits were obtained by adjusting form loss coefficients.

Table XII. Calculated initial conditions for the SCWR designs with water moderator.

\begin{tabular}{|c|c|c|}
\hline \multirow[t]{2}{*}{ Parameter } & \multicolumn{2}{|c|}{ Value } \\
\hline & $\begin{array}{l}\text { Design with water } \\
\text { rods }\end{array}$ & $\begin{array}{c}\text { Design with power } \\
\text { channels }\end{array}$ \\
\hline Core power, MWt & 3022 & 3022 \\
\hline Steam line pressure, $\mathrm{MPa}$ & 25.0 & 25.0 \\
\hline Feedwater temperature, ${ }^{\circ} \mathrm{C}$ & 280 & 280 \\
\hline Feedwater flow, $\mathrm{kg} / \mathrm{s}$ & 1561 & 1561 \\
\hline Steam line temperature, ${ }^{\circ} \mathrm{C}$ & 498 & 499 \\
\hline \multicolumn{3}{|l|}{ Flow rates, $\%$} \\
\hline Water rod/moderator & 90.0 & 95.0 \\
\hline Downcomer & 9.0 & 3.0 \\
\hline Core bypass & 4.0 & $\mathrm{NA}^{1}$ \\
\hline Outlet nozzle leakage, \% & 1.0 & $1.0^{2}$ \\
\hline Upper head bypass, \% & $\mathrm{NA}^{1}$ & $1.0^{2}$ \\
\hline Average mass flux in the core, $\mathrm{kg} / \mathrm{s}-\mathrm{m}^{2}$ & 761 & 1225 \\
\hline Core differential pressure, MPa & 0.200 & 0.412 \\
\hline Average fluid density in the core, $\mathrm{kg} / \mathrm{m}^{3}$ & 498 & 572 \\
\hline \multicolumn{3}{|l|}{ Maximum cladding temperature, ${ }^{\circ} \mathrm{C}$} \\
\hline High-powered channel & 690 & 601 \\
\hline Average-powered channel & 628 & 576 \\
\hline Low-powered channel & 570 & 552 \\
\hline \multicolumn{3}{|l|}{ Maximum fuel centerline temperature, ${ }^{\circ} \mathrm{C}$} \\
\hline High-powered channel & 2108 & 1900 \\
\hline Average-powered channel & 1371 & 1223 \\
\hline Low-powered channel & 956 & 874 \\
\hline Average linear heat generation rate, $\mathrm{kW} / \mathrm{m}$ & 19.5 & 19.1 \\
\hline
\end{tabular}

1. Not applicable.

2. Combined into a single flow path.

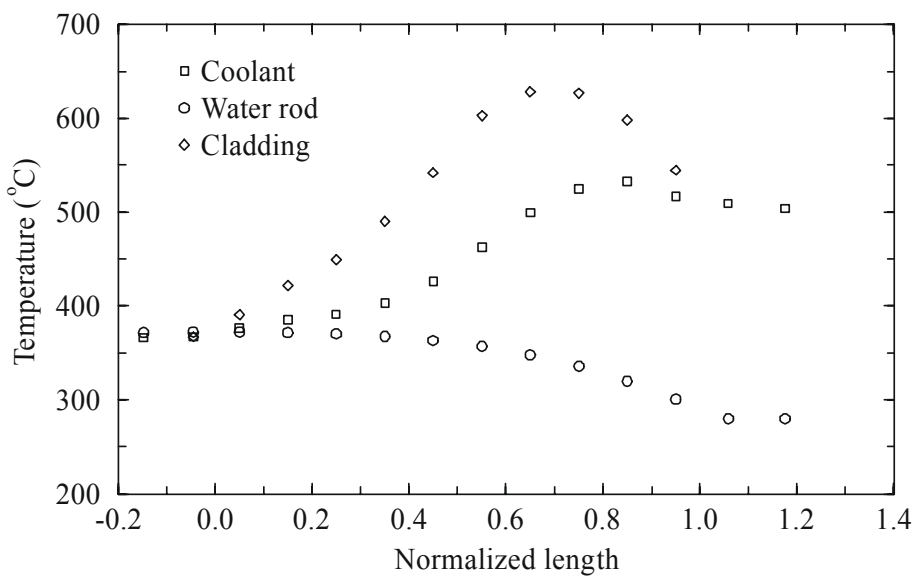

Figure 28. Axial temperature distributions in the core region for the design with water rods.

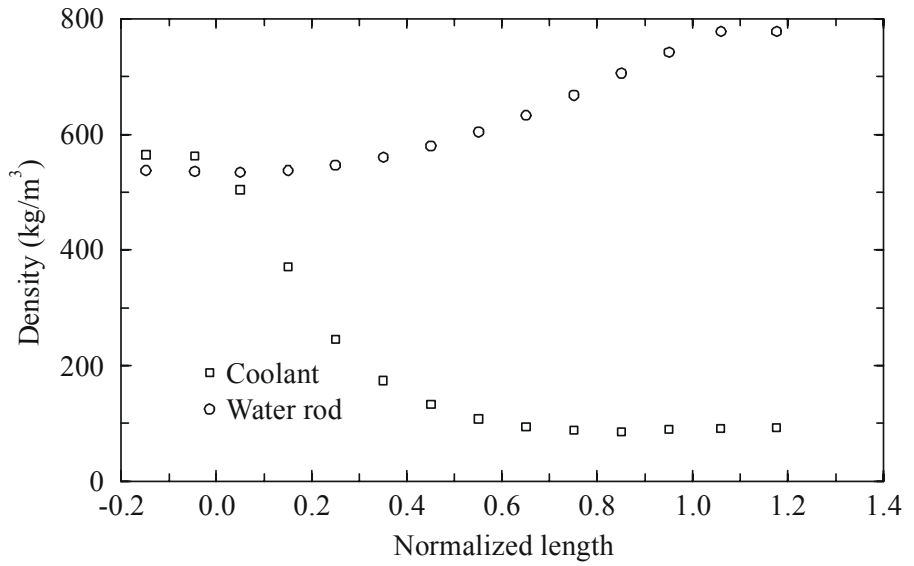

Figure 29. Axial density distributions in the core region for the design with water rods. 


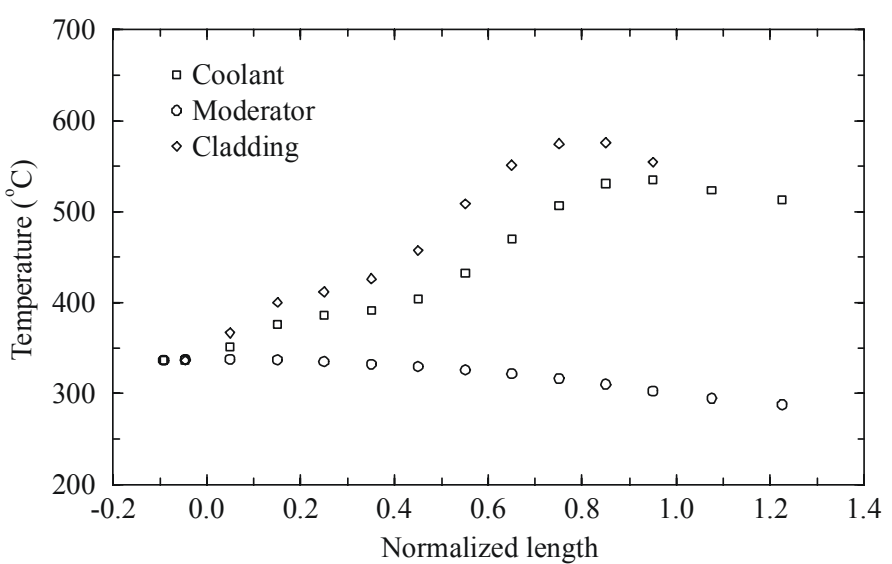

Figure 30. Axial temperature distributions in the core region for the design with power channels.

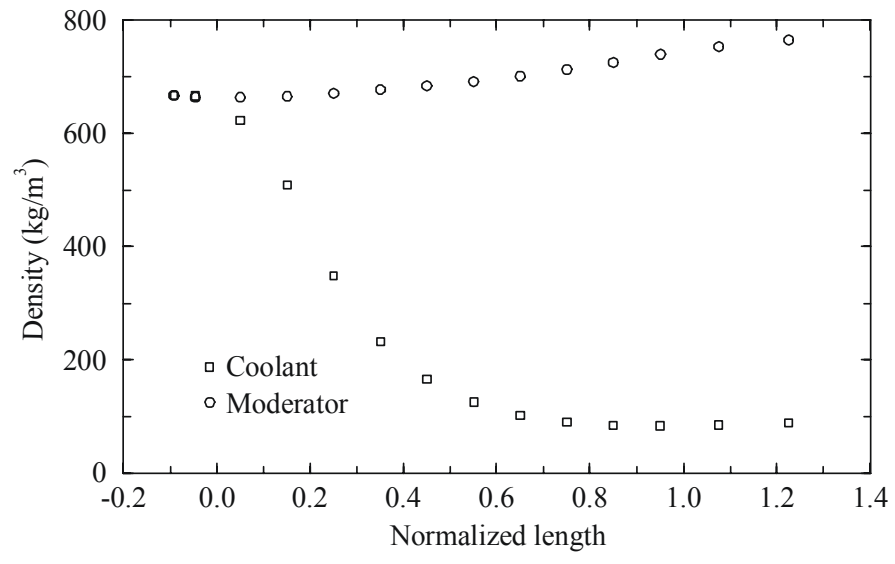

Figure 31. Axial density distributions for the design with power channels.

Table XII shows that the average mass flux in the core is significantly larger in the design with power channels. The larger mass flux is a result of the triangular lattice and more compact vessel as shown in Table XI. The larger mass flux and the smaller hydraulic diameter shown in Table XI result in a significantly larger pressure drop across the core in the design with power channels. Most of the pressure drop is due to the orifice at the bottom of the channels in both models. The effective area of the orifice at the bottom of the average-powered channel was about $10 \%$ of the channel area in both models.

Table XII also shows that the maximum cladding temperatures are significantly lower in the design with power channels. The lower cladding temperatures are principally caused by the higher core mass flux, which increases the heat transfer coefficient and reduces the difference between the cladding and fluid temperatures as shown by a comparison of Figures 28 and 30. The lower cladding temperatures are also partially caused by the insulation in the power channels, which reduces the heat transfer to the moderator. The reduced heat transfer lowers the fluid temperature at the bottom of the core and throughout most of the assemblies compared to the design with water rods. For the design with water rods, the maximum cladding temperature of the high-powered channel significantly exceeds the steady-state operating temperature limit of $620^{\circ} \mathrm{C}$.

The maximum fuel centerline temperatures are also significantly lower in the design with power channels because of the lower cladding temperatures discussed previously. The differences in centerline temperatures are larger than the differences in cladding surface temperatures because the thermal conductivity of the uranium dioxide fuel decreases sharply with temperature over the range of interest. The maximum centerline temperatures occur lower in the core, in a region of higher heat flux, than the maximum cladding temperatures.

A comparison of Figures 29 and 31 shows that the insulation also significantly increases the fluid density of the moderator in the power channels compared to the density of the moderator in the water rods. Consequently, the average fluid density in the core is significantly higher in the design with power channels as shown in Table XII. The neutronic calculations shown in Figure 32 indicate that the fuel cycle cost for the SCWR with water rods is comparable with a PWR if the average water density is 500 $\mathrm{kg} / \mathrm{m}^{3}$. Since the calculated density is $498 \mathrm{~kg} / \mathrm{m}^{3}$ for the water rod design without insulation, the fuel cycle costs are acceptable. The fuel cycle cost for the design with power channels is a few percent lower because of the higher average fluid density (see Figure 17 in Section 3.1 above). 
A sensitivity calculation was performed in which 1 $\mathrm{mm}$ of zirconium oxide was used to insulate the water rods. The insulation increased the average fluid density in the core to $570 \mathrm{~kg} / \mathrm{m}^{3}$, which is comparable to the value calculated for the design with power channels. The insulation reduced the maximum cladding temperature during normal operation by $56{ }^{\circ} \mathrm{C}$ from the value shown in Table XII. However, the maximum cladding temperature was not as low as for the design with the power channels because of the increased mass flux and heat transfer coefficient in that design. Although the economics of the fuel cycle are acceptable without insulating the water rods, insulation appears to be necessary to meet the steady-state cladding thermal limit.

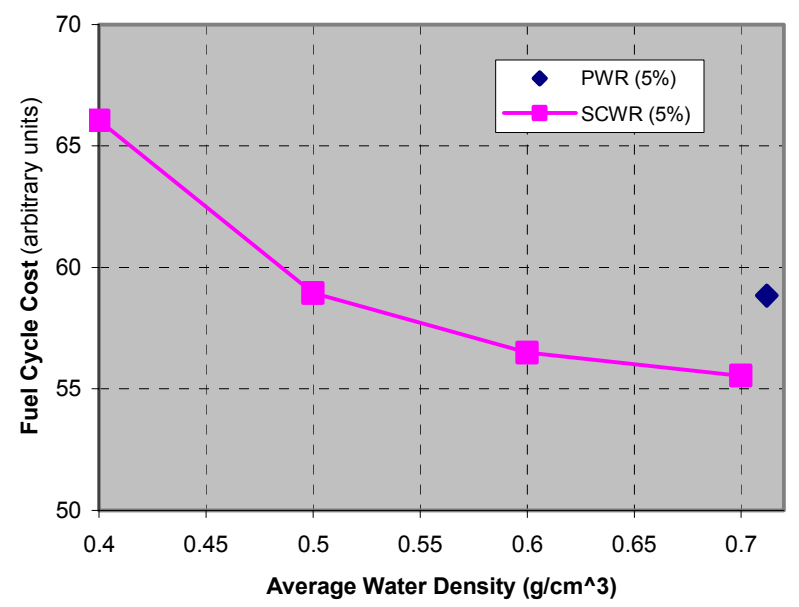

Figure 32. Estimated fuel-cycle costs as a function of average moderator water density.

Table XII shows that $90 \%$ of the total main feedwater flow is directed towards the water rods. The original design directed $30 \%$ of the flow towards the water rods. Preliminary calculations of the original design were performed using the Dittus-Boelter (Equation A1 in appendix A) and Jackson (Equation A7 in Appendix A) forced convection correlations and the Jackson mixed convection correlation (Equations (A7) and (A11)). The calculated density profiles in the water rod in the average-powered channel with these three correlations are shown in Figure 33. The density profiles calculated with the Dittus-Boelter and Jackson forced convection correlations were in reasonable agreement. However, the mixed convection correlation predicted that buoyancy significantly affected the density profile. The flow through the water rods is downward, and, as shown in Figure A5 in Appendix A, buoyancy enhances the heat transfer coefficient for downward flow. Mixed convection increased the heat transfer coefficient on the inside surface of the water rods by an average factor of 2.2, resulting in an unacceptably low average fluid density in the core. Increasing the flow to the water rods to $90 \%$ of the total reduced the effects of buoyancy on the heat transfer coefficient to an average value $24 \%$ higher than the value from the forced convection

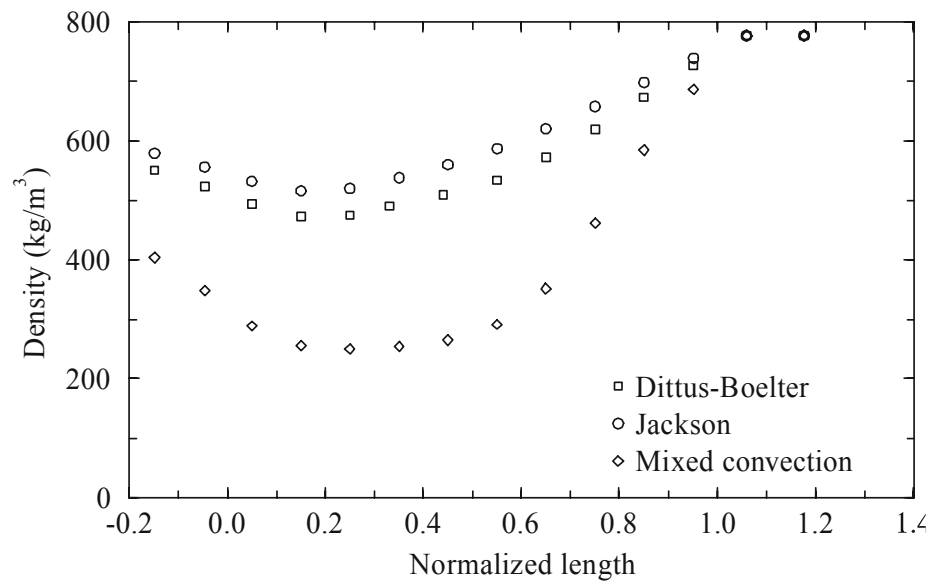

Figure 33. The effect of different heat transfer correlations on the density profile in the water rod with $30 \%$ of the flow directed towards the water rods.

correlation. For comparison, the average enhancement of the heat transfer coefficient on the outside surface of the hexagonal power channel due to buoyancy was $16 \%$.

\subsubsection{Conclusions}

Steady-state analyses were performed for SCWR designs with solid moderator, water rod moderator boxes, and hexagonal power channels with water moderation between the power channels. Please note that the design with solid moderator had an outlet temperature of $450{ }^{\circ} \mathrm{C}$ and the two water-moderated 
designs had an outlet temperature of $500{ }^{\circ} \mathrm{C}$. Therefore the peak cladding temperatures and the margins to the thermal limits are not strictly comparable.

The steady-state analyses of the water rod moderator box design showed that buoyancy significantly affected the heat transfer rate from the fuel assemblies to the moderator. For example, buoyancy increased the average heat transfer coefficient on the inside of the water rods by a factor of 2.2 in the original design that directed $30 \%$ of the total feedwater flow to the water rods. Consequently, the current design directs $90 \%$ of the total feedwater flow towards the water rods to suppress the heat transfer enhancement due to buoyancy. Even with the current design, buoyancy increased the average heat transfer coefficient by more than $20 \%$ and thus must be accounted for in the computer models.

The steady-state analyses showed that both the water rod and power channel designs could achieve relatively high average water densities in the core and thus acceptable fuel cycle costs. Previous analyses showed that the fuel cycle costs in the SCWR with water rods would be comparable to a PWR if the average fluid density in the core was $500 \mathrm{~kg} / \mathrm{m}^{3}$. The calculated average density for the design with water rods was $498 \mathrm{~kg} / \mathrm{m}^{3}$, which was shown in Section 3.1 to result in fuel cycle costs comparable with a PWR. The calculated average density for the design with power channels was $572 \mathrm{~kg} / \mathrm{m}^{3}$, which implies that the fuel cycle costs would be a few percent lower than in a PWR. The higher density in the design with power channels was achieved with a $0.5-\mathrm{mm}$ thick insulating layer of zirconium oxide on the inside surface of the power channel wall. A similar average density was obtained with a 1-mm thick layer of insulation in the design with water rods.

The steady-state analyses showed that lower cladding temperatures could be obtained during normal operation with the power channel design as compared to the water rod moderator box design. These lower cladding temperatures were a result of a higher mass flux through the assembly, which increased the heat transfer coefficient, and the zirconium-oxide insulation, which reduced the fluid temperature in the assembly. The maximum cladding temperature was $601{ }^{\circ} \mathrm{C}$ for the design with power channels, which is below the $620{ }^{\circ} \mathrm{C}$ steady-state limit. For the design with water rod moderator boxes, the maximum cladding temperature was $690{ }^{\circ} \mathrm{C}$, which significantly exceeds the steady-state limit. A sensitivity calculation showed that a $1-\mathrm{mm}$ thick layer of zirconium-oxide insulation would reduce the maximum cladding temperature to $636^{\circ} \mathrm{C}$, which slightly exceeds the limit. The analysis indicates that although insulation is not necessary for the design with water rods to achieve acceptable fuel cycle cost, insulation is necessary to meet the steady-state thermal limit.

Finally, the calculated results for the SCWR are sensitive to the choice of heat transfer correlation. Figure 25 shows large variations in calculated results due to the choice of correlation. Furthermore, the databases of the existing correlations do not cover a sufficiently wide range of thermal-hydraulic conditions to fully support analysis of the reactor at off-normal conditions and during transients. Heat transfer experiments that are prototypical with respect to thermal-hydraulic conditions and geometry should be performed to support analysis of the reactor. The experiments should cover the transitions between the forced convection, natural convection, and laminar heat transfer regimes as these transitions will be encountered during transients. These transitions may also be important in the normal operation of SCWR designs utilizing water for neutron moderation. Figure 33 shows that substantially different density profiles were obtained using forced and mixed convection correlations. 


\section{Task 2 Results: Corrosion and Stress Corrosion Cracking Studies}

\subsection{Progress of Work at the University Of Michigan ( $\mathrm{J}$. McKinley, S. Teysseyre, and G. S. Was)}

The work conducted at the University of Michigan in Year 2 of this NERI project provides information on the deformation and cracking behavior of $304 \mathrm{~L}$ and $316 \mathrm{~L}$ stainless steels in flowing argon at $500{ }^{\circ} \mathrm{C}$, and in deaerated supercritical water at $500{ }^{\circ} \mathrm{C}$. Data on nickel-based Alloy 625 in $500{ }^{\circ} \mathrm{C}$ deaerated supercritical water and information on oxide layer growth on all the alloys in both argon and water are also provided. The results of last year's experiment on the 304L sample in non-deaerated supercritical water are compared with the 304L sample tested in deaerated SCW. Results are also presented on the first proton irradiation of austenitic alloys that will be tested in Year 3.

\subsubsection{Alloys Investigated}

The commercial purity stainless steels 304L and 316L and the nickel-based Alloy 625 were tested. The composition of each alloy is shown in Table XIII. Both 304L and 316L are used for core internal components in light water reactors and the extensive database on the behavior of these alloys in BWR and PWR environments provides a reference condition against which the data in SCW can be compared. Inconel 625 has been used in reactor core and control rod components in LWRs as well as during the fabrication of bench-scale and pilot plant reactors used for waste destruction by SCW oxidation.

The alloys were first heat treated and then machined into bars $38 \mathrm{~mm}$ long with threaded ends and a gage dimension of $2 \mathrm{~mm} \times 1.5 \mathrm{~mm} \times 21 \mathrm{~mm}$. The $304 \mathrm{~L}$ alloy was used in the as-received condition, which contained a grain size of $40 \mu \mathrm{m}$. The $316 \mathrm{~L}$ alloy was solution annealed at $1100{ }^{\circ} \mathrm{C}$ for 20 minutes and water quenched. The grain size after this heat treatment was $44 \mu \mathrm{m}$. The Inconel 625 alloy was solution annealed at $1040{ }^{\circ} \mathrm{C}$ for 30 minutes to assure the dissolution of the carbides and to adjust the grain size to a final average of slightly less than 25 microns. Stress corrosion cracking (SCC) bars were machined from the heat-treated material by electric discharge machining. Both alloys were mechanically polished using standard metallographic techniques and then electropolished to obtain a mirror finish.

Table XIII. Elemental analysis of alloys used in SCC experiments (wt\%).

\begin{tabular}{|c|c|c|c|c|c|c|c|c|c|c|c|c|c|}
\hline Alloys & $\mathbf{C}$ & $\mathbf{M n}$ & $\mathbf{F e}$ & $\mathbf{S}$ & $\mathbf{S i}$ & $\mathbf{N i}$ & $\mathbf{C r}$ & $\mathbf{M o}$ & $\mathbf{C u}$ & $\mathbf{N}$ & $\mathbf{C o}$ & $\mathbf{N b}$ & $\mathbf{P}$ \\
\hline $316 \mathrm{~L}$ & 0.022 & 1.86 & $\mathrm{Bal}$ & .001 & 0.65 & 10.12 & 16.62 & 2.06 & 0.24 & 0.02 & 0.05 & $\mathrm{NM}$ & 0.03 \\
\hline $304 \mathrm{~L}$ & 0.035 & 1.38 & $\mathrm{Bal}$ & 0.03 & 0.65 & 8.5 & 18.3 & 0.37 & $\mathrm{NM}$ & 0.068 & $\mathrm{NM}$ & $\mathrm{NM}$ & 0.02 \\
\hline 625 & 0.02 & 0.11 & 4.64 & 0.001 & 0.13 & $\mathrm{Bal}$ & 21.72 & 9.18 & 0.17 & $\mathrm{NM}$ & 0.15 & 3.59 & $\mathrm{NM}$ \\
\hline
\end{tabular}

NM: Non Measured

\subsubsection{Mechanical Behavior of Austenitic Alloys in Argon}

Constant extension rate tensile experiments on $304 \mathrm{~L}$ and on $316 \mathrm{~L}$ were first performed in argon. The purpose of these tests was two-fold 1) to provide baseline stress-strain behavior and 2) to determine the cracking propensity of the alloys in an inert environment. As stress corrosion cracking involves an interaction of corrosion and deformation-based phenomena, it is necessary to know the deformation mode of each alloy in an inert environment in order to be able to understand the mechanism involved in the crack initiation and propagation. 
Experiments were performed in flowing argon at $500{ }^{\circ} \mathrm{C}$ at atmospheric pressure using the same strain rate as that for the stress corrosion cracking experiments in water. The test conditions and results are summarized in Table XIV.

Table XIV. Test conditions and results of CERT tests performed in flowing argon at $500{ }^{\circ} \mathrm{C}$.

\begin{tabular}{|c|c|c|c|c|c|c|c|c|c|}
\hline Alloy & $\begin{array}{c}\text { 316L } \\
\text { Test }\end{array}$ & $\begin{array}{c}\text { Temp } \\
\left({ }^{\circ} \mathbf{C}\right)\end{array}$ & $\begin{array}{c}\mathbf{O}_{2} \\
(\mathbf{m b a r})\end{array}$ & $\begin{array}{c}\text { Strain } \\
\text { rate } \mathbf{( s}^{-1} \mathbf{)}\end{array}$ & $\begin{array}{c}\text { Test } \\
\text { duration } \\
(\mathbf{h r})\end{array}$ & $\begin{array}{c}\text { Strain to } \\
\text { failure } \\
(\%)\end{array}$ & $\begin{array}{c}\text { TS } \\
(\mathbf{M P a})\end{array}$ & $\begin{array}{c}\text { YS } \\
\mathbf{( M P a})\end{array}$ & Failure mode \\
\hline $304 \mathrm{~L}$ & & 500 & $\sim 0.03$ & $3 \times 10^{-1}$ & 250 & 27 & 360 & 130 & $\begin{array}{l}\text { Intergranular cracks } \\
\text { initiated fracture }\end{array}$ \\
\hline $316 \mathrm{~L}$ & 2 & 500 & $\sim 0.03$ & $3 \times 10^{-7}$ & 320 & 36 & 375 & 160 & $\begin{array}{l}\text { Ductile with intergranular } \\
\text { cracks on the surfaces }\end{array}$ \\
\hline $316 \mathrm{~L}$ & 3 & 500 & $\sim 0.03$ & $3 \times 10^{-1}$ & 240 & 27 & 335 & 145 & $\begin{array}{l}\text { Ductile with intergranular } \\
\text { cracks on the surfaces }\end{array}$ \\
\hline
\end{tabular}

Figures 34 and 35 show the stress - strain plots for the experiments in Table XIV. Test 3 provides a better measure of the effects of an inert environment than Test 2 since the sample used in Test 2 was exposed to supercritical water for several hours prior to removal and testing in argon. Subsequent comparisons will use Test 3. The serrated sections of the plots correspond to Type C Portevin le-Chatelier (PLC) yielding, a type of dynamic strain aging. The PLC effect began early in the test for the 304L sample and lasted until $22 \%$ strain, whereas the effect occurred at higher strain in the $316 \mathrm{~L}$ sample and occurred to a lesser extent.

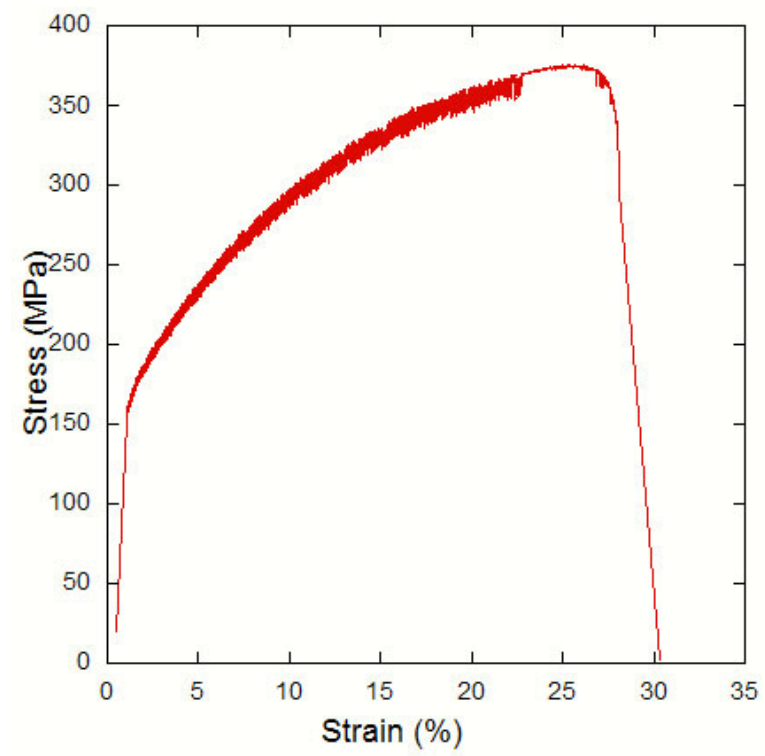

Figure 34. Stress - strain curve for the 304L sample strained in flowing argon at $500{ }^{\circ} \mathrm{C}$. The serrations in the curve are due to Type $C$ PLC effect.

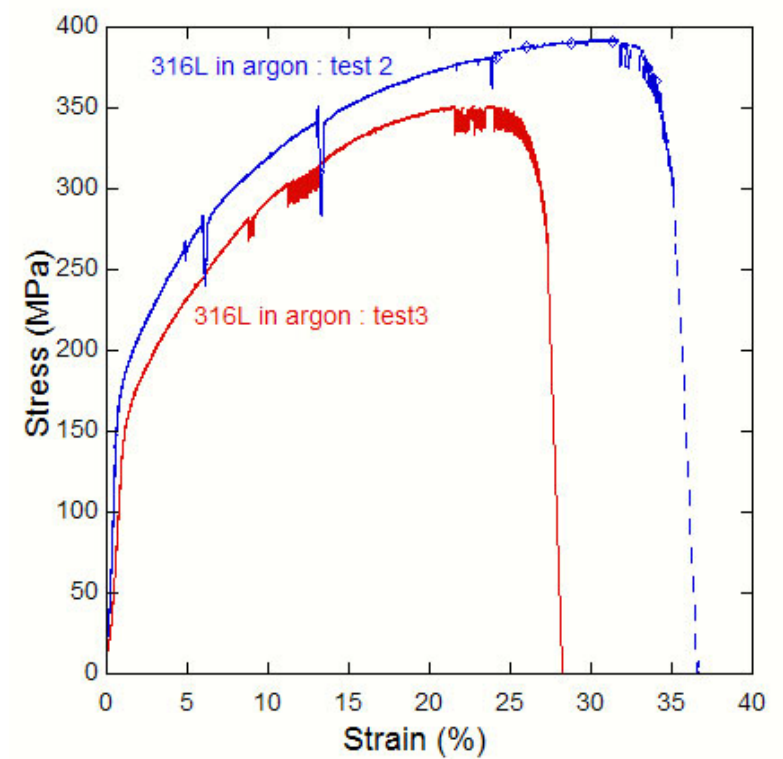

Figure 35. Stress - strain curve for the 316L sample strained in flowing argon at $500{ }^{\circ} \mathrm{C}$. The serrations in the curve are due to Type $\mathrm{C}$ PLC effect.

The side surfaces of both of the alloys after the tensile experiments showed evidence of intergranular cracking that extended through the oxide (created by the oxygen impurity in the argon) and into the metal, but the cracks were confined to the highly deformed region near the fracture as shown in Figure 36. 
a)

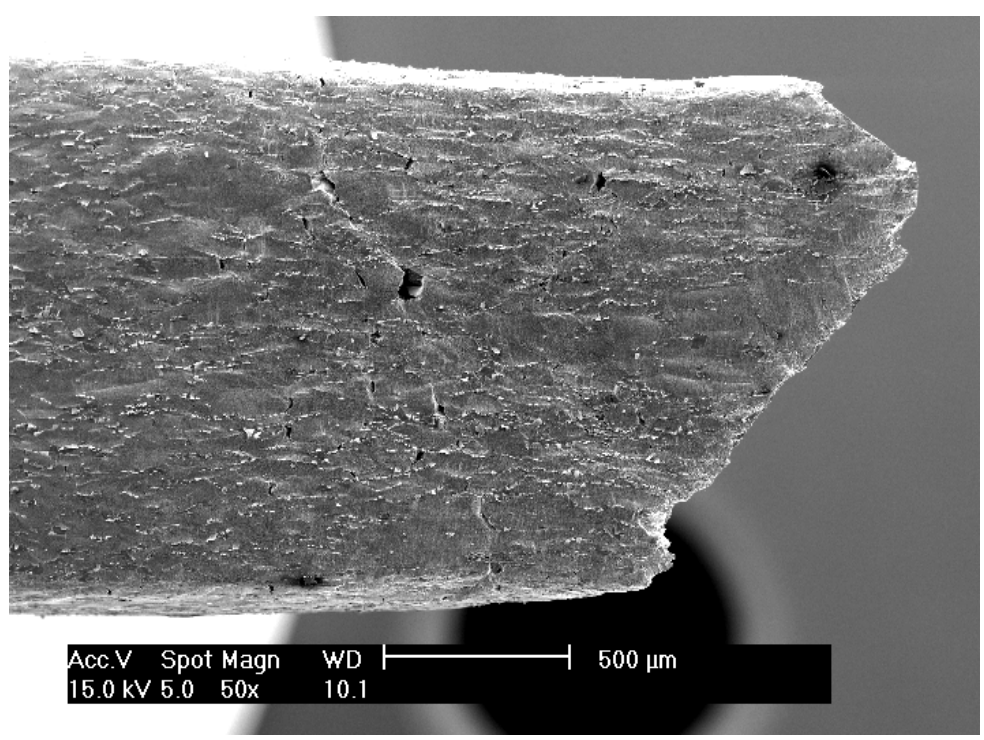

b)
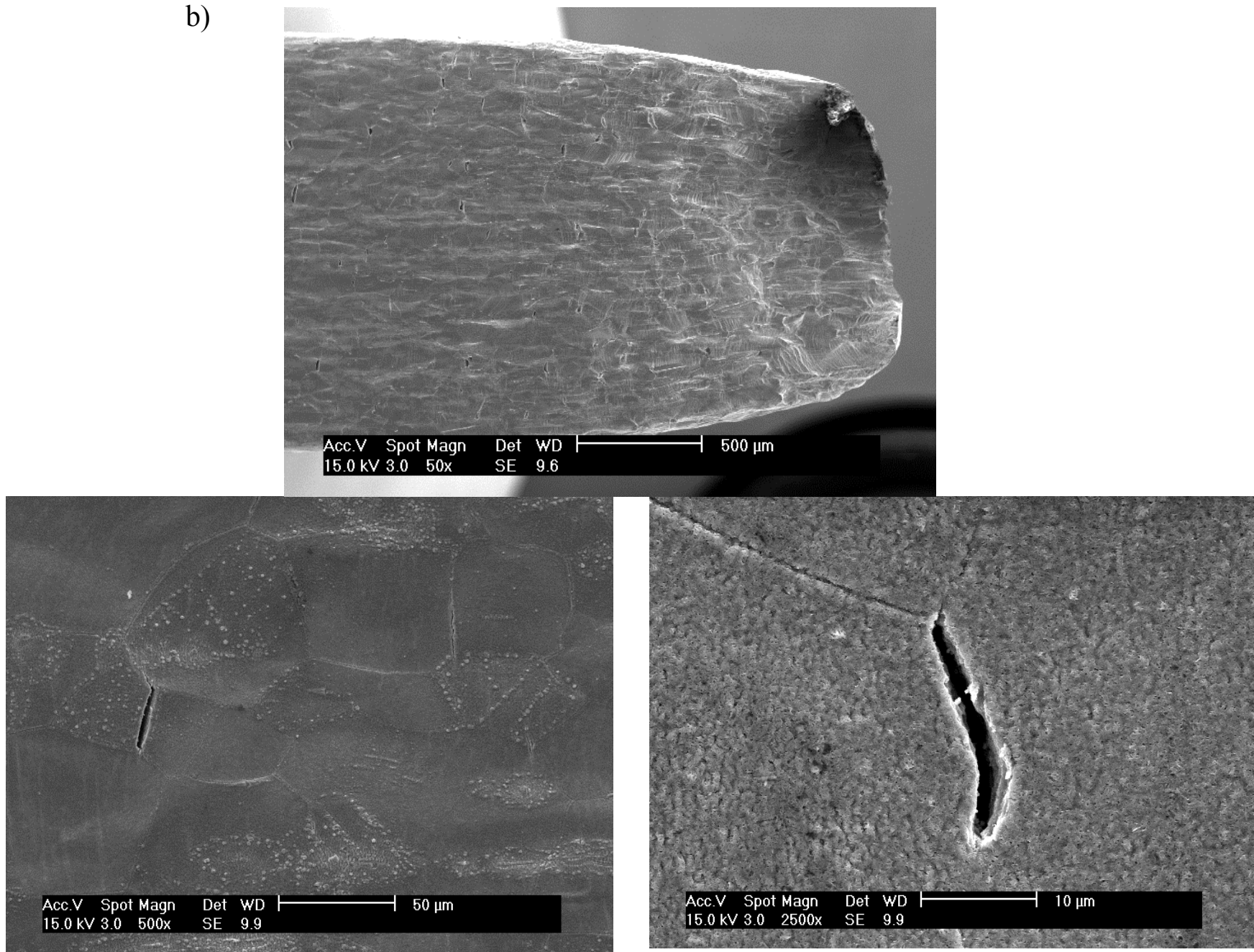

Figure 36. Side surface of the 304L (a) and 316L sample from Test 3 (b) strained to failure in argon: numerous intergranular cracks can be seen but only in the highly deformed neck region near the fracture. 
Figure 37 shows SEM micrographs of the fracture surfaces for each of the samples. The 304L sample had between 5 and 10 percent intergranular fracture while the fracture surface of the 316L sample was completely ductile. Some of the intergranular facets present on the fracture surface of the 304L sample were found in the center of the sample, which is likely due to intergranular creep cracking and is not affected by the environment. Many of the cracks seen on the edges of the sample, however, do appear smooth as would be expected for environmentally caused cracking.

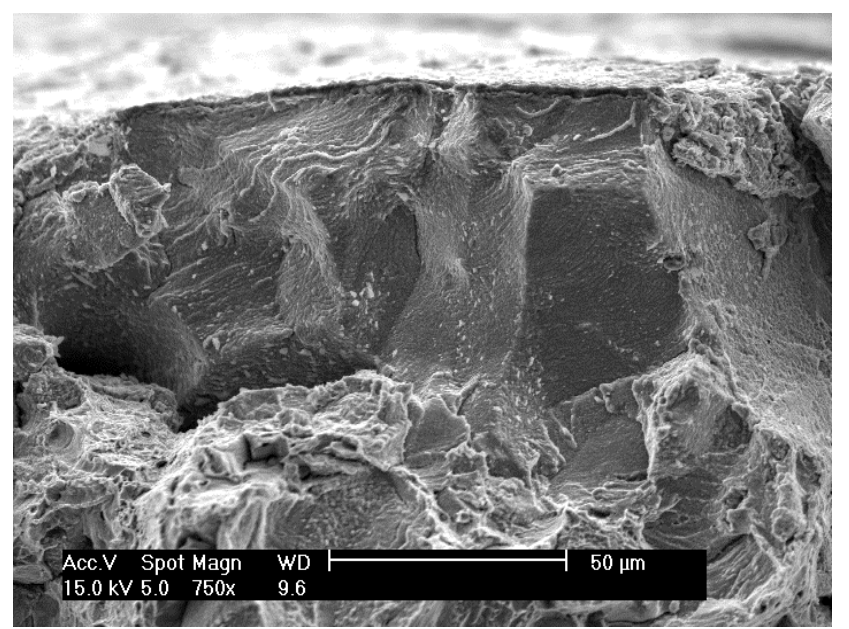

Figure 37a. Intergranular cracking present on the edge of the fracture surface of a 304L sample strained in flowing argon at $500{ }^{\circ} \mathrm{C}$.

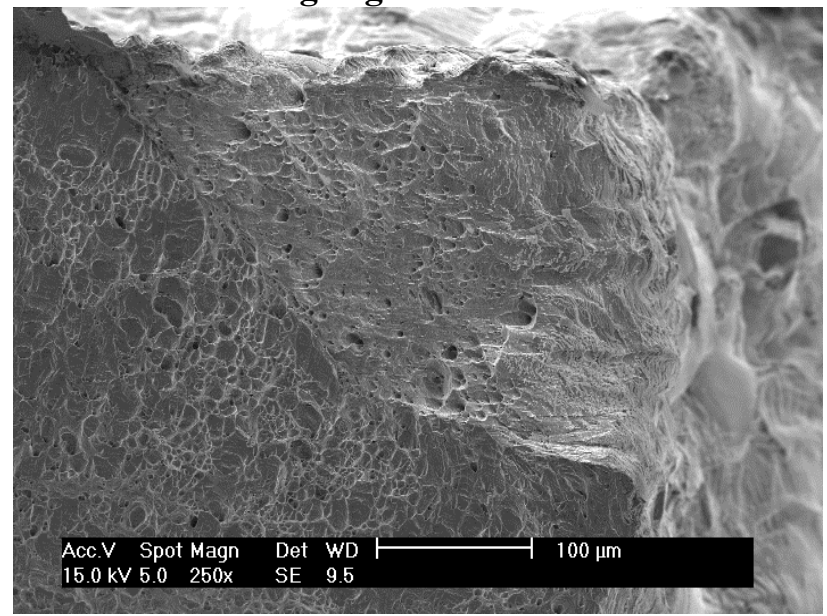

Figure 37c. Fully ductile rupture surface of the $316 \mathrm{~L}$ sample strained in flowing argon at $500{ }^{\circ} \mathrm{C}$.

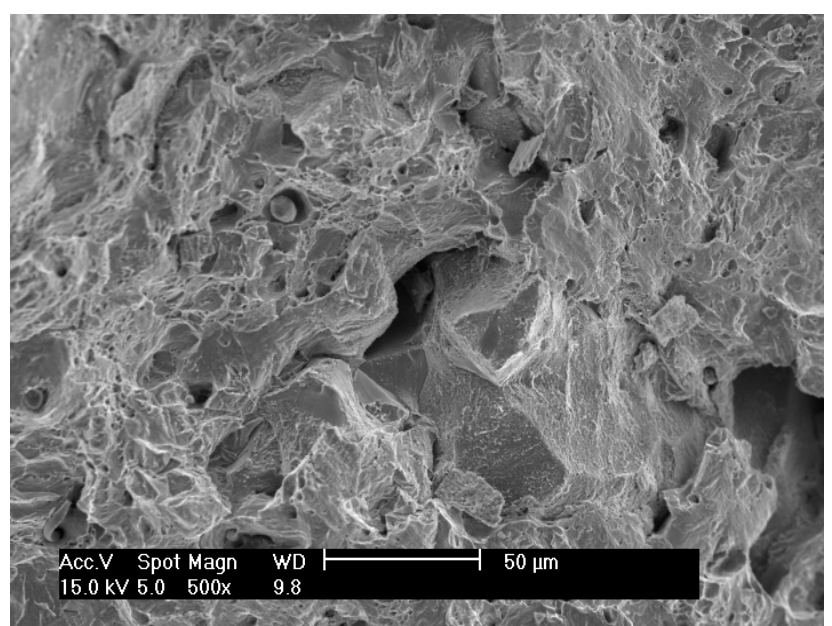

Figure 37b. Intergranular cracking present in the center of the fracture surface of a $304 \mathrm{~L}$ sample strained in flowing argon at $500{ }^{\circ} \mathrm{C}$.

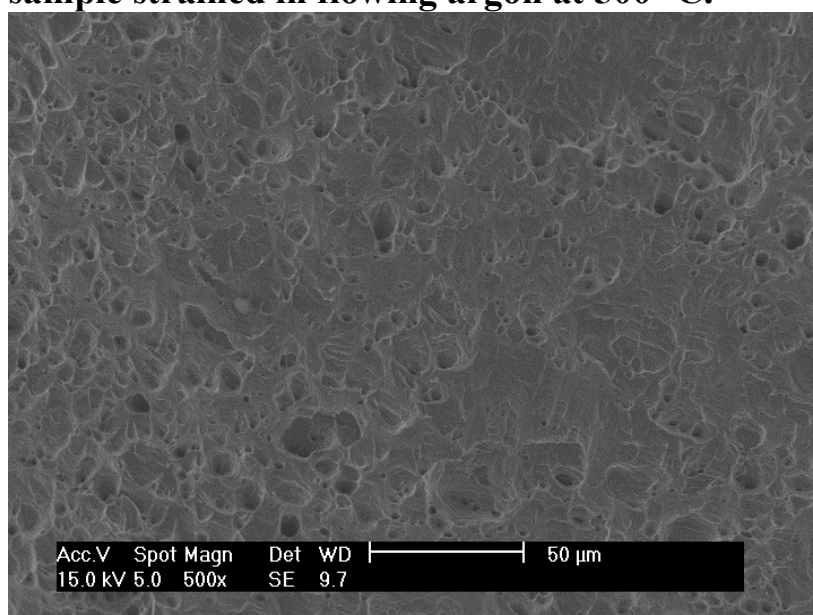

Figure 37d. Ductile rupture in the center of the fracture surface of the $316 \mathrm{~L}$ sample strained in flowing argon at $500{ }^{\circ} \mathrm{C}$.

We conclude that at the temperature used in these experiments, the deformation is characterized by a pronounced PLC yielding effect. This effect occurs at certain combinations of temperature and strain rate, specific for each alloy. The intergranular cracking observed could either be purely mechanical or due to the small amount of oxygen present in the environment. It has been shown that PLC can modify the propagation of a crack when SCC occurs [Fournier 2001]. A creep mechanism could also be involved. 


\subsubsection{Stress Corrosion Cracking Behavior of Austenitic Alloys in Deaerated Supercritical Water}

Constant extension rate tensile tests were performed on 304L and 316L stainless steel samples and on the nickel-based Alloy 625 in $500{ }^{\circ} \mathrm{C}$ deaerated supercritical water. The environment was controlled in order to achieve a low conductivity $(<0.1 \mu \mathrm{S} / \mathrm{cm})$ and low dissolved oxygen content $(<10 \mathrm{ppb})$. The test conditions are summarized in Table XV.

The 316L stainless steel and nickel-based Alloy 625 samples were pulled to failure and the 304L stainless steel sample was pulled to $25 \%$ strain. The experimental results are summarized in Table XVI. The stress recorded under supercritical conditions exhibited variations up to $\pm 20 \mathrm{MPa}$. Those variations may be due to the pressure balance system and probably do not represent stress fluctuations experienced by the sample. (The variations are relatively uniform in magnitude and stochastic in frequency. Also, they do not occur during the argon tests.)

\section{Table XV. Supercritical water environment for SCC tests.}

\begin{tabular}{|l|l|}
\hline Environment & SCW \\
\hline Temperature $\left({ }^{\circ} \mathrm{C}\right)$ & 500 \\
\hline Pressure $(\mathrm{MPa})$ & 25.5 \\
\hline $\mathrm{O}_{2}(\mathrm{ppb})$ & $<10$ \\
\hline Conductivity. $(\mu \mathrm{S} / \mathrm{cm})$ & $<0.1$ \\
\hline Flow rate $(\mathrm{ml} / \mathrm{min})$ & 10 \\
\hline Strain rate $\left(\mathrm{s}^{-1}\right)$ & $3 \times 10^{-1}$ \\
\hline
\end{tabular}

Table XVI. Results of SCC experiments in deaerated supercritical water at $500{ }^{\circ} \mathrm{C}$.

\begin{tabular}{|l|l|l|l|}
\hline Alloy & $\mathbf{3 0 4 L}$ & $\mathbf{3 1 6}$ & $\mathbf{6 2 5}$ \\
\hline Test duration $(\mathrm{hr})$ & 230 & 305 & 500 \\
\hline Strain to failure (\%) & $25^{1}$ & 33 & 48 \\
\hline Max stress (MPa) & $290^{1}$ & 280 & 680 \\
\hline Yield strength (MPa) & 100 & 100 & 270 \\
\hline Fracture surface & $\begin{array}{l}\text { Intergranular and ductile. } \\
\text { Intergranular cracks } \\
\text { initiated fracture }\end{array}$ & $\begin{array}{l}\text { Ductile with intergranular } \\
\text { cracks on the sides }\end{array}$ & $\begin{array}{l}\text { Intergranular and ductile. } \\
\text { Intergranular cracks on the side } \\
\text { surfaces }\end{array}$ \\
\hline $\begin{array}{l}\text { Surface intergranular } \\
\text { crack density }\left(\# / \mathrm{mm}^{2}\right)\end{array}$ & 7 & $\mathrm{NM}$ & 25 \\
\hline
\end{tabular}

'experiment was stopped before failure, $\mathrm{NM}=$ not measured

The stress-strain curve for 304L in deaerated water is plotted in Figure 38 with the strain-stress curves obtained in nondeaerated SCW and in argon for comparison. The stress-strain behaviors of the 304L samples in non-deaerated and deaerated SCW were similar up to $22 \%$ strain. The experiment in deaerated SCW was stopped after $25 \%$ strain due to an experimental problem. The stress discontinuity at $22 \%$ strain was due to an interruption in the test at that strain level. Subsequent examination revealed that the 304L sample in deaerated water did not neck, similar to the behavior observed in non-deaerated SCW. Also, there were a significant number of cracks on the sample surface (see Figure 39a). Inspection of the cracks at high magnification (see Figure 39b) revealed that they were intergranular cracks. The crack density was about 7 cracks $/ \mathrm{mm}^{2}$, or approximately one-third of the magnitude of that observed on the 304L sample tested in non-deaerated water. Also, the cracks covered the entire gage surface, contrary to that observed in argon.

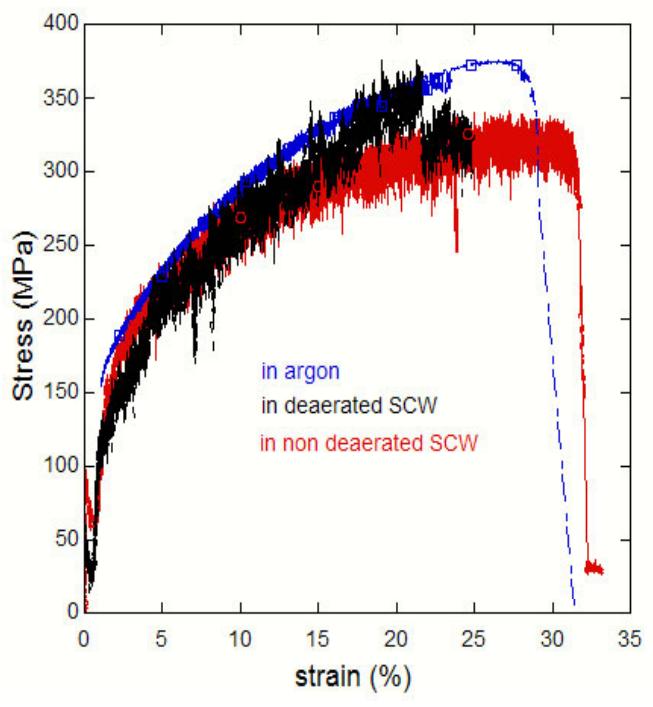

Figure 38. Stress-strain curves obtained with 304L samples in SCW and argon. 


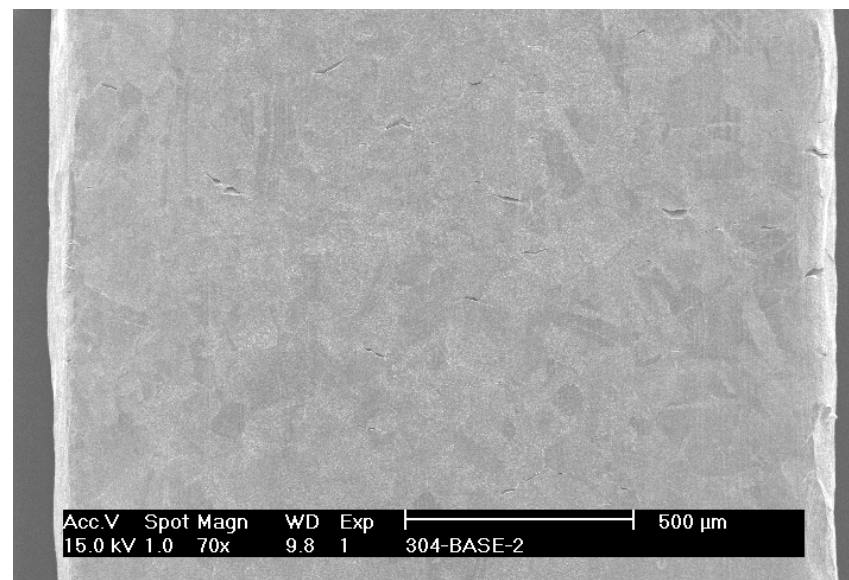

a)

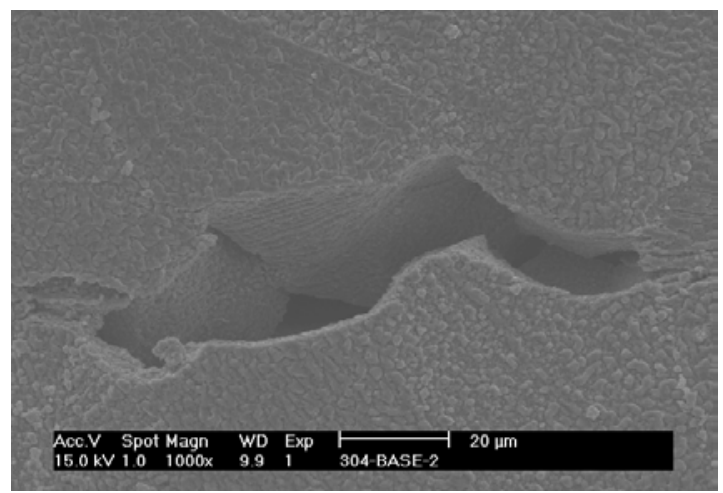

b)

Figure 39. The Alloy 304L sample strained to $25 \%$ in deaerated SCW: a) the surface of the sample showing a high density of cracks, and b) a crack at high magnification showing the intergranular nature of the crack.

The 316L sample strained in deaerated SCW exhibited a behavior similar to that of the $316 \mathrm{~L}$ sample strained in argon (Figure 40), but it had a slightly higher strain at rupture than the sample strained in argon. Figure 41 shows the sample surface after failure. The sample did neck and cracks are present on the sample gage surface. Many of the cracks penetrated only the oxide layer, but some cracks, as shown Figure 41-b, are in the metal. The difficulty in discerning between these two types of cracks made crack density measurement impossible. The nature of those cracks, transgranular or intergranular, has not been defined. The fracture surface is totally ductile.

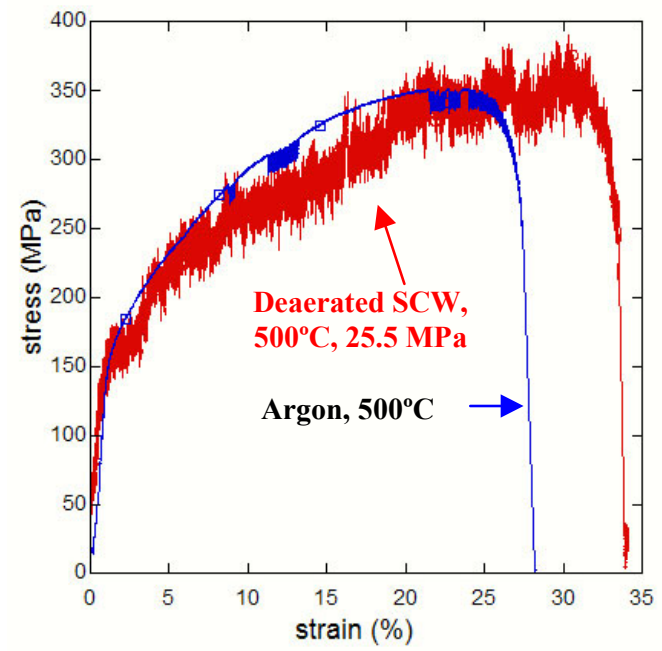

Figure 40. Stress-strain curves for 316L in argon and deaerated SCW at 500C.

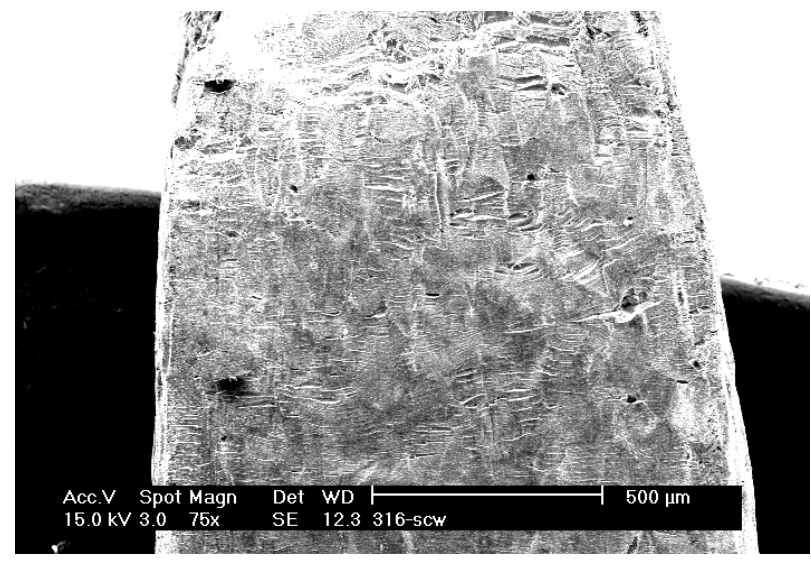

a)

Figure 41. The Alloy 316L sample after failure in deaerated SCW; a) the surface of the sample, and b) a crack at higher magnification. 
The stress-strain curve for the Alloy 625 sample is plotted in Figure 42. The sample reached $680 \mathrm{MPa}$ and $48 \%$ strain before rupture, which occurred abruptly. Observation of the gage section of the sample revealed that the sample did not neck and that numerous intergranular cracks were present as shown in Figure 43. The cracking occurred all over the surface of the sample and some cracks were up to $500 \mu \mathrm{m}$ long. The crack density was around $25 \mathrm{cracks} / \mathrm{mm}^{2}$. The fracture surface (Figure 44) shows that intergranular cracking occurred close to the edges, with crack depths of approximately $50 \mu \mathrm{m}$. An important difference between the cracking in the 304 and 316 stainless steel and the Alloy 625 is that in the latter, the cracks are much longer - spanning several grain facets rather than just a single facet. And, there are numerous places where it looks like the cracks ran together or coalesced. This suggests that significant crack growth occurred during the test.

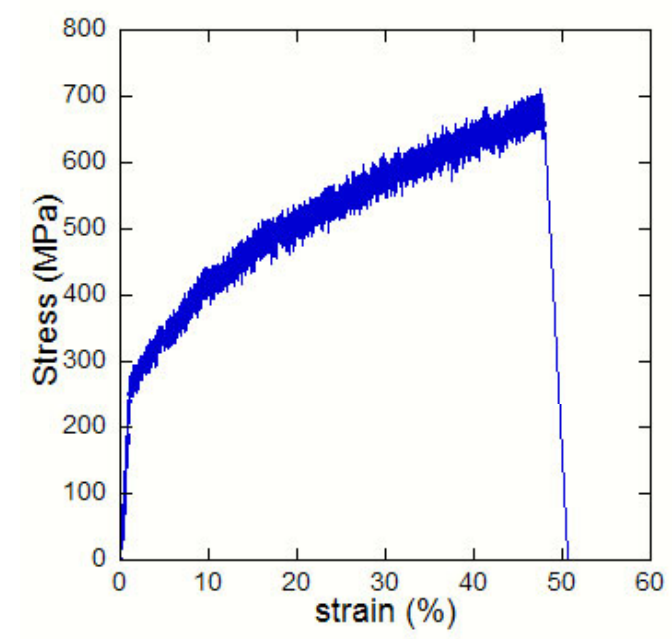

Figure 42. Stress-strain behavior of Alloy 625 in deaerated SCW.

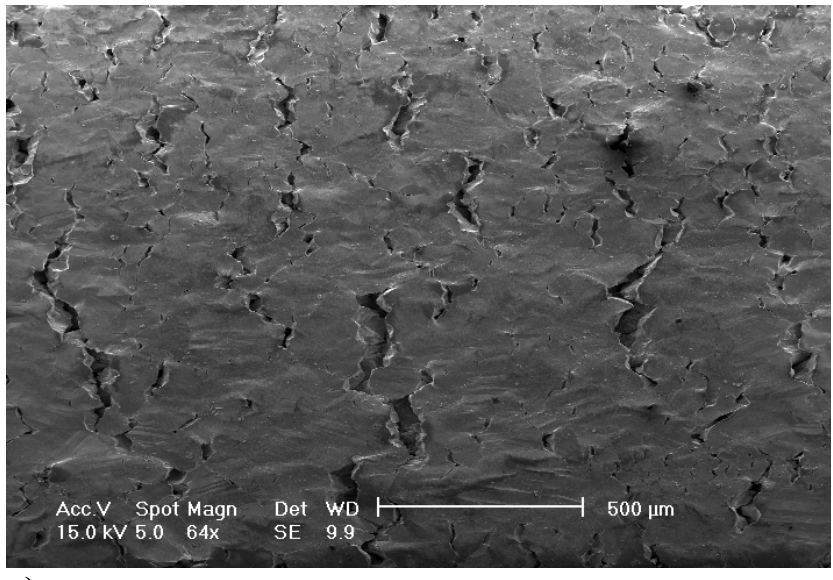

a)

Figure 43. Alloy 625 after failure in deaerated SCW; magnification.

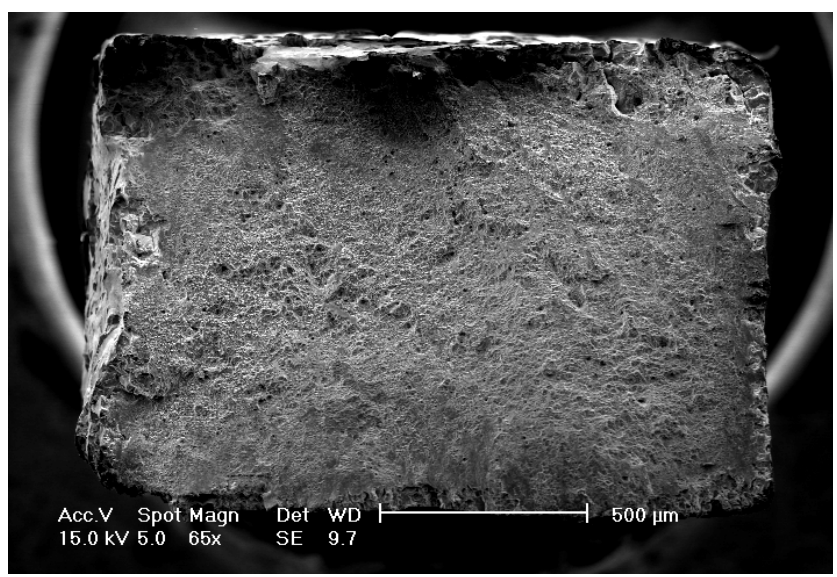

a)

Figure 44. a) Fracture surface of the Alloy 625 sample after failure in deaerated SCW, and b) edge of the sample at higher magnification.

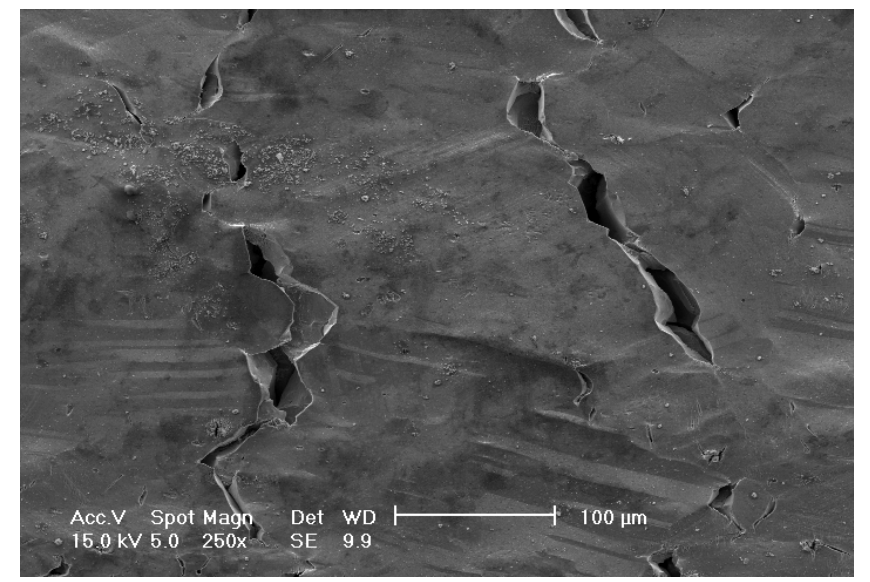

b)

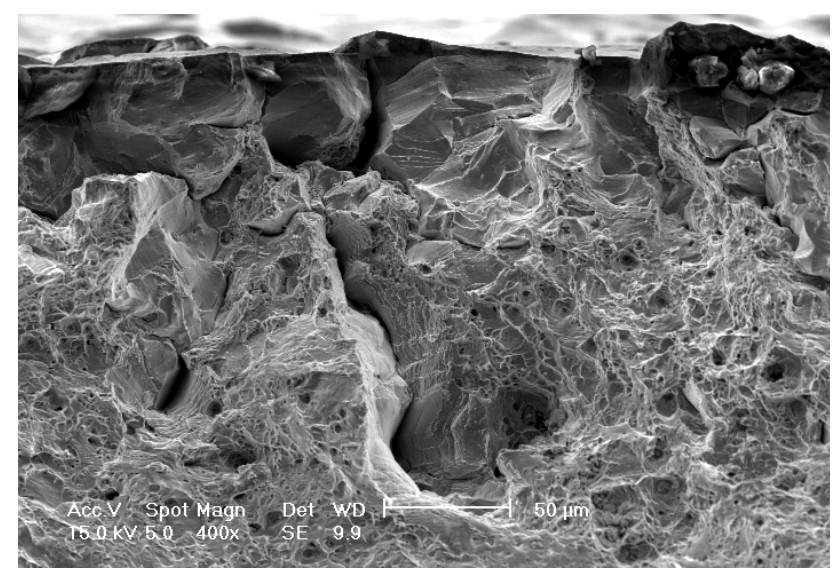

b) a) the surface of the sample, and b) a crack at higher 


\subsubsection{Corrosion Behavior of Austenitic Alloys in Supercritical Water.}

\subsubsection{Results of the Analysis of the Oxide Formed During Stress Corrosion Cracking Experiments}

The oxides formed on the 304L alloy tested in non-deaerated and deaerated water and the 316L samples were analyzed using a combination of electron backscattering analysis, energy dispersive spectroscopy (EDS) and X-ray photoelectron spectroscopy (XPS) on sample surfaces and cross-sections. These techniques provided information about the oxide thickness, composition and binding state of the elements in the oxide.

Table XVII presents the oxide thicknesses calculated from scanning electron microscope images like those shown in Figure 45 along with the conditions under which the experiments were performed. These oxide thicknesses are consistent with expectations in most cases. The 304L exposed to non-deaerated SCW formed a much thicker oxide layer than did the 304L sample exposed to deaerated SCW, which coincides with the presence of a more oxidizing environment in the non-deaerated SCW. The 316L sample exposed to deaerated SCW had a slightly thinner oxide than that on the 304L sample exposed to deaerated SCW.

Table XVII. Results of oxide thickness measurements compiled with the experimental conditions.

\begin{tabular}{|c|c|c|c|c|c|}
\hline Alloy & $\begin{array}{c}\text { Oxide Thickness } \\
(\boldsymbol{\mu} \mathbf{m})\end{array}$ & $\begin{array}{c}\text { Temperature } \\
\left({ }^{\circ} \mathbf{C}\right)\end{array}$ & $\begin{array}{c}\text { Pressure } \\
(\mathbf{M P a})\end{array}$ & $\begin{array}{c}\text { Exp. Time } \\
(\mathbf{h r s})\end{array}$ \\
\hline $304 \mathrm{~L}$ & 4.57 & 550 & 25.5 & Non-deaerated SCW & 160 \\
\hline $304 \mathrm{~L}$ & 1.58 & 500 & 25.5 & Deaerated SCW & 230 \\
\hline $316 \mathrm{~L}^{1}$ & 2.01 & 500 & $0.101^{2}$ & Argon & 320 \\
\hline $316 \mathrm{~L}$ & 1.25 & 500 & 25.5 & Deaerated SCW & 305 \\
\hline
\end{tabular}

1 After 5 days in SCW

${ }^{2}$ Under atmospheric pressure.

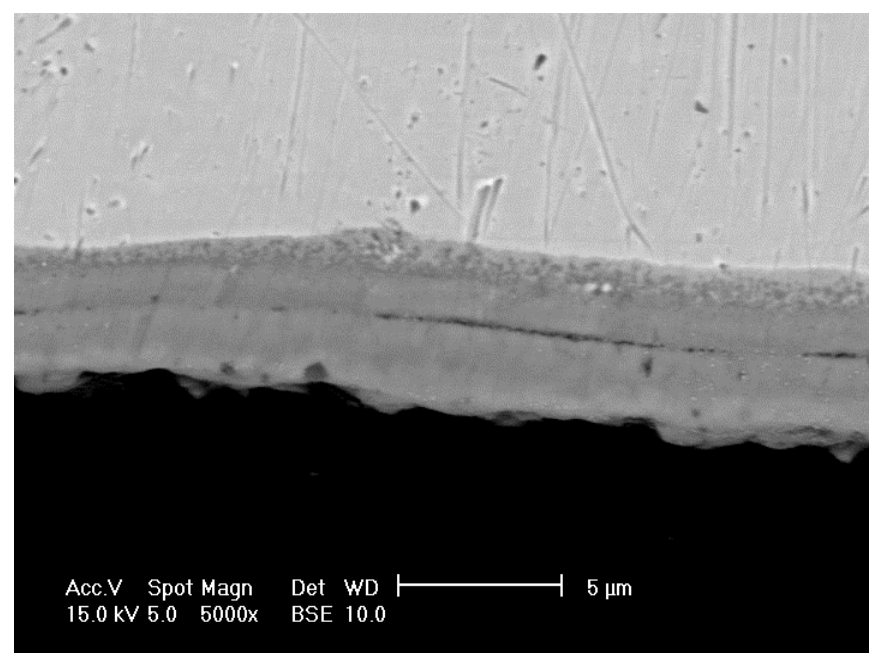

Figure 45a. SEM backscattered electron image of a cross-section of 304L exposed to non-deaerated SCW for $160 \mathrm{hrs}$ at $550{ }^{\circ} \mathrm{C}$ and $25.5 \mathrm{MPa}$.

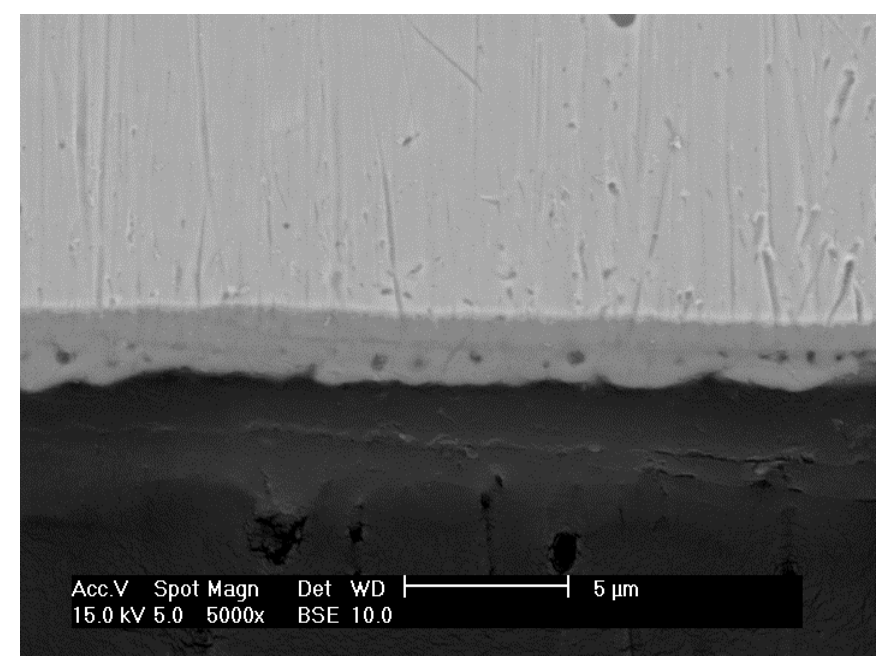

Figure 45b. SEM backscattered electron image of a cross-section of 304 $\mathrm{L}$ exposed to deaerated SCW for $230 \mathrm{hrs}$ at $500{ }^{\circ} \mathrm{C}$ and $25.5 \mathrm{MPa}$. 


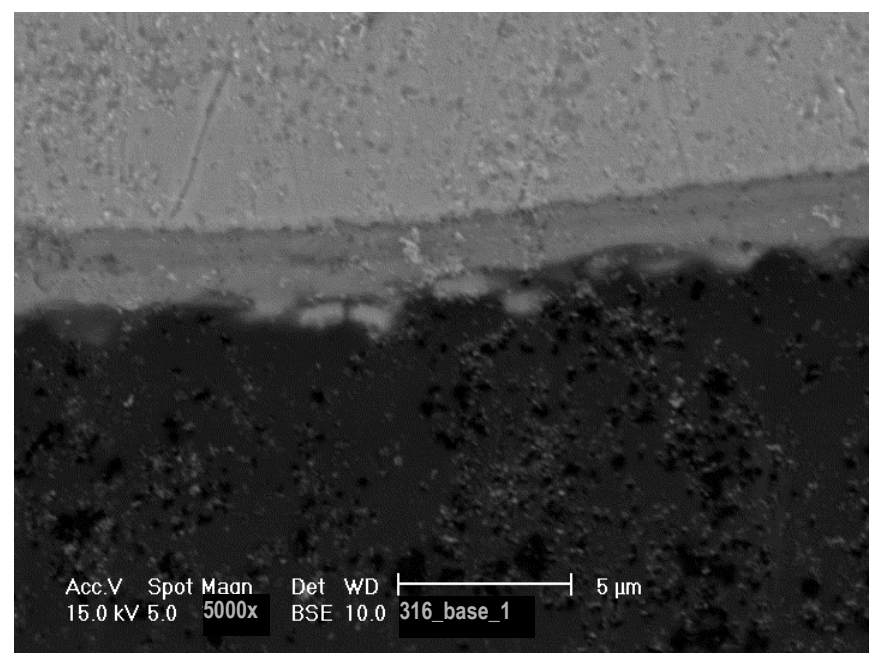

Figure 45c. SEM backscattered electron image of a cross-section of $316 \mathrm{~L}$ exposed to argon at atmospheric pressure for $320 \mathrm{hrs}$ at $500{ }^{\circ} \mathrm{C}$ after 5 days in deaerated SCW.

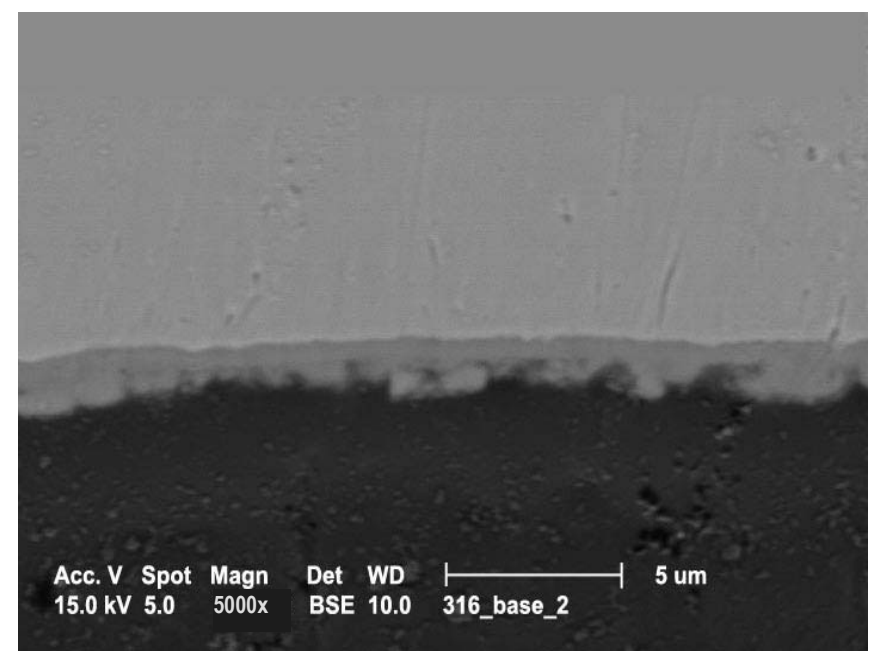

Figure 45d. SEM backscattered electron image of a cross-section of $316 \mathrm{~L}$ exposed to deaerated SCW for $305 \mathrm{hrs}$ at $500{ }^{\circ} \mathrm{C}$ and $25.5 \mathrm{MPa}$.

The results of the EDS measurements taken on the surfaces of each sample are presented in Table XVIII. These results show that the part of the oxide layer that is being measured (approximately $1 \mu \mathrm{m}$ depth) is composed primarily of iron oxides and contains proportionately less chromium and nickel than does the metal matrix. The 304L sample exposed to non-deaerated SCW is an exception in that it shows a much higher concentration of chromium in the oxide film. The fact that the proportion of iron to chromium in the oxide was of this magnitude indicates that the environment stabilizes iron oxides more than chromium or nickel oxides.

Table XVIII. Results of EDS measurements on the oxide formed on the SCC sample bars.

\begin{tabular}{|c|c|c|c|c|c|}
\hline & & \multicolumn{4}{|c|}{ Composition Measured by EDS ${ }^{\mathbf{1}}$ (wt\%) } \\
\hline Sample & Experimental Conditions & Fe & $\mathbf{C r}$ & $\mathbf{N i}$ & $\mathbf{0}$ \\
\hline $\mathbf{3 0 4 \mathrm { L }}$ & $550^{\circ} \mathrm{C}, 25.5 \mathrm{MPa}$, non-deaerated SCW & 57 & 23.5 & 2.5 & 17 \\
\hline $\mathbf{3 0 4 \mathrm { L }}$ & $500^{\circ} \mathrm{C}, 25.5 \mathrm{MPa}$, deaerated SCW & 68.2 & 7.8 & 2.8 & 21.2 \\
\hline $\mathbf{3 1 6 L}$ & $500^{\circ} \mathrm{C}, 25.5 \mathrm{MPa}$, deaerated SCW & 70 & 4.6 & 3.4 & 22 \\
\hline
\end{tabular}

${ }^{1}$ Compositions normalized to $100 \%$ for the elements of interest. Carbon contamination is not included.

The oxide composition across the oxide thickness was also analyzed. The EDS line scans across the oxide formed on the Alloy 304L and 316L are presented Figures 46a-c. The oxide on all the samples is mainly an iron oxide and is composed of either two or three layers. The 304L and 316L samples exposed to deaerated SCW have two layers. The layer in contact with the alloy is richer in chromium than the substrate and contains less iron (around $55 \mathrm{wt} \% \mathrm{Fe}$ and $35 \% \mathrm{Cr}$ for the $304 \mathrm{~L}$ sample and $45 \mathrm{wt} \% \mathrm{Fe}$ and $25 \% \mathrm{Cr}$ for the $316 \mathrm{~L}$ sample). Then, the chromium content decreases and the iron content increases as one moves towards the oxide surface with the amount of chromium negligible on the surface (around $2 \mathrm{wt} \%$ ). The oxide formed on the 304L exposed to the non-deaerated SCW has an additional layer on the sample surface in which the chromium content increases as the iron content decreases. The surface is then composed of $65 \mathrm{wt} \% \mathrm{Cr}$ and $25 \% \mathrm{Fe}$.

Each line scan reveals a slight increase in nickel at the interface between the oxide and the substrate 

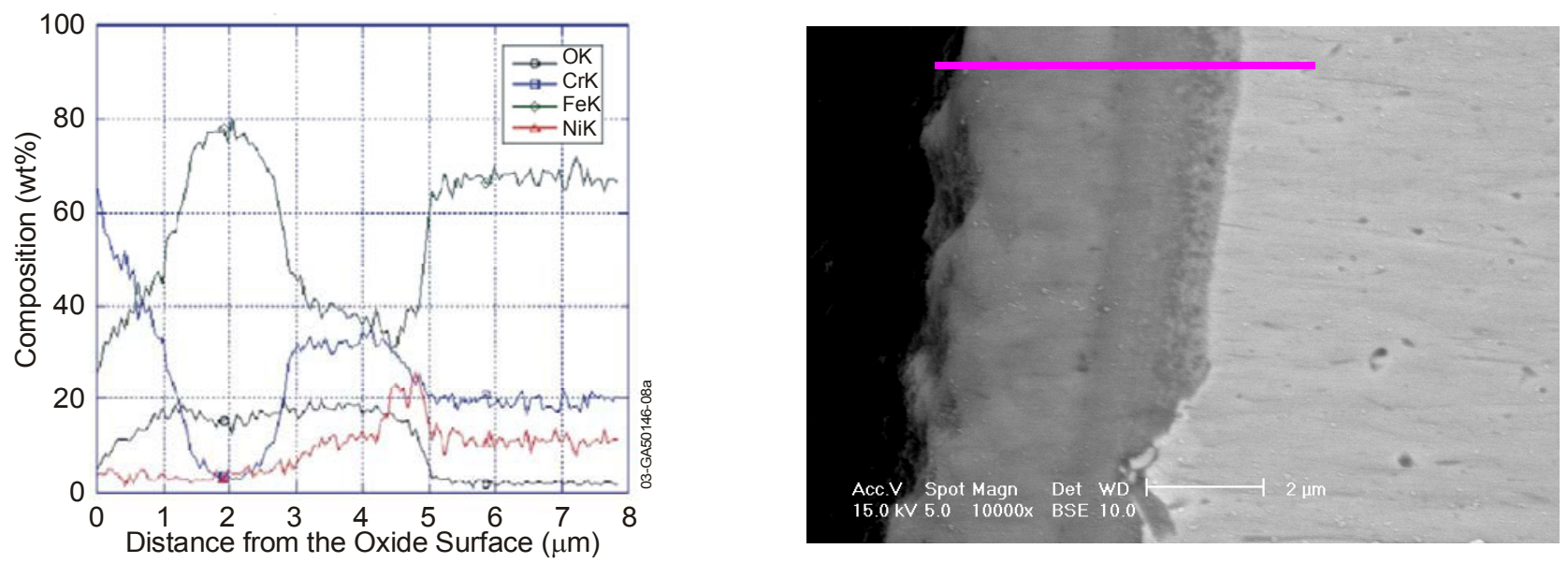

Figure 46a. EDS line scan across the oxide formed on 304L exposed in non-deaerated SCW and the resulting composition profile (data from the $K$ edges of the $x$-ray scan are shown).
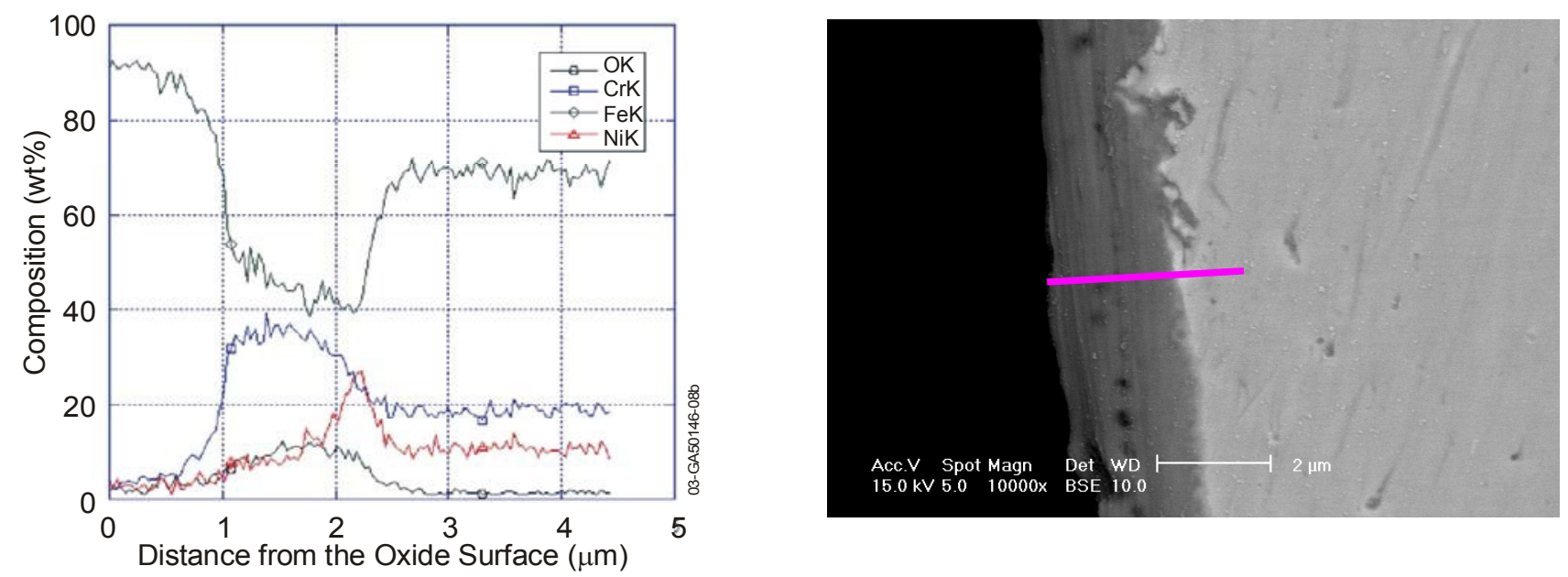

Figure 46b. EDS line scan across the oxide formed on 304L exposed in deaerated SCW and the resulting composition profile.
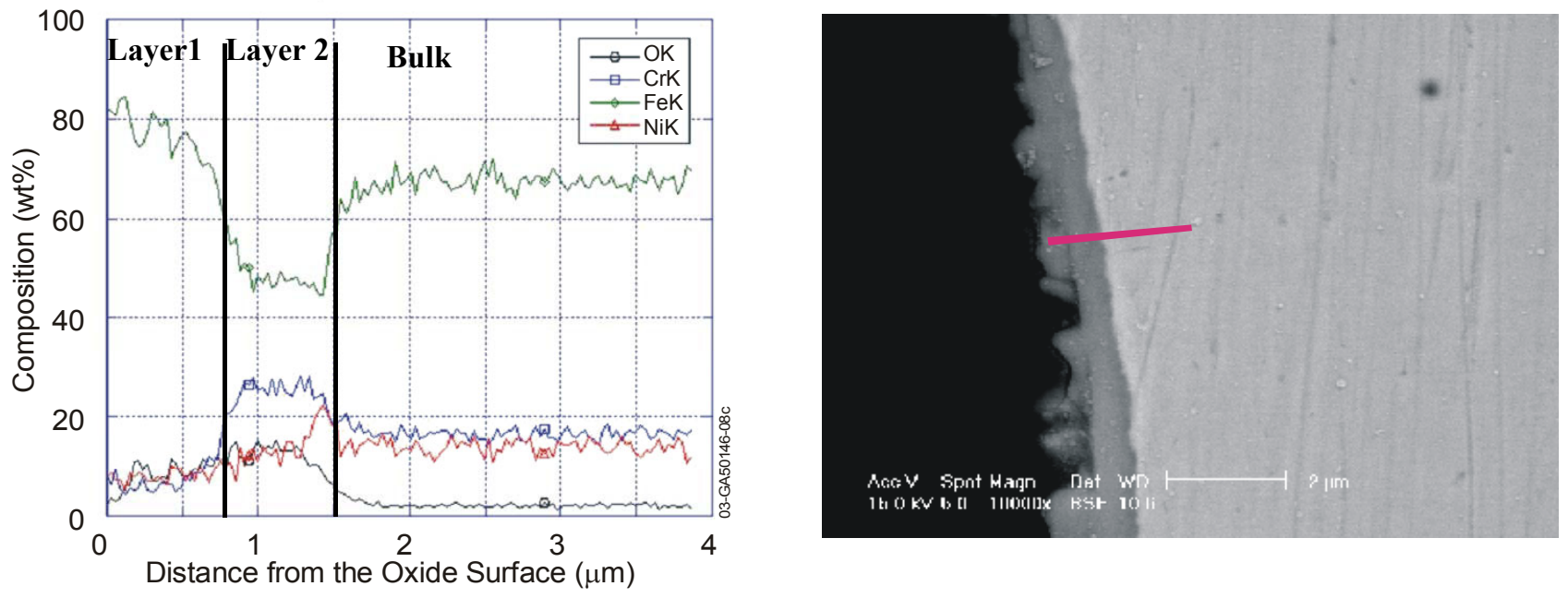

Figure 46c. EDS line scan across the oxide formed on 316 $\mathrm{L}$ exposed in deaerated SCW and resulting composition profile. 
XPS was used to determine the bonding state of the metallic constituents and oxygen. XPS survey scans for the $304 \mathrm{~L}$ sample exposed to $550{ }^{\circ} \mathrm{C}$ non-deaerated SCW and for the $316 \mathrm{~L}$ sample exposed to $500{ }^{\circ} \mathrm{C}$ deaerated SCW are shown in Figure 47. Both samples exhibit iron, chromium, and oxygen in the survey scans. Each sample was scanned in detail in the oxygen $1 \mathrm{~s}$, the iron $2 \mathrm{p}$, the chromium $2 \mathrm{p}$, and the nickel $2 p$ regions. The focused region scans for the oxidized $316 \mathrm{~L}$ sample are presented in Figure 48 . While these results are preliminary, it appears that all of the nickel, iron, and chromium are in an oxidized or hydroxylated state. Table XIX lists the bonding states of the metallic constituents of the oxide film formed on the samples.

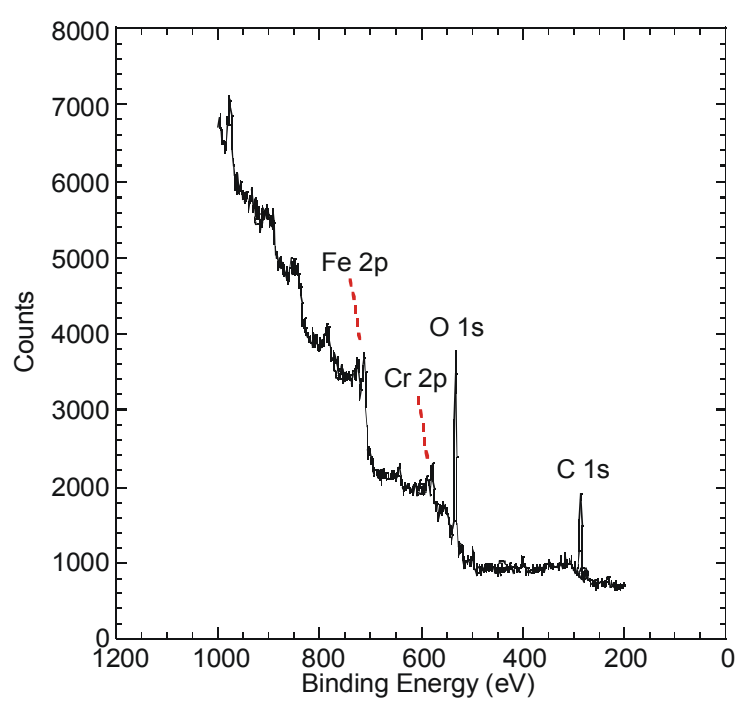

Figure 47a. XPS survey scan of the oxide on the 304L sample exposed to non-deaerated SCW for 160 hours at $550{ }^{\circ} \mathrm{C}$ and $25.5 \mathrm{MPa}$.

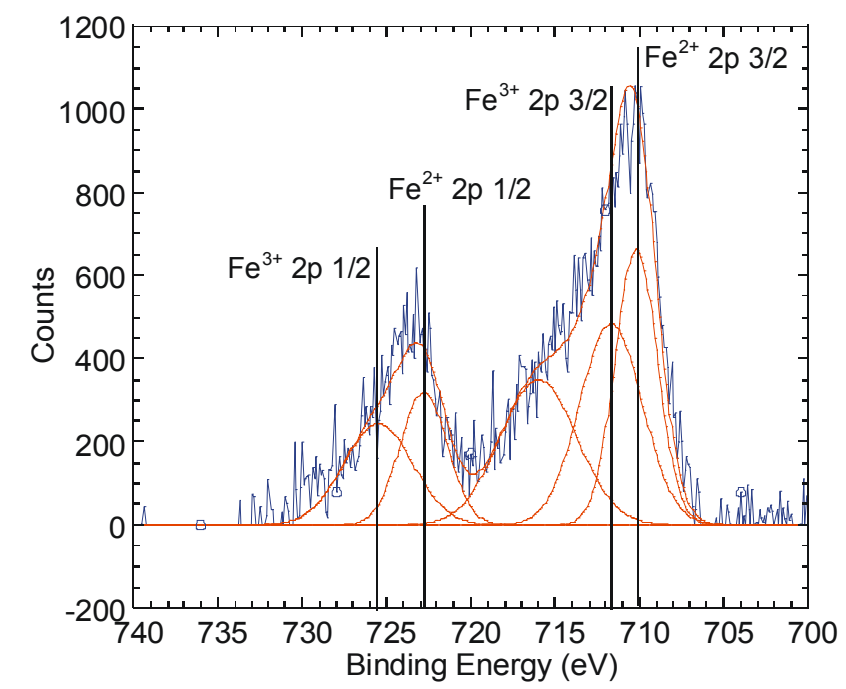

Figure 48a: XPS results for oxidized 304L in the iron $2 p$ region. The curve fit includes $\mathrm{Fe}^{2+}, \mathrm{Fe}^{3+}$, and the corresponding satellite peak. The iron metal peak at $706.8 \mathrm{eV}$ is not present.

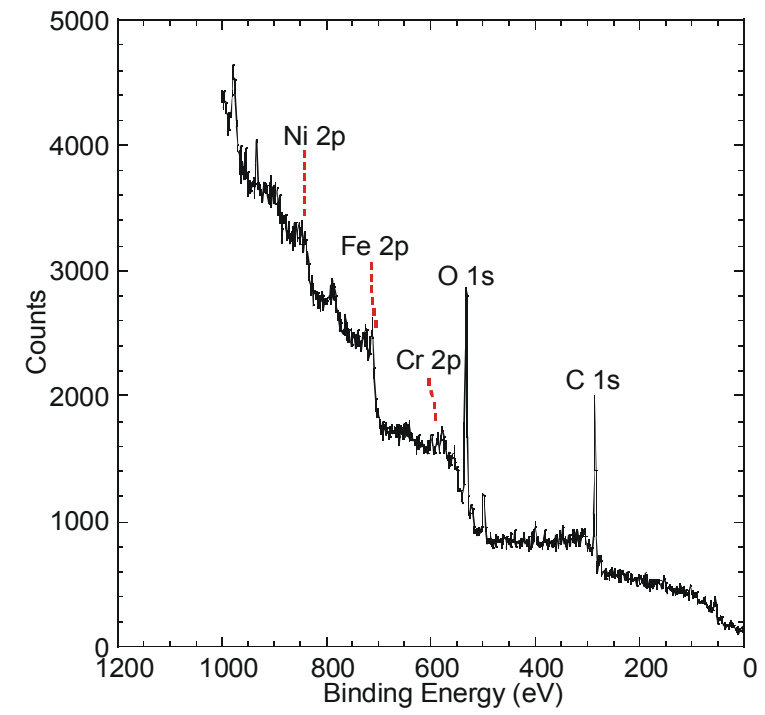

Figure 47b. XPS survey scan of the oxide on the 316L sample exposed to deaerated SCW for 305 hours at $500{ }^{\circ} \mathrm{C}$ and $25.5 \mathrm{MPa}$.

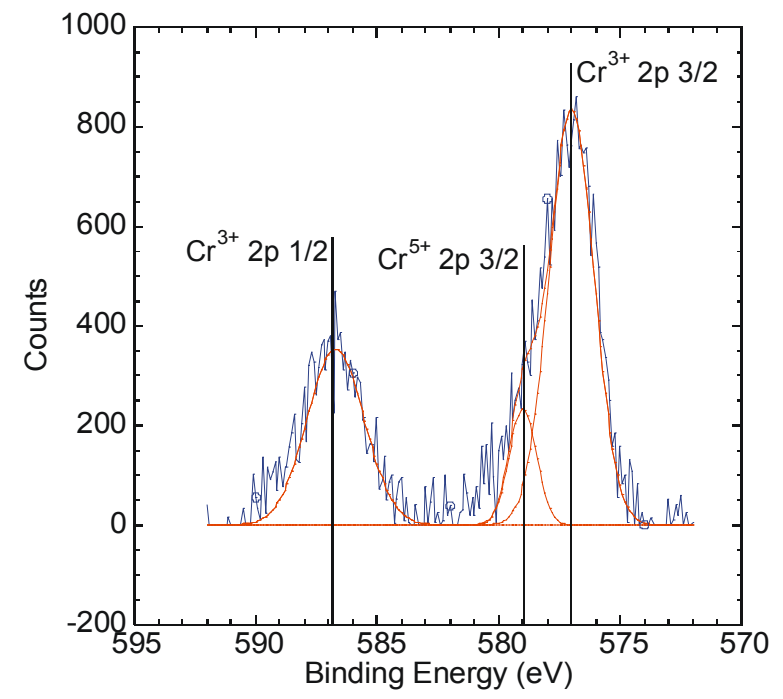

Figure 48b: XPS results for oxidized 304L in the chromium $2 p$ region. The chromium is present in the $\mathrm{Cr}^{3+}$ state. The chromium metal peak at 574.0 $\mathrm{eV}$ is not present 


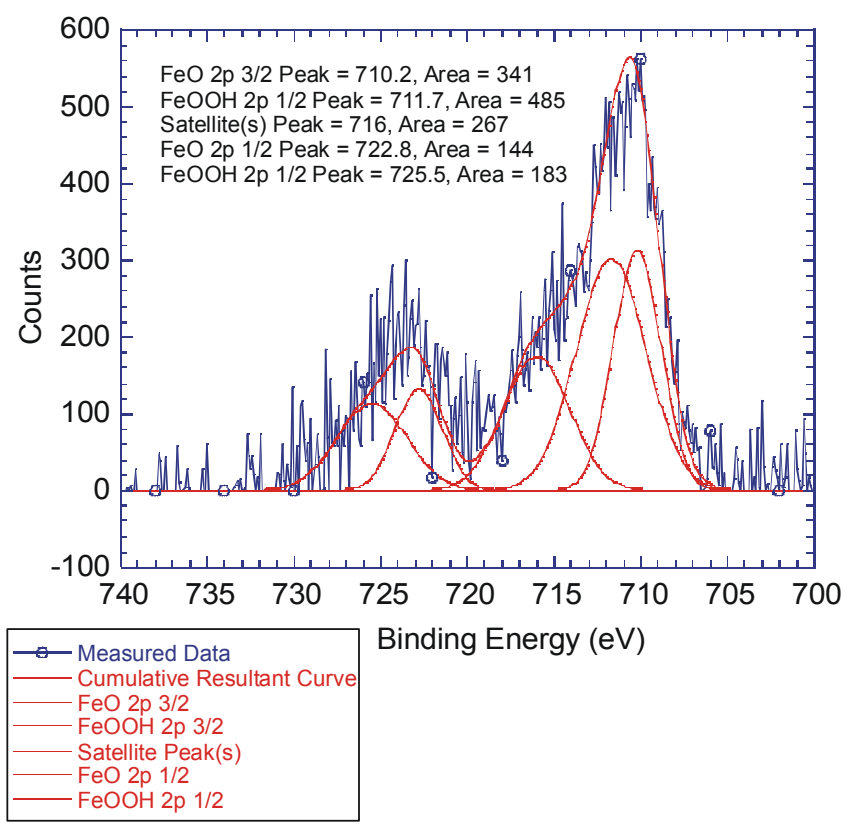

Figure 48c. XPS results for oxidized 316L in the iron $2 p$ region. The curve fit includes $\mathrm{Fe}^{2+}, \mathrm{Fe}^{3+}$, and the corresponding satellite peak. The iron metal peak at $706.8 \mathrm{eV}$ is not present.

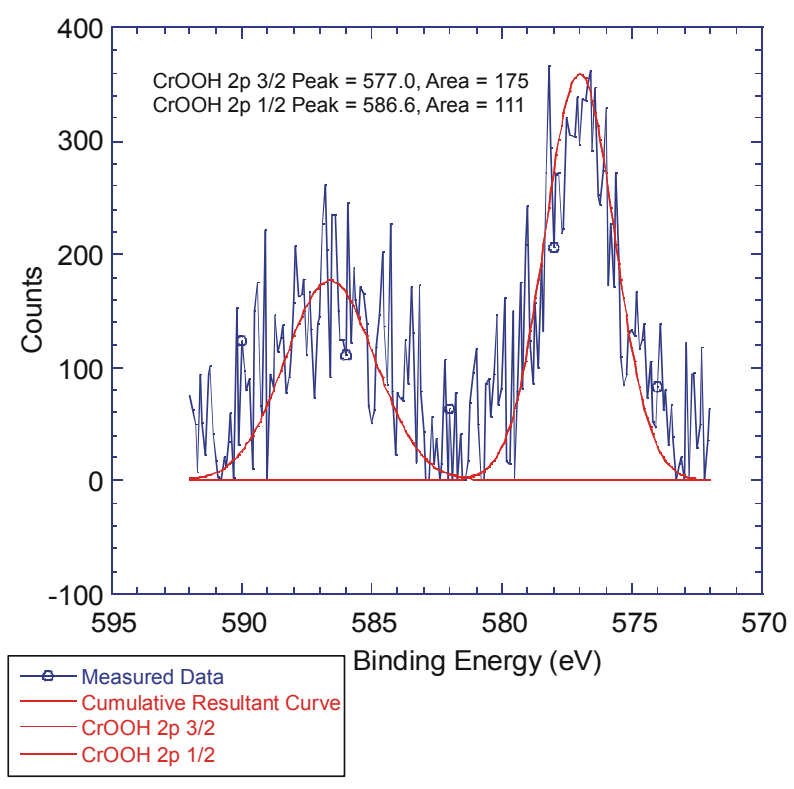

Figure 48d. XPS results for oxidized 316L in the chromium $2 p$ region. The chromium is present in the $\mathrm{Cr}^{3+}$ state. The chromium metal peak at 574.0 $\mathrm{eV}$ is not present.

Table XIX. Bonding state of the metallic constituents of the oxide film formed on the SC samples.

\begin{tabular}{|l|c|c|c|}
\hline & $\mathbf{F e}$ & $\mathbf{C r}$ & $\mathbf{N i}$ \\
\hline $304 \mathrm{~L}$ in non deaerated SCW & $\mathrm{Fe}^{2+}, \mathrm{Fe}^{3+}$ & $\mathrm{Cr}^{3+}, \mathrm{Cr}^{5+}$ & $\mathrm{Ni}^{2+}$ \\
\hline $316 \mathrm{~L}$ in deaerated SCW & $\mathrm{Fe}^{2+}, \mathrm{Fe}^{3+}$ & $\mathrm{Cr}^{3+}$ & $\mathrm{Ni}^{2+}$ \\
\hline
\end{tabular}

\subsubsection{Discussion of the Oxide Analyses Results}

It is interesting to compare the oxide composition and layer structure formed in pure supercritical water to that formed in vacuum, air, and subcritical water. At $600{ }^{\circ} \mathrm{C}$ in vacuum, Zielinksy et al. [2000] found that the oxide film is composed of 2 layers: an outer layer consisting mainly of iron oxide, $\mathrm{Fe}_{2} \mathrm{O}_{3}$ (identified by diffraction in TEM), and an inner layer consisting of chromium oxide. Nickel oxide is not present and there is a near surface zone that contains a reduced concentration of chrome and a high concentration of nickel. These observations are close to what we observed in $500{ }^{\circ} \mathrm{C} \mathrm{SCW}$. They also observed as many as 7 layers to the oxide after exposure of stainless steel in air with iron oxide dominating the outer layers and chromium oxide more prevalent in the inner layers. But they observed a much higher content of nickel and Mo in the outer layer.

Briggs et al. [1990] found that oxidation in air at most temperatures showed that a duplex oxide is formed: the outer-most layer consisting of alpha- $\mathrm{Fe}_{2} \mathrm{O}_{3}$, forming before the inner oxide, an iron chromium oxide. At reduced oxygen partial pressures, a thin chromium-rich oxide forms first through which grows an iron oxide over-layer. At very low oxygen pressure (below $10^{-3} \mathrm{~Pa}$ ) and temperatures above $350{ }^{\circ} \mathrm{C}$, chromium predominates throughout the oxide layer. 
Da Cunha Belo et al. [1998] studied the oxide film formed in primary water for $2000 \mathrm{hr}$. The outermost part of the film consisted of $\mathrm{Ni}_{073} \mathrm{Fe}_{2,25} \mathrm{O}_{4}$ inverse spinel. In the intermediate part, both $\mathrm{Ni}_{0}{ }_{73} \mathrm{Fe}_{2,25} \mathrm{O}_{4}$ and $\mathrm{Fe}_{3} \mathrm{O}_{4}$ inverse spinels were detected. Finally, the inner part of the film consisted of mixed chromium oxides $\left(\mathrm{Cr}_{2} \mathrm{O}_{3}+\mathrm{FeCr}_{2} \mathrm{O}_{4}\right)$ and $\mathrm{Fe}_{3} \mathrm{O}_{4}$. This analysis also shows the high concentration of nickel and iron in the outer layer and chrome in the inner one.

Montenor et al. [2000] studied the effect of $\mathrm{pH}$. They found that when the $\mathrm{pH}$ is just above 5, only chromium oxide is present. When the $\mathrm{pH}$ increases, the chromium concentration of the film decreases in favor of iron and nickel. The concentration profile of the oxide formed on their $316 \mathrm{~L}$ sample at $\mathrm{pH} 8$ for $720 \mathrm{~h}$ is similar to what we obtained for $316 \mathrm{~L}$ in $500{ }^{\circ} \mathrm{C}$ deaerated water except that the nickel content is higher. However, after $2200 \mathrm{hr}$ in the same environment, the outer layer is mainly chromium oxide [Gosser et al. 2002].

Finally, Haymard et al. [2003] exposed Alloy 316 to degassed, oxygenated water and water containing $3 \% \mathrm{H}_{2} \mathrm{O}_{2}$ at $40 \mathrm{MPa}$ and $420{ }^{\circ} \mathrm{C}$. They found that the introduction of $\mathrm{H}_{2} \mathrm{O}_{2}$ increased the oxidation rate by a factor of 10 over that in pure water. The difference between degassed water and oxygenated water is not significant.

\subsubsection{Results of Corrosion Exposure Tests}

The capability to perform exposure tests on unstressed samples simultaneously with the SCC test, and in the same autoclave, has been added to our facility. Alloy 625 samples were exposed for 500 hours in 500 ${ }^{\circ} \mathrm{C}$ deaerated and deionized water alongside the SCC test sample.

SEM analysis performed after the test showed that pitting occurred at numerous locations on the surface of the sample. Pit diameters as large as 5 microns were recorded, as shown in Figure 49. Pitting of Alloy 625 samples has also been observed after 171 hours exposure to nondeaerated, deionized water at a temperature of $400{ }^{\circ} \mathrm{C}$ and a pressure of $24 \mathrm{MPa}$, as reported in Section 4.2 of this report. The pit diameters were on the order of $2.5-8 \mu \mathrm{m}$.

\subsubsection{Irradiation of Austenitic Alloys}

The austenitic stainless steels 304L and

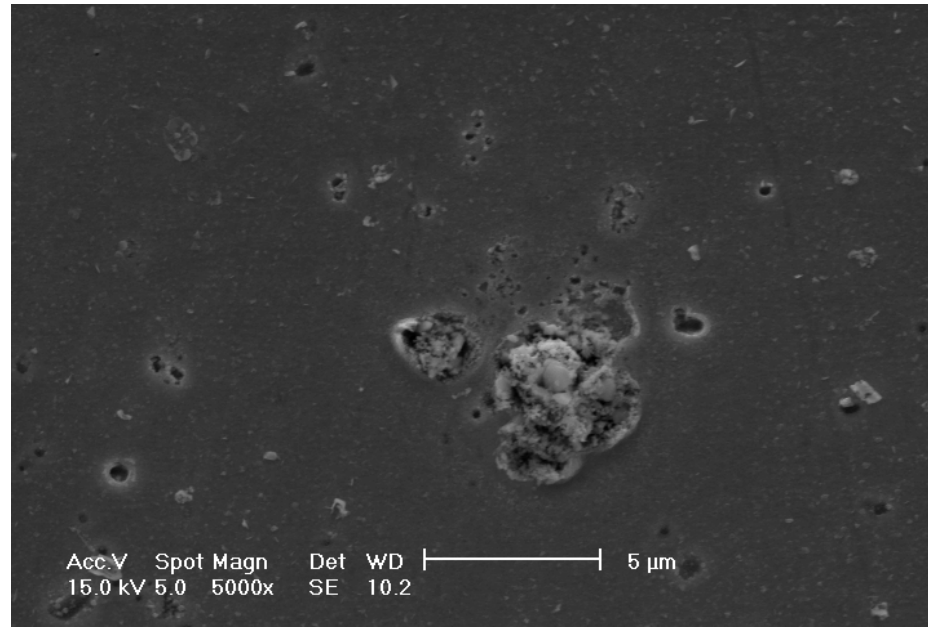

Figure 49. SEM micrographs of the exposed surfaces of an Alloy 625 sample after 450 hours at $500{ }^{\circ} \mathrm{C}$ in deaerated and deionized water.

316L, and the austenitic nickel-based alloys 625 and 690 constitute the first set of alloys to be proton irradiated for this study. One tensile sample and one TEM bar for each alloy will be irradiated. The tensile samples will be used in Year 3 for SCC experiments, and the TEM bars will be used to make TEM samples for the study of the radiation stability of these candidate alloys.

The irradiation will be performed at $500{ }^{\circ} \mathrm{C}$ to a dose of $10 \mathrm{dpa}$ using $3.2 \mathrm{MeV}$ protons. The dose was chosen such that the resulting microstructure will reach saturation. The radiation induced segregation, dislocation loop size and number density, and hardness increases with dose will be measured. 


\subsubsection{Conclusions}

Results from Year 2 show that:

- The stainless steel alloys 304L and 316L are susceptible to intergranular stress corrosion cracking in $500{ }^{\circ} \mathrm{C}$ deaerated water. The Alloy $304 \mathrm{~L}$ sample exhibited a higher crack density than did the $316 \mathrm{~L}$ sample. Alloy 304L SCC is more severe in non-deaerated water than in deaerated water.

- The oxide growth on the 304L and 316L samples tested in deaerated supercritical water were similar in composition. The oxide on the $316 \mathrm{~L}$ sample was slightly thinner than the oxide on the 304L sample. The oxide thickness on the 304L sample tested in non-deaerated water was significantly greater than the oxide thickness of the 304L sample tested in deaerated water.

- The nickel-based Alloy 625 is susceptible to SCC in deaerated supercritical water. Its yield stress and maximum stress is higher than those for the stainless steel alloys, but the intergranular cracking is more extensive.

- Unstressed Alloy 625 displays significant pitting when tested in $500{ }^{\circ} \mathrm{C}$ deaerated supercritical water.

- The PLC effect is present at $500{ }^{\circ} \mathrm{C}$ and a strain rate of $3 \times 10^{-7} \mathrm{~s}^{-1}$, and intergranular cracks appear on the Alloy 304L and 316L samples when the samples are pulled in flowing argon. It is possible that PLC is in part, responsible for the observed IG cracking.

\subsection{Progress on Task 2 at the Massachusetts Institute of Technology (MIT)}

\subsubsection{Introduction.}

During the first quarter, a meeting was held with representatives of INEEL to discuss which alloys should be assessed. At that time, the need to expand the test matrix was recognized. The proposed system upgrade was delayed due, in part, to the need for the system to be relocated and rebuilt. An expanded, and upgraded, system is currently being assembled (Third and fourth quarters of the year) in the Department of Nuclear Engineering with MIT funding. The upgrade will permit a large number of samples to be tested and will incorporate improved chemistry control. It is anticipated that the upgraded facility will include the following:

- Three autoclave sections: (i) a 1 liter autoclave in which coupon samples can be tested; (ii) a tubing section in which the transition from temperatures below to above the pseudo critical temperature can be assessed; (iii) and a smaller autoclave section where wire samples can be tested.

- The capability of operating in the temperature range $100-500{ }^{\circ} \mathrm{C}$.

- Complete chemistry control and data acquisition including oxygen, $\mathrm{pH}$, and conductivity.

It is expected that the upgraded system will be employed to enhance the current understanding of the association among temperature, corrosion, oxidation and dissolved oxygen level for the various alloys tested. In addition, data generated will be used in a kinetic model that it is considered will provide a basis for extrapolation to longer time periods. The autoclave test matrix will include two temperatures (300 and $500{ }^{\circ} \mathrm{C}$ ) and two oxygen concentrations (deaerated, $\sim 5 \mathrm{ppb} \mathrm{O}_{2}$, and oxygenated, $200 \mathrm{ppb}-7 \mathrm{ppm}$ ) for time periods of up to 200 hours. Oxygen, $\mathrm{pH}$, and conductivity will be monitored during an experiment. The samples from the various temperature regions will be mounted and metallogaphically prepared. The 
instrumented tube tests will be performed in deaerated water. Evaluation will include optical, electronoptical, and analytical techniques. The results of all the tests will be compared and contrasted in future reports.

\subsubsection{Test Materials and Experimental Apparatus.}

The same commercial purity stainless steel Alloy 316L and the nickel-based Alloy 625 materials were used for the coupon corrosion experiments at MIT as were used for the SCC experiments at the University of Michigan work discussed above. The composition of each of these alloys is shown in Table XIII above. The heat treatment, machining, and polishing of the samples is described in Section 4.1.1. Alloys for the corrosion tube experiments were obtained in tube form (approximately $3.2 \mathrm{~mm}$ outside diameter and $1.1 \mathrm{~mm}$ inside diameter) and used in the as-received condition. Prior to an experiment, the tube inside diameter was cleaned with acetone and subsequently rinsed with $15 \mathrm{M} \Omega$ deionized water.

Figure 50 presents a schematic representation of the supercritical corrosion system configuration at MIT, used for the Year 2 experiments, including a traditional Alloy 625 autoclave (right of figure) and an instrumented tube (left of figure) system. The temperature of the feed stream is increased to supercritical temperature by a preheater. Pressure is provided by a backpressure regulator and an HPLC pump. The temperature and pressure are controlled by a computer and lexan shields are provided for safety.

When the autoclave system is in use, standard mass loss or u-bend samples are mounted on a

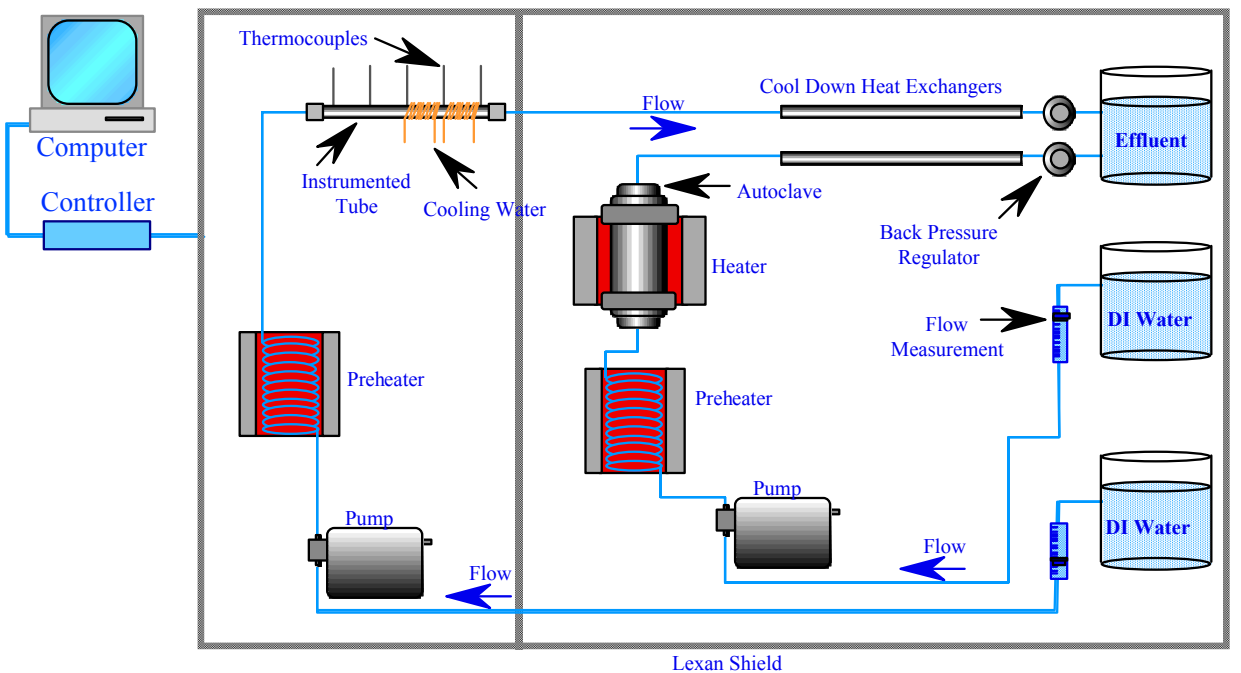

Figure 50. Schematic drawing of the flowing supercritical test system for studying corrosion at MIT. rack and inserted into the autoclave. Subsequent to an experiment samples are removed and assessed both metallographically and analytically. In the case of the instrumented tube experiments, a tube of the alloy to be tested is used as the autoclave, and micro-thermocouples are attached externally along the length of the vessel.

\subsubsection{Corrosion Results.}

After experiencing some challenges during the previous year in achieving the temperature drop needed to assess both the super- and subcritical temperature regimes, the apparatus was modified to incorporate water cooling with external copper tubes positioned between the final two thermocouples. Water at an elevated temperature and pressure is pumped into one end of the test sample tube and permitted to cool as it transverses the tube. In general, once steady state is achieved, temperature fluctuations are minor $(+/-$ $\left.2^{\circ} \mathrm{C}\right)$.

A 1/8 inch outside diameter type 316 stainless steel tube was exposed for approximately 192 hours to non-deaerated 15 mega ohm water at a pressure of 3500 psig. The highest temperature achieved was in 
excess of $395{ }^{\circ} \mathrm{C}$, which was lower than desired. Analyses of the tube cross-section revealed substantial oxide development at the highest temperature, with decreasing oxide development at lower temperatures as presented in Figure 51. The elemental analysis indicated the presence of an oxide layer and did not reveal the preferential elemental dissolution previously seen in SCW oxidation systems.
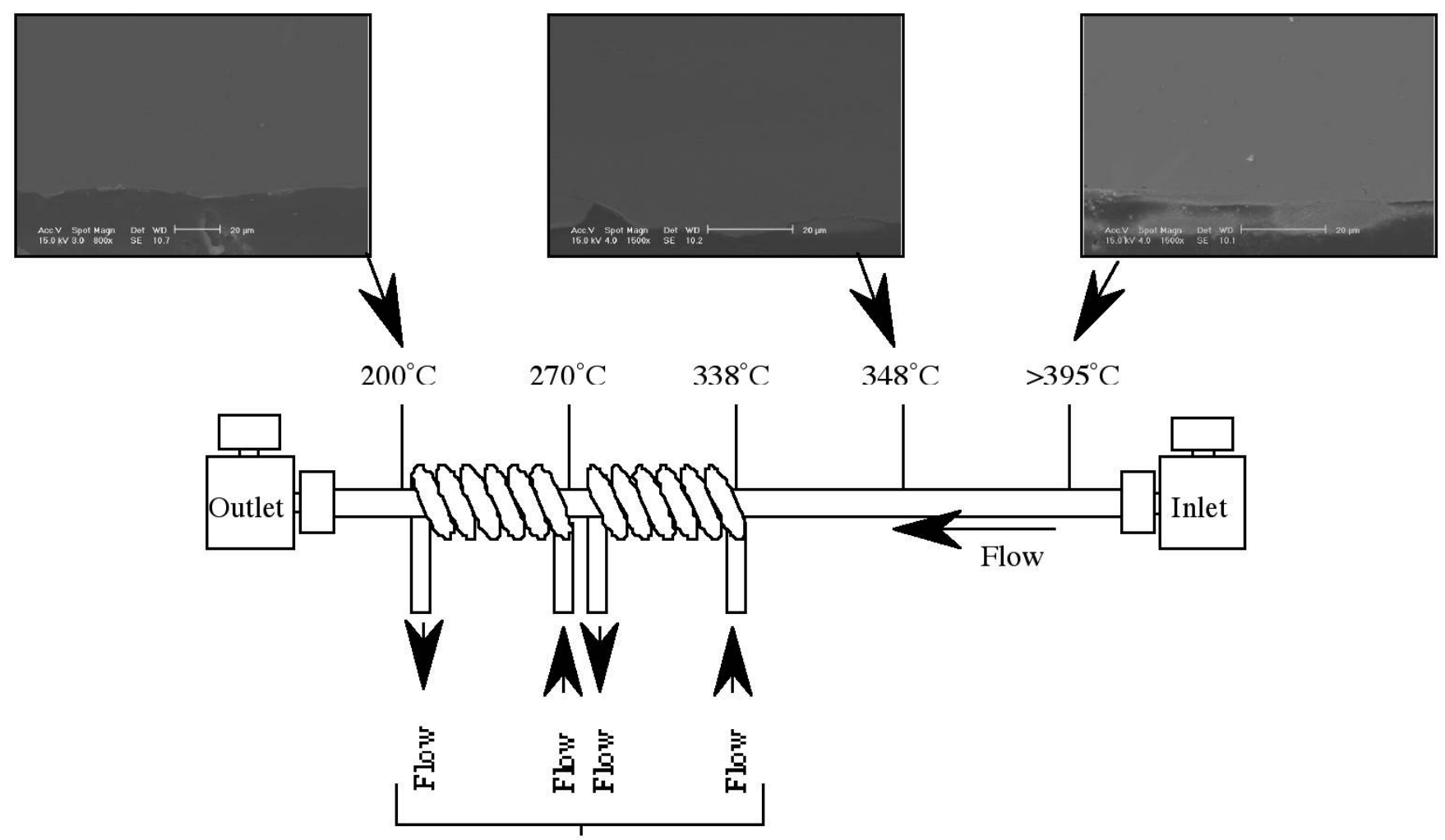

Cooling water lines

Figure 51. Experimental configuration, and micrographs of the 316L stainless steel tube crosssection at several temperatures after exposure to non-deaerated 15 mega ohm water for 192 hours.

Quantitative analysis of the exposed samples was performed by EPMA (Electron Probe Micro Analyzer). Both the metal matrix and oxide phase of the sample were analysed. As shown in Figure 52, the oxide was identified by SEM and EDS (energy dispersive spectrometer) elemental mapping.

The EPMA data was employed to generate elemental concentration data, which are tabulated in Table $\mathrm{XX}$. The multi-cation oxide phase is likely a combination of $\mathrm{Cr}_{2} \mathrm{O}_{3}, \mathrm{Fe}_{2} \mathrm{O}_{3}, \mathrm{NiO}, \mathrm{MoO}_{3}$, considering the thermodynamics of stable oxide species and elemental concentration data in at $\%$. Because of the relatively thin (less than $3 \mu \mathrm{m}$ at the highest temperature) and non-uniform oxide phase (due to surface roughness), the tube was filled with epoxy resin after the testing phase to protect the oxide layer.

Table XX. Elemental concentration of the oxide phase and alloy matrix.

\begin{tabular}{|l|l|l|l|l|l|l|l|l|l|l|l|l|}
\hline & \multicolumn{1}{l}{ Norm wt\% } & \multicolumn{1}{l|}{ Norm At\% } \\
\hline Element & $\mathrm{Cr}$ & $\mathrm{Mo}$ & $\mathrm{Fe}$ & $\mathrm{Ni}$ & $\mathrm{Mn}$ & $\mathrm{O}$ & $\mathrm{Cr}$ & $\mathrm{Mo}$ & $\mathrm{Fe}$ & $\mathrm{Ni}$ & $\mathrm{Mn}$ & $\mathrm{O}$ \\
\hline Matrix & 17.12 & 2.0811 & 67.47 & 11.58 & 1.7395 & 0 & 18.418 & 1.2131 & 67.564 & 11.034 & 1.7707 & 0 \\
\hline Oxide & 19.74 & 0.8211 & 40.07 & 7.88 & 0.6502 & 30.84 & 11.939 & 0.2692 & 22.57 & 4.22 & 0.3722 & 60.629 \\
\hline
\end{tabular}




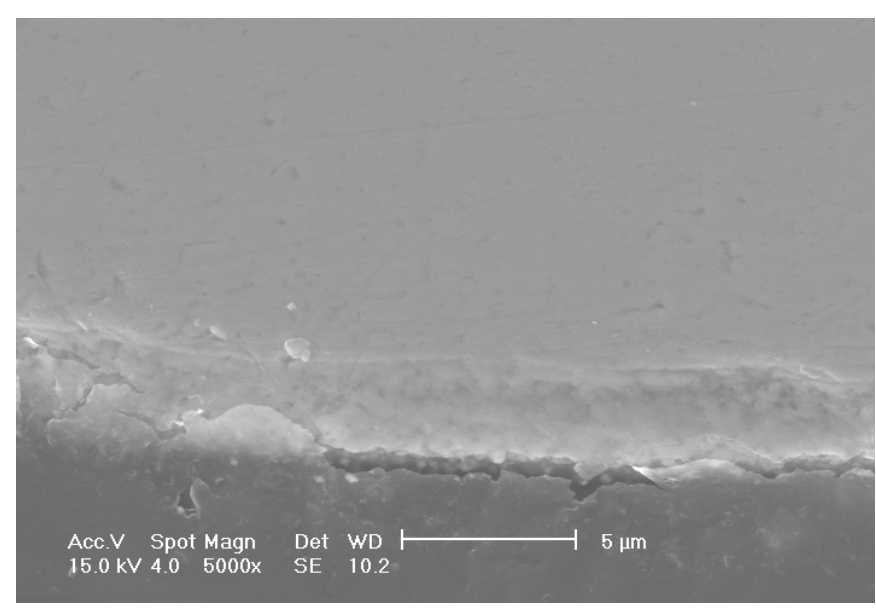

(a) SEM Image

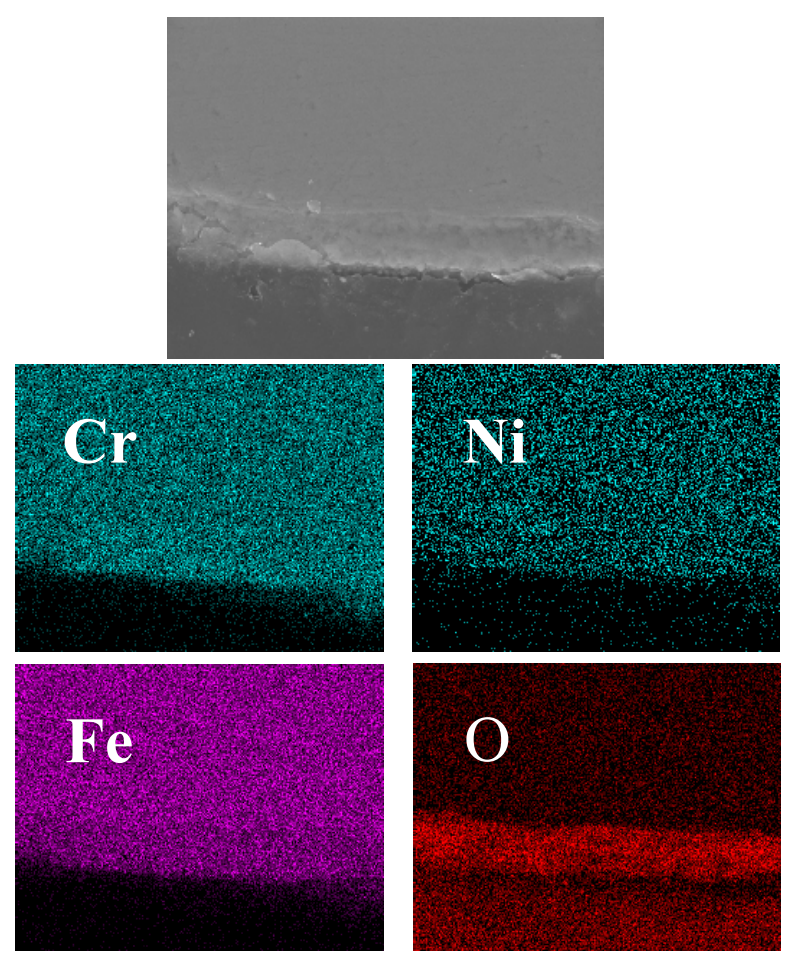

(b) EDS elemental mapping

Figure 52. Elemental analysis of the 316L stainless steel tube cross section exposed to nondeaerated 15 mega ohm water for approximately 192 hours at temperatures in the range of 200 $395^{\circ} \mathrm{C}$.

Oxide development was faster in the higher temperature range (above the pseudo critical temperature) than in the lower temperature zone (temperatures below the pseudo critical temperature). At the lower temperatures, below $360{ }^{\circ} \mathrm{C}$, oxide growth was difficult to detect as the thickness of the oxide was limited relative to the oxide thickness at higher temperatures. The E-pH diagram constructed for $\mathrm{Cr}, \mathrm{Ni}$ and $\mathrm{Fe}$ at $300{ }^{\circ} \mathrm{C}$, suggests that the oxides will be stable in the SCW environment in the neutral pH range [Mitton et al. 1996]. Oxide development has been relatively slow at the temperature of exposure. The fact that the tube reflects a decrease in the extent of oxidation as a function of decreasing temperature is in agreement with tests on mass loss coupons. After extended exposure (10-12 days) Type 316 stainless steel exhibits an average mass gain (standardized to area and exposure time) on the order of $0.0042 \mathrm{mg} / \mathrm{cm}^{2} /$ day at a temperature of $300{ }^{\circ} \mathrm{C}$. This value increases to $0.0125 \mathrm{mg} / \mathrm{cm}^{2} /$ day at $500{ }^{\circ} \mathrm{C}$.

A similar experiment with an Alloy 625 tube was then accomplished with a temperature profile covering the range from $300-420{ }^{\circ} \mathrm{C}$. This sample was exposed for approximately 210 hours to non-deaerated 15 mega ohm water at a pressure of 3500 psig. Micrographs of the Alloy 625 tube cross section at several temperatures after exposure are shown in Figure 53.

Analysis of the 625 tube revealed substantially less oxide development in the high temperature region than was seen for the stainless steel tube sample. This is in agreement with previous work carried out in this laboratory [Mitton et al. 1994]. As presented in Figure 54, surface analysis by EDX mapping indicated that there was an oxide present, and while the oxide has not yet been identified, the indication is that the chromium level is relatively high. Neither preferential dissolution nor crack development have been observed to date. 

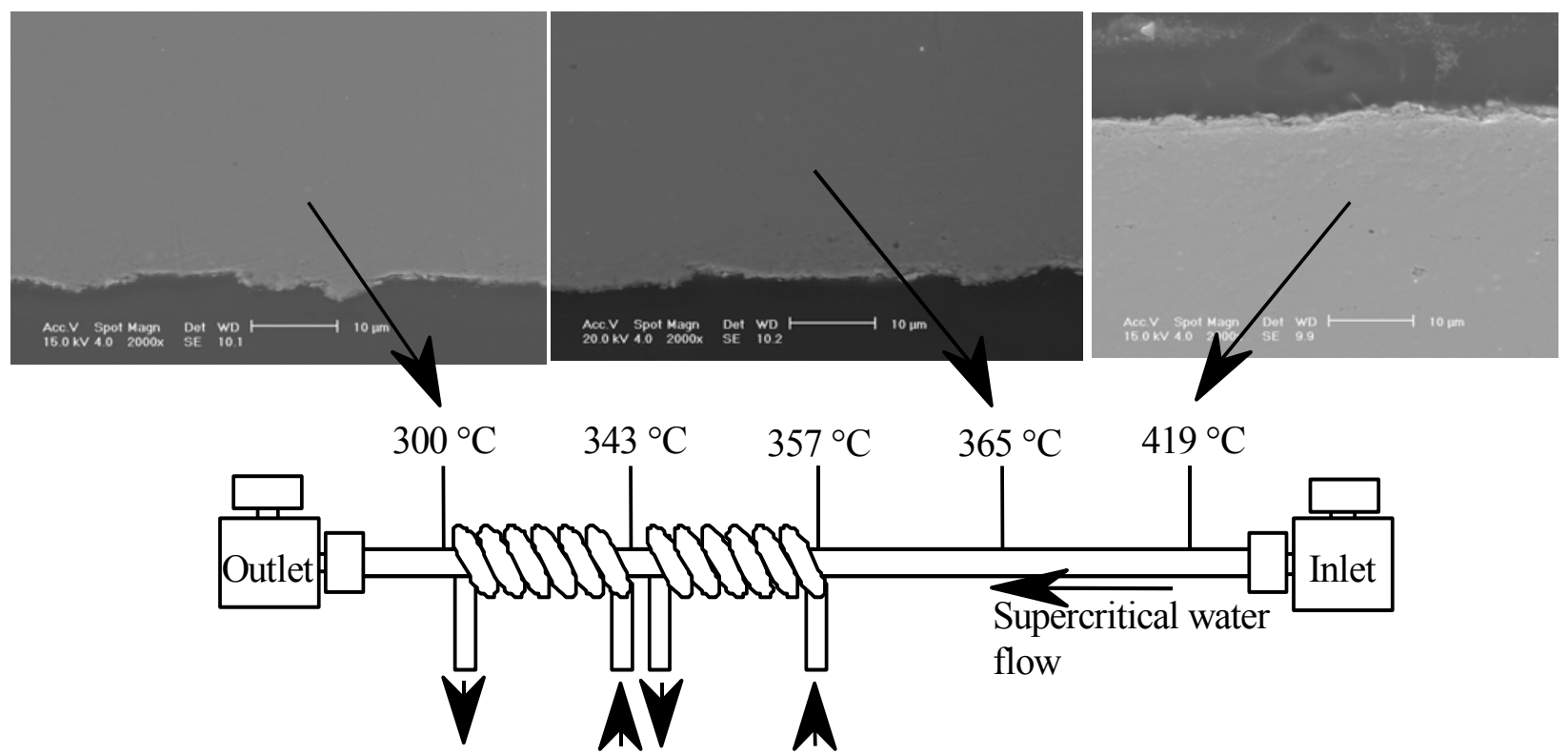

Cooling water lines

Figure 53. Experiment configuration, and micrographs of the Alloy 625 tube cross section at several temperatures after exposure to non-deaerated 15 mega ohm water for approximately 210 hours.
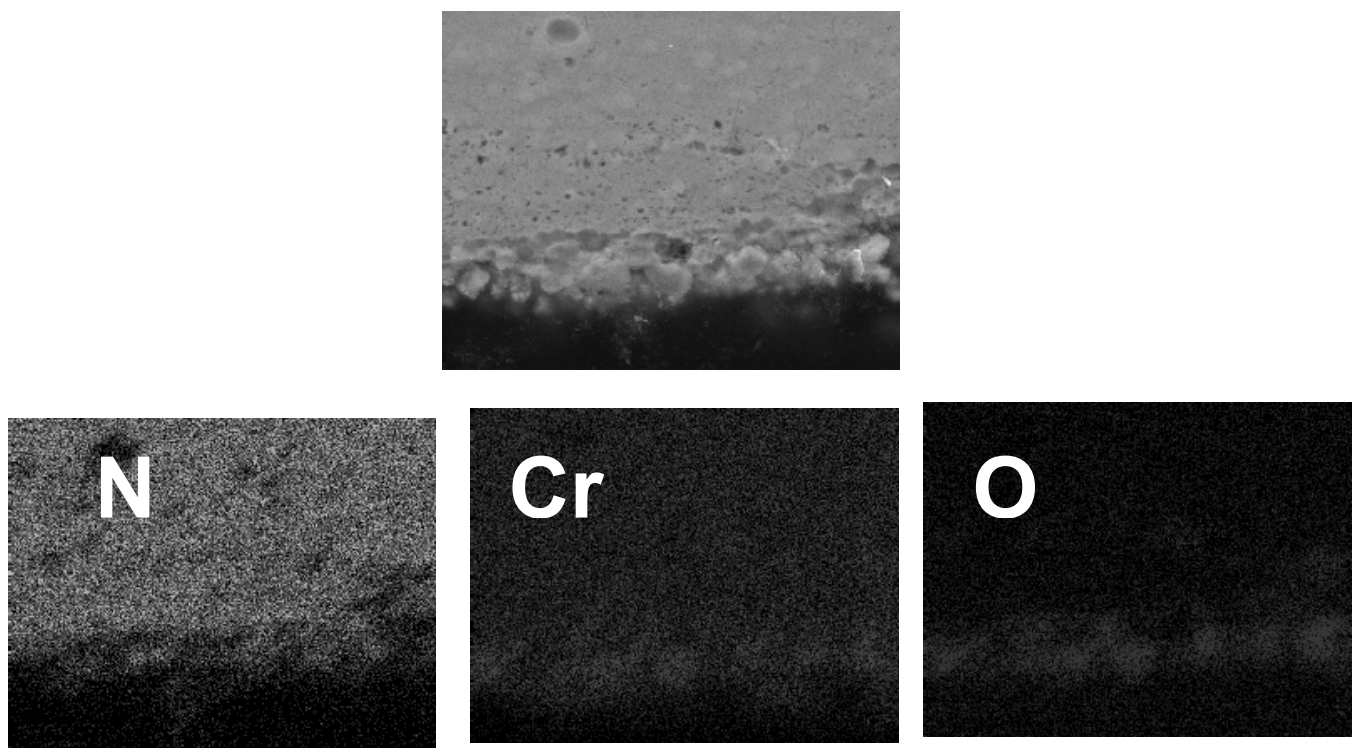

Figure 54. Elemental analysis of the Alloy 625 tube cross section exposed to non-deaerated 15 mega ohm water for approximately 210 hours at a temperature greater than $419{ }^{\circ} \mathrm{C}$.

Coupon tests in planar geometry are underway to provide more reliable and quantitative data. Using these coupon samples, we expect to characterize the structure of the oxide phase by XRD, and to determine the oxidation state of the elements by XPS. 


\section{Task 3 Results: Plant Engineering and Reactor Safety Analysis}

\subsection{VIPRE-W Modeling of the Supercritical Water Reactor (Vefa Kucukboyaci and Luca Oriani, Westinghouse Electric Co.)}

\subsubsection{Introduction}

Simplified analyses were performed to characterize the core thermal hydraulic behavior of a reactor using supercritical water as a coolant and moderator during the $1^{\text {st }}$ year of the program. The results of that work were summarized in the $1^{\text {st }}$ year Annual Report and, in more detail, in the quarterly report for the $3^{\text {rd }}$ quarter of the first year. The high enthalpy rise in the SCWR core was identified as a critical parameter and a major feasibility issue for this reactor design. Therefore we decided to improve the understanding of the SCWR core thermal-hydraulic performance by developing a more detailed analysis using a subchannel analysis code.

The VIPRE-W code, used by Westinghouse for detailed core thermal-hydraulic design analysis and licensing purposes, was adapted for use in the supercritical water reactor project. The code was already capable of handling supercritical water conditions, and so most of the required modifications were associated with the implementation of constitutive models (heat transfer correlations, friction loss correlations). Several routines in the VIPRE-W code were modified to accommodate axial friction factor and heat transfer correlations suitable for supercritical water reactor operating conditions.

Section 5.1.2 of this report includes a description of the VIPRE-W modifications that were implemented to analyze the SCWR. The modified code has been verified against standard Westinghouse benchmarking problems to ensure that acceptable responses were obtained in the subcritical region. The modified code was then used to develop SCWR specific models for the reference geometry described in Section 2 of this report. A description of the geometry and sub-channel analyses is provided in Section 5.1.3. Note that the fuel assembly design of the SCWR is still in progress. Therefore, several sensitivity studies were performed (and are still being performed) on the reference assembly to better characterize the system and identify the optimal design. Section 5.1.3 also provides an overview of the analyses developed so far.

\subsubsection{Technical Description of the Software Changes}

The following section provides a brief overview of the modifications that were applied to the VIPRE-W code to perform SCWR analyses.

\subsubsection{Friction Factor and Heat Transfer Correlations}

The axial friction pressure drop is calculated for turbulent flow at supercritical pressures using the Petrov and Popov [1988] correlation. Three heat transfer correlations are considered and implemented in this version of the code: Bishop et al. [1964], Oka-Koshizuka [2000], and Jackson[1979, 2002]. All these correlations are described in Appendix A. 


\subsubsection{Other VIPRE Code Modifications}

The VIPRE code uses a set of steam tables based on the original model developed by EPRI for its thermal-hydraulics codes (VIPRE, RETRAN, etc.). While these tables support the analyses of some supercritical water conditions, they are limited to relatively low temperature, and do not compute some of the required properties for the SCWR correlations in the supercritical region. The best approach to solve this issue would be the implementation of different water properties, possibly based on INEEL experience with modifications of the RELAP code, to handle supercritical water conditions. However, because of the code structure, this effort was incompatible with the funding level of this program. Testing and validation of the new property tables would have significantly limited the amount of analyses that could be performed on the SCWR core. An alternative solution was developed which allowed use of the default VIPRE properties, with some minor change in those areas that did not provide the required capability. While this approach is clearly not the optimal one, it allowed proceeding more effectively toward the relevant objective of this work: the analysis of the SCWR core.

During the third year, an effort will be made to re-evaluate the option of implementing a more appropriate set of water properties with a reduced effort, but the limited funding level available will limit the potential of success of this activity.

\subsubsection{Supercritical Water Reactor Sub-Channel Analysis}

\subsubsection{VIPRE-W Model}

A quarter-core is considered with an explicit channel/gap and fuel rod representation in the central fuel assembly in the VIPRE-W model. The channels and rods are lumped in all the other assemblies, hence each fuel assembly is represented by a single channel and fuel rod. The water channels are not modeled (assumed adiabatic boundaries), since it is assumed that their presence will not have a significant impact on the channel thermal-hydraulics (they are isolated from the channels). While this assumption is not necessarily correct, modeling of the water channels will complicate the model within the limitations of the VIPRE-W code.

On the basis of preliminary SCWR analyses, it was decided to develop and use two separate core models to support the complete model discussed here. One model is to be used for core-wide analyses, for example, to evaluate the flow splits between the assemblies, the size of the inlet orificing for optimal flow distribution, and parallel channel stability. This model will be identical to the model described in the following paragraphs, except for the central assembly, which will also be lumped into a single channel. Table XXI shows the summary of the current SCWR reference design. All sub-channel data in this model are based on the information provided in this table. The subchannel analysis was initiated before the latest changes to the design were implemented, hence the inconsistencies in reactor power, flow and thermal efficiency between this table and Table I. However, we believe that the qualitative conclusions drawn in this section apply also to the latest design described in Section 2.

Figure 55 shows the quarter-core VIPRE-W model of the SCWR. A total of 169 channels, of which 133 are in the central assembly, are present in this model. The channels are divided into 129 axial nodes with $\sim 1.5$ inch axial length and 204 gaps connect the channels in the central assembly. Each fuel assembly has a $25 \times 25$ rod arrangement with 36 water channels occupying 324 rod positions. There are 300 fuel rods and a single instrumentation rod per assembly. Note that since the SCWR design employs canned fuel assemblies, there are no cross-flows and hence no gaps between assemblies. In VIPRE-W modeling, a sub-channel is defined by the flow area, wetted perimeter, and heated perimeter; gaps are defined by the channel indices that they connect, gap widths, and centre-to-centre distance between the channels. 
Table XXI. Summary table for the SCWR reference design.

\begin{tabular}{|c|c|}
\hline Parameter & Value \\
\hline Thermal power & $3022 \mathrm{MW}$ \\
\hline Electric power & $1315 \mathrm{MW}$ \\
\hline Thermal efficiency & $43.5 \%$ \\
\hline Operating pressure & $25 \mathrm{MPa}$ \\
\hline Reactor inlet/outlet temperature & $280 / 500^{\circ} \mathrm{C}$ \\
\hline Reactor flow rate & $1561 \mathrm{~kg} / \mathrm{s}$ \\
\hline \multicolumn{2}{|l|}{ FUEL PIN } \\
\hline Fuel pin outside diameter & $10.2 \mathrm{~mm}$ \\
\hline Fuel pin pitch & $11.2 \mathrm{~mm}$ \\
\hline Cladding thickness & $0.63 \mathrm{~mm}$ \\
\hline Cladding materials & ODS steel \\
\hline Fuel pellet outside diameter & $8.94 \mathrm{~mm}$ \\
\hline Fuel composition & $\mathrm{UO}_{2}, 95 \% \mathrm{TD}$ \\
\hline Fuel enrichment & $5 \%$ wt. average \\
\hline Average burnup at discharge & $45,000 \mathrm{MWD} / \mathrm{t}$ \\
\hline Burnable poisons & $\mathrm{Gd}_{2} \mathrm{O}_{3}$ \\
\hline Heated length & $4.27 \mathrm{~m}$ \\
\hline Fission gas plenum length & $0.39 \mathrm{~m}$ \\
\hline Total fuel pin height & $4.66 \mathrm{~m}$ \\
\hline Fill gas pressure at room temperature & $3.0 \mathrm{MPa}$ \\
\hline \multicolumn{2}{|l|}{ FUEL ASSEMBLY } \\
\hline Fuel pin lattice & Square \\
\hline Number of fuel pins per assembly & 301 \\
\hline Number of water rods per assembly & 36 \\
\hline Water rod side & $32.6 \mathrm{~mm}$ \\
\hline Water rod wall thickness & $0.4 \mathrm{~mm}$ \\
\hline Water rod wall materials & TBD \\
\hline Number of instrumentation rods per assembly & 1 \\
\hline Number of CR fingers per assembly & 36 \\
\hline CR material & $\mathrm{B}_{4} \mathrm{C}$ for scram, $\mathrm{Ag}-\mathrm{In}-\mathrm{Cd}$ for control \\
\hline Number of spacer grids & 14 \\
\hline Assembly wall thickness & $3 \mathrm{~mm}$ \\
\hline Assembly wall material & ODS steel \\
\hline Assembly side & $292.2 \mathrm{~mm}$ \\
\hline Inter-assembly gap & $4 \mathrm{~mm}$ \\
\hline Assembly pitch & $296.2 \mathrm{~mm}$ \\
\hline \multicolumn{2}{|l|}{ CORE } \\
\hline Number of fuel assemblies & 121 \\
\hline Equivalent diameter & $3.68 \mathrm{~m}$ \\
\hline Core barrel ID/outside diameter & $4.1 / 4.2 \mathrm{~m}$ \\
\hline Axial/Radial/Local/Total Peaking Factor & $\begin{array}{l}\text { 1.4/1.3/1.1/2.0 (best estimate) } \\
1.4 / 1.4 / 1.2 / 2.35 \text { (for safety analysis) }\end{array}$ \\
\hline Average power density & $66.7 \mathrm{~kW} / \mathrm{L}$ \\
\hline Average linear power & $19.5 \mathrm{~kW} / \mathrm{m}$ \\
\hline Peak linear power at steady-state conditions & $39 \mathrm{~kW} / \mathrm{m}$ \\
\hline Core pressure drop & $0.15 \mathrm{MPa}$ \\
\hline Water rod flow & $468 \mathrm{~kg} / \mathrm{s}$ \\
\hline \multicolumn{2}{|l|}{ REACTOR PRESSURE VESSEL } \\
\hline ID/outside diameter/Height & $4.6 / 5.34 / 12.40 \mathrm{~m}$ \\
\hline Material & Carbon steel clad with stainless steel \\
\hline Cold/hot nozzles & $2 / 2$ \\
\hline Operating temperature & $280^{\circ} \mathrm{C}$ \\
\hline Design pressure & $27.5 \mathrm{MPa}$ \\
\hline
\end{tabular}




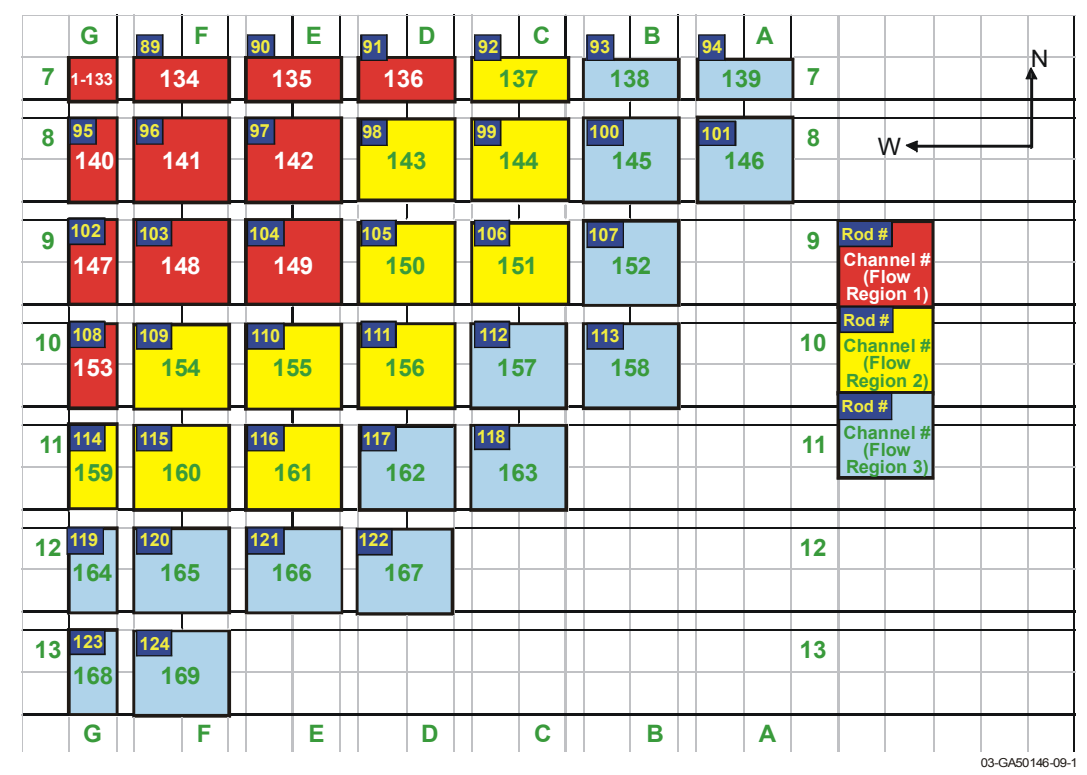

Figure 55. VIPRE-W Core model for the SCWR.

Tables XXII, XXIII and XXIV show how the flow areas and wetted and heated perimeters are calculated for the different types of channels. Figure 56 shows the detailed channel, gap and fuel rod configurations in the central assembly.
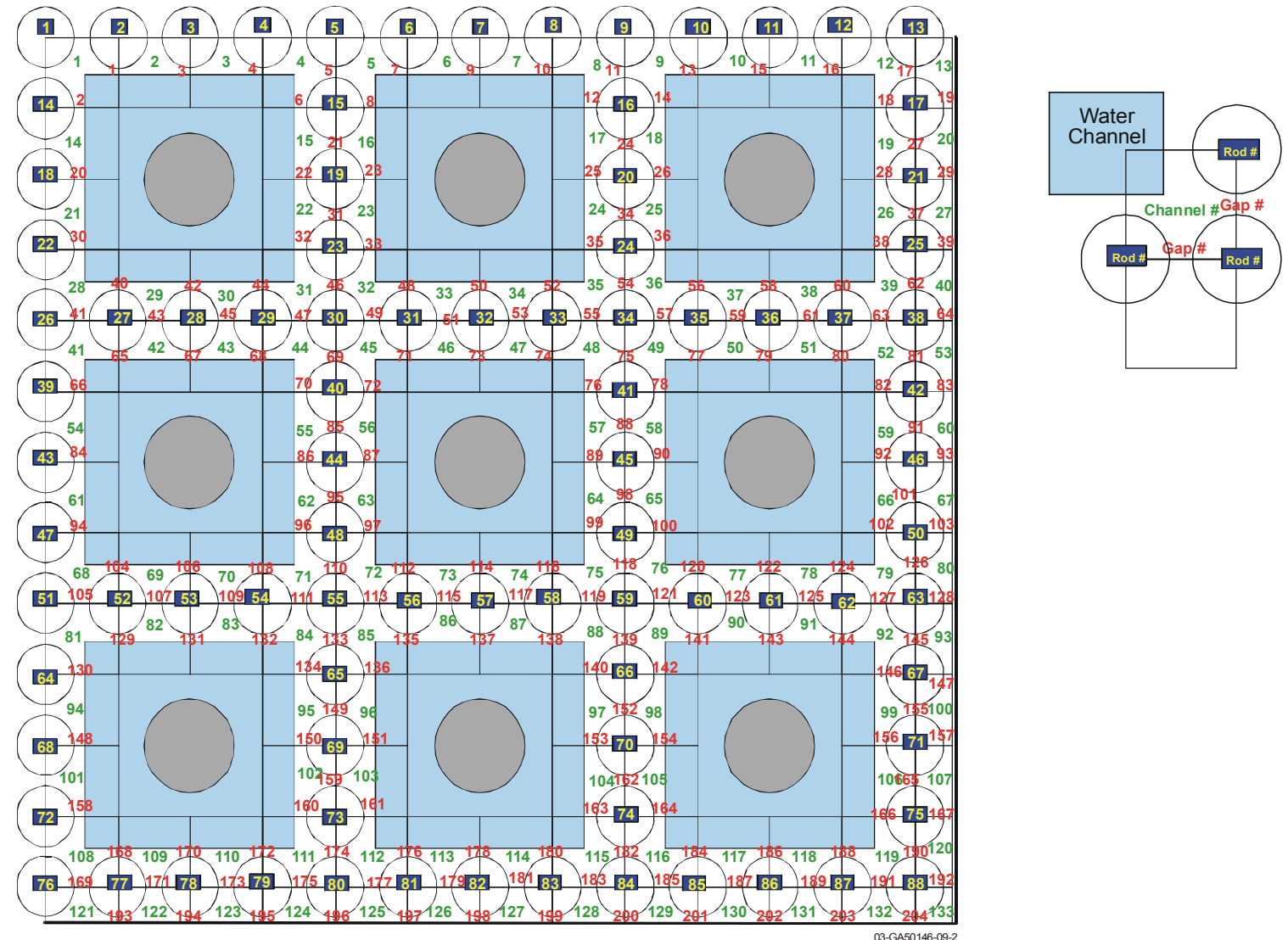

Figure 56. Channels, gaps, and rods in the central fuel assembly. 
Table XXII. Calculation of the flow areas used in the SCWR model.

\begin{tabular}{|c|l|c|}
\hline $\begin{array}{c}\text { Flow Area } \\
\text { Type }\end{array}$ & \multicolumn{1}{|c|}{ Flow Area Equation } & Flow Area $\left(\mathbf{i n}^{2}\right)$ \\
\hline $\mathbf{1}$ & $\frac{3}{4} P_{\text {rod }}^{2}-\frac{3}{4} * \pi * \frac{D_{r o d}^{2}}{4}$ & 0.0508329 \\
\hline $\mathbf{2}$ & $\frac{1}{2} P_{\text {rod }}^{2}-\frac{1}{2} * \pi * \frac{D_{\text {rod }}^{2}}{4}$ & 0.0338886 \\
\hline $\mathbf{3}$ & $\frac{1}{4} P_{r o d}^{2}-\frac{1}{4} * \pi * \frac{D_{r o d}^{2}}{4}$ & 0.0169443 \\
\hline $\mathbf{4}$ & $\frac{1}{2}\left(P_{a s s y}^{2}-301 * \pi * \frac{D^{2}}{4}-36 *\left(9 * P_{r o d}^{2}\right)\right)$ & 10.2004771 \\
\hline $\mathbf{5}$ & $P_{a s s y}^{2}-301 * \pi * \frac{D^{2}}{4}-36 *\left(9 * P_{r o d}^{2}\right)$ & 20.4009541 \\
\hline
\end{tabular}

$\mathrm{P}_{\text {assy }}=$ fuel assembly pitch, $\mathrm{P}_{\text {rod }}=$ fuel pin pitch, $\mathrm{D}_{\text {rod }}=$ fuel pin diameter,

$\mathrm{D}=$ fuel assembly diameter

Table XXIII. Calculation of the wetted perimeters used in the SCWR model.

\begin{tabular}{|c|l|c|}
\hline $\begin{array}{c}\text { Wetted Perimeter } \\
\text { Type }\end{array}$ & \multicolumn{1}{|c|}{ Wetted Perimeter Equation } & Wetted Perimeter (in) \\
\hline $\mathbf{1}$ & $\frac{3}{4} * \pi * D_{r o d}+P_{r o d}$ & 1.3871332 \\
\hline $\mathbf{2}$ & $\frac{1}{2} * \pi * D_{r o d}+P_{r o d}$ & 1.0717371 \\
\hline $\mathbf{3}$ & $\frac{1}{4} \pi * D_{r o d}$ & 0.3153961 \\
\hline $\mathbf{4}$ & $\frac{1}{2}\left(4 * P_{a s s y}+301 * \pi * D+36 * 4 *\left(3 * P_{r o d}\right)\right)$ & 307.1597982 \\
\hline $\mathbf{5}$ & $4 * P_{a s s y}+301 * \pi * D+36 * 4 *\left(3 * P_{r o d}\right)$ & 614.3195964 \\
\hline
\end{tabular}

Table XXIV. Calculation of the heated perimeters used in the SCWR model.

\begin{tabular}{|c|l|l|}
\hline $\begin{array}{c}\text { Heated Perimeter } \\
\text { Type }\end{array}$ & $\begin{array}{c}\text { Heated Perimeter } \\
\text { Equation }\end{array}$ & $\begin{array}{c}\text { Heated Perimeter } \\
\text { (in) }\end{array}$ \\
\hline $\mathbf{1}$ & $\frac{3}{4} * \pi * D_{\text {rod }}$ & 0.946188338 \\
\hline $\mathbf{2}$ & $\frac{1}{2} * \pi * D_{\text {rod }}$ & 0.630792225 \\
\hline $\mathbf{3}$ & $\frac{1}{4} * \pi * D_{\text {rod }}$ & 0.315396113 \\
\hline $\mathbf{4}$ & $\frac{1}{2}(300 * \pi * D)$ & 189.2377000 \\
\hline $\mathbf{5}$ & $300 * \pi * D$ & 378.4753000 \\
\hline
\end{tabular}


Three different radial power distributions are considered for the central assembly, based on the results of the neutronic analyses at INEEL. One radial power distribution assumes a single enrichment, one assumes the five different enrichments in the assembly depicted in Figure 57, and one is a uniform power distribution. The uniform power distribution assumes that the enrichments are adjusted for each individual fuel rod. The three radial power distributions in the central assembly are listed in Table $\mathrm{XXV}$. Note that for this analysis, zero power is assumed for the channels outside the central assembly.

A symmetric chopped cosine axial power profile with a peaking factor of 1.55 is used for all rods in the assembly. The total heated length is 168.11 inches and the axial power profile starts at $\sim 10$ inches relative to the channel inlet, considering the inlet nozzle and other non-power structures in the assembly. The total inlet flow is specified as 859.5815 $\mathrm{lbm} / \mathrm{s}$ and uniformly split among the channels as equal mass flux per channel.

Equation A14 in Appendix A of this report is

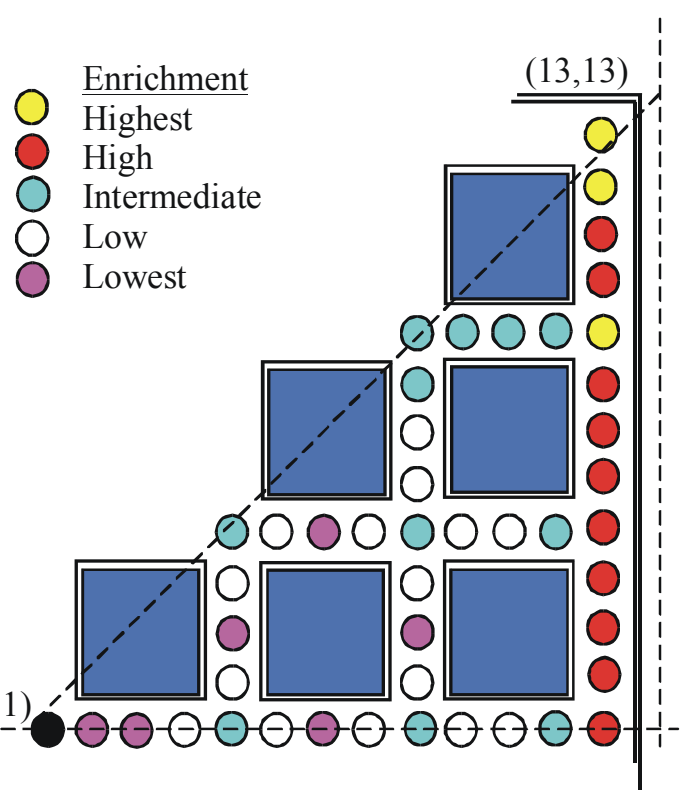

Figure 57. Enrichment configuration used to calculate the local power distribution.

used in the VIPRE-W code as the axial friction factor correlation. Typical PWR axial friction coefficients are used at the inlet, outlet and mid-grids $(2.37,0.97$, and 0.725 , respectively). As for the lateral resistance, the Idel'chik correlation for cross-flow over banks of tubes is used, in which the lateral drag coefficient is calculated as:

Lateral drag coeff $=1.52 *\left\{\left(\frac{\text { Pitch }}{\text { Diameter }}\right)-1.0\right\}^{-0.5}$

\subsubsection{Thermal-Hydraulic Profiles in the Hot and Cold Channels for Different Radial Power Distributions:}

Using the model described above, VIPRE-W simulations were performed to obtain thermalhydraulic profiles of interest, including pressure drops, flow velocities, densities, temperatures, and enthalpy rise. The results are presented for both the hot and cold channels, where the hot channel is defined as the channel where the maximum temperature occurs and the cold channel is the channel with the lowest exit temperature in the bundle.

The analyses presented in the following two sections were developed with three main objectives:

1. As discussed above, VIPRE-W code modifications were minimized. These analyses, therefore, were reviewed critically to identify those areas where additional code development efforts are required and where a more comprehensive code verification effort is needed. A list of top priorities is being compiled and based on the funding available, the most critical issues will be addressed during the third year of this NERI project. Some other less important or more time consuming issues will only be identified and left for eventual follow-up programs. 
Table XXV. Radial power distributions used in the VIPRE-W calculations

\begin{tabular}{|c|c|c|c|}
\hline \multirow[b]{2}{*}{ Pin Number } & \multicolumn{3}{|c|}{ Normalized Power } \\
\hline & $\begin{array}{c}\text { Uniform } \\
\text { enrichment }\end{array}$ & $\begin{array}{l}5 \text { enrichments } \\
\text { (not optimized) }\end{array}$ & $\begin{array}{l}\text { Ideal enrichment } \\
\text { distribution }\end{array}$ \\
\hline$(1,1)$ & 0 (inst.pin) & 0 (inst. pin) & 0 (inst.pin) \\
\hline$(1,2)$ & 1.2129 & 1.0362 & 1.000 \\
\hline$(1,3)$ & $\mathbf{1 . 2 7 1 0}$ (hot pin) & 1.0959 & 1.000 \\
\hline$(1,4)$ & 1.1643 & 1.1470 & 1.000 \\
\hline$(1,5)$ & 1.0542 & 1.1486 (hot pin) & 1.000 \\
\hline$(1,6)$ & 1.1388 & 1.0857 & 1.000 \\
\hline$(1,7)$ & 1.2191 & 1.0482 & 1.000 \\
\hline$(1,8)$ & 1.1294 & 1.0794 & 1.000 \\
\hline$(1,9)$ & 1.0132 & 1.0345 & 1.000 \\
\hline$(1,10)$ & 1.0798 & 0.9907 & 1.000 \\
\hline$(1,11)$ & 1.1201 & 1.0033 & 1.000 \\
\hline$(1,12)$ & 0.9808 & 0.9571 & 1.000 \\
\hline$(1,13)$ & 0.7741 & 0.8864 & 1.000 \\
\hline$(2,5)$ & 1.1588 & 1.0976 & 1.000 \\
\hline$(2,9)$ & 1.1062 & 1.0314 & 1.000 \\
\hline$(2,13)$ & 0.8164 & 0.9593 & 1.000 \\
\hline$(3,5)$ & 1.2316 & 1.0725 & 1.000 \\
\hline$(3,9)$ & 1.1863 & 0.9823 & 1.000 \\
\hline$(3,13)$ & 0.8599 & 1.0111 & 1.000 \\
\hline$(4,5)$ & 1.1523 & 1.0716 & 1.000 \\
\hline$(4,9)$ & 1.1014 & 1.0354 & 1.000 \\
\hline$(4,13)$ & 0.8214 & 0.9680 & 1.000 \\
\hline$(5,5)$ & 1.0396 & 1.0514 & 1.000 \\
\hline$(5,6)$ & 1.1345 & 1.0632 & 1.000 \\
\hline$(5,7)$ & 1.2119 & 1.0386 & 1.000 \\
\hline$(5,8)$ & 1.1243 & 1.0657 & 1.000 \\
\hline$(5,9)$ & 0.9963 & 1.0622 & 1.000 \\
\hline$(5,10)$ & 1.0659 & 0.9815 & 1.000 \\
\hline$(5,11)$ & 1.1031 & 1.0076 & 1.000 \\
\hline$(5,12)$ & 0.9703 & 0.9502 & 1.000 \\
\hline$(5,13)$ & 0.7713 & 0.8859 & 1.000 \\
\hline$(6,9)$ & 1.0969 & 1.0292 & 1.000 \\
\hline$(6,13)$ & 0.8111 & 0.9322 & 1.000 \\
\hline$(7,9)$ & 1.1651 & 1.0849 & 1.000 \\
\hline$(7,13)$ & 0.8437 & 0.9977 & 1.000 \\
\hline$(8,9)$ & 1.0812 & 1.0766 & 1.000 \\
\hline$(8,13)$ & 0.7960 & 0.9298 & 1.000 \\
\hline$(9,9)$ & 0.9601 & 0.9528 & 1.000 \\
\hline$(9,10)$ & 1.0290 & 1.0118 & 1.000 \\
\hline$(9,11)$ & 1.0579 & 1.0462 & 1.000 \\
\hline$(9,12)$ & 0.9359 & 0.8842 & 1.000 \\
\hline$(9,13)$ & 0.7412 & 0.9318 & 1.000 \\
\hline$(10,13)$ & 0.7658 & 0.8654 & 1.000 \\
\hline$(11,13)$ & 0.7773 & 0.8953 & 1.000 \\
\hline$(12,13)$ & 0.7027 & 0.8934 & 1.000 \\
\hline$(13,13)$ & 0.6112 & 0.7574 & 1.000 \\
\hline
\end{tabular}


2. It was found that VIPRE-W had several problems in reaching a convergent solution, especially in some specific analyses. In particular, to size the orificing, a VIPRE option should be used to distribute the coolant flow between the assemblies so as to create uniform pressure distributions above the top plate and before the bottom plate. This option is typically used for BWR analyses. With the model described in the previous section it was not possible to get a converged solution because of code convergence issues with the specific problem conditions (passage from a low velocity high density fluid to a high velocity low density fluid at the exit). These issues were related to several different areas including the code development (better water property tables should be used) and the model used (increasing pressure losses at the channel inlet favor stability), but also the complexity of the model was a factor. To address this issue, it was decided that for future analyses a two-pass model will be used to replace the once-pass approach described above. With a two-pass approach, a whole core analysis is developed first to compute the coolant flow to each assembly and the overall core conditions. This is also the part that can be coupled to the neutronic analysis. The model is similar to the core model presented above, except that the hot assembly is lumped to a single channel with no cross flow. Eliminating cross flow from the problem should simplify the code convergence issues. In a second step, the results from the core-wide analysis would be fed (as inlet conditions of flow, temperature and power) to the hot assembly model to perform a detailed subchannel analysis of the hot assembly. Beside this fundamental change in approach, several other modifications were assessed as part of the sensitivity studies discussed in this report and are still in progress.

3. The final and most important purpose of these analyses was to improve our understanding of the SCWR core thermal-hydraulic performance. The overall goal of this evaluation is to complete our feasibility evaluations by the end of this program, and identify design options that would contribute to the feasibility of the design. The discussion of these results is provided in the following sections.

\subsection{Nominal Power and Flow Conditions:}

A first analysis was performed to evaluate the thermalhydraulic characteristics of the SCWR core at nominal reactor conditions. The SCWR core model was analyzed assuming boundary conditions directly derived from the reference configuration presented in Table XXI.

Figure 58 shows the pressure drops versus length in the hot and cold channels of the hot assembly with single enrichment (the pressure drops are identical). For both

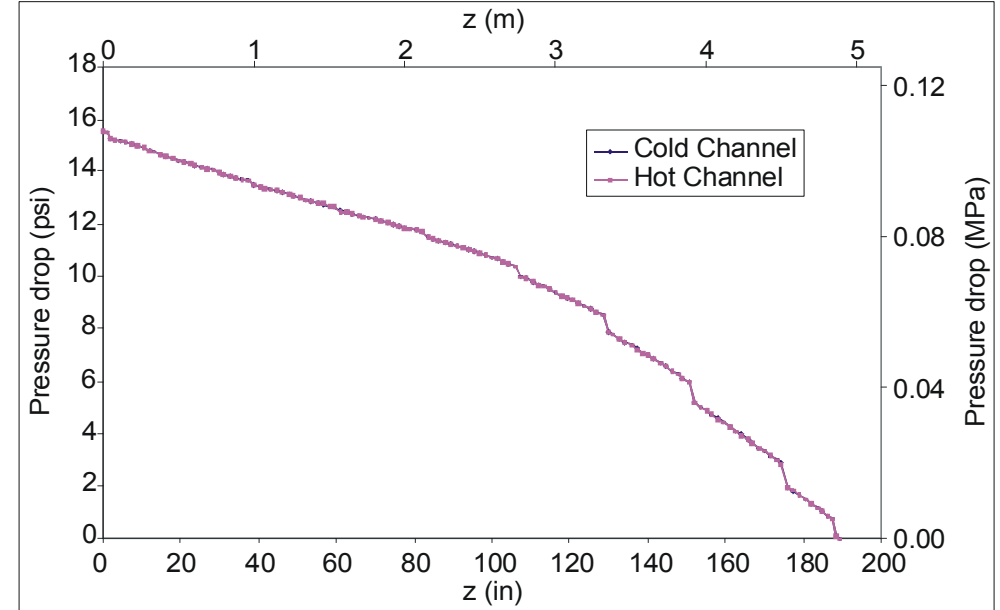

Figure 58. Pressure drop in hot and cold channels for an assembly with single fuel enrichment. 
hot and cold channels, the total pressure drop calculated is $\sim 15.6 \mathrm{psi}$, which is comparable to light water reactor cores. The figure also shows axial pressure losses associated with the grid spacers, placed uniformly along the channel. Note that both grid design and location are still open design issues, so generic assumptions were made based on PWR and BWR related experience. Similar values are obtained for cases of assembly with 5 different enrichments and uniform power distribution.

Figure 59 shows the flow velocity profile along hot and cold channels. In the lower core part (up to about 60 inches), the hot and cold velocities are almost identical. Above about 60 inches the flow velocities start to differ due to the density differences shown in Figure 60 . The exit velocity in the hot channel is $\sim 1.35$ times larger than in the cold channel. This difference is even larger (a factor of 1.9) for the single enrichment case, and very small $(\sim 1$.) for the uniform power distribution case.

Figure 60 also shows the drastic density change across the height of the core; in the hot channel the difference between the inlet and outlet densities is greater than an order of magnitude. This effect clearly confirms that the SCWR core will be very sensitive to hot channel factors, as indicated in our previous simplified analyses [MacDonald et al. 2002a]. Reducing the power peaking factors is clearly essential for the SCWR core (see the difference between the three power distribution cases). This will require an optimized assembly design to adjust the enrichment in each fuel rod. Also, this analysis does not have any allowance for uncertainties. As demonstrated in previous analyses and as is common knowledge for PWR and BWR core designers, hot channel factors due to uncertainties

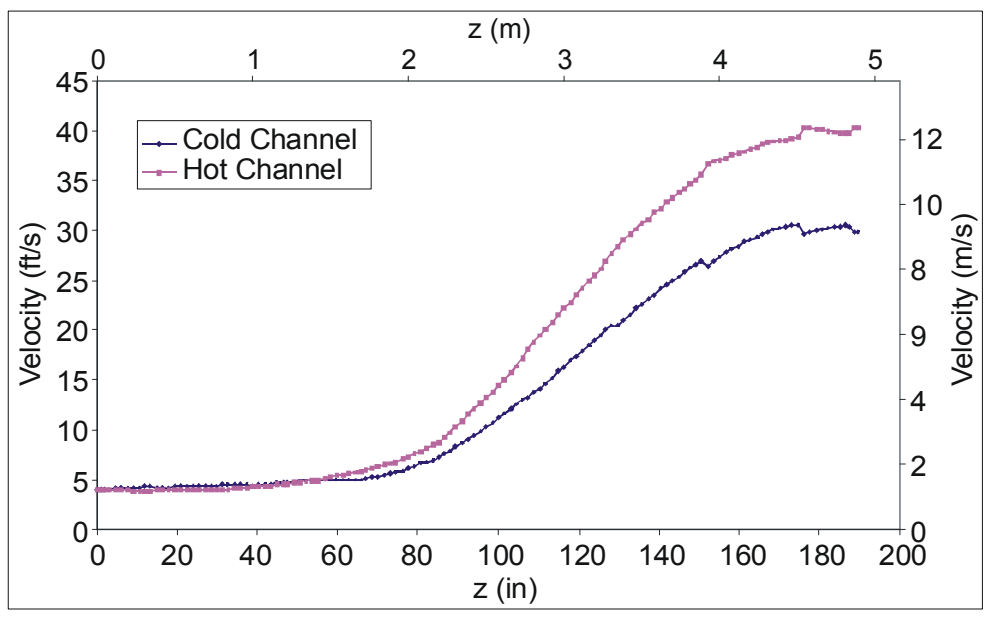

Figure 59. Flow velocity in hot and cold channels for an assembly with 5 different enrichments.

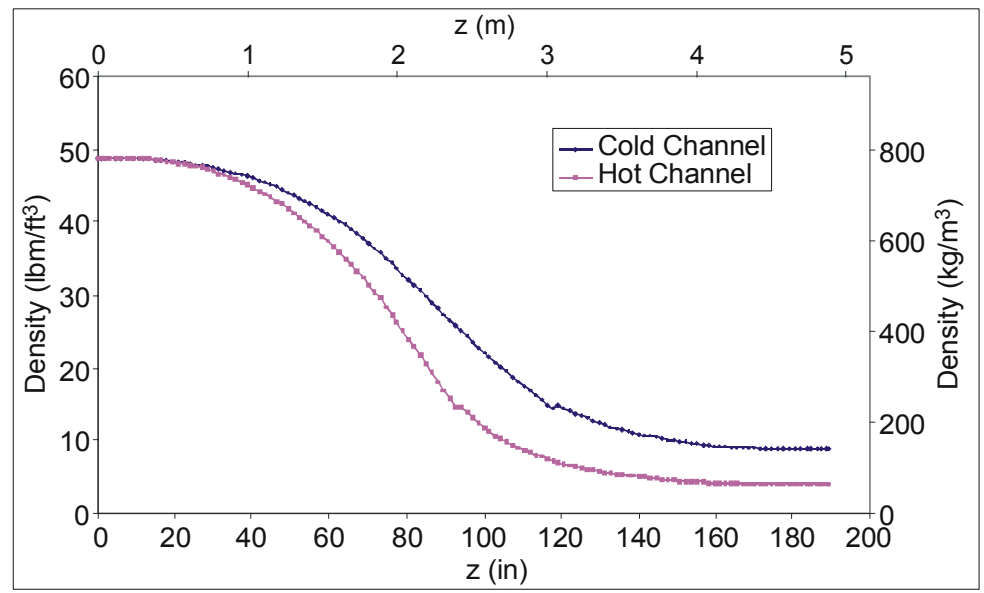

Figure 60. Coolant density profiles in hot and cold channels for an assembly with 5 different enrichments. are responsible for significant penalties in core analysis. These effects will only be amplified by the SCWR design.

Figures 61 and 62 show the hot and cold channel temperature and enthalpy profiles for the three different assembly power distributions. In the assembly with a single enrichment, the temperature rise in the cold channel is calculated as $108^{\circ} \mathrm{C}\left(195{ }^{\circ} \mathrm{F}\right)$, where as it is $488{ }^{\circ} \mathrm{C}(878$ ${ }^{\circ} \mathrm{F}$ ) in the hot channel. For the 5 enrichment case, the temperature rises in the cold and hot 
channels are $131{ }^{\circ} \mathrm{C}\left(235^{\circ} \mathrm{F}\right)$ and $368^{\circ} \mathrm{C}\left(663{ }^{\circ} \mathrm{F}\right)$, and for the uniform power case, $194{ }^{\circ} \mathrm{C}(349.7$ $\left.{ }^{\circ} \mathrm{F}\right)$ and $365^{\circ} \mathrm{C}\left(657^{\circ} \mathrm{F}\right)$, respectively.

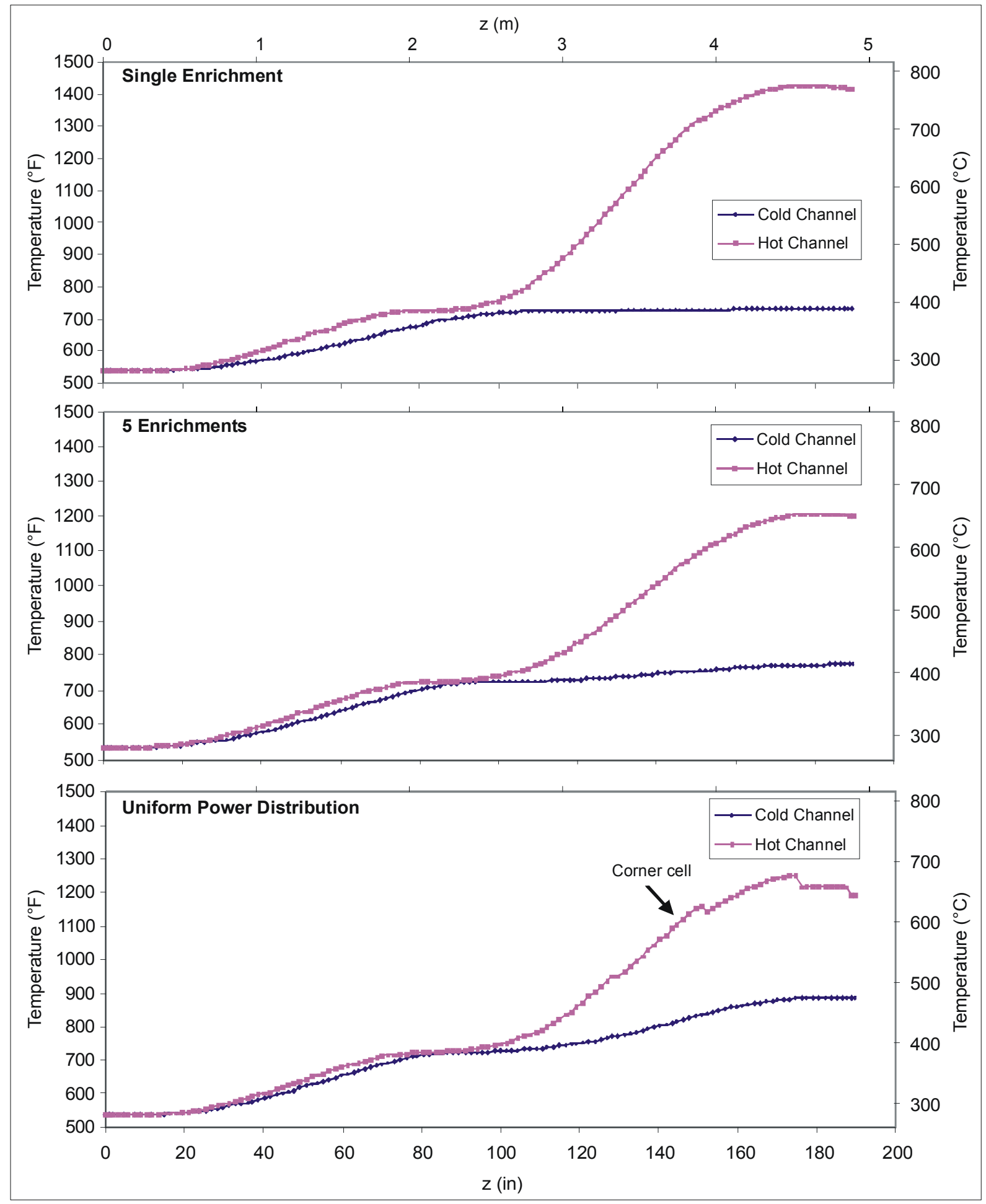

Figure 61. Hot and cold channel temperature profiles for different assembly power distributions 


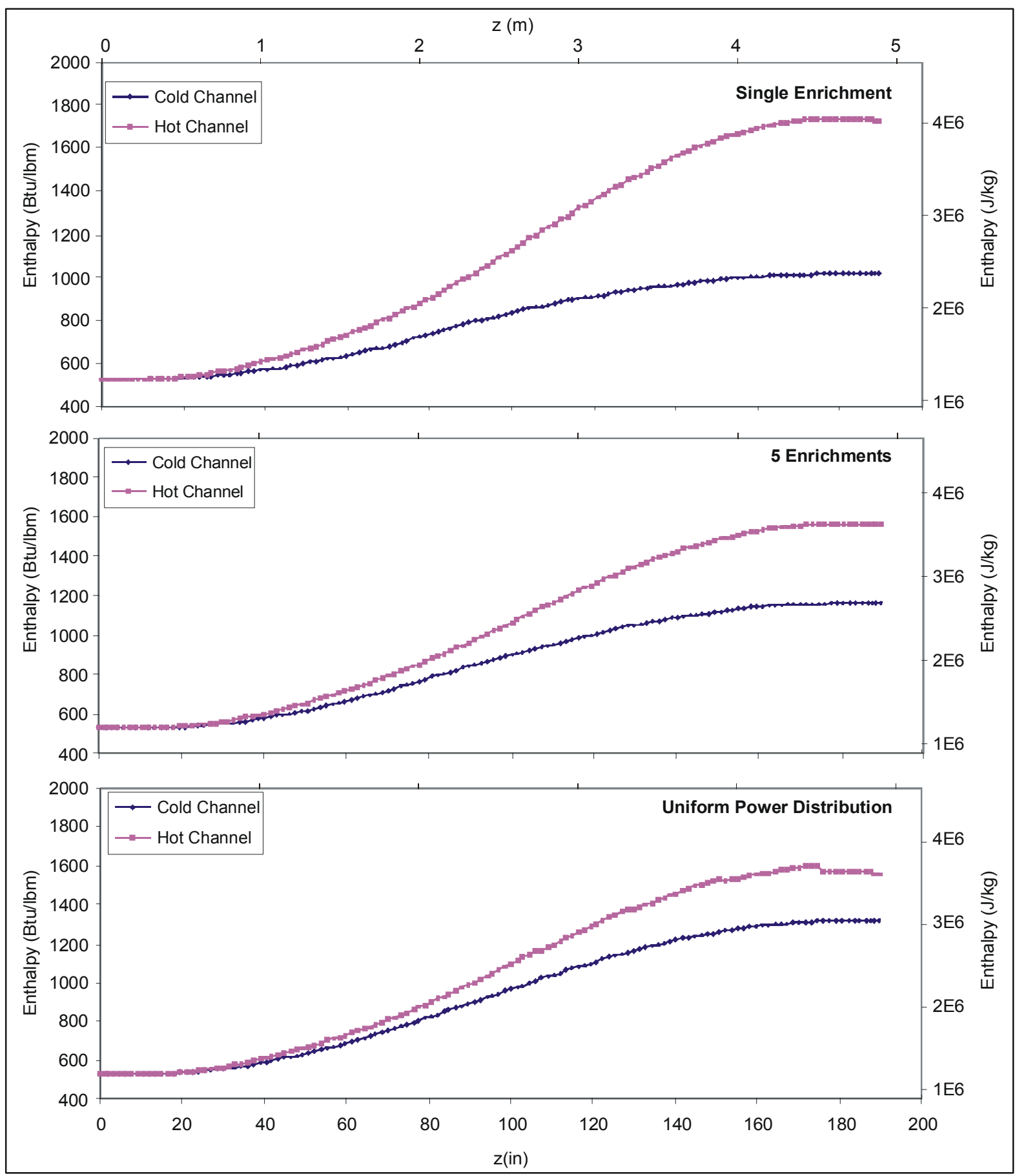

Figure 62. Coolant enthalpy in the hot and cold channels for different assembly power distributions.

These results indicate that multiple enrichments in the fuel assembly are essential for a lower peaking factor and acceptable temperature differences between hot and average channels. Even the current design would not achieve an acceptable performance, since the difference in the temperature rise between the hot and cold channels is too large. 
It should be noted that the results of the uniform enrichment case might mislead the analyst to a pessimistic interpretation: if the temperature difference for this ideal case is still so high, no acceptable SCWR design would be possible. This conclusion would be incorrect because the high temperature differences in this case are due to the assembly geometry. The $25 \times 25$ canned assembly described in Section 2 of this report with water boxes presents some channels with a very high wetted perimeter compared to the flow area (mainly in the subchannels near the boundary of the assembly). In the upper core region, where a low-density fluid with high velocities is present, the effect on the pressure losses on each channel would be significant, thus depleting flow in the side channels and directing more flow to the central channels. This naturally gives rise to an unbalanced design with high temperature differences between different subchannels. This issue can be solved by a better assembly design (that provides a larger flow area to the lateral channels) or by optimizing the radial power distribution not for a flat profile but for a peaked-to-the-center distribution. Both solutions are feasible and will allow dramatic improvements in the performance in this "ideal distribution" case. It can be easily inferred from these results that if the assembly design is optimized to better split flow between channels, the ideal case would yield temperature differences that are very small. This analysis indicates once again the importance of any parameter that affects the hot channel factors on the SCWR core response.

Figure 63 shows three-dimensional coolant temperature profiles in the central assembly at nominal conditions. Note that quarter symmetry is used in the calculations and that the southwest corner channel is the instrumentation channel. The temperature profile closely follows the assembly power distribution. Channels around the water boxes (e.g., Channels 2, 3, 6, 7, etc of Figure 56) generally have higher temperatures than the channels between the water box corners (e.g., Channels 31, 32, 44, 48, etc.), due to the differences in the hydraulic diameters (as discussed above, they have a larger wetted perimeter compared to the flow area). As evident from Figure 63, the temperature distribution becomes more uniform and the hot channel temperature is reduced in the multiple enrichment case. In the ideal case of uniform power distribution, the temperature variation between channels is minimal with the exception of the north-east corner channel (as discussed above). A design optimization of the assembly can eliminate or significantly reduce this penalty.

\subsection{Above Nominal Power and Flow Conditions:}

Following the characterization of the SCWR hot assembly discussed in the previous section, a series of numerical tests were performed to evaluate the thermal-hydraulic behavior of the SCWR for different power levels and flow rates. Starting from a base case $(100 \%$ of nominal flow and $100 \%$ of nominal power), both the power and flow rate were varied from $100 \%$ to $130 \%$. The test matrix is shown in Tables XXVI and XXVII. Note that in typical PWR and BWR analyses, a hot channel enthalpy rise factor (essentially a measure of power input in the hot assembly versus power input to the average assembly) can be up to $40 \%$. Also note that we have only examined the cases either with increased power or increased power and flow. Delivering more flow to channels with lower relative power would simply mean that some other core areas would be depleted of flow. 

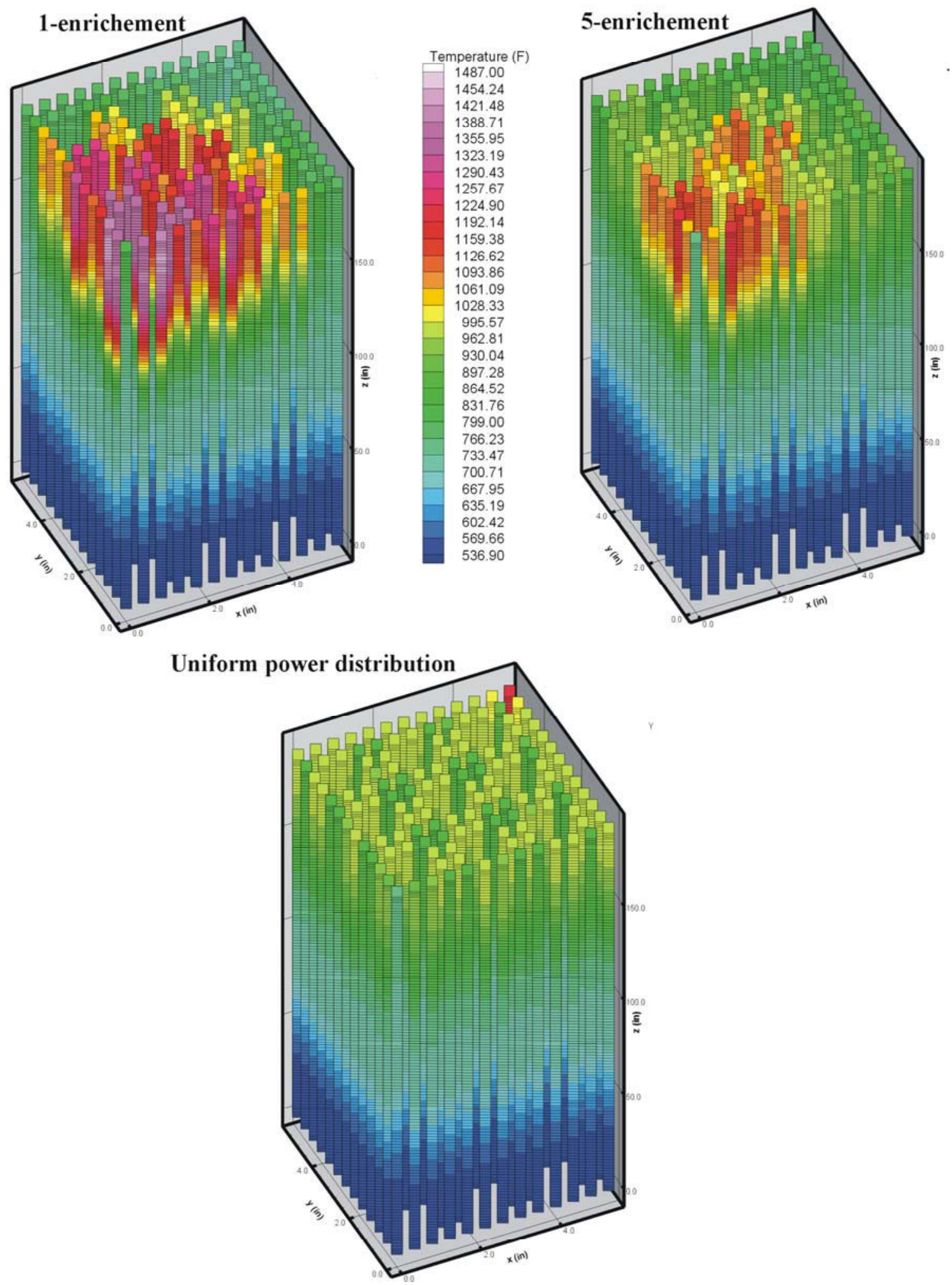

Figure 63. Channel temperature profiles for three local radial power distributions at the nominal power. 

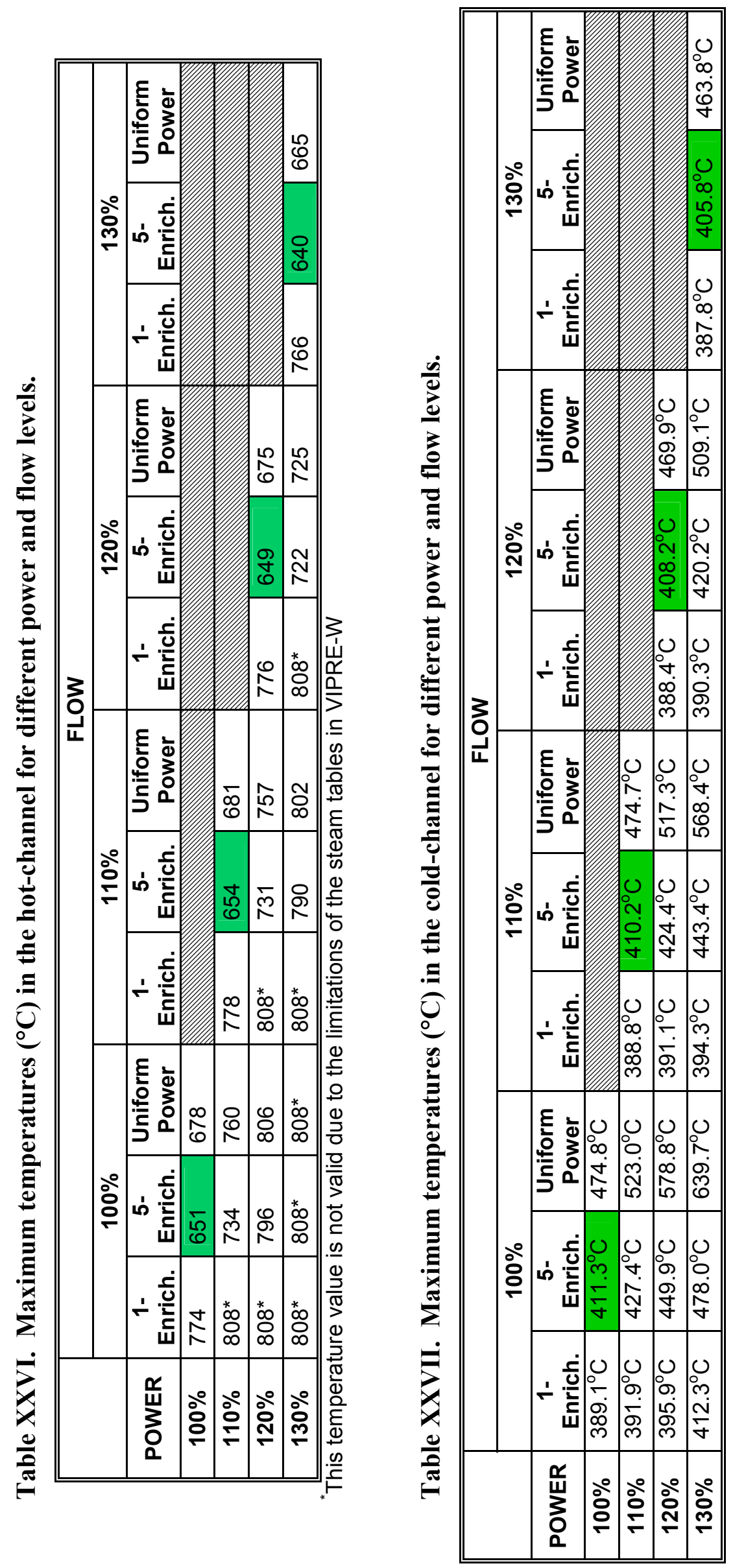
The peak cladding temperature limit for anticipated operational occurrences has been tentatively defined as $620{ }^{\circ} \mathrm{C}\left(1148{ }^{\circ} \mathrm{F}\right)$. Since these analyses are performed at normal steady state conditions, naturally some margin to the safety analysis limit will have to be demonstrated. Also, note that no attempt to calculate cladding temperatures is performed here. The approach used is to optimize the assembly design on the basis of fluid temperatures (the cladding temperature will obviously be higher) and then perform detailed peak cladding temperature calculations only for the cases that have acceptable fluid temperatures.

Figure 64 shows the temperature profiles in the assembly with 5 enrichments for power levels from 100\% to $130 \%$ while keeping the flow rates constant at $110 \%$ of the nominal value. At the nominal power level, the maximum temperature in the assembly is calculated as $651{ }^{\circ} \mathrm{C}\left(1203{ }^{\circ} \mathrm{F}\right)$. A $10 \%$ power increase raises the maximum temperature by a factor of $\sim 1.1255$; a $20 \%$ increase by $\sim 1.217$, and a $30 \%$ increase by $\sim 1.236$. This trend can be attributed to the decreasing heat capacity of water with increasing temperature at these pressures and temperatures. The ratios are more interesting than the absolute values, since the reference assembly design needs to be optimized on the basis of the considerations provided above.

Tables XXVI and XXVII above present a summary of the results in terms of hot- and cold-channel maximum temperatures. Here again, the tables show that the most promising cases are the ones using 5enrichments in the assembly. Note that the uniform power distribution case does not reflect ideal results due to that corner channel mentioned above. The case with a nominal flow and $130 \%$ power can be used again to verify the need for a flow distribution that matches as closely as possible the radial power distribution. If this is not the case, the hot channel temperatures will rapidly become unacceptable.

\subsection{Preliminary Sensitivity Study}

As mentioned above, the assembly design used for the analyses can only be considered a starting point, a reference to improve the understanding of the SCWR core relevant characteristics and then identify improvements. Based on the previous analysis, this will be a time-consuming iterative process that is beyond the scope and budget of our project. The need to optimize the assembly and core power profiles to a level beyond that of current LWRs so as to achieve acceptable performance (in terms of temperature distributions and peak cladding temperatures) will require a complex and detailed assembly design, with multiple levels of enrichments and a geometry optimized for improved thermal-hydraulic performance. "Simplicity" can not, and should not, be a feature of the SCWR core.

In this section, the sensitivity of the temperature changes in the hot and cold channels to different design parameters are considered. Four parameters were selected for this purpose: fuel rod pitch, lateral loss coefficient, axial friction factor correlation, and coolant inlet temperature. Note this is only an initial effort; several more sensitivity analyses will be performed next year before an improved design can be developed.

Fuel Pitch. The fuel pitch was increased from $11.2 \mathrm{~mm}(0.44094$ in.) to $11.3 \mathrm{~mm}(0.4448 \mathrm{in}$.). This increase in the fuel pitch results in a slightly larger flow area, but maintains the heated and wetted perimeters. As seen in Figure 65, the change in the hot-channel temperature profiles is minimal. The maximum temperatures in the hot channel are reduced by $6.2,4.6$, and $6.9{ }^{\circ} \mathrm{C}$ in the 1 -enrichment, 5 enrichment, and uniform power assemblies, respectively. The cold channel temperatures are increased by $0.5,0.78$, and $0.83{ }^{\circ} \mathrm{C}$ in the same order. 

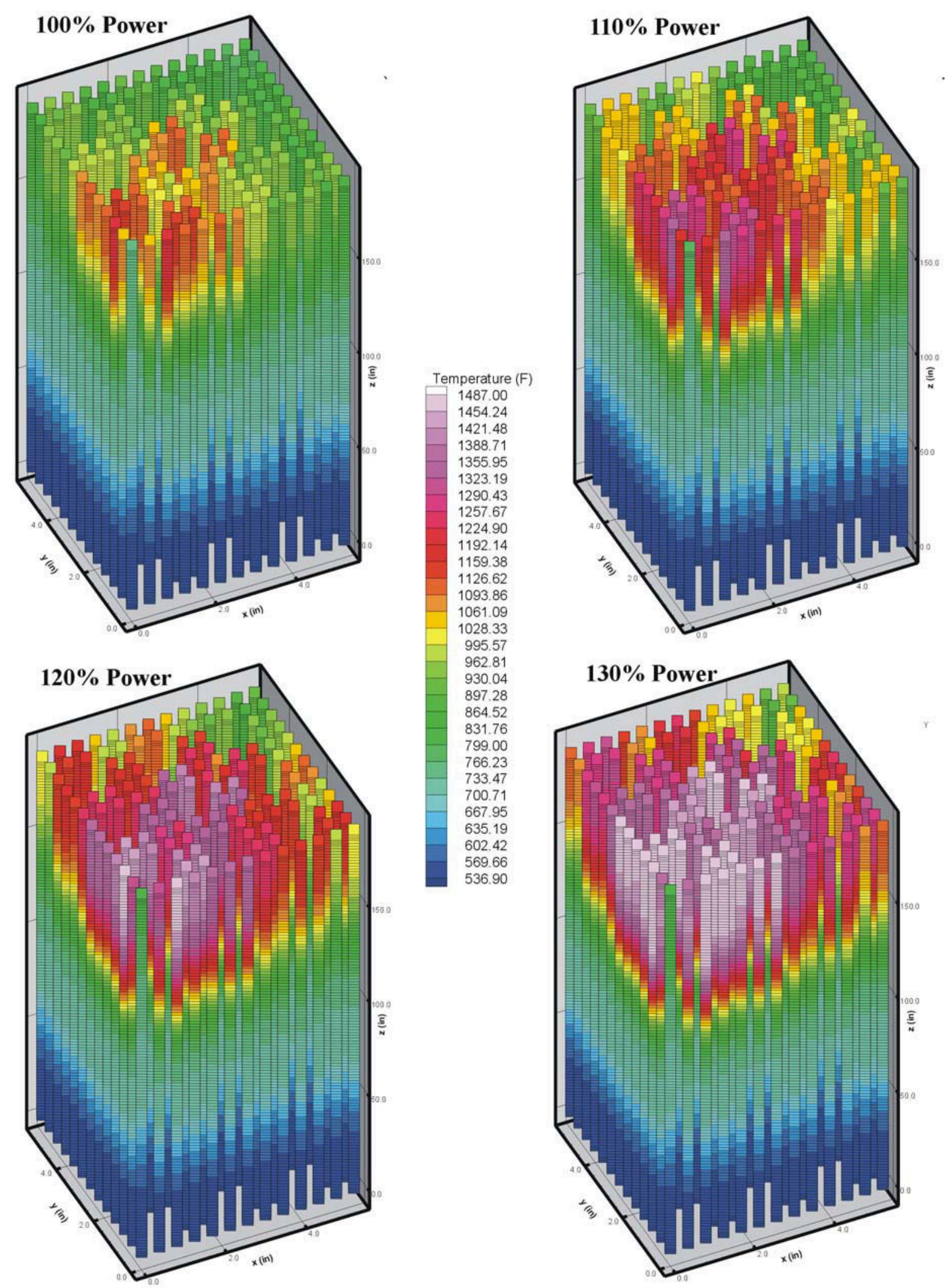

Figure 64. Temperature profiles for power levels from $100 \%$ to $130 \%$ in the assembly with 5 different enrichments. 
Lateral Loss Coefficient. The lateral loss coefficient was artificially reduced from its calculated value of 4.85 to 0.485 , providing less resistance for crossflow among channels inside the assembly. The results are similar to the previous case, yet less pronounced. The maximum temperatures in the hot channel are reduced by $4.1{ }^{\circ} \mathrm{C}, 0.2{ }^{\circ} \mathrm{C}$, and 0.06 ${ }^{\circ} \mathrm{C}$ in the 1-enrichment, 5enrichment, and uniform power assemblies, respectively. Cold channel temperatures are increased by $0.2,0.2$, and $1.6^{\circ} \mathrm{C}$ in the same

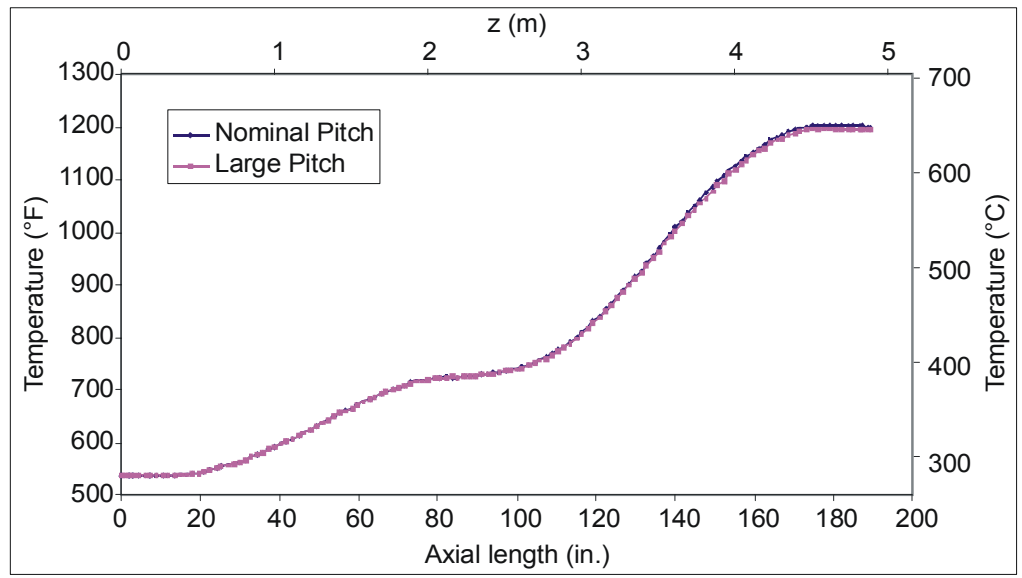

Figure 65. Hot-channel temperature profile using nominal and large fuel pitch for the assembly with 5 enrichments.

order. The results in these two sections are an indication that assumptions related to cross flow calculations (gap width, centroid distance, and lateral loss coefficient) do not have a critical impact on the temperature distributions. This is a typical result for LWR cores and is a required justification of the use of a sub-channel analysis code, which has the fundamental assumptions of a dominant flow direction (axial).

Axial friction factor correlation. Analyses have been performed so far using the axial friction factor given in Equation A14 in Appendix A. Here, we replace that equation with the conventional Blasius formula, in which the coefficients are calculated as:

$$
\mathrm{f}=0.18 * \mathrm{Re}^{-0.2}+64
$$

The Blasius formulation calculates $\sim 0.97$ psia larger total pressure drop as compared to Equation A14 as shown in Figure 66. Using the Blasius formulation raises the maximum temperatures in the hot-channel by $10.3,7.4$, and $14.8{ }^{\circ} \mathrm{C}$ in the 1-enrichment, 5enrichment, and uniform power assemblies, respectively. Cold channel temperatures are reduced by 1.3, 3.1, and $2.2{ }^{\circ} \mathrm{C}$, in the same order. The effect is due to the fact that if a higher friction loss coefficient is calculated, then the effects discussed in the previous sections regarding flow depletion in the lateral channels become more important.

Coolant inlet temperature. The coolant inlet temperature

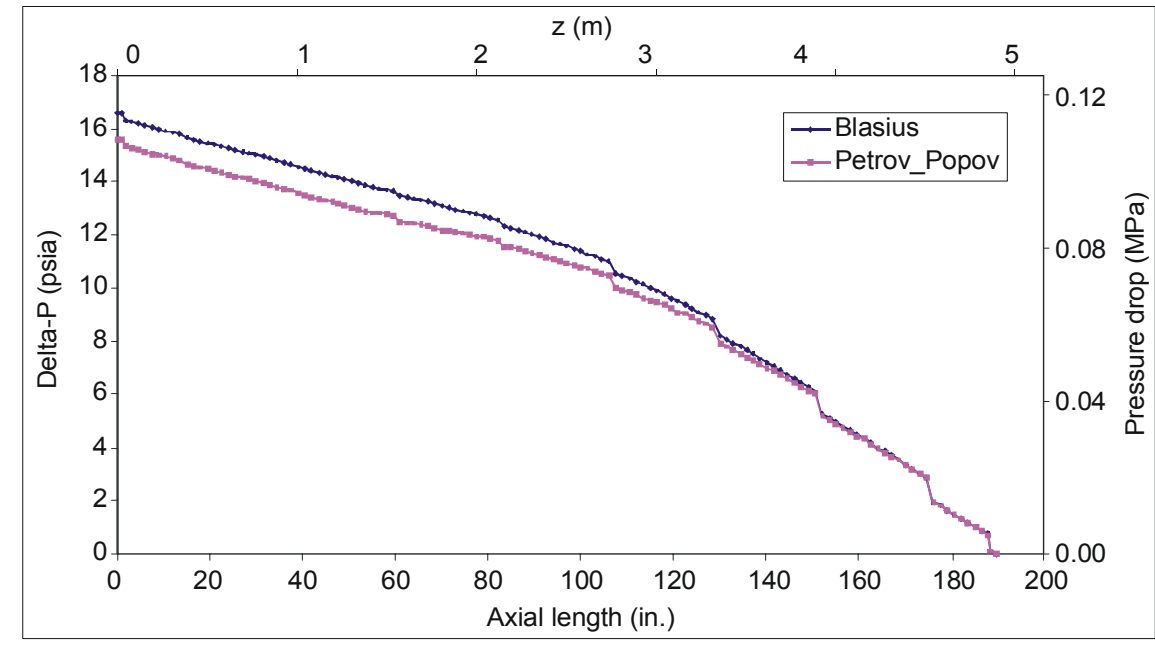

Figure 66. Pressure losses from different correlations in the hot channel of the 5-enrichment case. 
is increased by 2.22 and 5.56

${ }^{\circ} \mathrm{C}$ and the resulting effect is observed in Figure 67. A 2.2 ${ }^{\circ} \mathrm{C}$ increase in the inlet temperature raises the maximum hot channel temperatures by $3.72,4.61$, and $3.78{ }^{\circ} \mathrm{C}$ in the 1enrichment, 5-enrichment, and uniform power assemblies, respectively. Similarly, a $5.6^{\circ} \mathrm{C}$ increase in the inlet temperature leads to 7, 11, and $10.61{ }^{\circ} \mathrm{C}$ increase in the hot channels. For the cold channels the effect is relatively small: $0.22,0.94$, and $2.5^{\circ} \mathrm{C}$ for $2.2{ }^{\circ} \mathrm{C}$ increase and $0.611,2.78$, and $7.06{ }^{\circ} \mathrm{C}$

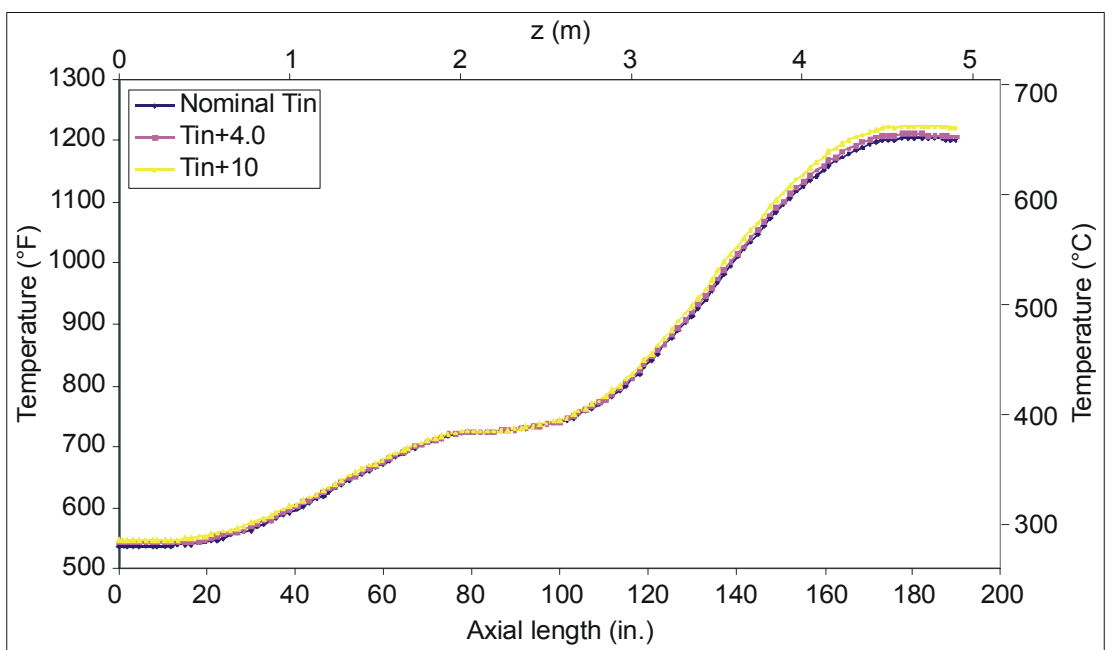

Figure 67. Hot channel temperature profiles for different inlet temperatures in the 5-enrichments case. for $5.6^{\circ} \mathrm{C}$ increase.

\subsubsection{Summary and Conclusions}

During the second year, the VIPRE_W code was modified for supercritical water applications, a VIPREW model of the SCWR core was completed and preliminary ${ }^{5}$ sub-channel analyses to investigate the thermal-hydraulic behavior of the SCWR core were performed. These preliminary analyses were used to assess the code's capability and the appropriateness of the SCWR core model used in the analyses. The following main action items where identified:

1. A revised SCWR core model for thermal-hydraulic analysis that relies on a two-pass rather than onepass approach should be used. Two different models would be used: a complete core model should be used for the coupled neutronic-thermal hydraulic calculations to evaluate the flow distributions in the assembly and to compute the input power in each assembly. Using results from the core-wise model as boundary conditions, a detailed subchannel model of the hot assembly should be used for the detailed peak cladding temperature calculations and verification of the design limits. Both models have been already completed.

2. While the modified VIPRE-W code performed relatively well in the analyses, an important limit was evident. Use of the default water properties for the SCWR analyses significantly limits the code capabilities. In particular, at temperatures above $760^{\circ} \mathrm{C}\left(1400^{\circ} \mathrm{F}\right)$, the EPRI functions lose validity. This would have little impact on the final analyses $\left(760{ }^{\circ} \mathrm{C}\right.$ is well above the maximum allowable peak cladding temperature for normal operation), but is considered an excessive limitation for these preliminary analyses and for transient and accident analyses. Therefore, the need to implement a more appropriate set of properties is considered a top priority. To be consistent with other analysis tools used for the SCWR analysis and to benefit from the INEEL expertise, the same water properties adapted by INEEL for RELAP will be implemented in the modified code.

\footnotetext{
${ }^{5}$ The authors would like to stress the preliminary nature of these calculations. Model qualification and code verification not being complete, the results in this report should be considered only indicative and verified against engineering judgment.
} 
Using the code and the core model discussed in this report, and taking into account their limitations, a set of preliminary analyses were performed to characterize the SCWR core. Using three different local power distributions in the central assembly, temperature distributions in the hot assembly were evaluated for different conditions, which ultimately demonstrate the limitations of the current design and the challenges in the design of a SCWR core. The current model does not address fuel or clad temperature behavior, nevertheless coolant temperature is still a valid indicator of design feasibility. The results of the VIPRE-W calculations indicate that multiple enrichments in the fuel assemblies that result in flatter power distributions within each fuel assembly, an optimized assembly geometry for better flow distribution within the fuel assemblies, and orificing to carefully control the coolant flow to each assembly are essential to lower the hot channel temperatures. The effort to minimize local peaking factors in the hot assembly will lead to a complex assembly design that will have to rely on the BWR assembly design experience.

Analyses were also performed to evaluate the thermal-hydraulic performance of the SCWR core at different power and flow levels. Furthermore, sensitivity studies were performed in which some of the design parameters were slightly perturbed (e.g., lateral loss coefficient factors and inlet temperatures) or different correlations (axial friction factor) were used. These analyses constitute only the initial part of a more complete effort that will be used to characterize the SCWR core, providing a better understanding of the core thermal hydraulic behavior that will be necessary to provide an improved assembly design to provide adequate performance. These analyses will be completed in the final year of the program. Once these analyses are completed, a revised assembly design will be provided and detailed analyses will be performed on this revised design. Since the current funding level does not allow implementation of a statistical approach for the SCWR core analysis, a simplified methodology will be used to evaluate the peak cladding temperatures during some limiting transients.

Given the complexity that can be expected from the core and assembly design of the SCWR core, it will only be possible to draw some preliminary conclusion on the design in the frame of this program.

\subsection{Supercritical Water Cooled Reactor Fuel Rod Design Requirements (Hans Garkish, Westinghouse)}

During the first year of the program a preliminary assessment of the fuel design criteria for LWRs was performed. This effort was refined in the second year, to provide a more detailed treatment of the fuel performance criteria. Note that for this discussion a reference cladding material (MA 956) was selected and its properties are discussed in Section 5.2.4 below. While this assessment applies only to this "strawman" material, the process outlined in this work can be used as a basis to develop a set of performance criteria for different claddings.

\subsubsection{Design Bases}

This section summarizes the fuel rod design bases to minimize fuel damage and provide limiting values for parameters such that any fuel damage is limited to acceptable levels. The design bases must be responsive to the acceptance criteria for fuel designs established in the U.S. federal regulations 10 CFR Part 50.46 and the General Design Criteria for Nuclear Power Plants in Appendix A to Part 50, in particular Criterion 10. The NRC Standard Review Plan, Section 4.2 also addresses specific fuel rod failure modes and mechanisms, which affect safety. The primary design bases acceptance criteria are listed in Tables XXVIII, XXIX, and XXX.

The criteria listed in these tables are written for LWR fuel. The SCWR concept does not fall into this category. Although most criteria of the NRC Standard Review Plan are applicable to SCWR fuel rods, 
for example the fuel melting criteria, others are not. These include limits specified for Zirconium alloy cladding. They need to be replaced by design and material specific criteria.

Table XXVIII. Design basis acceptance criteria for fuel system damage.

\begin{tabular}{|c|c|}
\hline Paragraph & Acceptance Criteria Description (from NRC Standard Review Plan Section 4.2-II-A-1) \\
\hline (a) & $\begin{array}{l}\text { Stress, strain, or loading limits for spacer grids, guide tubes, thimbles, fuel rods, control rods, } \\
\text { channel boxes, and other fuel system structural members should be provided. Stress limits that } \\
\text { are obtained by methods similar to those given in Section III of the ASME Code are acceptable. } \\
\text { Other proposed limits must be justified. }\end{array}$ \\
\hline (b) & $\begin{array}{l}\text { The cumulative number of strain fatigue cycles on the structural members mentioned in (a) } \\
\text { above should be significantly less than the design fatigue lifetime, which is based on } \\
\text { appropriate data and includes a safety factor of } 2 \text { on stress amplitude or a safety factor of } 20 \text { on } \\
\text { the number of cycles. Other proposed limits must be justified. }\end{array}$ \\
\hline (c) & $\begin{array}{l}\text { Fretting wear at contact points on the structural members mentioned in paragraph (a) above } \\
\text { should be limited. The allowable fretting wear should be stated in the Safety Analysis Report } \\
\text { and the stress and fatigue limits in paragraphs (a) and (b) above should presume the existence } \\
\text { of this wear. }\end{array}$ \\
\hline (d) & $\begin{array}{l}\text { Oxidation, hydriding, and the buildup of corrosion products (crud) should be limited. } \\
\text { Allowable oxidation, hydriding, and crud levels should be discussed in the Safety Analysis } \\
\text { Report and shown to be acceptable. These levels should be presumed to exist in paragraphs } \\
\text { (a) and (b) above. (Hydriding is not applicable to non-Zirconium alloy cladding.) }\end{array}$ \\
\hline (e) & $\begin{array}{l}\text { Dimensional changes such as rod bowing or irradiation growth of fuel rods, control rods, and } \\
\text { guide tubes need not be limited to set values (i.e., damage limits), but they must be included in } \\
\text { the design analysis to establish operational tolerances. }\end{array}$ \\
\hline (f) & $\begin{array}{l}\text { Fuel and burnable poison rod internal gas pressures should remain below the nominal } \\
\text { system pressure during normal operation unless otherwise justified. }\end{array}$ \\
\hline (g) & $\begin{array}{l}\text { Worst-case hydraulic loads for normal operation should not exceed the holddown capability } \\
\text { of the fuel assembly (either gravity or holddown springs). }\end{array}$ \\
\hline (h) & $\begin{array}{l}\text { Control rod reactivity must be maintained. This may require the control rods to remain } \\
\left.\text { watertight if water-soluble or leachable materials (e.g., } B_{4} C\right) \text { are used. }\end{array}$ \\
\hline
\end{tabular}

Table XXIX. Design basis acceptance criteria for fuel rod failure.

\begin{tabular}{|c|c|}
\hline Paragraph & Acceptance Criteria Description (from NRC Standard Review Plan Section 4.2-II-A-2) \\
\hline (a) & $\begin{array}{l}\text { Internal Hydriding: Hydriding as a cause of failure (i.e., primary hydriding) is prevented by } \\
\text { keeping the level of moisture and other hydrogenous impurities within the fuel very low during } \\
\text { fabrication. Acceptable moisture levels for Zircaloy-clad uranium oxide fuel should be no greater } \\
\text { than } 20 \mu \mathrm{g} / \mathrm{g}(20 \mathrm{ppm}) \text {. Current ASTM specifications for } \mathrm{UO}_{2} \text { fuel pellets state an equivalent limit } \\
\text { of } 2 \mu \mathrm{g} / \mathrm{g}(2 \mathrm{ppm}) \text { of hydrogen from all sources. For other materials clad in Zircaloy tubing, an } \\
\text { equivalent quantity of moisture or hydrogen can be tolerated. A moisture level of } 2 \mathrm{mg} \mathrm{H}_{2} \mathrm{O} \text { per } \\
\mathrm{cm} \text { of hot void volume within the Zircaloy cladding has been shown (Reference. } 832) \text { to be } \\
\text { insufficient for primary hydride formation. (Hydriding is generally not affecting or limiting in non- } \\
\text { Zirconium alloy cladding.) }\end{array}$ \\
\hline (b) & $\begin{array}{l}\text { Cladding Collapse: If axial gaps in the fuel pellet column occur due to densification, the } \\
\text { cladding has the potential of collapsing into a gap (i.e., flattening). Because of the large local } \\
\text { strains that accompany this process, collapsed (flattened) cladding is assumed to fail. }\end{array}$ \\
\hline (c) & $\begin{array}{l}\text { Fretting: Fretting is a potential cause of fuel failure, but it is a gradual process that would not be } \\
\text { effective during the brief duration of an abnormal anticipated operational occurrence or a } \\
\text { postulated accident. Therefore, the fretting wear requirement in paragraph (c) of subsection } \\
\text { II.A.1, Fuel Damage, is sufficient to preclude fuel failures caused by fretting during these } \\
\text { transients. }\end{array}$ \\
\hline (d) & $\begin{array}{l}\text { Overheating of Cladding: It has been traditional practice to assume that failures will not occur if } \\
\text { the thermal margin criteria (DNBR for PWRs and CPR for BWRs) are satisfied. For normal } \\
\text { operation and anticipated operational occurrences, violation of the thermal margin criteria is not } \\
\text { permitted. For postulated accidents, the total number of fuel rods that exceed the criteria has } \\
\text { been assumed to fail for radiological dose calculation purposes. }\end{array}$ \\
\hline
\end{tabular}




\begin{tabular}{|c|c|}
\hline Paragraph & Acceptance Criteria Description (from NRC Standard Review Plan Section 4.2-II-A-2) \\
\hline$(\mathrm{e})$ & $\begin{array}{l}\text { Overheating of Fuel Pellets: It has also been traditional practice to assume that failure will } \\
\text { occur if centerline melting takes place. This analysis should be performed for the maximum } \\
\text { linear heat generation rate anywhere in the core, including all hot spots and hot channel factors, } \\
\text { and should account for the effects of burnup and composition on the melting point. For normal } \\
\text { operation and anticipated operational occurrences, centerline melting is not permitted. The } \\
\text { assumption that centerline melting results in fuel failure is conservative. }\end{array}$ \\
\hline (f) & $\begin{array}{l}\text { Excessive Fuel Enthalpy: For a severe reactivity initiated accident (RIA) in a BWR at zero or } \\
\text { low power, fuel failure is assumed to occur if the radially averaged fuel rod enthalpy is greater } \\
\text { than } 711 \mathrm{~J} / \mathrm{g}(170 \mathrm{cal} / \mathrm{g}) \text { at any axial location. For full-power RIAs in a BWR and all RIAs in a } \\
\text { PWR, the thermal margin criteria (DNBR and CPR) are used as fuel failure criteria to meet the } \\
\text { guidelines of Regulatory Guide } 1.77 \text { as it relates to fuel rod failure. The } 711 \mathrm{~J} / \mathrm{g} \text { ( } 170 \text { cal/g) } \\
\text { enthalpy criterion is primarily intended to address cladding overheating effects, but it also } \\
\text { indirectly addresses pellet/cladding interactions (PCI). Other criteria may be more appropriate } \\
\text { for an RIA, but continued approval of this enthalpy criterion and the thermal margin criteria may } \\
\text { be given until generic studies yield improvements. ( } A \text { new SCWR energy limiting criteria needs } \\
\text { to be set or the above criterion be evaluated for applicability.) }\end{array}$ \\
\hline$(\mathrm{g})$ & $\begin{array}{l}\text { Pellet/Cladding Interaction (PCI): There is no current criterion for fuel failure resulting from } \\
\mathrm{PCl} \text {, and the design basis can only be stated generally. Two related criteria should be applied, } \\
\text { but they are not sufficient to preclude } \mathrm{PCl} \text { failures. } \\
\text { - The uniform strain of the cladding should not exceed } 1 \% \text {. In this context, uniform strain } \\
\text { (elastic and inelastic) is defined as transient-induced deformation with gage lengths } \\
\text { corresponding to cladding dimensions; steady-state creepdown and irradiation growth are } \\
\text { excluded. Although observing this strain limit may preclude some } \mathrm{PCl} \text { failures, it will not } \\
\text { preclude the corrosion-assisted failures that occur at low strains, nor will it preclude highly } \\
\text { localized overstrain failures. } \\
\text { Fuel melting should be avoided. The large volume increase associated with melting may } \\
\text { cause a pellet with a molten center to exert a stress on the cladding. Such a PCI is avoided } \\
\text { by avoiding fuel melting. Note that this same criterion was invoked in paragraph (e) to } \\
\text { ensure that overheating of the cladding would not occur. }\end{array}$ \\
\hline (h) & $\begin{array}{l}\text { Bursting: To meet the requirements of } 10 \text { CFR } 50.46 \text { as it relates to ECCS performance } \\
\text { evaluation, a calculation of the swelling and rupture of the cladding resulting from the } \\
\text { temperature distribution in the cladding and from pressure differences between the inside and } \\
\text { outside of the cladding should be included in the ECCS evaluation model. Regulatory Guide } \\
1.157 \text { provides guidelines for performing a realistic (i.e., best-estimate) model to calculate the } \\
\text { degree of cladding swelling and rupture. Alternatively, Appendix K of } 10 \text { CFR } 50 \text { presents } \\
\text { acceptable features of an evaluation model for predicting the degree of swelling and rupture in } \\
\text { the Zircaloy cladding. (Some of this guidance may not apply to non-Zircaloy cladding.) }\end{array}$ \\
\hline (i) & $\begin{array}{l}\text { Mechanical Fracturing: A mechanical fracture refers to a defect in a fuel rod caused by an } \\
\text { externally applied force such as a hydraulic load or a load derived from core-plate motion. } \\
\text { Cladding integrity may be assumed if the applied stress is less than } 90 \% \text { of the irradiated yield } \\
\text { stress at the appropriate temperature. Other proposed limits must be justified. Results from the } \\
\text { seismic and LOCA analysis may show that failures by this mechanism will not occur for less } \\
\text { severe events. }\end{array}$ \\
\hline
\end{tabular}


Table XXX. Design basis acceptance criteria for fuel coolability.

\begin{tabular}{|c|l|}
\hline Paragraph & Acceptance Criteria Description (from NRC Standard Review Plan section 4.2-II-A-2) \\
\hline (a) & $\begin{array}{l}\text { Cladding Embrittlement: To meet the requirements of 10 CFR Part 50, } 550.46, \text { as it } \\
\text { relates to cladding embrittlement for a LOCA, acceptance criteria of } 1204^{\circ} \mathrm{C}\left(2200{ }^{\circ} \mathrm{F}\right) \text { on } \\
\text { peak cladding temperature and } 17 \% \text { on maximum cladding oxidation must be met. Similar } \\
\text { temperature and oxidation criteria may be justified for other accidents. }\end{array}$ \\
\hline (b) & $\begin{array}{l}\text { Violent Expulsion of Fuel: In severe reactivity initiated accidents, such as rod ejection in } \\
\text { a PWR or rod drop in a BWR, the large and rapid deposition of energy in the fuel can result } \\
\text { in melting, fragmentation, and dispersal of fuel. The mechanical action associated with fuel } \\
\text { dispersal can be sufficient to destroy the cladding and the rod-bundle geometry of the fuel } \\
\text { and to produce pressure pulses in the primary system. To meet the guidelines of } \\
\text { Regulatory Guide 1.77 as it relates to preventing widespread fragmentation and dispersal } \\
\text { of the fuel and avoiding the generation of pressure pulses in the primary system of a PWR, } \\
\text { a radially averaged enthalpy limit of 1.17 kJ/g (280 cal/g) should be observed. This 1.17 } \\
\text { KJ/g (280 cal/g) limit should also be used for BWRs. }\end{array}$ \\
\hline (c) & $\begin{array}{l}\text { Generalized Cladding Melting: Generalized (i.e., non-local) melting of the cladding could } \\
\text { result in the loss of rod-bundle fuel geometry. Criteria for cladding embrittlement in } \\
\text { paragraph (a) above are more stringent than melting criteria would be; therefore, additional } \\
\text { specific criteria are not used. }\end{array}$ \\
\hline (d) & $\begin{array}{l}\text { Fuel Rod Ballooning: To meet the requirements of 10 CFR 50.46 as it relates to } \\
\text { evaluating ECCS performance during accidents, burst strain and flow blockage caused by } \\
\text { ballooning (swelling) of the cladding must be accounted for in the analysis of the core flow } \\
\text { distribution. Regulatory Guide 1.157 describes models, correlations, data, and methods } \\
\text { that are acceptable for meeting the requirements for a realistic calculation of ECCS } \\
\text { performance during a LOCA. Alternatively, Appendix K to 10 CFR 50 presents acceptable } \\
\text { features of a conservative evaluation model to consider burst strain and flow blockage. } \\
\text { (Some of this guidance may not apply to non-Zircaloy cladding.) }\end{array}$ \\
\hline
\end{tabular}

In practice the fuel rod criteria for structural evaluations are based on ASME Boiler and Pressure Vessel Code Section III rationale. The higher operating temperature of the SCWR core (above $425{ }^{0} \mathrm{C}$ ) and expected loading and irradiation conditions will require that thermal creep and creep damage be considered in the structural evaluations. Article NH3000 of the PVC Section III Code provides guidance on how to implement the effect of creep and creep-fatigue interaction in the evaluations.

In addition to the criteria established to meet the NRC Standard Review Plan safety related criteria, it is prudent to impose additional constraints on the design to assure a reliable and economic operation of the fuel at the design conditions to the performance targets (burnup, failure rate). The fuel rod performance is being evaluated with a modification of the FRAPCON Code, which has been calibrated to predict LWR fuel performance. Preliminary results from this effort are presented in Section 5.3 of this report.

\subsubsection{SCWR Fuel Rod Failure Modes}

The following fuel rod failure modes are considered in this review. It should be noted that this list should not be considered complete, but it provides a sufficiently detailed and sufficient set of failure modes for the current stage of the investigation.

- Fracture induced by rod pressure and fuel cladding mechanical interaction, assisted by irradiation assisted stress corrosion cracking and stress corrosion induced embrittlement of the cladding.

- Creep rupture burst due to over-pressure or sustained stress induced by fuel-cladding differential thermal expansion.

- Cladding failure induced by fuel cladding mechanical interaction during steady state and then transient operation at high burn-up.

- Cladding fatigue failure, an unlikely failure mode for a reactor in base load operation. 
- Excessive cladding growth and swelling exceeding the functional constraints of the fuel assembly, an unlikely failure mode in a thermal flux environment.

- Cladding corrosion, which thins the cladding and increases cladding temperatures. A thick corrosion layer on the cladding increases the cladding and fuel temperatures and can induce failure.

- Due to the high system operating pressure, cladding collapse under external differential pressure.

- End-plug weld failure.

\subsubsection{Fuel Rod Design Criteria}

The criteria established in the following sections are applied to operating Conditions I and/or II events and ensure that no design related failures occur. Specific criteria applicable for Conditions III and Condition IV events are also specified to comply with safety requirements for the reactor system.

The operating conditions, some fuel design features, and the material options of the SCWR fuel have not been tested and a reliable database for design does not exist. Therefore, the design limits are based on the expected performance characteristics of the fuel and primarily the cladding, based on the best available information. The absence of irradiated material property data, and data obtained in a supercritical steam environment require judgment in defining design limits. On the other hand, the design limit selection must be based on realistic expectations and cannot be overly conservative.

The basis for the proposed design criteria are derived from the NRC-Standard Review Plan acceptance criteria summarized in the tables above. In some cases the basis for the criteria is derived from the ASME Boiler and Pressure Vessel Code Section III Article NH-3000, which covers the design of reactor components at elevated temperatures, even though the code is not applicable to fuel rods. However, the approach for estimating the stress, strain and fatigue limits for cladding at elevated temperatures are applicable.

\subsubsection{Rod Internal Pressure Criterion}

The rod internal pressure of the lead rod in the reactor shall not exceed the pressure that could:

- Cause the diametral gap between the fuel and the cladding to increase during steady state operation, cause ballooning, and affect the coolant flow.

- Exceed the rupture pressure of the cladding (if known).

- Cause local overheating of the cladding

Basis: Table XXVIII, Paragraphs d, h; Table XXIX, Paragraphs f; NRC Standard Review Plan II, A-1-d, h; NRC Standard Review Plan II, A-2-f; and NRC Standard Review Plan II, A-3-d.

Implementation: With the pressures, temperatures, and cladding strain, stress, and gap conditions obtained from FRAPCON, perform additional calculations and projections to determine the margin to exceeding the design limit. In general, except for Condition II and IV transients, the cladding strain criterion should be more limiting. The limit on DNB propagation, a limit in PWR cores, will not be applicable in the core system.

\subsubsection{Cladding Stress Criterion}

Where creep is significant, the ASME Boiler \& Pressure Vessel Code Section III Articles NH-3000 and NH-3250 specify that the strain-limiting criteria, rather than stress-limiting criteria can be applied. The 
FRAPCON code can be used to calculate deformation-controlled strains. In this case the strain and deformation limits of Figure NH-3221-1 of the code apply.

However, simplified elastic methods can be used to establish conservative load-controlled stress limits following the logic of Figure NH-3221-1 of the code. This is accepted practice in LWR fuel rod design. The stress criterion is applicable for the high temperature design conditions of the SCWR fuel rod, assuming that the selected cladding material, such as MA956, retains its ductility during irradiation beyond the yield stress. The conservatism in the ASME stress limits can account for the reduction in strength due to service conditions, such as irradiation and water chemistry effects. Stress criteria on the cladding require less conservatism than criteria applied to a support structure covered by the ASME code, such as a vessel, the reactor internals, or piping. The fuel rod cladding is not covered by the code. However, by applying criteria based on the code approach, a design finds acceptance with the NRC without further justification.

The fuel rod cladding is loaded by:

- Primary membrane loads $\mathrm{P}_{\mathrm{m}}$ causing sustained primary membrane stress. These loads include the rod internal and external pressure and sustained (loads which do not relax due to plastic deformation or creep) cladding-fuel mechanical interaction.

- Primary local membrane loads $\mathrm{P}_{1}$ and primary bending $\mathrm{P}_{\mathrm{b}}$ causing sustained local membrane and bending stress. These loads are caused by rod bending spacer-cladding interference and are generally not calculated explicitly by fuel performance codes, but may be considered as stress adders in the design evaluation procedure.

- Secondary loads Q, primarily thermal stresses. For simplicity they are often simply added to the primary stress.

The allowable stresses are derived from the material data, primarily the $0.2 \%$ yield stress $S_{y}$, the ultimate stress $\mathrm{S}_{\text {ult, }}$ and the time-dependent stress-to-rupture $\mathrm{S}_{\mathrm{t}}$. The maximum allowable general primary membrane stress $\mathrm{S}_{0}$, which is normally used as a reference for stress calculations under design loading, is defined by the ASME code for each material.

A design load per NH-3113.1 is not specified for fuel rods. Instead $\mathrm{S}_{\mathrm{m}}$, the lowest stress intensity value among the time-independent strength quantities, is used to calculate stresses due to service life under Condition I and II operation (Level A and B service). For materials not included in the code, and therefore not covered by the code, the lowest design membrane stress intensity $\mathrm{S}_{\mathrm{m}}$ can be derived as follows, see Section III, Article III-2000, III-2100, Mechanical Property Criteria, and of the ASME Boiler \& Pressure Vessel Code:

$\mathrm{S}_{\mathrm{m}}=\min$. of $\mid \begin{gathered}2 / 3 \mathrm{~S}_{\mathrm{y}} \text { at ambient (room) temperature } \\ 2 / 3 \mathrm{~S}_{\mathrm{y}} \text { at service temperature }\left(90 \% \text { of } \mathrm{S}_{\mathrm{y}} \text { at temperature but }<2 / 3 \mathrm{~S}_{\mathrm{y}}\right. \\ \text { at ambient (room) temperature for stainless steel) } \\ 1 / 3 \mathrm{~S}_{\mathrm{ult}} \text { at ambient (room) temperature } \\ 1 / 3 \mathrm{~S}_{\mathrm{ult}} \text { at service temperature }\end{gathered}$

The lowest time-dependent design membrane stress intensity $S_{m t}$ can be derived as the lower of $S_{m}$ or the temperature and time-dependent stress intensity limit $S_{t}$. The time-dependent design membrane stress intensity $\mathrm{S}_{\mathrm{t}}$ can be derived as follows from data, see Section III, Division 1, Article NH-3000 of the ASME Boiler \& Pressure Vessel Code:

\begin{tabular}{l|l}
$\mathrm{S}_{\mathrm{t}}=$ min. of & $\begin{array}{l}100 \% \text { of the stress to cause } 1 \% \text { strain. } \\
80 \% \text { of the stress to initiate tertiary creep, } \\
67 \% \text { of the minimum stress to cause rupture }\end{array}$
\end{tabular} 
Comments:

- A $1 \%$ permanent strain limit is assumed for cladding design, including irradiation induced creep strains, but excluding elastic strain as the code requires. The strain is calculated by FRAPCON.

- Initiation of tertiary creep under irradiation at the SCWR temperatures may be difficult to define.

- Stress-to-rupture can be defined from the material data. The $67 \%$ limit may be too conservative if all uncertainties are considered.

- A creep damage fraction rule, see fatigue below, can be used to account for stress and temperature changes:

$$
\mathrm{D}=\sum_{\mathrm{l}=1}^{\mathrm{q}}\left(\frac{\Delta \mathrm{t}_{1}}{\mathrm{~T}_{\text {rupture }}}\right)<1
$$

where:

$\mathrm{D}$ is the damage fraction

$\Delta \mathrm{t}_{1}$ is the time at stress 1

$\mathrm{T}_{\text {rupture }}$ is the time to rupture at stress 1

The time independent stress intensity limits for the load categories are as follows with: $\mathrm{P}_{\mathrm{m}}$ the primary membrane stress, $\mathrm{P}_{\mathrm{b}}$ the primary bending stress, and $\mathrm{Q}$ the secondary stress:

$$
\begin{array}{ll}
\mathrm{S}_{\text {in }}\left(\mathrm{P}_{\mathrm{m}}\right) & <1.0 \mathrm{~S}_{\mathrm{m}} \\
\mathrm{S}_{\text {in }}\left(\mathrm{P}_{\mathrm{m}}+\mathrm{P}_{1}+\mathrm{P}_{\mathrm{b}}\right) & <1.5 \mathrm{~S}_{\mathrm{m}} \\
\mathrm{S}_{\text {in }}\left(\mathrm{P}_{\mathrm{m}}+\mathrm{P}_{\mathrm{b}}+\mathrm{P}_{1}+\mathrm{Q}\right) & <3.0 \mathrm{~S}_{\mathrm{m}}
\end{array}
$$

where $S_{\text {in }}$ is the stress intensity, i.e., the absolute value of the maximum difference between the three principal stresses. Article NH-3000 of the ASME Boiler \& Pressure Vessel Code does not include the secondary stress category, because deformation at high temperature tends to relax those stresses due to creep and plastic deformation. The stress adder Q is included to assure that the transient thermal stresses do not exceed stresses that could exhaust the deformation capability of materials brittle due to irradiation. The stress adder Q is only used in the low temperature design criteria of ASME Boiler \& Pressure Vessel Code, Section III, Division 1, Article 3000. The time-dependent stress intensity limit $\mathrm{S}_{\mathrm{mt}}$ can only be applied in simplified analysis where stress and temperature do not change or when a worst combination of time temperature and stress is not overly conservative.

Basis: Table XXVIII, Paragraphs a; NRC Standard Review Plan II, A-1-a; ASME Boiler \& Pressure Vessel Code, Section III, Article III-2000, III-2100; and ASME Boiler and Pressure Vessel Code, Section III, Division 1, Article NH-3000

Implementation: The time-independent design stresses are derived from $\mathrm{S}_{\mathrm{y}}, \mathrm{S}_{\mathrm{ult}}$,, and $\mathrm{S}_{\mathrm{rupture}}$ as a function of temperature for the selected material. As an example, Figure 68 below shows the MA956 rupture stress curves derived from a Larson-Miller plot, see Figure 3 in Harper [2002], see also Wright [2000]. 

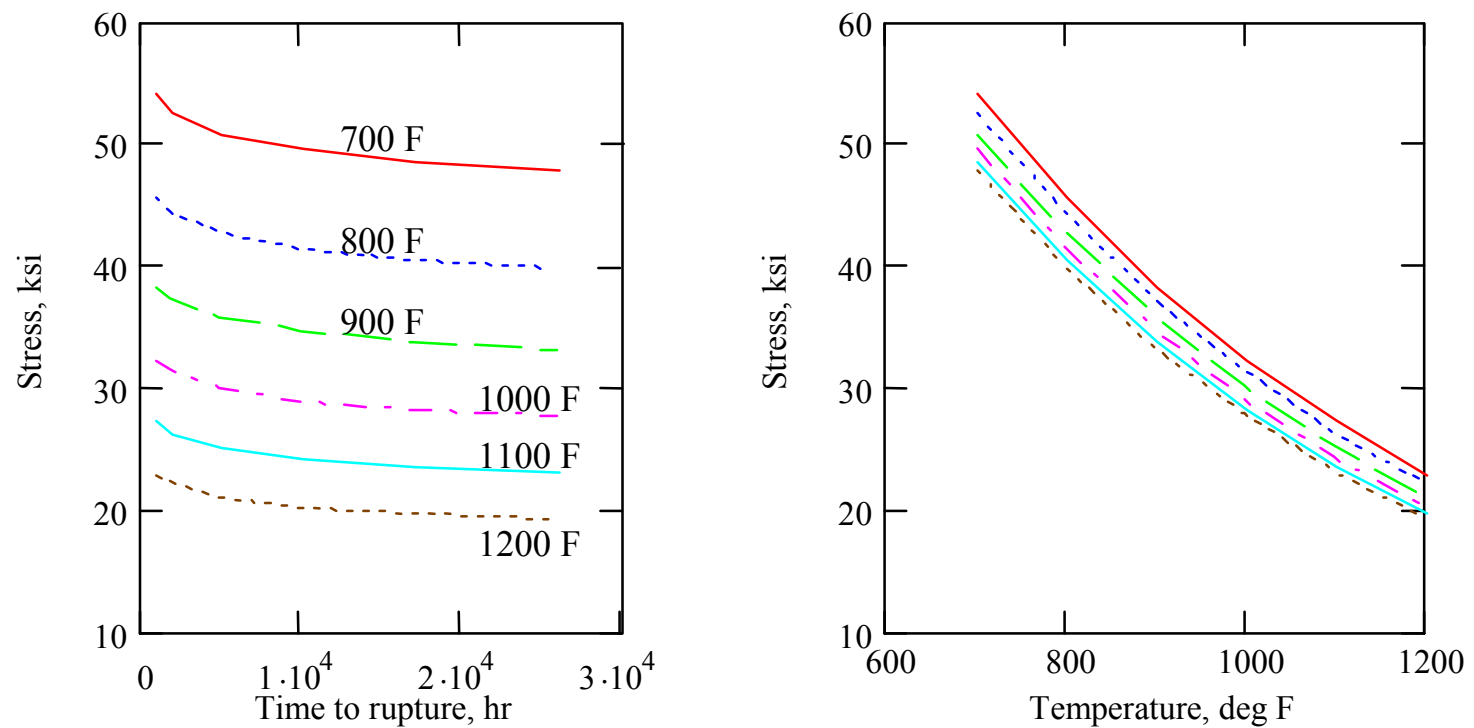

Figure 68. Stress rupture of MA956 as a function of rupture time with temperature as parameter and as a function of temperature with rupture time $(1000 \mathrm{hr}$ to $26000 \mathrm{hr})$ as parameter.

Figure 69 compares the stress rupture strength of MA956 with that of MA957 as reported by PNNL [2000]. The FRAPCON code calculates the cladding stresses in the hoop and axial direction during steady state and quasi- transient spikes. The cladding stress intensity is determined by combining stresses. In practice the cladding is primarily under hoop stress. The margin between the cladding stress and the stress limit is determined for each time step. The secondary stresses are added during transients to determine if the stress criterion is met. In addition, the tensile permanent deformations are accumulated during each time step and compared with the permanent strain deformation limit, $1 \%$ as a design value, see strain limit below.

Figure 70 below shows the creep rupture strength for MA956 in two directions, in longitudinal and circumferential direction. The lower, circumferential creep strength

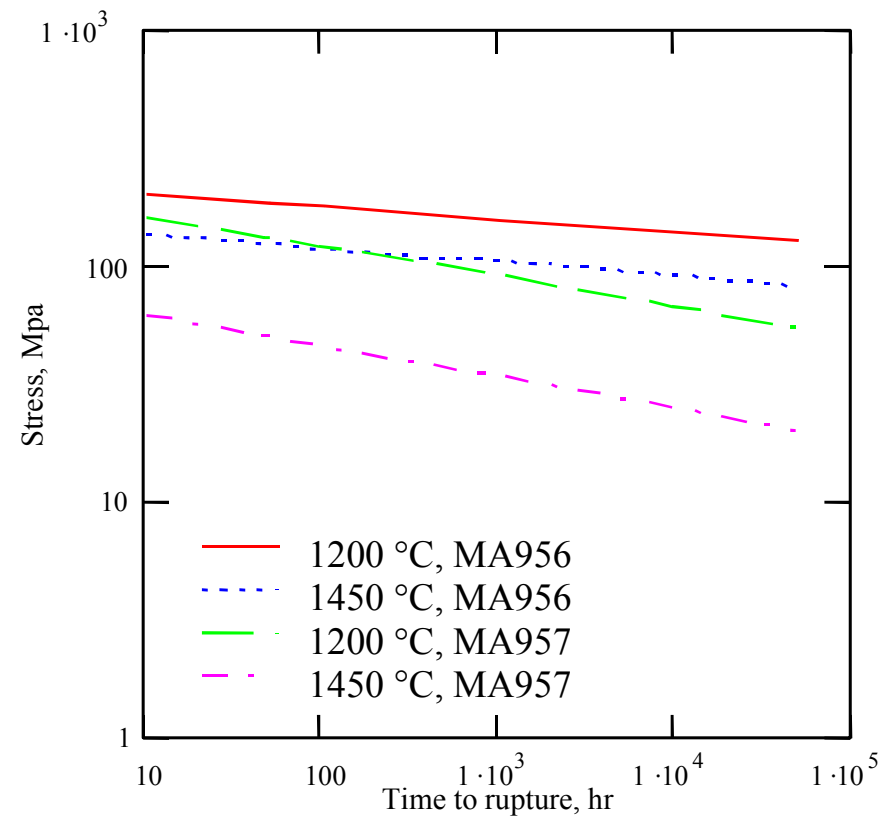

Figure 69. Comparison of stress rupture of MA956 (direction not known) and MA957 in hoop direction. would be limiting for fuel rods. At the present time, the drawn tubing has only approximately $1 / 4$ to $1 / 10$ the strength in the circumferential direction as in the longitudinal direction. The cause is apparently the orientation of the $\mathrm{Y}_{2} \mathrm{O}_{3}$ strengthened grains. Efforts are under way to improve the homogeneity of the material. 


\subsubsection{Cladding Strain Criterion (Steady State and Transient)}

The total plastic uniform strain from beginning of life, including permanent thermal and irradiation tensile creep and plastic strain due to pellet cladding interaction (PCI) shall not exceed:

$1 \%$ membrane strain

$2 \%$ bending strain

$5 \%$ local strain

The intent of this requirement is to limit cladding damage due to slow rate strain accumulation at which the stress does not reach the stress limit (yield stress). The cladding loading mechanism is the rod internal differential pressure and cladding straining caused by the pellet expansion and PCI. A bending strain and local strain are not calculated by FRAPCON and the limit is not applied at this time.

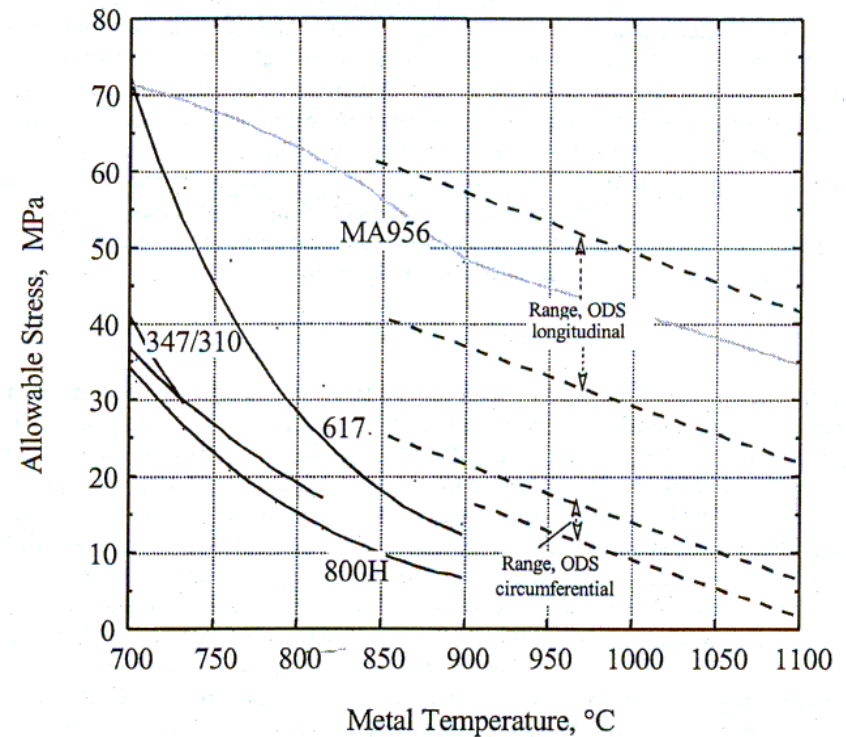

Figure 70. Allowable stresses for ASME Code high temperature alloys based on $2 / 310000 \mathrm{hr}$ creep rupture strength (from Figure 1 in Harber. 2002).

This requirement assumes that the cladding retains more than approximately 3 to $5 \%$ ductility during irradiation at a slow strain rate. Austenitic steels and Zirconium alloys lose ductility during irradiation and embrittle due to different mechanisms. Some ferritic steels, such as HT-9 and oxide dispersion strengthened steels, retain their ductility to higher irradiation doses. Test data of the selected cladding material will be required to support the selected strain limit.

Basis: Table XXVIII, Paragraph a, and NRC Standard Review Plan II, A-1-a, and ASME Boiler and Pressure Vessel Code Section III Article NH-3000, pg.25.

Implementation: Fuel performance calculations with FRAPCON yield the elastic, plastic, thermal, and irradiation induced creep strains. The main strain component is the membrane strain. The contribution of the (primarily circumferential) permanent strain, induced by temperature gradients, can probably be shown to be small on a generic basis.

\subsubsection{Fuel Temperature Criterion}

Requirement: During Condition I and Condition II events the peak fuel rod power shall not exceed a value that will cause the $\mathrm{UO}_{2}$ to melt with a $95 \% / 95 \%$ probability and confidence level. The unirradiated fuel melting temperature is $2805{ }^{\circ} \mathrm{C}$. The $\mathrm{UO}_{2}$ melting temperature decreases by $58{ }^{\circ} \mathrm{C}$ for every 10000 $\mathrm{MWd} / \mathrm{MTU}$ burnup. The $\mathrm{UO}_{2}$ melting temperature in rods with Gadolinia mixed into the fuel is reduced by $3.75{ }^{\circ} \mathrm{C}$ for each $\mathrm{w} / \%$ of Gadolinia oxide.

For preliminary design purposes of high burnup fuel it is prudent to limit the maximum fuel temperature to approximately $2600{ }^{\circ} \mathrm{C}$ unless the evaluation includes uncertainties.

Basis: Table XXVIII Paragraph e; NRC Standard Review Plan II, A-2-e; and 10CFR Part 50, Appendix A, Criterion 10. 
Implementation: Fuel performance calculations with FRAPCON yield the steady state and transient temperatures. Appropriate hotspot-factors must be applied.

\subsubsection{Cladding Fatigue Criterion}

The cumulative number of strain cycles shall be less than the design fatigue lifetime, with a safety factor of 2 on stress amplitude and a safety factor of 20 on the number of cycles. The damage caused by fatigue cycles with varying amplitude and frequency can be determined by different methods. The method that is generally accepted for calculation of the cumulative life fraction is:

$$
\begin{aligned}
& \mathrm{N}_{\mathrm{k}} \text { = number of cycles of type } \mathrm{k} \\
& \mathrm{N}_{\mathrm{k} \_\mathrm{al}}=\text { number of allowable cycles of type } \mathrm{k} \\
& \mathrm{m}=\text { number of cycle types (frequency, amplitude) } \\
& \text { Life Fraction }=\sum_{\mathrm{k}=1}^{\mathrm{m}} \frac{\mathrm{N}_{\mathrm{k}}}{\mathrm{N}_{\mathrm{k} \_\mathrm{al}}}<1
\end{aligned}
$$

The fatigue damage is part of the total material damage caused by cyclic deformation, independent of time effects. At high temperatures where creep causes damage and increases the fatigue damage of a cycle with a hold time, the combined effect of creep and fatigue on the total creep-fatigue damage accumulation must be considered. The ASME Boiler and Pressure Vessel Code, Article NH-3000 and non-mandatory Appendices, T-1400 provides guidance for the accumulation of fatigue and creep damage. The ASME Boiler and Pressure Vessel Code Section III Article NH-3000, Appendix T, T-1400 established rules for evaluating the accumulated creep-fatigue damage has the form:

$$
\begin{aligned}
& \mathrm{D}=\sum_{\mathrm{k}=1}^{\mathrm{m}} \frac{\mathrm{N}_{\mathrm{k}}}{\mathrm{N}_{\mathrm{k} \_\mathrm{al}}}+\sum_{1=1}^{\mathrm{q}}\left(\frac{\Delta \mathrm{t}_{1}}{\mathrm{~T}_{\mathrm{D} \_\mathrm{al}}}\right)<1 \\
& \mathrm{~N}_{\mathrm{k}}=\text { number of cycles of type } \mathrm{k} \\
& \mathrm{N}_{\mathrm{k} \_\mathrm{al}}=\text { number of allowable cycles of type } \mathrm{k} \\
& \mathrm{m}=\text { number of cycle types (frequency, amplitude) } \\
& \Delta \mathrm{t}_{1}=\text { duration of hold time at stress } 1 \\
& \mathrm{~T}_{\mathrm{D} \_\mathrm{al}}=\text { allowable duration at stress } 1 \text { (rupture time, see Figures } 68 \text { and } 69 \text { above) } \\
& \mathrm{q}=\text { number hold times (at stress } 1) \\
& \mathrm{D}=\text { creep-fatigue damage, see ASME Boiler and Pressure Vessel Code Section III Article } \mathrm{NH}- \\
& 3000 \text {, Appendix T, Figure T-1420-2 }
\end{aligned}
$$

Note: Simplified methods to evaluate the fatigue damage are appropriate for concept design or for no load-follow service and are described in the ASME Boiler and Pressure Vessel Code.

Basis: Table XXVIII, Paragraph b; NRC Standard Review Plan II, A-1-b; and ASME Boiler and Pressure Vessel Code Section III Article NH-3000.

Implementation: The frequency of the power and fatigue cycles are typically specified in the design specification and procedure, for example three power spikes per cycle plus the startup and shutdown. Cladding stress and strain are obtained from the fuel performance calculation. The allowable number of fatigue cycles at the strain range and the creep to rupture curve are obtained from the material data. Separate evaluations are required to determine the fatigue or creep-fatigue damage. 
Cladding fatigue should not be limiting unless a load follow program is implemented and the creep to rupture time is marginal.

\subsubsection{Cladding Collapse Criterion}

The fuel cladding shall be free standing (that is, not supported by the fuel) at beginning of life operation until the fuel has densified during hot hydrostatic testing. This requirement allows the fuel column to shrink due to densification without opening of gaps between pellets. The cladding can creep down on the fuel and reduce the fuel-cladding gap after the fuel densification, which is desirable to reduce the fuel center temperature. Also, the cladding shall not collapse in the gas plenum region, where the cladding is not supported by the fuel. A spring or a similar device must support the cladding. If the fuel shrinks and gaps open in the fuel column, the cladding in the maximum postulated unsupported length shall not collapse into the gap.

The collapse evaluation may need to consider, in addition to elastic deformation and tube ovality, the plastic, thermal, and irradiation creep deformation of the material.

Basis: Table XXVIII, Paragraph b and NRC Standard Review Plan II, A-2-b.

Implementation: Formulas and procedures for estimating the elastic-plastic-creep collapse of tubes are available in the literature. The required material data include stress-strain curves and relevant thermal and irradiation creep information.

The high external system pressure in the SCWR will require support of the cladding by internal back-fill pressure to reduce the pressure differential on the cladding. The clad collapse evaluation will determine the required back-fill pressure.

\subsubsection{Fuel Rod Length Change Criterion}

The fuel rod length changes due to irradiation effects and differential thermal expansion shall not result in interference with the fuel assembly structure. The differential growth between the fuel rod and the assembly structure length changes need to be considered. The fuel rod axial expansion is controlled by the difference between the axial thermal expansion and creep growth (swelling is assumed to be negligible in the thermal flux of the SCWR) of the cladding and the expansion of the fuel assembly structure.

Basis: Table XXVIII, Paragraph e and NRC Standard Review Plan II, A-1-e.

Implementation: From the fuel cladding expansion, thermal swelling, and creep the total length change of the cladding can be estimated with the axial temperature and axial growth profile as input. Similar calculations are required to estimate the growth of the assembly structure. The differential between both must show a gap between the rod length and the assembly structure.

This evaluation is a critical design input because it determines the assembly length.

\subsubsection{End Plug Weld Stress Criterion}

The fuel rod end-plug weld shall maintain integrity during Condition I and II operation. During Condition III and IV events the cladding and the weld are assumed to fail. However, the end-cap failure 
should not result in failure propagation (separation of the end-cap and projection of a missile, for example.

Evaluation of the end-cap weld must include the maximum pressure differences between rod internal pressure and system pressure, including system depressurization. Evaluation of the end-cap weld with standard weld stress procedures is sufficient. Weld burst tests will eventually assure that the limting design pressures have sufficient margin against burst.

Basis: Included in Table XXVIII, Paragraph a and f and NRC Standard Review Plan II, A-1-a \& f.

\subsubsection{Corrosion Criterion}

Cladding corrosion reduces the effective thickness of the cladding and decreases the effective thermal conductivity of the cladding and thus increases the cladding and fuel temperatures. The corrosion rate of the cladding in a supercritical steam environment and under irradiation needs to be determined experimentally. The progress to date on that work is reported in Section 4 of this report.

Basis: Table XXVIII, Paragraph d; and NRC Standard Review Plan II, A-1-d.

Implementation: The strength of the cladding reduces proportionally with the growth of the corrosion layer and decrease of the effective cladding thickness.

\subsubsection{Required Design Data}

This section focuses on the oxide dispersion strengthened MA956 steel performance characteristics. A significant amount of effort has been devoted to determining the properties and understanding the behavior of a similar alloy, MA957, to define its potential usefulness as a cladding material, in the fast breeder reactor program. The results of that work have been summarized by Hamilton et al. [2000] as follows:

"The alloy is a ferritic stainless steel developed by International Nickel Company specifically for structural reactor applications. It is strengthened by a very fine, uniformly distributed yttria dispersoid. Its fabrication involves a mechanical alloying process and subsequent extrusion, which ultimately results in a highly elongated grain structure. While the presence of the dispersoid produces a material with excellent strength, the body centered cubic structure inherent to the material coupled with the high aspect ratio that results from processing operations produces some difficulties with ductility. The alloy is very sensitive to variations in a number of processing parameters, and if the high strength is once lost during fabrication, it cannot be recovered. The microstructural evolution of the alloy under irradiation falls into two regimes. Below about $550{ }^{\circ} \mathrm{C}$, dislocation development, $\alpha$ precipitation, and void evolution in the matrix are observed, while above about $550{ }^{\circ} \mathrm{C}$ damage appears to be restricted to cavity formation within oxide particles."

"The thermal expansion of the alloy is very similar to that of HT9 up to the temperature where HT9 undergoes a phase transition to austenitic. Pulse magnetic welding of end caps onto MA957 tubing can be accomplished in a manner similar to that in which it is performed on HT9, although the welding parameters appear to be very sensitive to variations in the tubing that result from small changes in fabrication conditions." 
"The tensile and stress rupture behavior of the alloy are acceptable in the unirradiated condition, being comparable to HT9 below about $700{ }^{\circ} \mathrm{C}$ and exceeding those of HT9 at higher temperatures. Neither tensile nor rupture strength appear to be degraded by irradiation to fast fluences on the order of $8 \times 10^{22} \mathrm{n} / \mathrm{cm}^{2}$ in the range of $370-760{ }^{\circ} \mathrm{C}$, although some loss of ductility has been observed. The impact resistance of the alloy is very poor in the unirradiated condition, and is significantly degraded by irradiation."

MA957 has inferior high temperature strength compared to MA956, but use of these data would be conservative and adequate to demonstrate the MA956 performance in absence of more detailed MA956 data. Also, the properties of thin walled tubing, primarily in the hoop direction, are needed because the fabricated ODS tubing is up to ten times stronger in the axial direction than in hoop direction. The published data for ODS, in particular MA956, bar and sheet give no indication how to relate the data to clad tubing strength in hoop direction. The reason for the strong orthropic properties of the iron base ODS material is the alignment of the yttrium oxide particles in the extrusion direction, see Bhadeshia [2000], pp. 15-28.

\subsubsection{Physical Properties}

They are:

- Melting point

- Thermal expansion, see Figure 71

- Thermal conductivity

- Modulus of elasticity

- Poisson's ratio

Data for these properties are available in the Aerospace Structural Metals Handbook and industry pamphlets.

\subsubsection{Stress and Strain}

The materials under consideration have much higher strength than austenitic steels and ferritic HT-9 in the un-irradiated and irradiated condition. The cladding retains sufficient ductility as fuel cladding material. However, the effect of irradiation on stress and strain needs to be considered in conceptual studies. The yield and ultimate strength after significant irradiation typically increase, the ductility, total and uniform elongation decrease.

Figure 72 shows the tensile properties of annealed MA956. The material retains adequate ductility $(\sim 10$ $\%$ ) below $540{ }^{\circ} \mathrm{C}\left(1000{ }^{0} \mathrm{~F}\right)$. However, the stress-

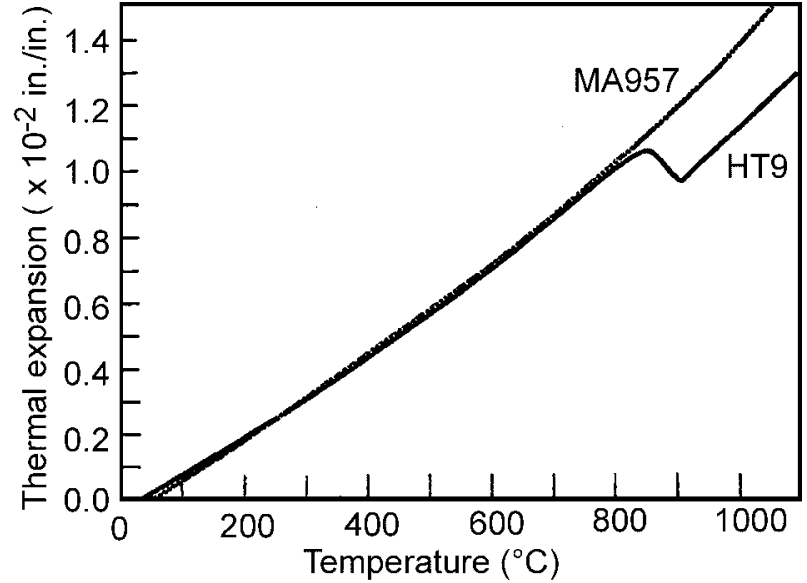

Figure 71, Comparison between MA957 and HT-9 thermal expansion [Hamilton et al. 2000].

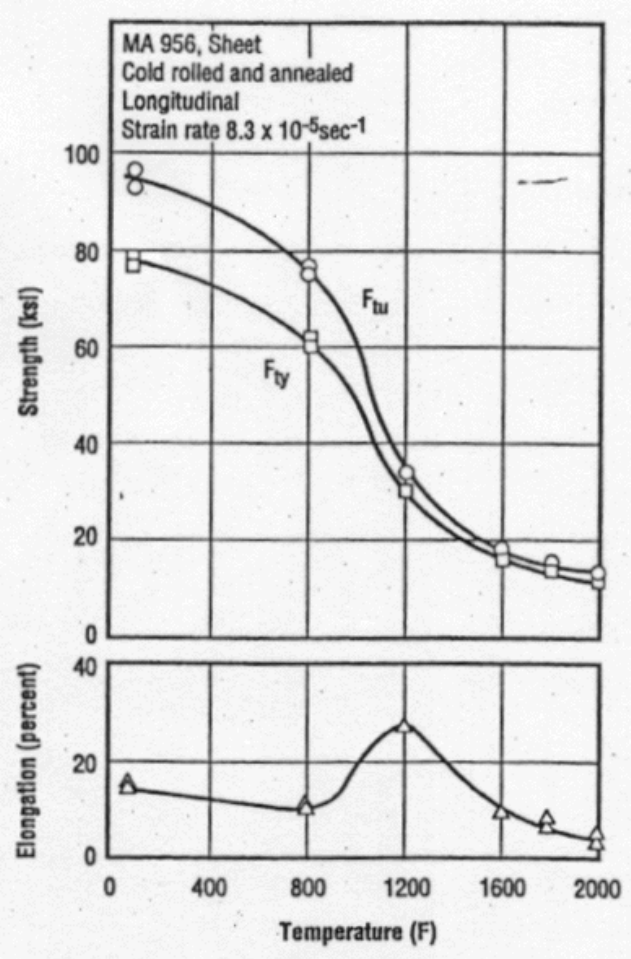

Figure 72. Effects of temperature on tensile properties of annealed MA956 sheet [Aerospace Structural Metals Handbook]. 
strain curves for MA956, shown in the Aerospace Structural Metals Handbook, indicate little hardening of the material after it reaches its yield strength. The abrupt transition from elastic deformation to plastic flow, with severe necking, is indicated by the small difference between the yield and ultimate strength. This also indicates that MA956 may have poor impact resistance, which Hamilton et al. [2000] observed in MA957.

Figure 73 shows a yield strength comparison of MA957 with other materials. The figure shows the superiority of this ODS material when compared with Type 316SS, HT-9 and another ODS alloy DT3503Y005. Above $500{ }^{\circ} \mathrm{C}$ the yield strength of that material decreases rapidly. Figure 73, which presents data for MA957, is included primarily for comparison with the next Figures 74 and 75 , which show:

- Below $500{ }^{0} \mathrm{C}$ the irradiated material is stronger than the un-irradiated material.

- The ductility in the $200{ }^{\circ} \mathrm{C}$ to $500{ }^{\circ} \mathrm{C}$ range reduces to $\sim 2 \%$ total elongation after irradiation in a fast reactor. This is a marginal residual ductility for fuel design. Hopefully MA956 will not exhibit this behavior in a thermal irradiation environment.

\subsubsection{Thermal and Irradiation Induced Creep}

At SCWR operating temperatures the thermal creep component should be small and is generally considered as part of the irradiation induced creep.

MA956 irradiation induced creep has not been characterized in a reactor core environment. Hamilton et al. [2000] report some in reactor creep data for MA957 obtained in the fast reactor environment of FFTF, which are compared to other in reactor creep data, including data for HT9. MA957 has superior creep resistance compared to HT-9 and other ferritic materials at ${ }^{\prime} 400{ }^{\circ} \mathrm{C}$ and $\sim 600{ }^{\circ} \mathrm{C}$. A creep correlation correlating the data is not available.

Hamilton et al. [2000] conclude that the in-reactor creep response of MA957 tubing is comparable to other ferritic alloys in the temperature range 385 ${ }^{0} \mathrm{C}$ to $620{ }^{0} \mathrm{C}$ and is only superior to other ferritic

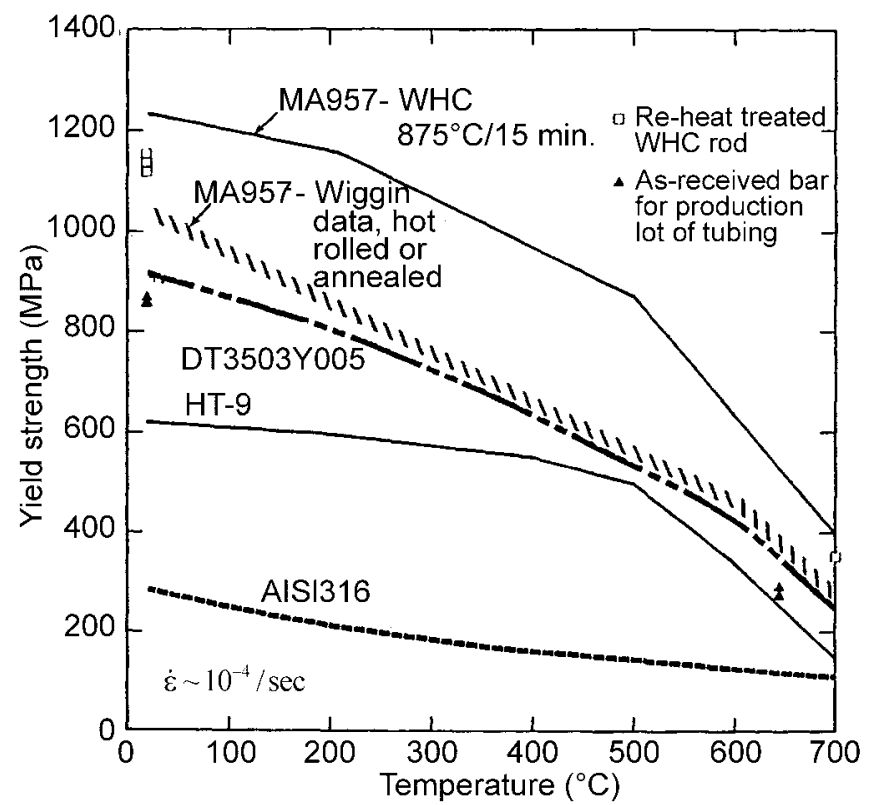

Figure 73. MA957 yield strength comparison [Hamilton et al. 2000].

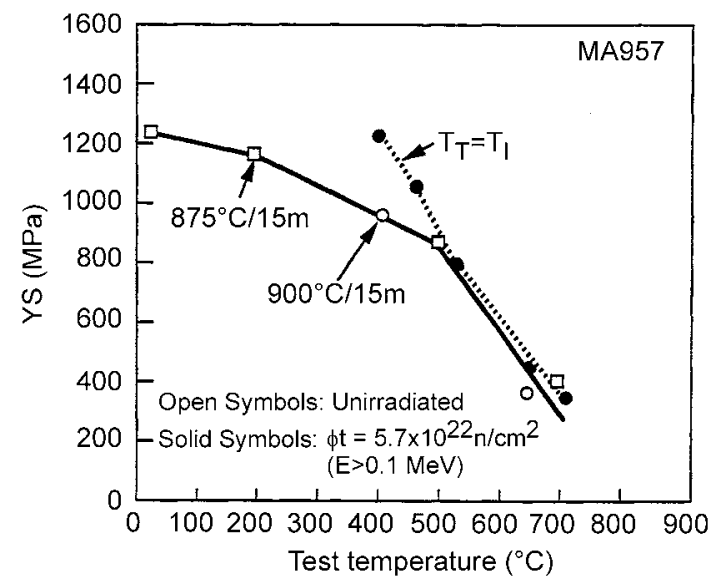

Figure 74. MA957 Irradiated and un-irradiated yield strength [Hamilton et al. 2000].

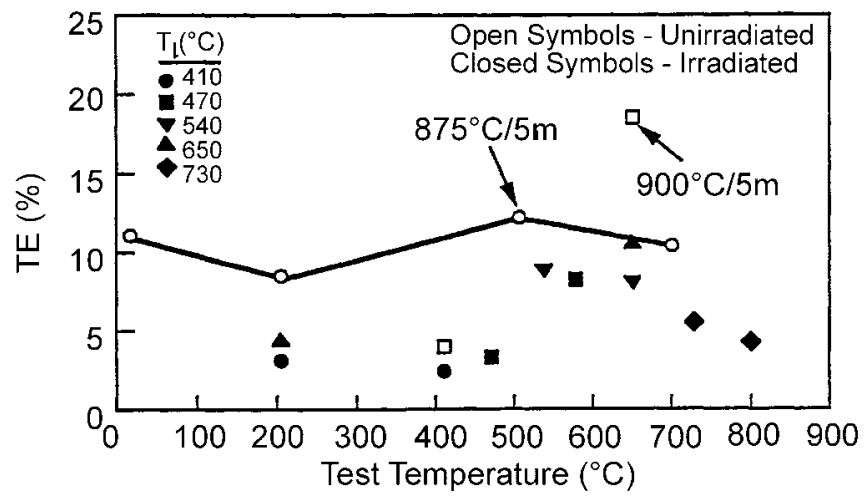

Figure 75. Total elongation of irradiated and unirradiated MA957 [Hamilton et al. 2000]. 
alloys at $670{ }^{\circ} \mathrm{C}$ and $760{ }^{\circ} \mathrm{C}$. The effective creep strain includes a primary creep and a secondary creep component.

If these conclusions are applied to MA956, which is stronger than MA957, then one might expect the following behavior:

- $\quad$ The in-reactor creep strains are equivalent or lower than those of MA957 and other ferritic alloys at temperatures below $620{ }^{\circ} \mathrm{C}$,

- The in-reactor creep strains are even lower than the MA957 creep strains at $670{ }^{\circ} \mathrm{C}$ and $760{ }^{\circ} \mathrm{C}$.

Most of the correlations for irradiation-induced creep of steel were determined from data obtained from fast flux environments. Later it was found that, relative to the creep rate in fast flux reactors, the stainless steel creep rate in thermal flux reactors rate increased by more than a factor of two (for the same fast flux dose), see Strasser et al. [1982]. The relation between the irradiation creep behavior of ferritic type materials in fast flux reactors relative to their irradiation creep behavior in thermal flux reactors is uncertain.

A design correlation for irradiation-induced creep, which includes thermal creep, is needed to predict cladding deformation, which can accommodate swelling of high burnup fuel.

\subsubsection{Irradiation Induced Cladding Swelling}

Irradiated stainless steel volume swelling has been observed in cladding and structural materials of fast reactors [Materials Science and Technology 1994 and Bailly et al. 1996 and 1999]. However, stainless steel swelling has not been observed in LWR environments. More recently, F. Garner has postulated the potential for irradiation-induced volume swelling of steel at a low LWR flux [Materials Science And Technology 1994]. Ferritic steels, such as HT-9, exhibit little or delayed swelling even in fast reactors. Cladding swelling probably does not need to be considered in SCWR core evaluations, but the cladding irradiation dose should be checked.

The fast fluence on the cladding depends on the rod power, the rod diameter, and the rod lattice spacing. Calculations will be completed during Year 3 of this NERI project to determine the peak displacements per atom (dpa) for the SCWR fuel cladding and structural materials.

\subsubsection{Cladding Creep Rupture}

Rupture of the cladding due to fuel rod internal fission gas pressure (exceeding the system pressure) or strains generated by fuel swelling and fuel-cladding mechanical interaction is a complex process. One has to distinguish between:

- Failures due to slow rate stress and strain accumulation during steady state operation.

- Failures due to stresses and strains generated during overpower transients or power changes.

- Failures due to transient events with high fuel and cladding temperatures.

For conceptual design studies the first priority is to find a cladding material, which can sustain the steady state operating conditions. This requires that the operating conditions and the load history of the cladding are sufficiently defined to determine the interaction between fuel and cladding and estimate the required cladding ductility. 
The longitudinal and circumferential creep rupture strength of MA956 is shown in Figure 76. The 1/3 lower rupture strength of that material in hoop direction is obvious. However, the fracture strain of the candidate materials appears to be more than $1 \%$ at PWR conditions.

Stress rupture strength and low cladding ductility are probably the performance limiting cladding failure modes. They are affected by environmental effects, which induce cracks at relatively low stresses and reduced ductility.

\subsubsection{Stress Corrosion Induced and Irradiation Assisted Stress Corrosion Cracking}

Over the last twenty-five years the issue of intergranular stress corrosion cracking (IGSCC) in reactor structures particularly in sensitized areas and in welds, has been investigated and discussed in groups such as the International Cooperative Group on Irradiated Assisted Stress Corrosion Cracking, ICGIASCC. Prior to 1980, it was found that the known IGSCC process that can cause failure well below the normal tensile strength can be enhanced by irradiation, a process which is called irradiation

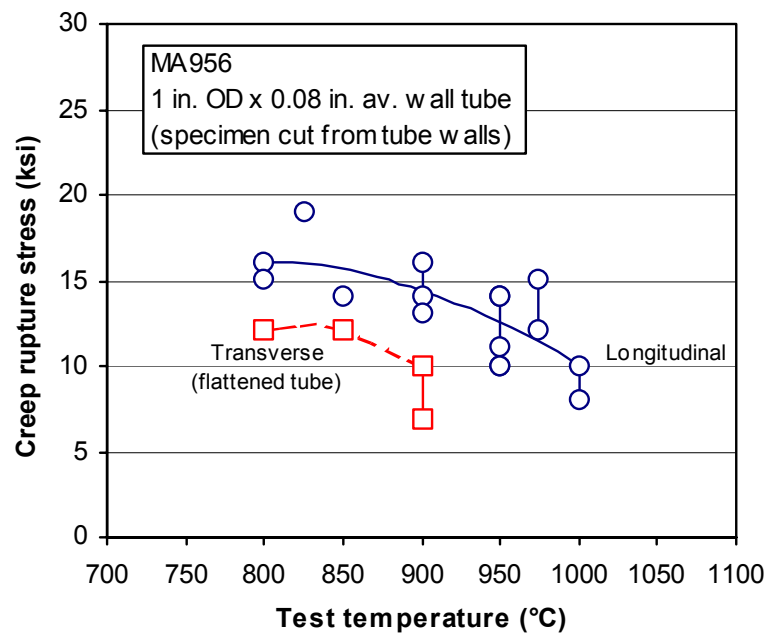

Figure 76. Comparison of Alloy MA956 tubing longitudinal versus circumferential creep rupture data [Aerospace Structural Metals Handbook].

assisted stress corrosion cracking, IASCC. Garzarolli and others performed tests to show the effect of fluence and PWR and BWR water chemistry on stainless steel IASCC. The results of low strain rate tests on tubing showed that the austenitic stainless steel and nickel-based alloys failed at strains between 0.2 and $1 \%$ strain, with the exception of a Type 348 composition steel which failed at $1.4 \%$ strain.

IGSCC and IASCC require attention in the material selection and the design of SCWR fuel rods.

\subsubsection{Cladding Fatigue}

Cladding fatigue is of concern for fuel rods in cores operating in load follow (power cycles) mode. However, for an SCWR operating in a base load mode a fatigue criterion should not be limiting. Low cycle fatigue data and design data are available. However, the degrading effects of irradiation, stress corrosion and embrittlement on fatigue need to be folded into the design curves.

\subsubsection{Cladding Corrosion}

The corrosion resistance of ODS steels in water with SCWR chemistry is not known. Corrosion of MA956 in a gas environment has been tested at very high temperatures, $900{ }^{\circ} \mathrm{C}$ and higher. The tests indicate a high resistance to corrosion product scaling. However, a protective $\mathrm{CrO}_{2}$ film may not form in a water vapor environment, instead the formation of $\mathrm{CrO}_{2}(\mathrm{OH})_{2}$ may remove chrome from the metal surface and degrade the corrosion resistance of the metal [Harper 2002]. There are no corrosion data available from tests of ODS material at SCWR conditions.

The fuel tests in EBRII have shown that the ODS materials used in those tests are compatible with $\mathrm{UO}_{2}$ fuel [Bottcher et al. 2002]. 


\subsubsection{Cladding Collapse}

Conventional cladding collapse (buckling) caused by the external system pressure is a concern for fuel rods operating under $25 \mathrm{Mpa}$ system pressure even with steel cladding. The theoretical fuel buckling, load is $>90 \mathrm{MPa}(>13000 \mathrm{psi}$ ), but cladding ovality reduces this buckling load to a much lower collapse load. It has to be verified that cladding collapse due to a combination of cladding ovalization and creep are not limiting failure modes.

\subsection{Preliminary Calculation of the Thermal Performance and Fission Gas Release of SCWR Fuel Rods (Larry Siefken, INEEL)}

The FRAPCON-3 code [Berna et al. 1997] was used to perform a preliminary calculation of the thermal and fission gas release performance of SCWR fuel rods from beginning of life to end of life (1350 days and rod average burnup of $77.6 \mathrm{MWd} / \mathrm{kgU}$ ). The analysis was performed for the hot rod in the hot channel of the reactor core. The analysis did not take into account fuel shuffling that would place the fuel rod in positions in the reactor core resulting in significantly less fuel rod power during a large fraction of its lifetime. The design of the analyzed fuel rod is summarized in Table XXXI. The fuel rod had a relatively large gas plenum volume to better accommodate released fission gases. The peak linear fuel rod power was $44.5 \mathrm{~kW} / \mathrm{m}$ and occurred at axial node 4 (elevation of $1.49 \mathrm{~m}$ ). The fuel rod power was assumed to remain constant with time. The cladding surface temperatures varied with elevation (axial nodalization) as shown in Figure 77. Axial node 1 was located at the bottom of the fuel rod and axial node 10 at the top of the fuel rod. The axial variation in cladding surface temperatures was calculated by RELAP5 taking into account the variations with respect to elevation of the coolant temperature and convective heat transfer coefficients [Davis 2003]. The cladding surface temperature varied from $632 \mathrm{~K}$ at the bottom of the fuel rod to $1010 \mathrm{~K}$ near the top of the fuel rod.

Table XXXI. Characteristics of analyzed fuel rod.

\begin{tabular}{|l|l|}
\hline Characteristic & Value \\
\hline \hline Fuel composition & $\mathrm{UO}_{2}$ \\
\hline Fuel density (fraction of theoretical density) & 0.95 \\
\hline Fuel pellet diameter $(\mathrm{mm})$ & 8.78 \\
\hline Height of fuel stack $(\mathrm{m})$ & 4.27 \\
\hline Cladding composition & Alloy MA956 \\
\hline Cladding OD (mm) & 10.2 \\
\hline Cladding thickness (mm) & 0.63 \\
\hline Length of gas plenum (m) & 0.78 \\
\hline Fill gas pressure at room temperature (MPa) & 6.0 \\
\hline Peak fuel rod power (kW/m) & 46.8 \\
\hline Elevation of peak fuel rod power $(\mathrm{m})$ & 1.07 \\
\hline
\end{tabular}


The relatively high cladding surface temperatures resulted in relatively high fuel temperatures and in a large fraction of fission product release. At both beginning of life and end of life, the peak centerline temperature occurred at axial Node 6 (linear power of $42.1 \mathrm{~kW} / \mathrm{m}$, cladding surface temperature of $939 \mathrm{~K}$ and elevation of 1.92 $\mathrm{m})$. The fuel centerline temperatures at this location at the beginning of life and end of life were $2208 \mathrm{~K}$ and $2311 \mathrm{~K}$, respectively.

The fuel centerline temperatures at each axial node as a function of time are shown in Figure 78. A large fraction of fission gas release was calculated to occur due to the relatively high fuel temperatures. After 250 days and a burnup of $14.4 \mathrm{MWd} / \mathrm{kgU}$, the fission gas release was calculated to be $20 \%$ of the inventory of produced fission gases.

The released fission gases increased the pressure of the gases inside the fuel rod. The history of the internal gas pressure is shown in Figure 79. At the time of 750 days and a rod average burnup of 43.1 $\mathrm{MWd} / \mathrm{kgU}$, the internal gas pressure was calculated to exceed the coolant pressure of $25 \mathrm{MPa}$.

In summary, the relatively high coolant temperatures in a SCWR result in a relatively large amount of fission gas release. The design of SCWR fuel rods and the power history imposed on the fuel rods need to take into account the effect of higher coolant temperatures on fission gas release.

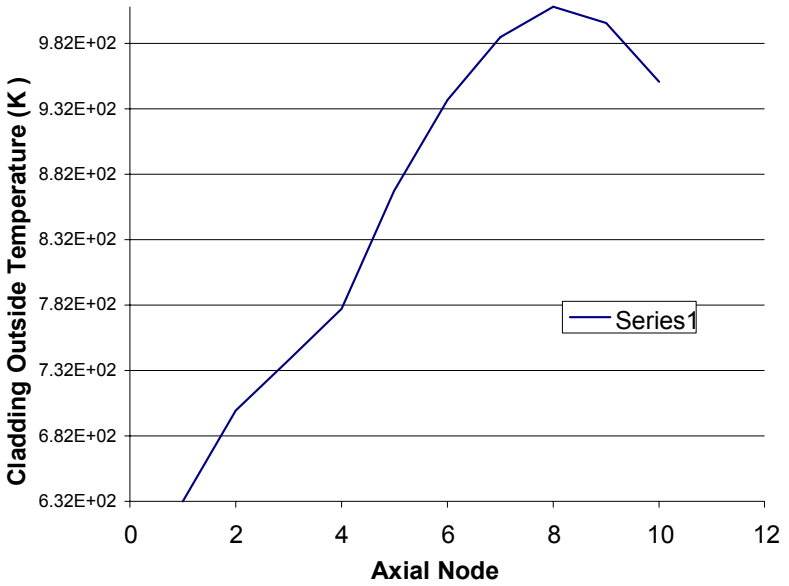

Figure 77. Cladding surface temperature as function of elevation.

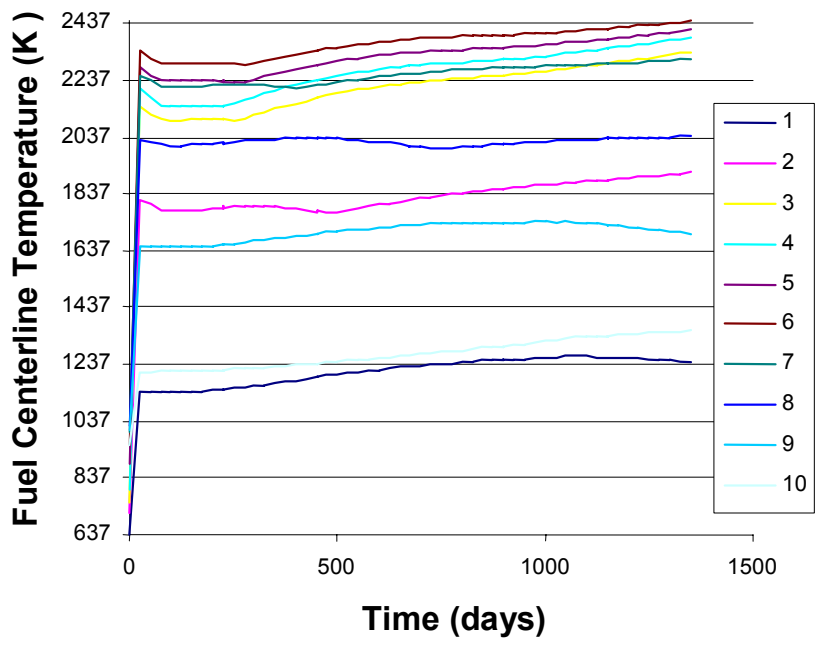

Figure 78. Fuel centerline temperatures at each axial node as function of time.

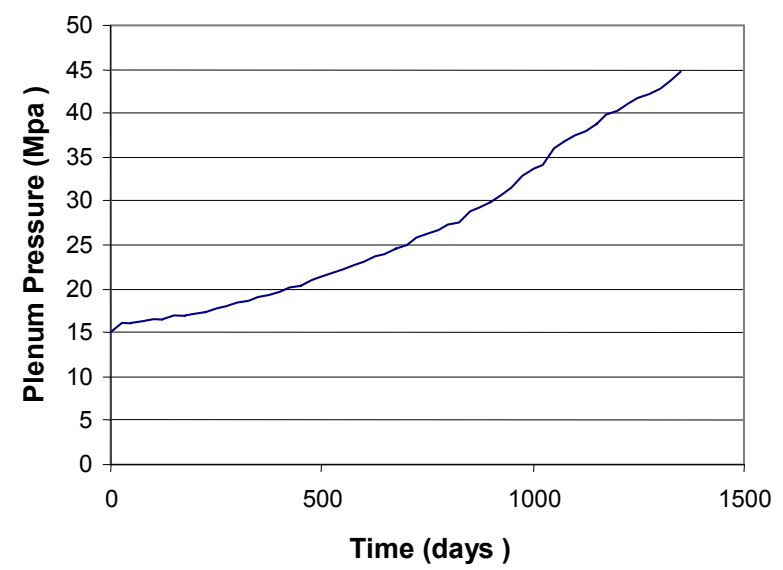

Figure 79. Fuel rod plenum pressure as a function of time in days. 


\subsection{Transient Thermal-Hydraulic Analyses of the SCWR (Cliff Davis, INEEL)}

As mentioned in Section 3, the RELAP5 computer code (INEEL 2002) was used for the thermalhydraulic analysis of several supercritical water reactor (SCWR) designs. The first design utilized solid moderator rods containing zirconium hydride. The neutronic and mechanical design of this reactor concept was discussed in detail in the $3^{\text {rd }}$ Quarterly and $1^{\text {st }}$ Annual Report for this project [MacDonald et al. 2002a and 2002b] and in papers presented at ICONE 11 [Buongiorno and MacDonald 2003a and 2003b]. The second design utilized square fuel bundles with downward flow of water through water rods to achieve neutron moderation. This design is the reference Generation IV design described in Section 2 of this report, although with lower power. The third design used hexagonal power channels with downward flow of water between the channels to achieve neutron moderation and is described in Section 3.2 above.

The purpose of these analyses was to perform simple parametric calculations to characterize the transient response of the reactor so that the time available for various safety systems to respond and capacity requirements could be determined. The transients analyzed included loss of feedwater, turbine trip, reactivity insertion, and a step change in feedwater temperature. The time available for the safety systems to respond was determined by comparing the calculated maximum fuel rod cladding temperature during the transient with a preliminary temperature limit of $840{ }^{\circ} \mathrm{C}$. In addition, loss-of-coolant accidents (LOCAs) were simulated for designs using water rods and power channels. The temperature limit applied for the LOCAs was $1204{ }^{\circ} \mathrm{C}$, which corresponds to the accident limit for current LWRs with Zircaloy cladding.

\subsubsection{Reactor with Solid Moderator Rods}

\subsubsection{Loss of Feedwater}

Calculations were performed to investigate the effects of various parameters on the peak cladding temperature during a loss-of-feedwater transient. This transient is of particular importance to the SCWR because the SCWR is a once-through flow system without recirculation. Loss of feedwater in the SCWR corresponds to a loss-of-flow event in current LWRs and has the potential for rapid overheating. The parameters investigated include the main feedwater (MFW) coast down time, occurrence of scram, auxiliary feedwater (AFW) flow rate, steam relief, step changes in MFW flow rate, and reactivity feedback coefficient. The calculations used the RELAP5 model illustrated in Figure 24 in Section 3.2, the Bishop forced convection heat transfer correlation (Equation A2 in Appendix A), and the heated wall effect on the friction factor shown in Equation A14. The heat transfer coefficient was calculated as the maximum of the values from the forced convection, natural convection, and laminar correlations.

Calculations were performed to investigate the effect of MFW coast down, with the coast down time ranging from 0 to $10 \mathrm{~s}$, during a

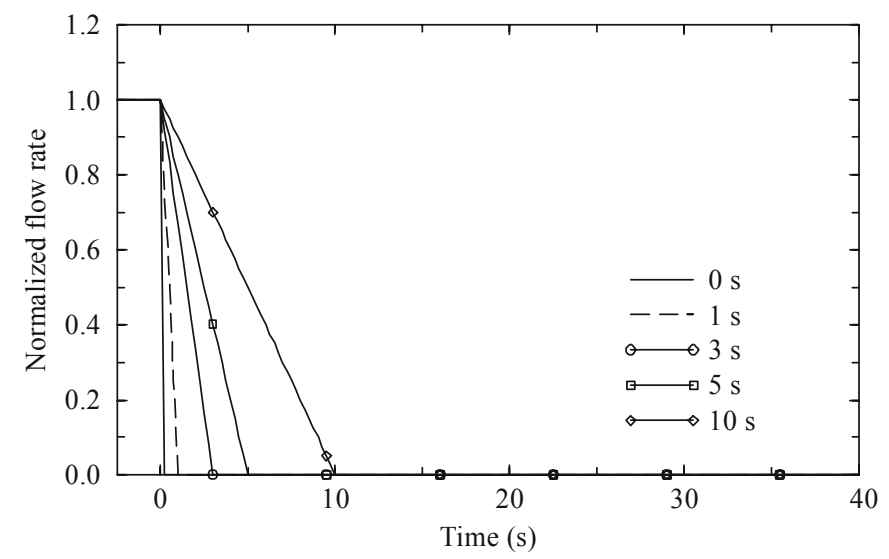

Figure 80. Normalized feedwater flow rates. 
total loss of flow. The normalized feedwater flow rates are shown in Figure 80. In each case, a linear flow coast down was assumed beginning at $0 \mathrm{~s}$. The point kinetics model was used to calculate reactivity feedback, but no scram was assumed. The reactor pressure was assumed to remain constant due to the operation of turbine bypass valves.

The effect of the flow coast down on the maximum cladding temperature is shown in Figure 81. The effect of additional MFW flow was to slow the increase in cladding temperature. Each additional second of full feedwater flow (for example, the 5-s coast down represents 2.5 full flow seconds) caused the peak cladding temperature to reach the $840{ }^{\circ} \mathrm{C}$ transient limit about one second later. In other words, the scram system does not have to respond as quickly if the coast down time can be extended.

Ishiwatari et al. [2002] assumed a 5-s coast down for the analysis of the Japanese SCWR. A 5-s value was also assumed in the Safety Analysis Report (Middle South Utilities) for the Grand Gulf BWR. Therefore, subsequent calculations were performed with a 5-s coast down. The maximum cladding temperature reached $840{ }^{\circ} \mathrm{C}$ at $4.8 \mathrm{~s}$ with a 5-s coast down.

The effect of scram on the peak cladding temperature is illustrated in Figure 82. The scram signal was assumed to be generated at $0.5 \mathrm{~s}$, corresponding to a $10 \%$ reduction in flow. The control rods began moving $0.8 \mathrm{~s}$ later, and were fully inserted $2.5 \mathrm{~s}$ later. The maximum cladding temperature exceeded the

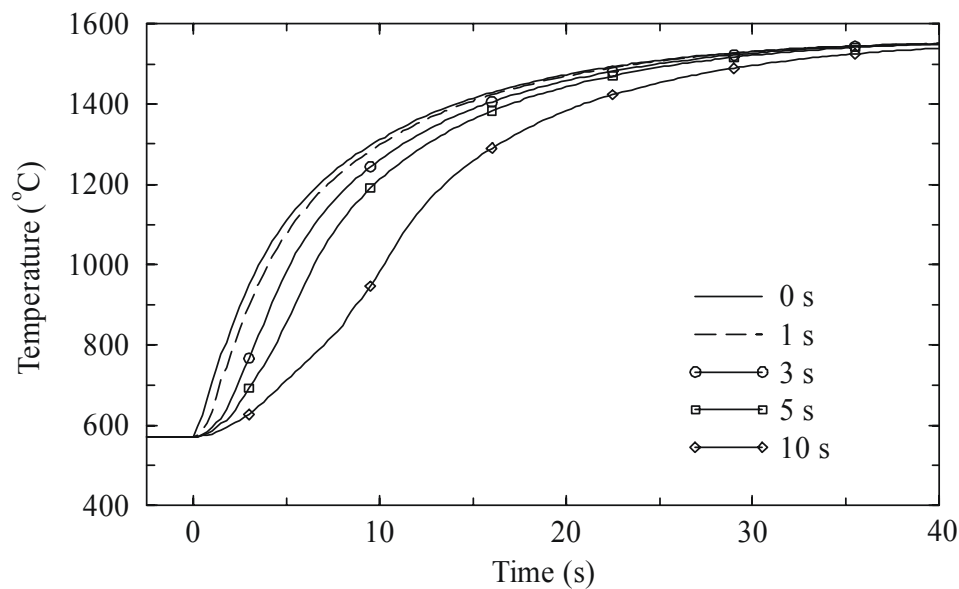

Figure 81. The effect of MFW flow coast down on maximum cladding temperature.

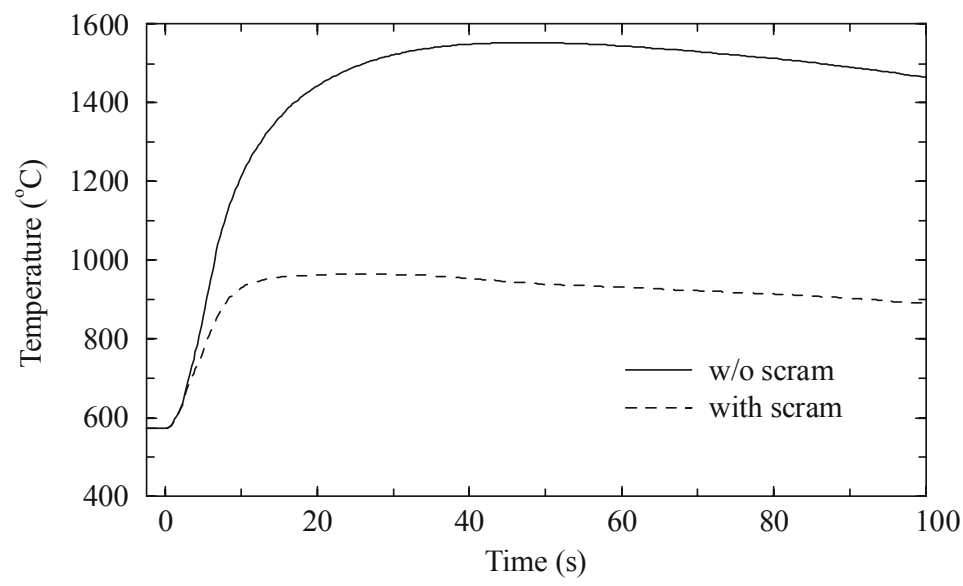

Figure 82. The effect of scram on maximum cladding temperature.

transient limit $6.5 \mathrm{~s}$ into the event with scram, compared to $4.8 \mathrm{~s}$ without scram. The peak cladding temperature with scram was $964{ }^{\circ} \mathrm{C}$ and occurred at $26 \mathrm{~s}$ into the transient. The cladding temperature then decreased slowly compared to current LWRs. The slower temperature decrease occurs because the thermal conductivity of the supercritical steam near the hot spot is less than that of subcooled liquid, there is no nucleate boiling in supercritical water, and the natural circulation flow rate is relatively small in the SCWR. Natural circulation occurs between the downcomer and the core because of flow through the bypass paths. The SCWR does not contain external loops that would enhance natural circulation in the absence of forced circulation.

Calculations were performed to determine the effect of AFW flow combined with a 5-s MFW flow coast down, reactor scram, and with the reactor pressure held constant by the turbine bypass valves. AFW flow rates corresponding to $10 \%, 20 \%$, and $30 \%$ of the initial feedwater flow were assumed as shown in Figure 83. The effect of the AFW flow rate on the maximum cladding temperature is shown in Figure 84. An 
interpolation of the calculated results indicates that the peak cladding temperatures will remain below the transient limit of $840{ }^{\circ} \mathrm{C}$ if the AFW flow is at least $15 \%$ of the initial MFW value. Considering that additional conservatisms may be required in the model, a higher AFW flow is desirable. The $15 \% \mathrm{AFW}$ flow rate would have to be generated within $4.25 \mathrm{~s}$ of the start of the event to be consistent with the assumed flow rates shown in Figure 83.

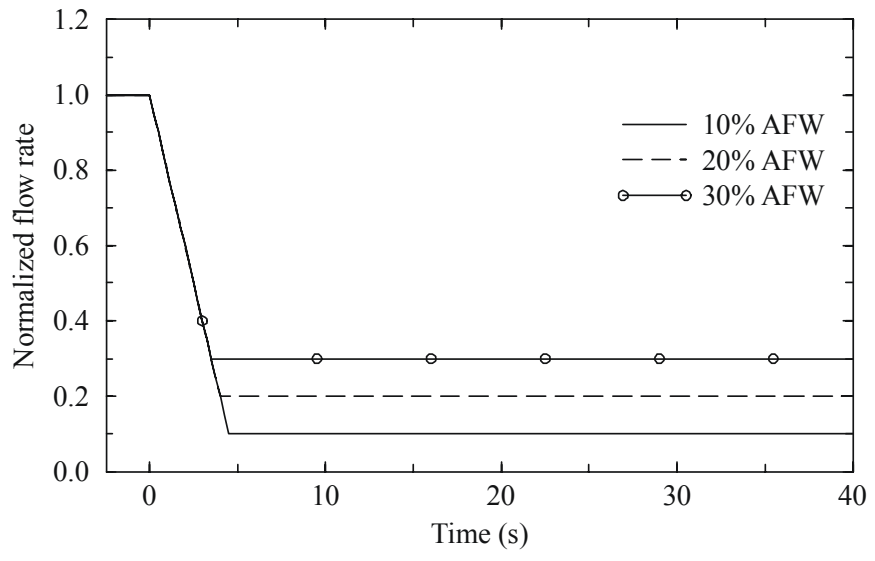

Figure 83. Total feedwater flow rates with AFW.

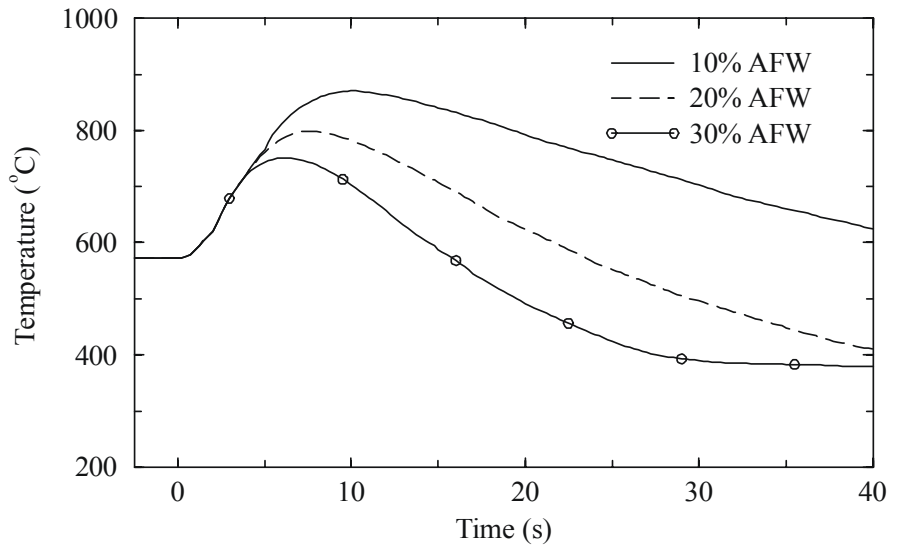

Figure 84. The effect of AFW on peak cladding temperature.

Calculations were performed to determine the effects of step reductions in MFW flow. The step reductions varied from $25 \%$ to $100 \%$ of the initial flow rate, with the latter value corresponding to a complete loss of feedwater flow. The calculations were performed without reactor scram. Turbine bypass valves were assumed to hold the reactor pressure constant. Figure 85 shows the effects of step reductions in MFW flow rate on the maximum cladding temperature. The flow reductions caused the cladding temperature to increase, with larger increases calculated for the more severe reductions in flow. Reactivity feedback caused the reactor power to decrease until a new steady state was obtained corresponding to the reduced flow and power.

The calculated results indicate that the peak cladding temperature will remain below the transient limit of $840{ }^{\circ} \mathrm{C}$ for step reductions in flow less than $52 \%$ of the initial value. In particular, it appears

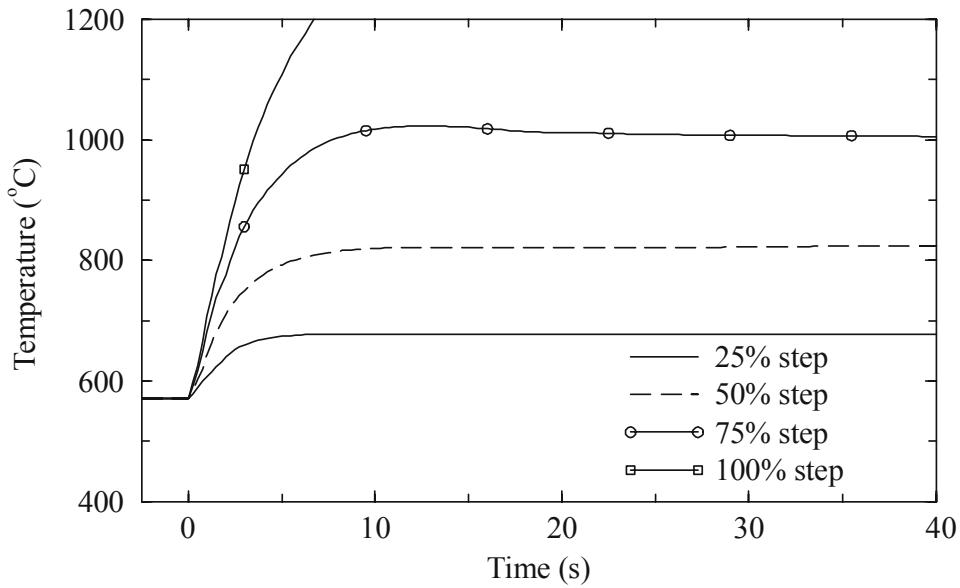

Figure 85. The effect of a step reduction in MFW flow on maximum cladding temperature.

that a scram is not required to meet the transient temperature limit for an instantaneous loss of half of the feedwater flow.

Calculations were also performed to determine the effectiveness of steam relief to enhance flow through the core. In the original calculation, the turbine bypass valves were assumed to modulate to hold the reactor pressure constant. A second calculation was performed in which a relief valve was opened at $2 \mathrm{~s}$. 
The relief valve was sized to discharge $20 \%$ of the rated steam flow at normal operating conditions. A check valve was placed in the main steam line to prevent steam from flowing from time-dependent Volume 405 (see Figure 24) through the relief valve. A third calculation was performed in which 100\% steam relief was simulated by assuming that the turbine throttle valves remained fully open. These calculations assumed scram, a 5-s MFW flow coast down, and no AFW flow.

Figure 86 shows the total steam flow for the three calculations. The steam flow rate closely followed the main feedwater flow rate when the turbine bypass valves modulated to hold the pressure constant. Slightly more steam flow was obtained when the $20 \%$ capacity relief valve opened at $2 \mathrm{~s}$ and significantly more flow was obtained in the case with $100 \%$ steam relief.

Figure 87 shows the calculated reactor pressures for the three cases. Opening the $20 \%$-capacity valve resulted in a significant reduction in pressure, but did not result in flashing of the cold

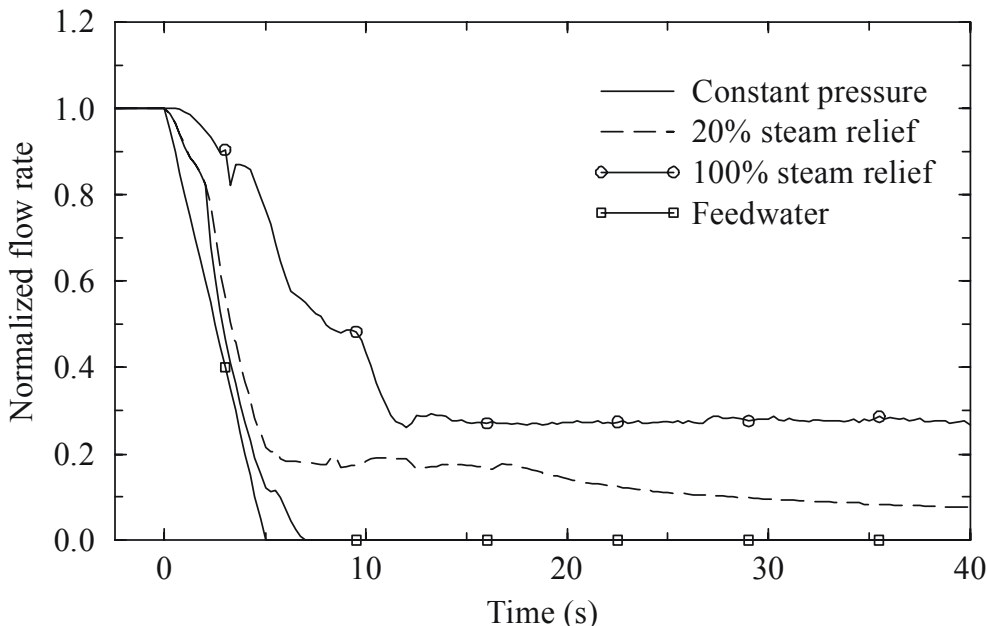

Figure 86. Steam flow rates following loss of feedwater.

fluid in the downcomer and lower plenum during the time period of interest. Without flashing, there was little enhancement of the core flow and a relatively small effect on cladding temperature as shown in Figure 88 . In the case with $100 \%$ steam relief, flashing in the downcomer and lower plenum occurred near $12 \mathrm{~s}$. This flashing caused a significant increase in core flow and a rapid reduction in cladding temperature. In the constant-pressure case, the peak cladding temperature was $964{ }^{\circ} \mathrm{C}$ and occurred at 26 s. The $20 \%$-capacity relief valve was relatively ineffective in reducing the peak cladding temperature. With $100 \%$ steam relief, the peak cladding temperature was $874{ }^{\circ} \mathrm{C}$ and occurred at $11 \mathrm{~s}$. The calculations show that a rapid opening of $100 \%$-capacity turbine bypass valves could help reduce peak cladding temperatures, but by itself would not be sufficient to prevent the peak cladding temperature from exceeding the transient limit of $840^{\circ} \mathrm{C}$.

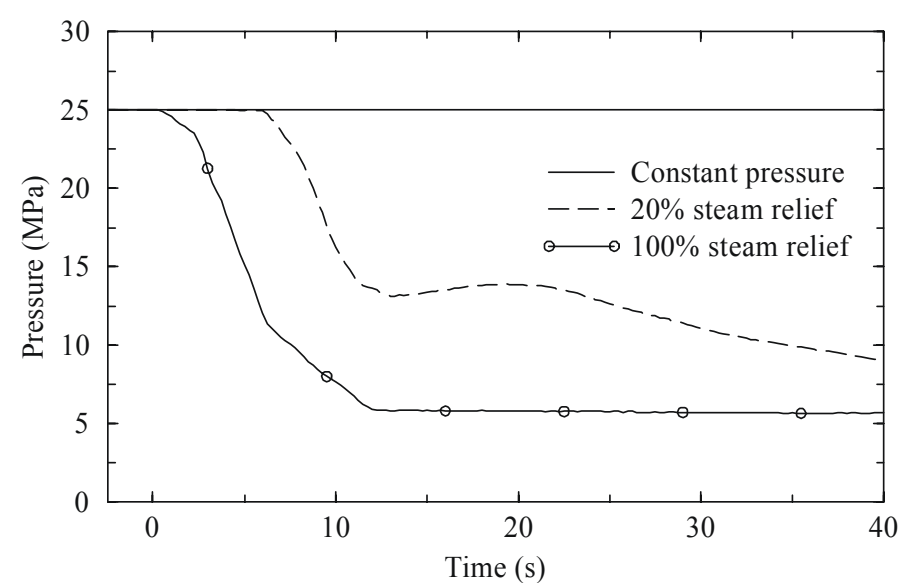

Figure 87. The effect of steam relief on reactor pressure.

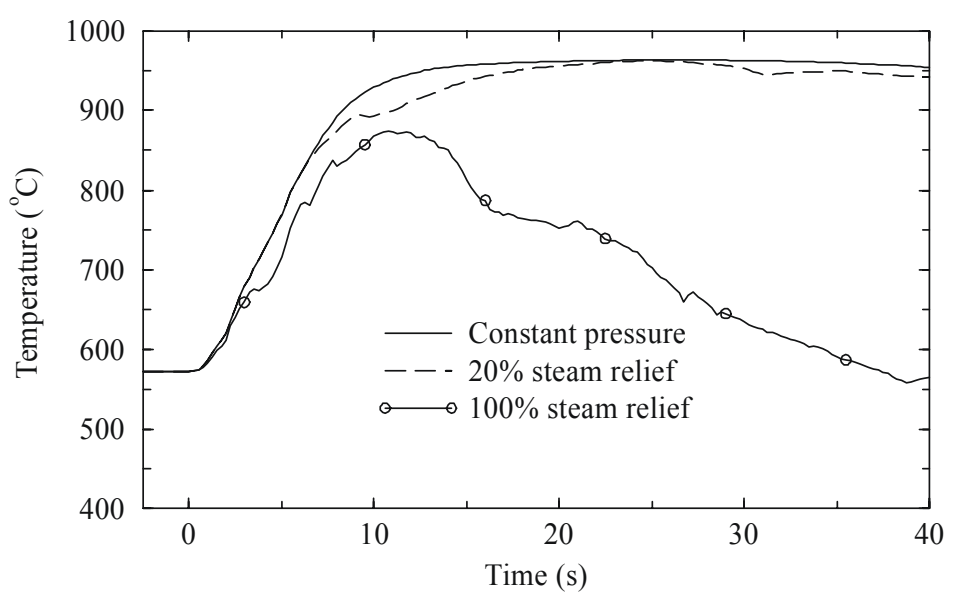

Figure 88. The effect of steam relief on maximum cladding temperature. 
The results shown previously were obtained with reactivity feedback coefficients that were calculated for a design with solid moderator rods. The Doppler feedback coefficient for a reactor design using water rods [Ishiwatari et al. 2002] is similar to that used here, but the coolant density feedback coefficient is about 19 times greater than that used here. Because burnup considerations favor a design with water rods, a sensitivity calculation was made in which the density feedback coefficient was increased to 43 $\mathrm{pcm} /\left(\mathrm{kg} / \mathrm{m}^{3}\right)\left[6.15 \times 10^{-2} \$ /\left(\mathrm{kg} / \mathrm{m}^{3}\right)\right]$ based on the calculations of Ishiwatari et al. [2002]. These sensitivity calculations are expected to show trends but will not exactly represent a design using water rods because the thermal response time of the water rods differs from that of the coolant. Calculations directly applicable to the design using water rods are presented later.

A calculation was performed to determine the effect of the coolant density feedback coefficient on a transient initiated by a 50\% step change in feedwater flow without reactor scram. Figure 89 shows that the reactor power decreased much faster, but tended to overshoot the equilibrium power, with the higher feedback coefficient. The equilibrium power was $67 \%$ of the initial value with the lower feedback coefficient, which corresponds to the solid moderator. With the higher coefficient, the equilibrium power was $54 \%$, just slightly exceeding the normalized feedwater flow rate. The more rapid reduction in power with the higher feedback coefficient resulted in a major reduction in peak cladding temperature as shown in Figure 90.

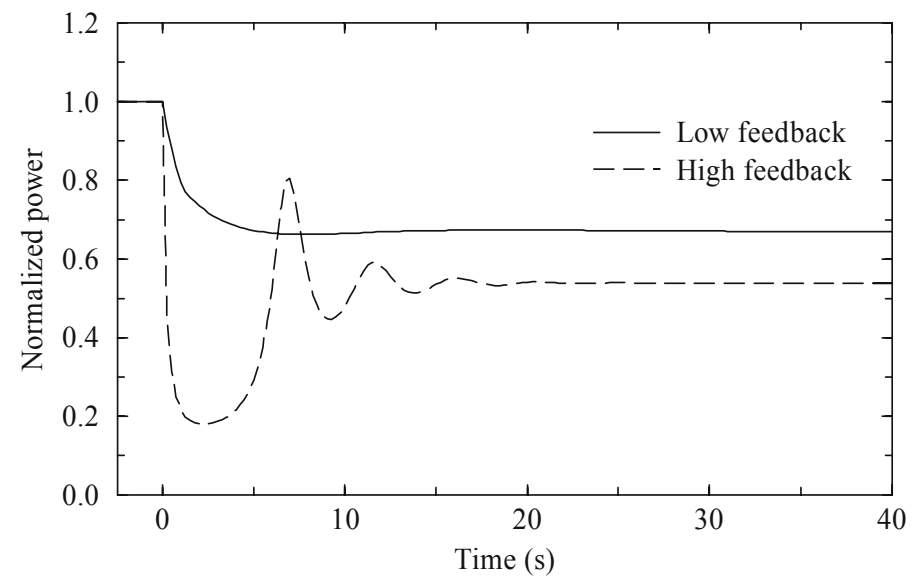

Figure 89. The effect of reactivity feedback on reactor power following a $50 \%$ step reduction in feedwater flow.

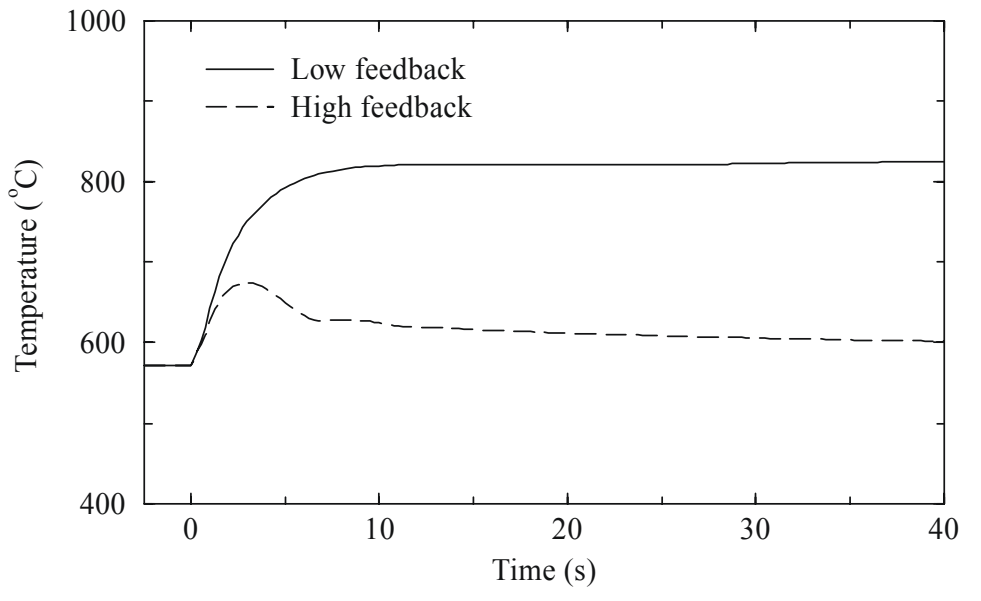

Figure 90. The effect of reactivity feedback on maximum cladding temperature following a 50\% step reduction in feedwater flow.

The effect of the reactivity coefficient on a transient initiated by a complete loss of feedwater was also determined. These calculations assumed a 5-s MFW coast down, no AFW, and a reactor scram at $0.5 \mathrm{~s}$. The higher feedback coefficient caused the reactor power to decrease significantly before the control rods were released as shown in Figure 91. The more rapid reduction in core power lowered the peak cladding temperature as shown in Figure 92. The peak cladding temperature was $860{ }^{\circ} \mathrm{C}$ with the higher feedback coefficient, slightly exceeding the transient limit of $840{ }^{\circ} \mathrm{C}$, but a significant improvement from the 964 ${ }^{\circ} \mathrm{C}$ calculated with the lower feedback coefficient. 


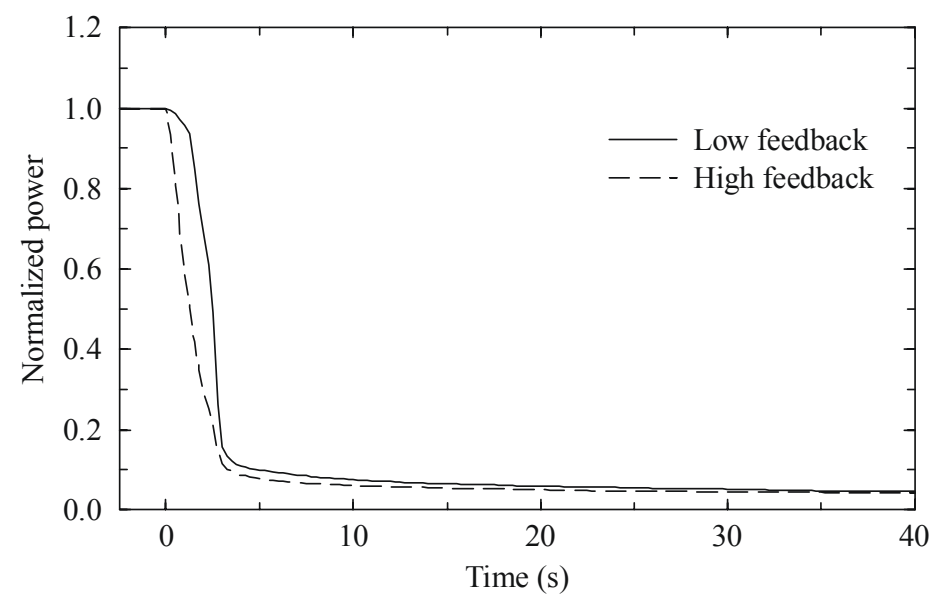

Figure 91. The effect of reactivity feedback on reactor power following total loss of feedwater.

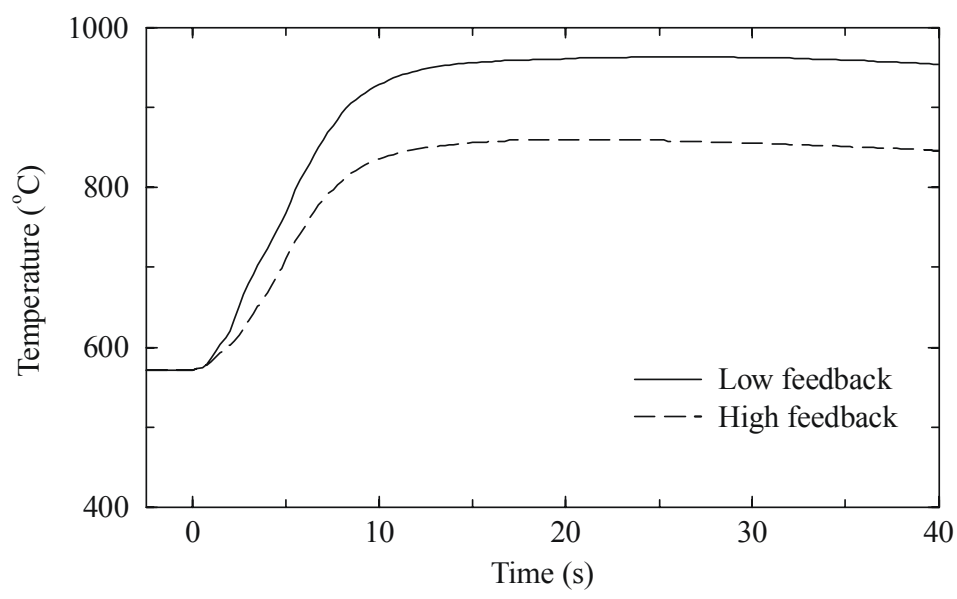

Figure 92. The effect of reactivity feedback on maximum cladding temperature following total loss of feedwater.

\subsubsection{Turbine Trip}

Three calculations of a turbine trip were simulated using the RELAP5 model shown in Figure 24 . The three calculations assumed an instantaneous closure of the turbine control valves and continued MFW flow at its rated value to obtain conservative predictions of the reactor vessel pressurization. The three calculations differed relative to their assumptions concerning scram and the capacity of the safety relief valves. The first calculation assumed that no scram occurred and that no safety relief valves were available, thus bounding the pressure response of the reactor. The second calculation assumed that no scram occurred and that the safety relief valve capacity was $90 \%$ of the steam flow at normal operating conditions. The third calculation assumed a relief capacity of $80 \%$ of the normal steam flow and that a scram signal was generated $0.1 \mathrm{~s}$ into the event; the safety rods began moving $0.8 \mathrm{~s}$ later with a drop time of $2.5 \mathrm{~s}$. The safety relief valves were assumed to open at a pressure of $27.0 \mathrm{MPa}$ and close at a pressure of $26.25 \mathrm{MPa}$.

The transient and accident pressure limits were the same as those developed by Ishiwatari et al. (2002). Specifically, the transient pressure limit was taken to be $28.87 \mathrm{MPa}$, which corresponds to 1.05 times the design pressure limit, which was assumed to be 1.10 times the operating pressure of $25.0 \mathrm{MPa}$. The accident pressure limit was assumed to be $30.25 \mathrm{MPa}$, corresponding to 1.10 times the design pressure of $27.5 \mathrm{MPa}$.

Figure 93 shows the pressure response from the three calculations. Without scram or safety relief valves, the pressure exceeds the accident limit at $0.45 \mathrm{~s}$. Without scram but with a safety relief valve capacity of $90 \%$, the pressure remains below the transient limit. The reactor approaches a new steady state with continuous flow through the safety relief valves. With scram, the relief capacity can be reduced to $80 \%$ of the steam flow at normal operating conditions and still remain below the transient limit. Intermittent operation of the safety valves occurs after $5 \mathrm{~s}$. The frequency of safety relief valve operation decreased and the duration of the operation increased after $5 \mathrm{~s}$ as the density upstream of the valves increased due to continued MFW flow. 
The calculated reactor power is shown in Figure 94. The maximum power remained relatively low even in the cases without scram. The maximum power was only $2.5 \%$ higher than the initial value with a relief capacity of $90 \%$ and without a reactor scram. For reference, in the Grand Gulf BWR6 (Middle South Utilities), the power increase for a turbine trip was about $6 \%$. However, this relatively low power increase was obtained by taking credit for a simultaneous trip of the recirculation pumps. In the Browns Ferry BWR4 (General Physics Corporation 1979), a turbine trip coupled with a failure of the turbine bypass system resulted in a power increase of $170 \%$. The BWR4 results are more comparable with the SCWR because they were obtained without the recirculation pump trip, which is consistent with the constant feedwater flow assumed here.

The relatively low power increase and the continued feedwater flow caused a relatively small increase in maximum cladding temperature as shown in Figure 95.

\subsubsection{3. Reactivity Accidents}

Calculations were performed to simulate reactivity insertion accidents from full power using the RELAP5 model illustrated in Figure 24. Reactivity insertion rates of 100,50 , and $5 \mathrm{pcm} / \mathrm{s}$ were simulated. In terms of dollars, the reactivity insertion rate varied between $0.15 \$ / \mathrm{s}$ and $0.0077 \$ / \mathrm{s}$. A scram signal was generated $0.5 \mathrm{~s}$ after the neutron power exceeded $118 \%$ of its normal value. The control rods began moving $0.8 \mathrm{~s}$ after the scram signal was generated and were fully inserted $2.5 \mathrm{~s}$ later. The MFW flow rate and reactor pressure were held constant during the calculations.

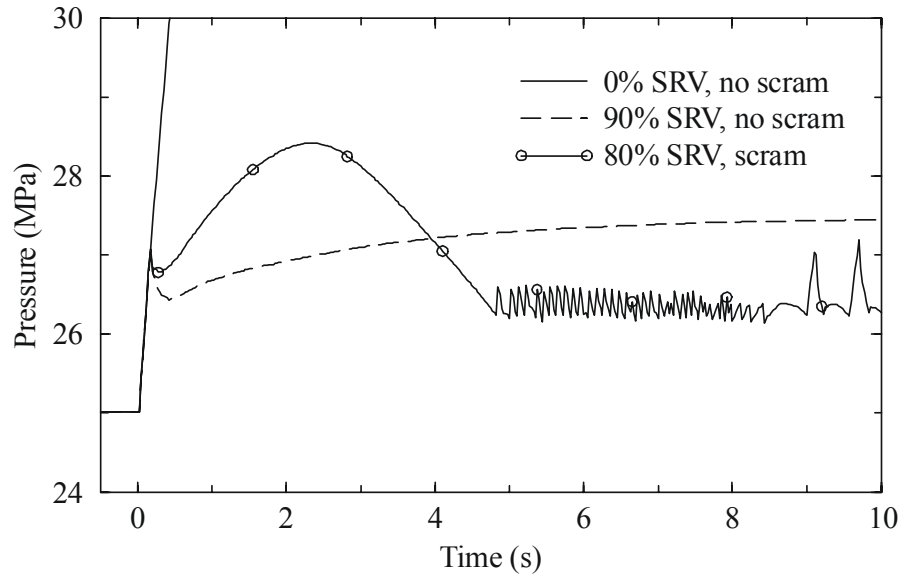

Figure 93. Reactor pressure following a turbine trip without steam bypass.

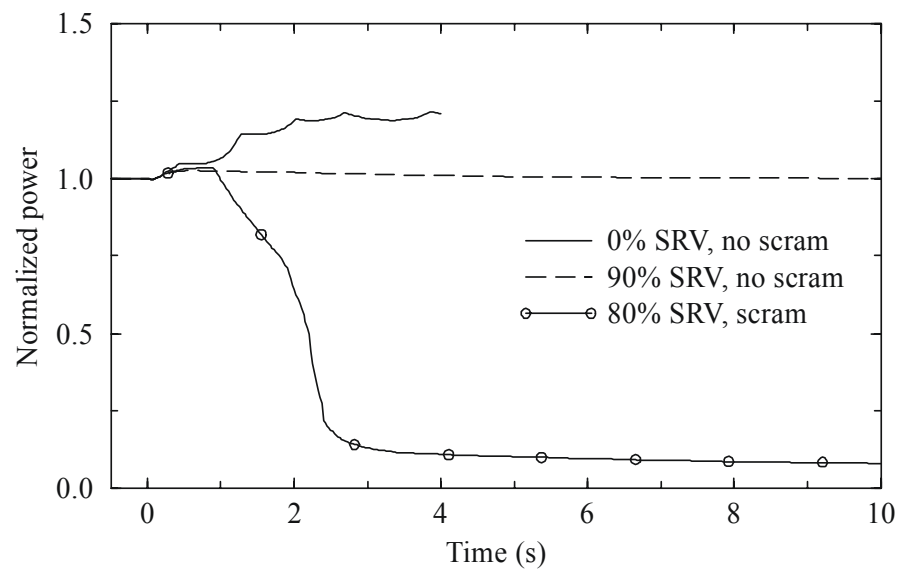

Figure 94. Total reactor power following a turbine trip without steam bypass.

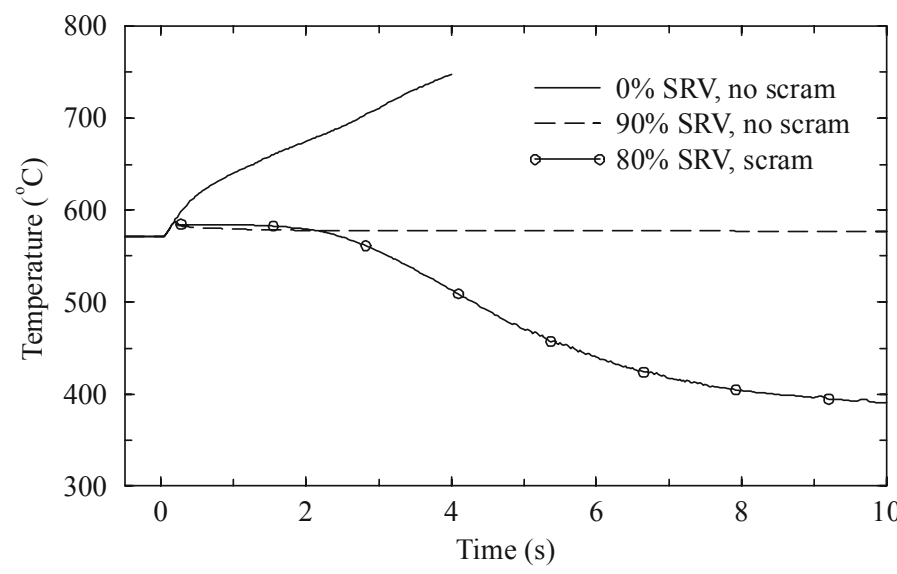

Figure 95. Maximum cladding temperature following a turbine trip without steam bypass. 
Figure 96 shows the effect of the reactivity insertion on normalized neutron power. The reactivity insertion caused the normalized power to increase until it reached the scram setpoint of 1.18. After a 1.3$\mathrm{s}$ delay, the control rods were released and shortly thereafter the power began to decrease. The maximum power was obtained with the highest reactivity insertion rate. Because of the brief duration of the power transient, the effect of the reactivity insertion on maximum cladding temperature was relatively small for the 100-pcm/s and 50-pcm/s cases (see Figure 97). The effect was larger for the $5-\mathrm{pcm} / \mathrm{s}$ case, but the peak cladding temperature remained well below the transient limit of $840{ }^{\circ} \mathrm{C}$.

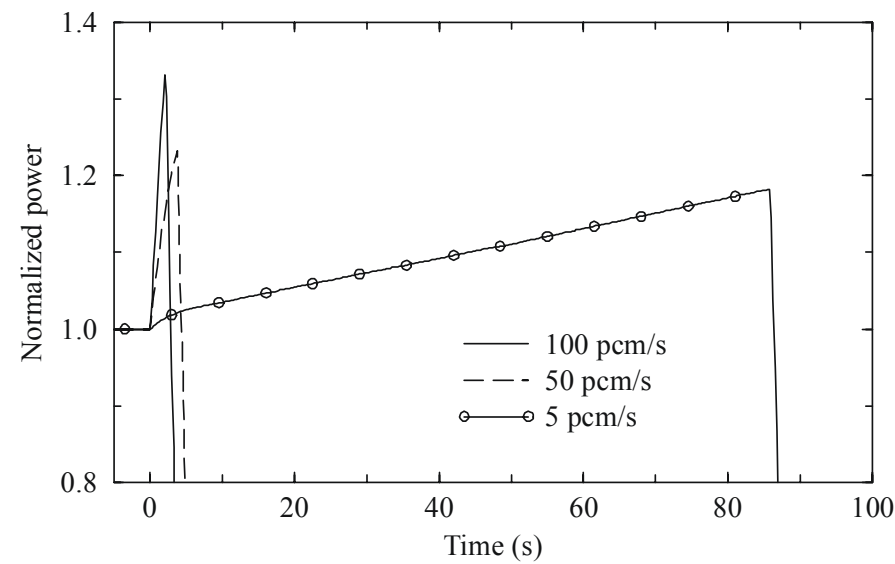

Figure 96. The effect of reactivity insertion on normalized neutron power.

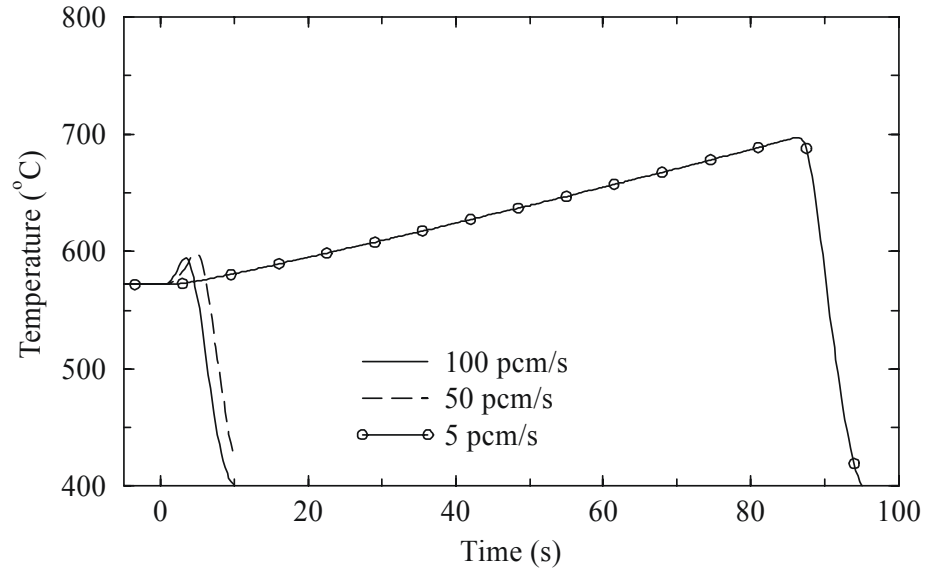

Figure 97. The effect of reactivity insertion on maximum cladding temperature.

\subsubsection{Reactors With Water Moderation}

Two different reactor designs that use water to achieve neutron moderation were studied. The first design used square fuel assemblies and water rods as illustrated in Figures 1, and 4 in Section 2 of this report. The second design used hexagonal power channels as illustrated in Figures 11 and 12 of Section 3. The primary purpose of this analysis was to compare the safety characteristics of the two designs following various transients. The transients analyzed included loss of feedwater and decrease in feedwater temperature. In addition, several LOCAs were analyzed. The RELAP5 models and steady-state results are described in Section 3.2 of this report.

\subsubsection{Loss of Feedwater}

Two loss-of-feedwater transients were analyzed to determine the relative safety characteristics of the designs with water rods and power channels. The first transient was initiated by a $50 \%$ step change in the MFW flow rate. The second transient was initiated by a complete loss of MFW and represented a 5-s flow coast down, scram, and the actuation of a 15\%-capacity AFW system. Based on the results shown previously in Figures 84 and 85 for the design with solid moderator rods, both of these transients were expected to produce peak cladding temperatures near the transient limit of $840{ }^{\circ} \mathrm{C}$.

The first transient was initiated by a 50\% step change in MFW flow at $0 \mathrm{~s}$. The calculations were performed without scram. The turbine bypass valves were assumed to hold the reactor pressure constant. Figure 98 shows the effect of 50\% step change in MFW flow rate on the maximum cladding temperature in the designs with water rods and with power channels. The temperatures presented are the maximum of 
the calculated values in the core and correspond to the hot rod of the high-powered bundle. The peak cladding temperature was nearly the same for the designs with water rods and power channels.

To determine the effects of the insulation, a sensitivity calculation was performed in which $1 \mathrm{~mm}$ of zirconium oxide insulation was added to the water rods. The insulation in the sensitivity calculation reduced the heat transfer to the water rods, which lowered the initial cladding temperature, but also kept more heat inside the coolant during the transient, resulting in a more rapid increase in coolant and cladding temperatures. The insulation also slowed the increase in the fluid temperature in the water rods during the transient, which slowed the decrease in moderator density. The slower decrease in moderator density reduced the reactivity feedback and resulted in the slower decrease in reactor power shown in Figure 99 and was partially responsible for the higher peak cladding temperature.

The calculated peak cladding temperatures remained below the transient limit of $840{ }^{\circ} \mathrm{C}$ for $50 \%$ step reductions in flow without scram. The calculated results are better than those shown previously for the core with solid moderator rods, i.e. the peak cladding temperatures are lower and the time at high temperatures is reduced. The peak cladding temperature is similar for the

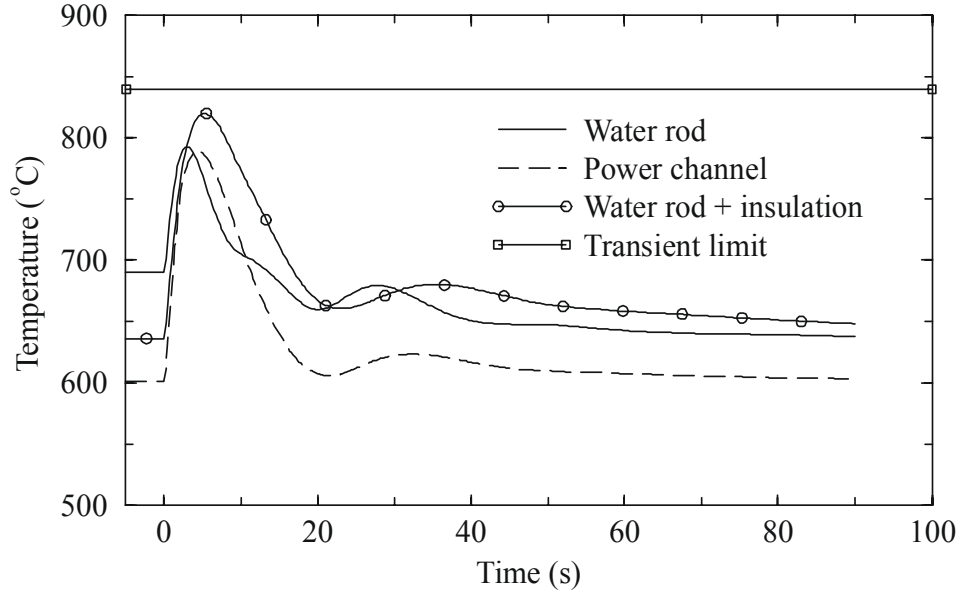

Figure 98. The effect of a $50 \%$ step reduction in MFW flow on maximum cladding temperature in the designs with water moderator.

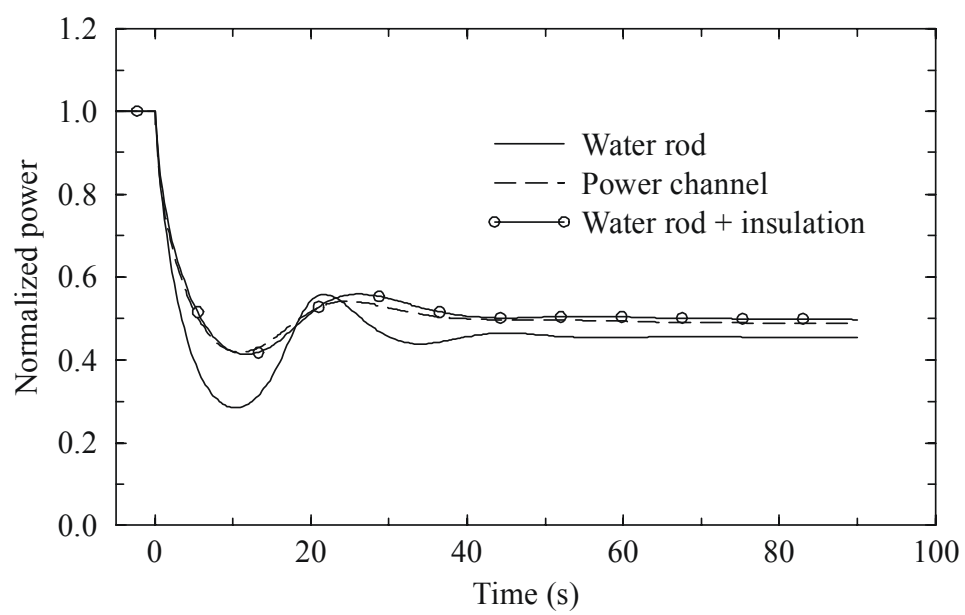

Figure 99. The effect of a 50\% step reduction in MFW flow on normalized reactor power in the designs with water moderator. designs with uninsulated water rods and insulated power channels. If insulation is added to the water rods, the safety performance is better in the design with power channels.

The second transient was initiated by a complete loss of MFW flow, which began to decrease at $0 \mathrm{~s}$ and decreased linearly until reaching zero flow at $5 \mathrm{~s}$. AFW flow was initiated at $4.25 \mathrm{~s}$ and corresponded to $15 \%$ of the initial MFW flow. The reactor scram signal was generated at $0.5 \mathrm{~s}$, corresponding to a $10 \%$ reduction in flow. The control rods began moving $0.8 \mathrm{~s}$ later and were fully inserted $2.5 \mathrm{~s}$ later. The reactor pressure was assumed to remain constant due to the operation of turbine bypass valves.

Figure 100 shows the effect of the complete loss of MFW on the calculated maximum cladding temperature for the designs with uninsulated water rods and insulated power channels. To determine the effects of the insulation, a sensitivity calculation was performed in which $1 \mathrm{~mm}$ of zirconium oxide insulation was added to the water rods. The peak cladding temperature was slightly higher for the design with power channels than for the design with water rods, primarily because of the effect of the insulation. 
As described for the previous transient, the insulation in the sensitivity calculation reduced the heat transfer to the water rods, which lowered the initial cladding temperature, but also kept more heat inside the coolant during the transient, resulting in a more rapid increase in coolant and cladding temperatures.

In summary, the designs with water rods and power channels respond similarly during loss-of-feedwater transients. The peak cladding temperatures were similar and less than the transient temperature limit for both designs during the events analyzed. Peak cladding temperatures

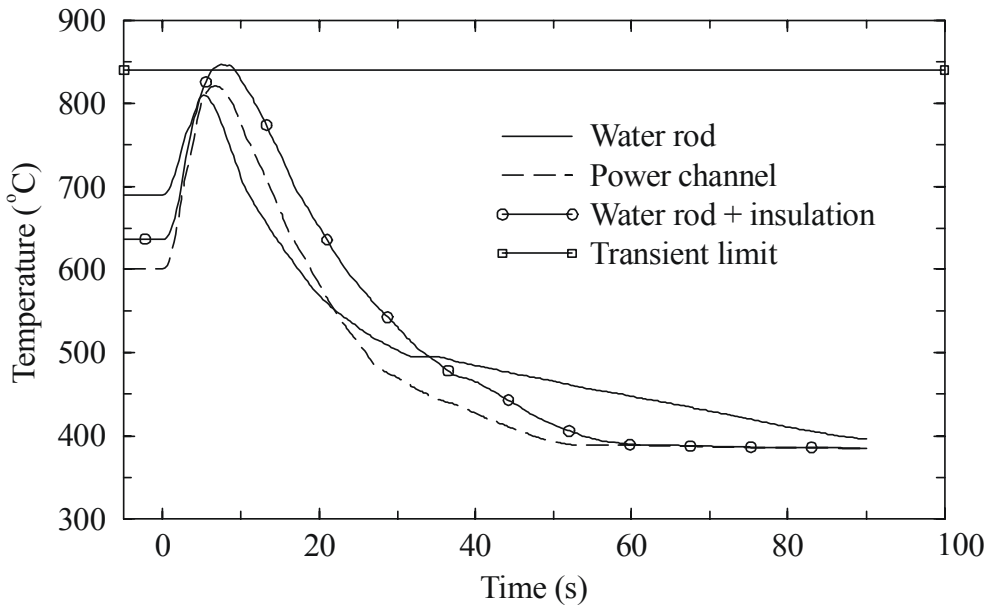

Figure 100. The effect of loss of MFW flow on maximum cladding temperature in the designs with water moderator. were 25 to $30^{\circ} \mathrm{C}$ lower with the power channel design when both designs were insulated.

\subsubsection{Decrease in Feedwater Temperature}

A transient initiated by a $30{ }^{\circ} \mathrm{C}$ step decrease in feedwater temperature was analyzed to determine the relative safety characteristics of the designs with water rods and power channels during an overcooling event. The change in temperature was consistent with that expected from the loss of the last stage of feedwater heaters. A loss of feedwater heaters would cause a relatively gradual change in feedwater temperature, but a step change was conservatively assumed here.

This transient was initiated at $0 \mathrm{~s}$ by the $30^{\circ} \mathrm{C}$ step change in MFW temperature. The MFW mass flow was held constant during the transient. The calculations were performed without scram. The turbine bypass valves were assumed to hold the reactor pressure constant.

The effect of the step reduction in MFW temperature on normalized reactor power is shown in Figure 101. The reactor power initially decreased because the decrease in the MFW temperature caused an increase in feedwater density, which resulted in a decrease in volumetric flow because the feedwater mass flow was held constant. The decrease in the volumetric flow of the feedwater caused a $5 \%$ decrease in the volumetric and mass flows through the core, which resulted in a slight overheating of the core and decrease in power due to reactivity feedback. The power then began to increase due to reactivity feedback as colder water reached the moderator. The power increased earlier and more rapidly in the design with the power channels because the flow path from the feedwater line to

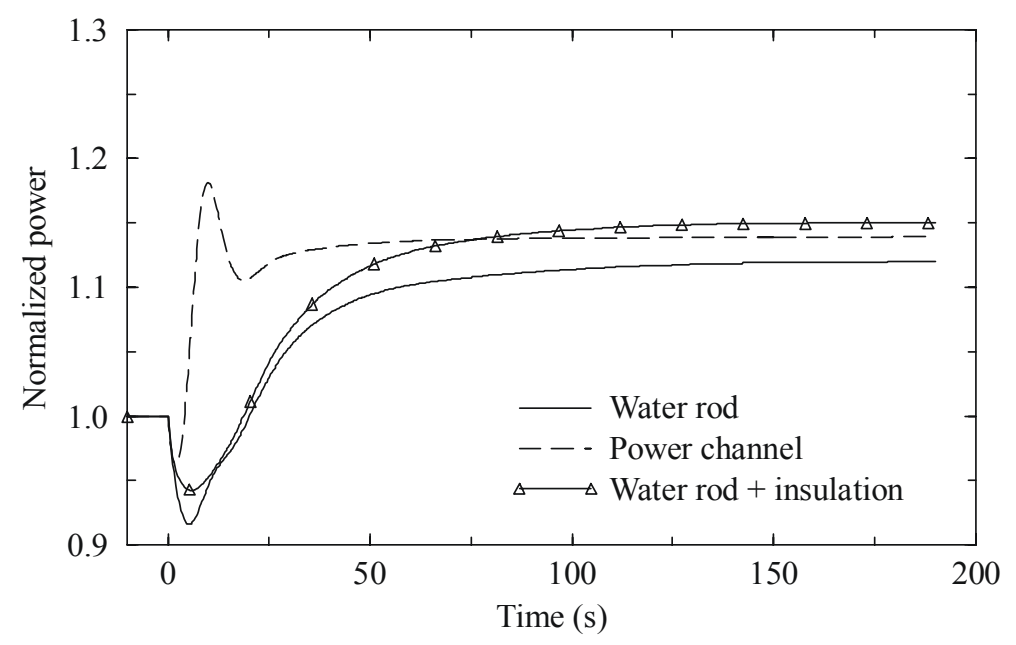

Figure 101. The effect of a $30^{\circ} \mathrm{C}$ step reduction in MFW temperature on normalized reactor power. 
the moderator at the top of the core was relatively direct. The power increased later in the design with water rods because of the time required for the feedwater to flow through the upper head, a relatively large component, to the water rods adjacent to the top of the core. The power increase caused an increase in the fuel temperature and a new steady state was reached where the Doppler reactivity feedback balanced the feedback due to the increase in moderator density. The equilibrium power was slightly higher in the design with power channels. A sensitivity calculation, in which the water rods were insulated with $1 \mathrm{~mm}$ of zirconium oxide, showed that the higher equilibrium power with the power channels was primarily caused by the insulation.

Figure 102 shows the effect of the step change in feedwater temperature on the maximum cladding temperature. The maximum cladding temperature increased earlier and more rapidly in the design with power channels, but the peak cladding temperature was more than $80{ }^{\circ} \mathrm{C}$ lower. The lower peak temperature was primarily caused by the lower initial temperature, which was a consequence of the higher coolant mass flux and insulation.

Both reactor designs met the transient temperature limit following a $30{ }^{\circ} \mathrm{C}$ step decrease in MFW temperature. The design with power channels had more margin to the transient temperature limit

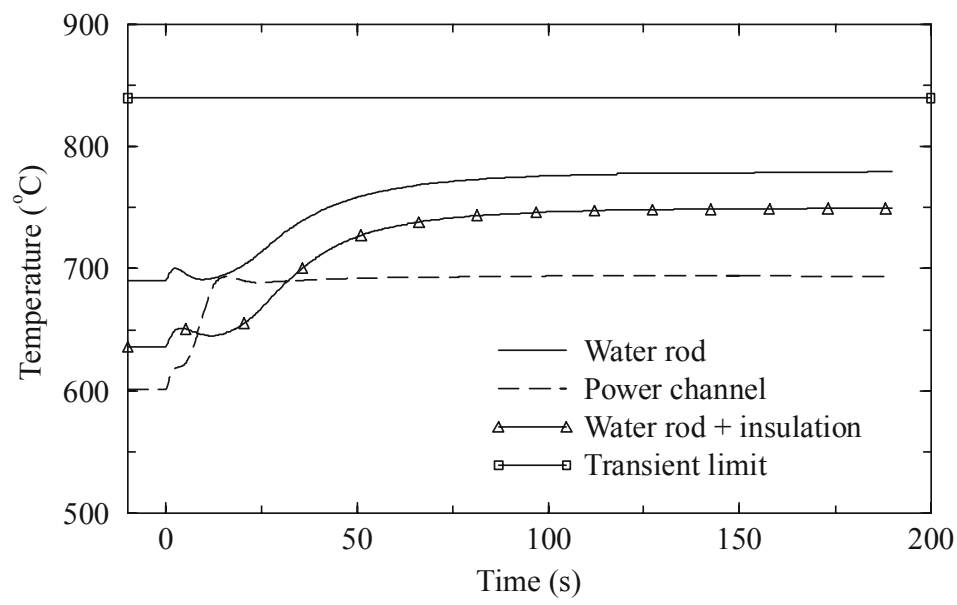

Figure 102. The effect of a $30^{\circ} \mathrm{C}$ step reduction in $\mathrm{MFW}$ temperature on maximum cladding temperature. because of the lower initial cladding temperature.

\subsubsection{Loss-of-Coolant Accidents}

Three LOCAs were analyzed to determine the relative safety characteristics of the designs with water rods and power channels. The three accidents were initiated by a $100 \%$ steam line break, a $100 \%$ feedwater line break, and a 5\% feedwater line break. The break areas correspond to the specified percentage of the areas of the feed and steam lines, which were based on an assumed diameter of $0.368 \mathrm{~m}$ as shown in Table XI. The calculations were performed without emergency core coolant and automatic depressurization systems to provide an indication of the time available for these systems to operate.

The first accident was initiated at $0 \mathrm{~s}$ by a $100 \%$ break in one of the two steam lines. A check valve in the other steam line quickly closed to prevent reverse flow. The main feedwater flow was terminated at $5 \mathrm{~s}$. The calculations were performed without scram as reactivity feedback due to the decrease in moderator density was able to quickly shut down the reactor. The pressure downstream of the break was set to atmospheric pressure.

Figure 103 shows calculated pressures in the upper plenum during the $100 \%$ steam line break. The pressures decreased quickly for both designs, but more quickly in the design with power channels. As shown in Table XI, the fluid volume in the design with power channels was about $30 \%$ less. Consequently, the smaller reactor vessel depressurized more quickly since the flow area of the break was the same in both designs. The end of blowdown, as measured by unchoking at the break, occurred at $86 \mathrm{~s}$ in the design with power channels and at $140 \mathrm{~s}$ in the design with water rods. The integrated mass flow rates out the break are shown in Figure 104. The integrated flow leveled out sooner, consistent with the 
more rapid blowdown, and at a lower value, consistent with the smaller fluid volume, in the design with power channels.

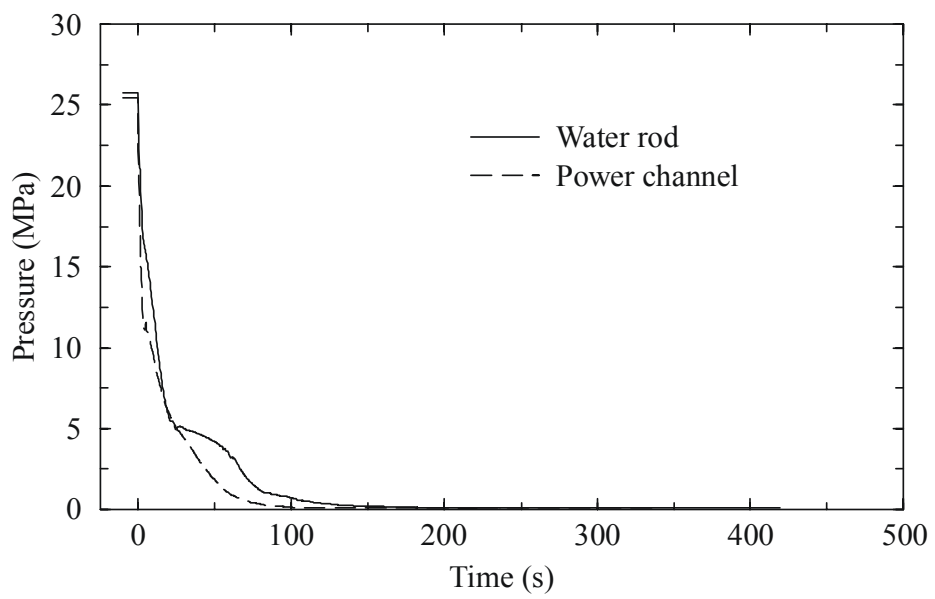

Figure 103. The effect of a $\mathbf{1 0 0 \%}$ steam line break on upper plenum pressure.

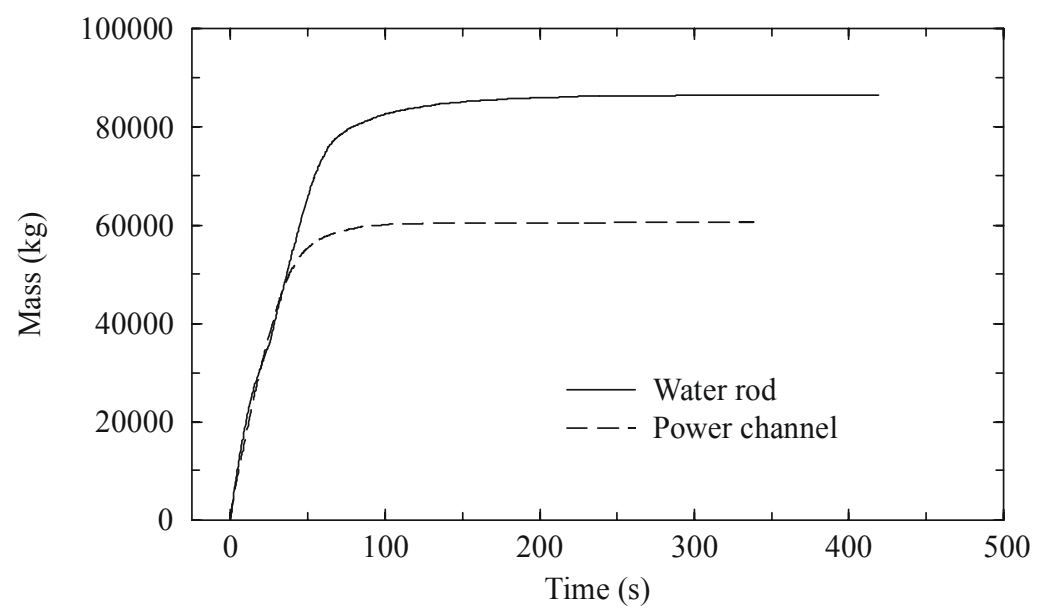

Figure 104. Integrated break flow during a $100 \%$ steam line break.

Calculated liquid levels in the core during the $100 \%$ steam line break are shown in Figure 105. The liquid levels correspond to the active fuel region in the average-powered core channel. The liquid levels are computed as the liquid volume fraction times the control volume height summed over the height of the core and then divided by length of the active fuel. The liquid levels are not physically meaningful at supercritical conditions because there is no phase change. The initial values shown in the figure were calculated by setting the liquid volume fraction to unity if the fluid temperature is less than the critical temperature and to zero if it exceeds the critical temperature. The liquid level increased significantly near $10 \mathrm{~s}$ in the design with power channels

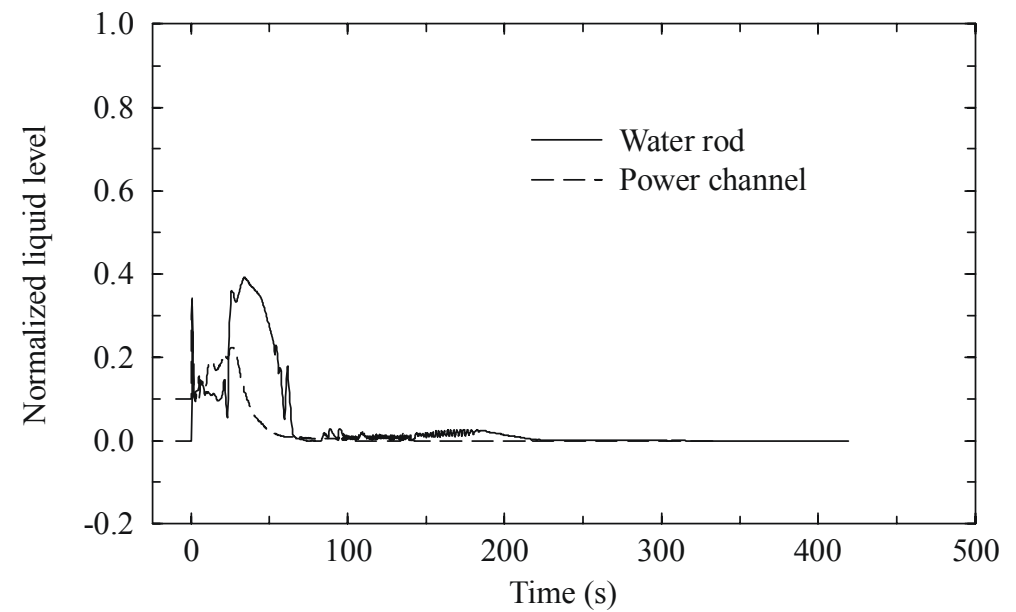

Figure 105. The effect of a $100 \%$ steam line break on collapsed liquid level in the core.

and near $20 \mathrm{~s}$ in the design with water rods as flashing in the colder regions, such as the lower plenum, downcomer, and upper head caused liquid to flow into the core. The level increase was much more pronounced in the design with water rods. The liquid level diminished to near zero earlier in the design with power channels because of the more rapid blowdown and possibly because the core was higher in the reactor vessel.

Figure 106 compares the normalized flow at the core midplane in the average-powered assembly with the normalized core power for the design with water rods. Figure 107 presents the same parameters for the design with power channels. Although difficult to see, there was a slight power excursion in both designs at the start of the transient due to a small increase in moderator density associated with the increased flow through the core. The fluid density then decreased due to the loss of mass through the break. The decrease in fluid density shut down the reactor due to reactivity feedback. The normalized flow exceeded 
the normalized power for more than $50 \mathrm{~s}$ with both designs. Consequently, the maximum cladding temperatures decreased as shown in Figure 108. The high coolant flow removed the energy initially stored in the fuel rod and reduced the fuel centerline temperature to near that of the cladding. The temperature began to rise near $65 \mathrm{~s}$ in the design with water rods due to the loss of liquid inventory and the slowing of the blowdown. The temperature began to rise about $25 \mathrm{~s}$ earlier in the design with power channels because of the more rapid blowdown and earlier decrease in the normalized flow. The additional liquid present in the core with water rods shown, in Figure 105, resulted in slightly enhanced heat transfer until about $200 \mathrm{~s}$, which resulted in a slower rate of temperature increase. The rate of temperature increase was also slower because the fuel rod diameter is larger in the design with water rods, which combined with the slight difference in linear heating rate, results in a $13 \%$ slower adiabatic heatup rate. The calculations were terminated when the peak cladding temperature reached $1205{ }^{\circ} \mathrm{C}$, which corresponds to the accident limit for Zircaloy cladding in current LWRs.

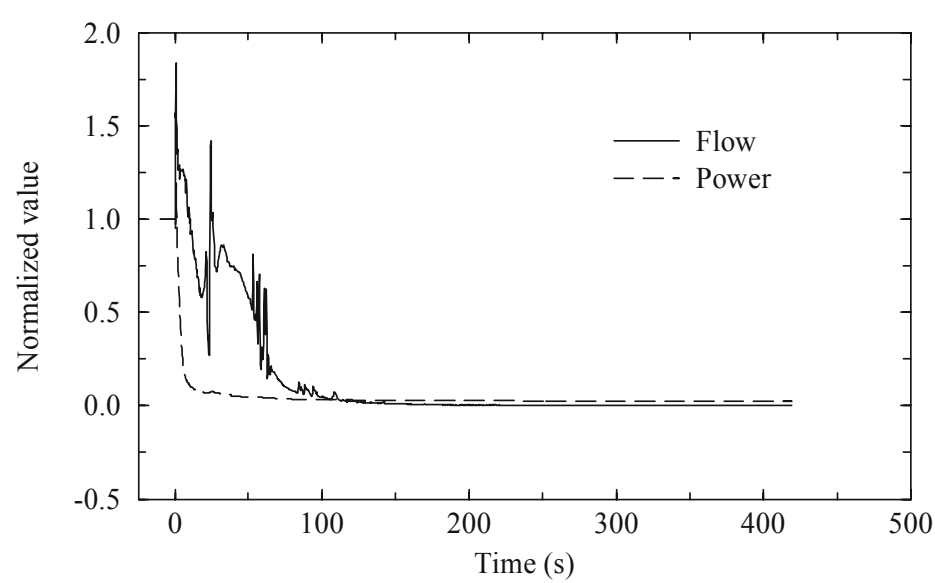

Figure 106. A comparison of normalized core flow rate and reactor power during a $100 \%$ steam line break in the design with water rods.

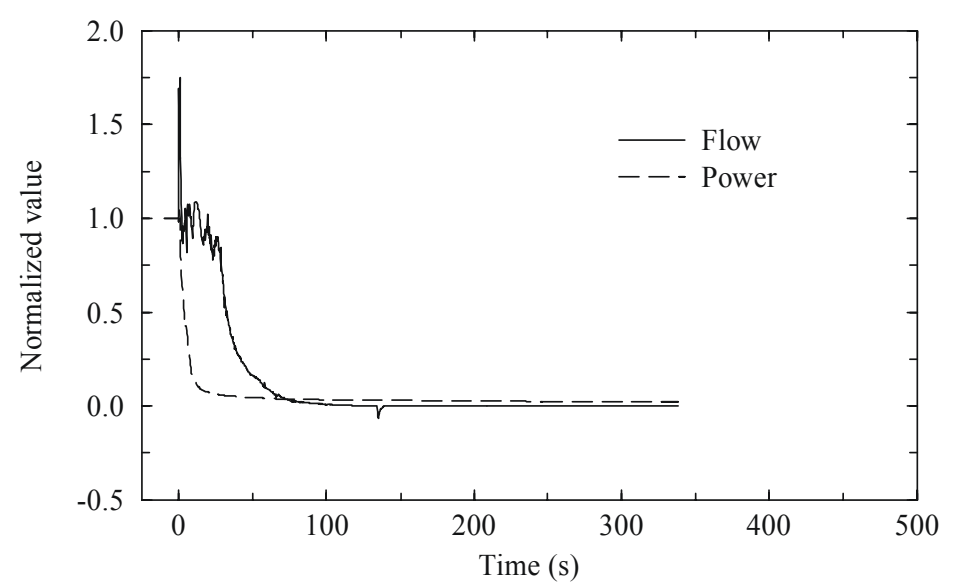

Figure 107. A comparison of normalized core flow rate and reactor power during a $100 \%$ steam line break in the design with power channels.

The smaller reactor vessel and fuel rods in the design with power channels result in a more rapid heatup of the cladding temperature following a large break in the steam line. The accident limit for current LWRs was reached $80 \mathrm{~s}$ earlier in the design with power channels. Thus, the safety characteristics of the design with water rods are better for this accident. However, there is ample time for the safety systems to respond to a large steam line break with both designs.

The second accident was initiated at $0 \mathrm{~s}$ by a $100 \%$ break in one of the feedwater lines. The main feedwater flow in the

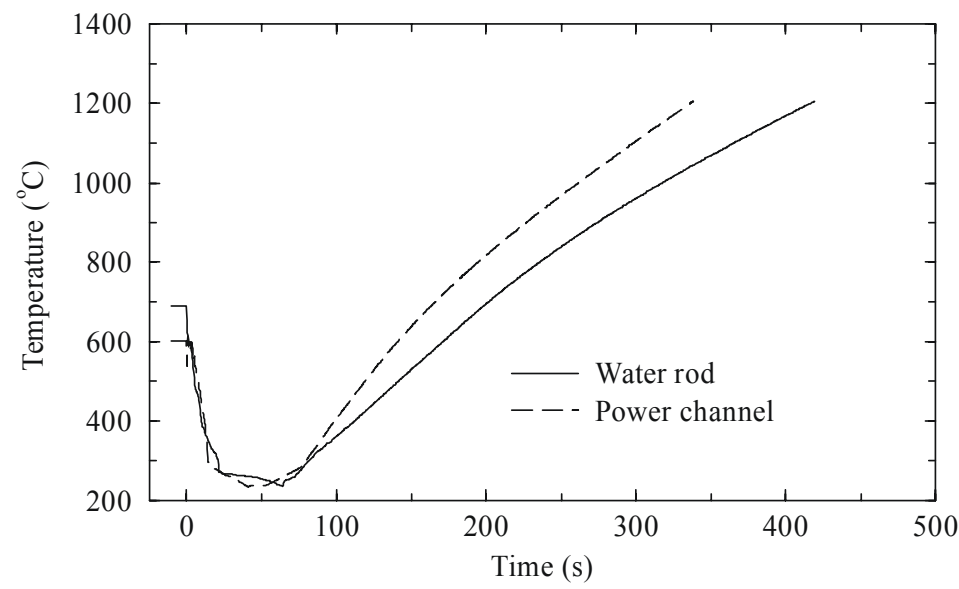

Figure 108. The effect of a $100 \%$ steam line break on maximum cladding temperature. other feedwater line was ramped linearly to zero over $5 \mathrm{~s}$. Check valves in the steam lines closed quickly to prevent reverse flow. The calculations were performed without scram as reactivity feedback due to the decrease in moderator density was able to 
quickly shut down the reactor. The time-dependent volume downstream of the break was set at atmospheric pressure.

Figure 109 shows calculated pressures in the upper plenum during the $100 \%$ feedwater line break. The pressure initially decreased more quickly in the design with power channels, which is consistent with the smaller fluid volume shown in Table XI.

The mass flow rates out the feedwater line break are shown in Figure 110. The initial break flows were more than six times the steady-state feedwater flow given in Table XI. The initial mass flow rate was considerably larger in the design with water rods because of the higher pressure shown in Figure 109 and a lower initial fluid temperature in the vessel near the break. The initial fluid temperature in the downcomer in the design with water rods was near the feedwater temperature whereas the initial fluid temperature was about $15 \mathrm{~K}$ higher in the other design because of heat transfer from the power channel walls. A higher fluid temperature significantly decreases the critical mass flow rate for subcooled conditions. The higher initial mass flow rate eventually resulted in a slightly lower pressure for the design with water rods.

The hydraulic response of the average-powered fuel channel is illustrated in Figures 111 and 112,

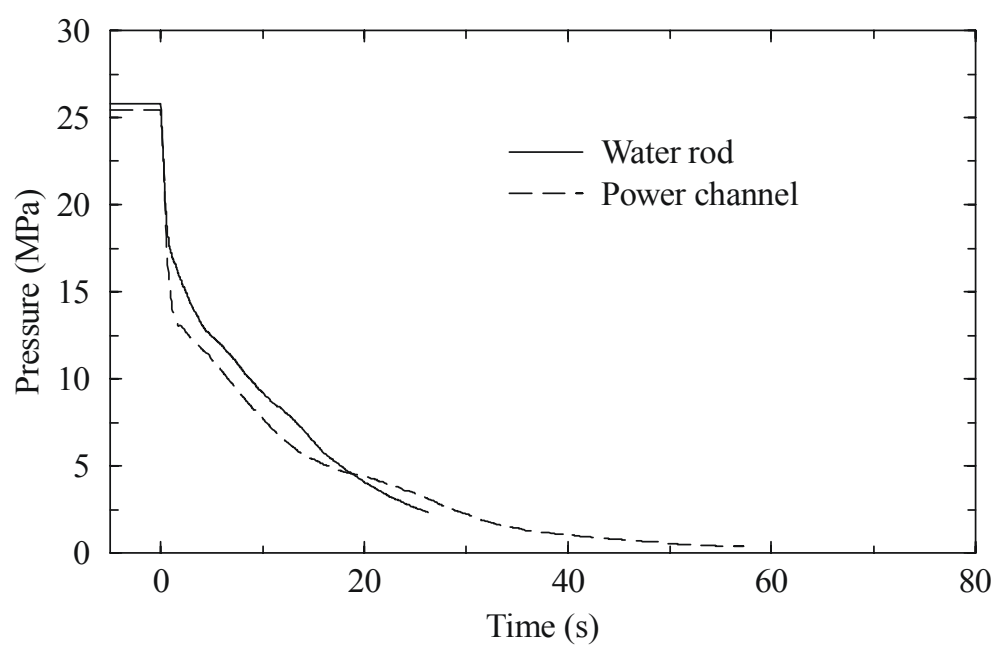

Figure 109. The effect of a $100 \%$ feedwater line break on upper plenum pressure.

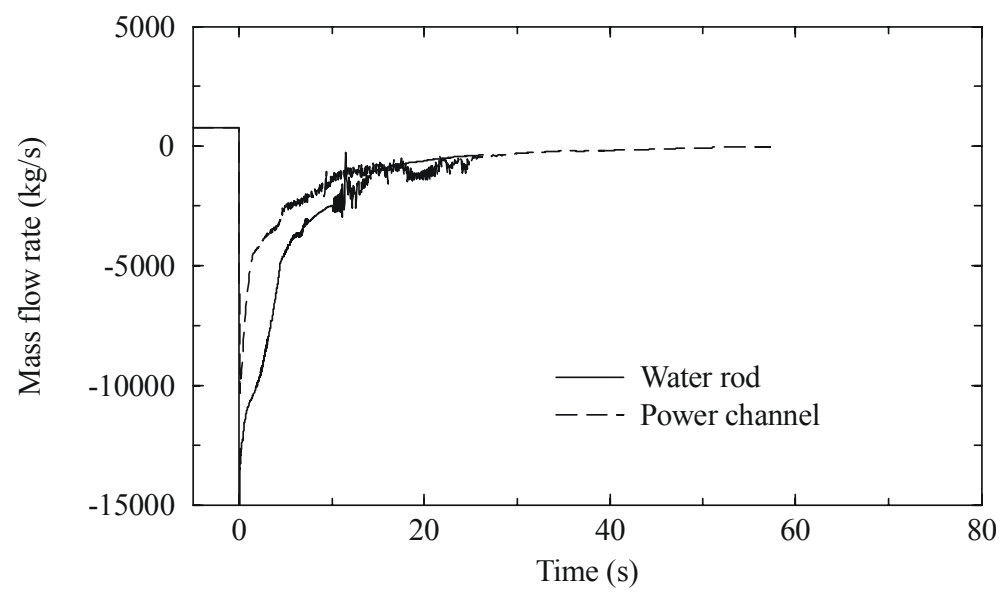

Figure 110. Break flow rate during a $100 \%$ feedwater line break.

which compare the normalized mass flow rate at core mid-plane and the normalized reactor power for the designs with water rods and power channels, respectively. The normalized flow rates showed the rapid reversal that is typical of large cold leg breaks in current PWRs. The flow then quickly decayed because it was primarily supplied by the upper plenum, which initially contained only steam. The volume of the upper plenum was also relatively small compared to the volumes of the downcomer, lower plenum, upper head, and moderator regions that supplied flow through the core due to the flashing of liquid during the steam line break discussed previously. The absolute value of the normalized flow was generally less than the normalized power with both designs, which differs considerably from the results shown previously for the steam line break during the same time frame. 


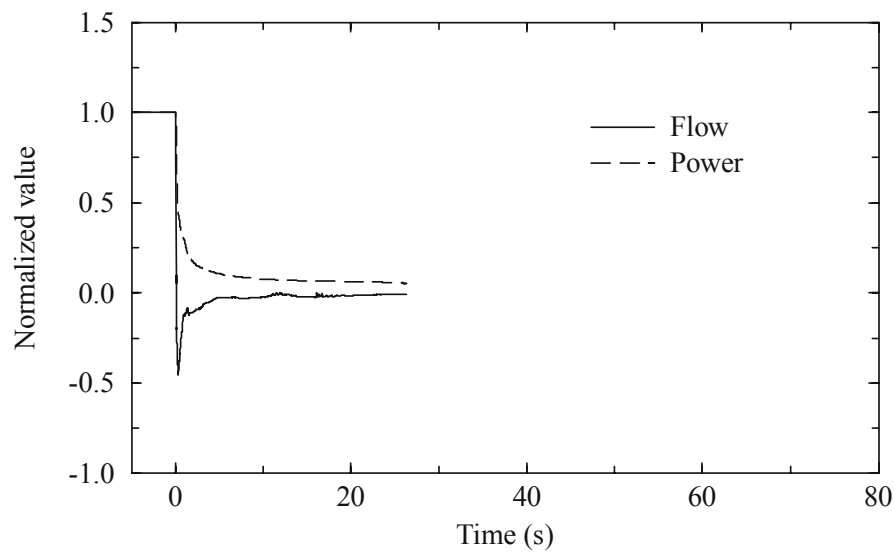

Figure 111. The effect of a $100 \%$ feedwater line break on normalized core flow rate and reactor power in the average-powered channel in the design with water rods.

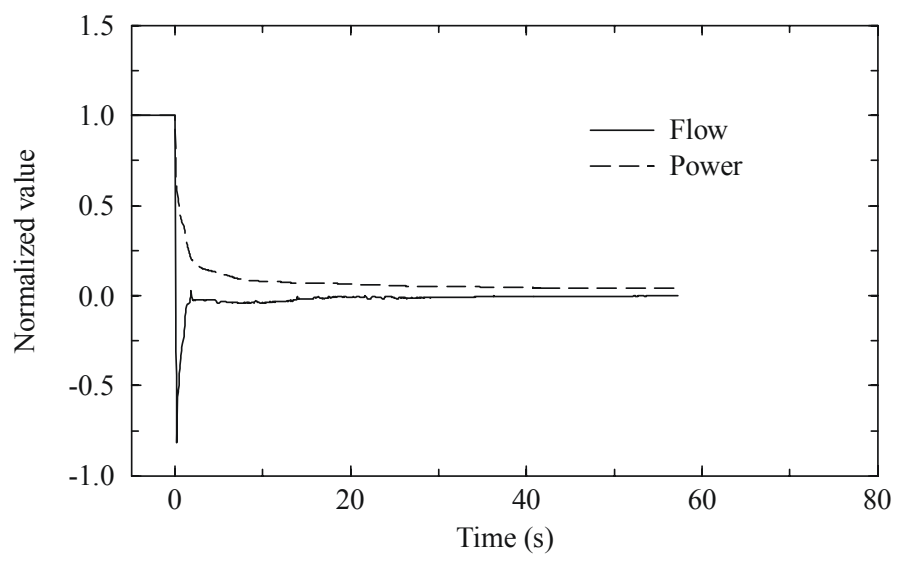

Figure 112. The effect of a $100 \%$ feedwater line break on normalized core flow rate and reactor power in the average-powered channel in the design with power channels.

Calculated maximum cladding temperatures for the two designs are shown in Figure 113. The maximum cladding temperatures increased rapidly following the feedwater line break. This temperature increase was caused by the flow reversal that resulted in the core being supplied by high-temperature steam from the upper plenum rather than lowtemperature liquid from the lower plenum and the reduction in the normalized flow rate compared to the normalized power. The decrease in flow reduced the heat transfer from the surface of the rod, which caused a re-distribution of stored energy within the fuel rod. The fuel centerline and cladding temperatures approached an average value due to the decrease in heat flow across the fuel rod. This re-

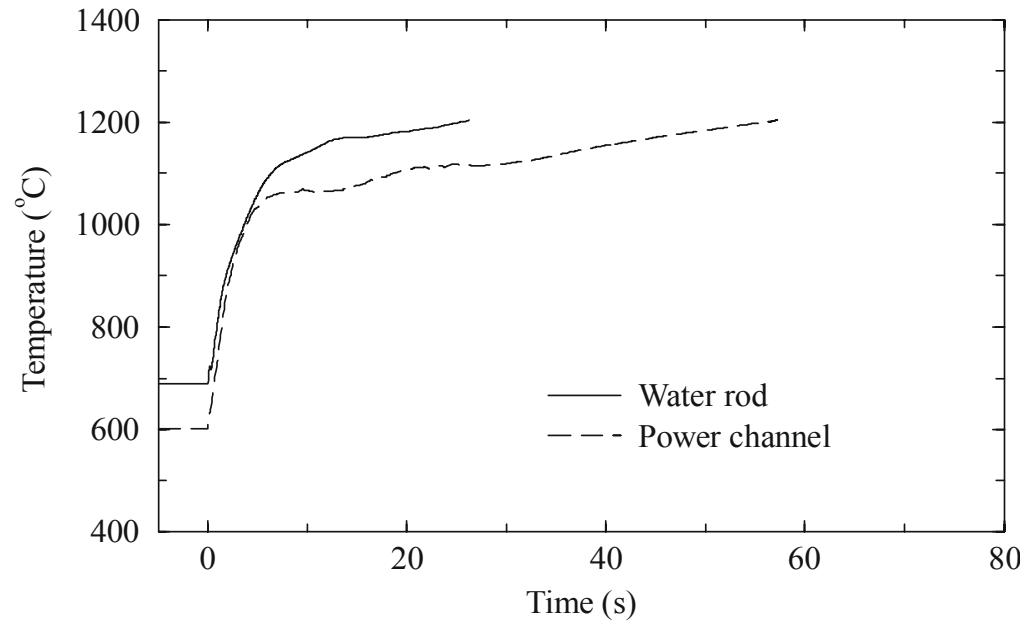

Figure 113. The effect of a $100 \%$ feedwater line break on maximum cladding temperature.

distribution of the stored energy was primarily responsible for the initial rapid temperature rise of the cladding. The energy re-distribution was completed near $10 \mathrm{~s}$ and the cladding and centerline temperatures then increased because the core decay power exceeded the heat removed at the surface of the fuel rods. The calculations were terminated when the maximum cladding temperature reached the $1205{ }^{\circ} \mathrm{C}$ limit for current LWRs, at $26 \mathrm{~s}$ for the design with water rods and at $57 \mathrm{~s}$ for the design with power channels. The design with power channels reached the accident temperature limit later primarily because of the lower initial cladding temperature, which resulted in a lower fuel centerline temperature and less stored energy in the fuel rod.

The calculated results for the SCWR are qualitatively similar to those in a PWR following a large cold leg break. For example, the maximum cladding temperature increased by $430{ }^{\circ} \mathrm{C}$ in $12 \mathrm{~s}$ during LOFT Test L2-5 (Bayless and Divine 1982), which simulated a large cold leg break in a PWR. The maximum 
temperature increased by about $470{ }^{\circ} \mathrm{C}$ in $12 \mathrm{~s}$ for both SCWR designs. A higher temperature rise was expected in the SCWR because its maximum linear heat generation rate was more than $20 \%$ larger than in the LOFT experiment. Also, the results presented here may be too conservative because radiation heat transfer between the fuel rods and the walls of the water rods or power channel was neglected. The assumed feedwater line area was also about two times bigger than the current value for the reference design after accounting for differences between rated powers.

The safety characteristics of the design with power channels were better for an accident initiated by a large feedwater line break. The improved safety performance was due to the lower initial cladding and fuel centerline temperatures, which caused the accident limit to be reached later. The amount of time available for the safety systems to respond and mitigate the accident seems reasonable, but will be less than for a PWR because of the higher operating temperatures in the SCWR. The amount of time available in the large feedwater line break is much less than that available in the large steam line break. Thus, an accident initiated by a large feedwater line break will likely be a limiting event for the design of the SCWR.

The third accident was initiated at $0 \mathrm{~s}$ by a $5 \%$ break in one of the feedwater lines. A scram signal was generated at $0.5 \mathrm{~s}$. The control rods began moving $0.8 \mathrm{~s}$ later and were fully inserted $2.5 \mathrm{~s}$ later. The feedwater flow continued for $5 \mathrm{~s}$ and was ramped linearly to zero over the subsequent $5 \mathrm{~s}$. Check valves in the steam lines closed quickly to prevent reverse flow. The time-dependent volume downstream of the break was set at atmospheric pressure.

Figure 114 shows calculated pressures in the upper plenum during the $5 \%$ feedwater line break. The pressure decreased more quickly in the design with power channels because of the smaller reactor vessel. The pressure increased slightly near $100 \mathrm{~s}$ in the design with water rods. This pressure increase was caused by a transition between single-phase liquid and two-phase flow at the break, which resulted in a period of relatively low volumetric flow out the break, combined with a period of boiling in the water rods. The net volume expansion produced by the boiling exceeded that relieved by the break, resulting in the pressure increase. The insulation between the power channels and the moderator reduced the boiling in the design with power channels, resulting in a smaller pressure increase.

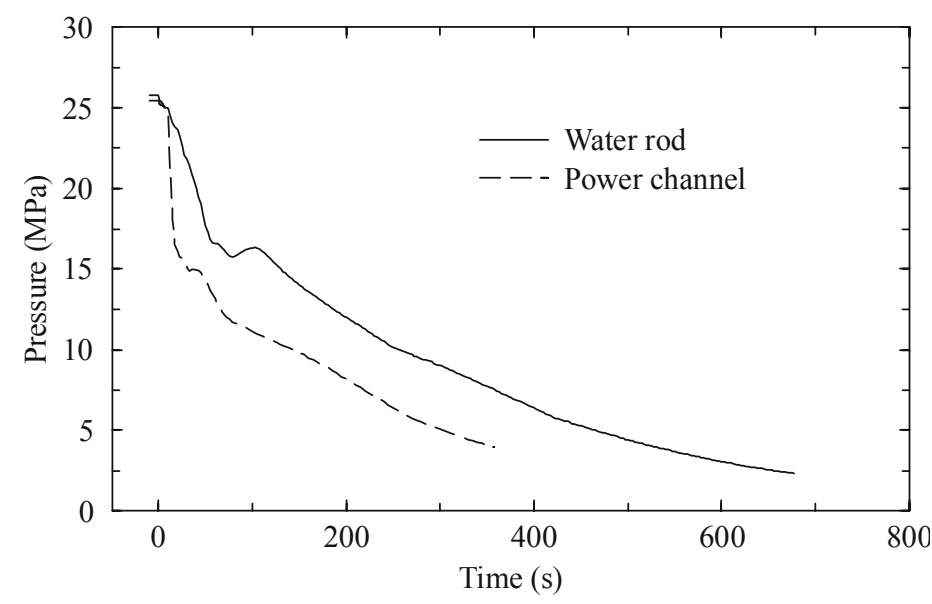

Figure 114. The effect of a $5 \%$ feedwater line break on upper plenum pressure in the designs with water moderator.

The mass flow rates out the feedwater line break are shown in Figure 115. The initial break flow was approximately half of the steady-state feedwater flow given in Table XI. The break mass flow rate decreased more quickly in the design with power channels because of the lower pressure shown in Figure 114 and the lower initial fluid temperature in the vessel near the break as discussed previously.

The moderator liquid levels are compared for the two designs in Figure 116. The parameters presented are the collapsed liquid levels in the moderator region (Component 380 in Figures 26 and 27) normalized to the active core height. The liquid level initially decreased more quickly in the design with water rods. The relatively higher fluid temperatures caused by the lack of insulation on the water rod wall resulted in more rapid voiding due to flashing once the pressure dropped below the supercritical value. The liquid 
level then increased until the upper head completed draining near $200 \mathrm{~s}$. Flashing and boiling then caused a gradual decrease in level for the remainder of the accident. The onset of flashing and the corresponding decrease in level were delayed in the design with power channels. The smaller fluid volume in the design with power channels eventually resulted in a lower liquid level.

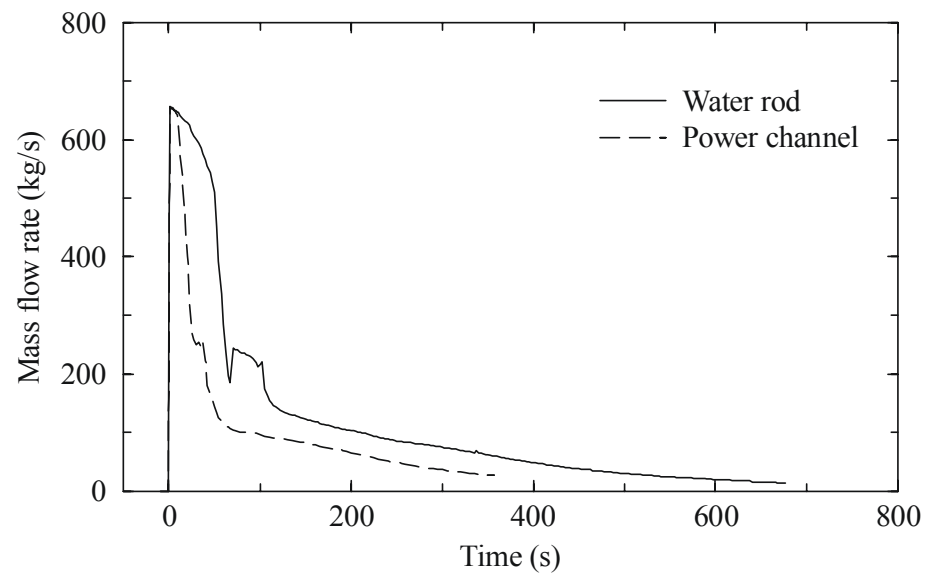

Figure 115. Break flow rate during a $5 \%$ feedwater line break.

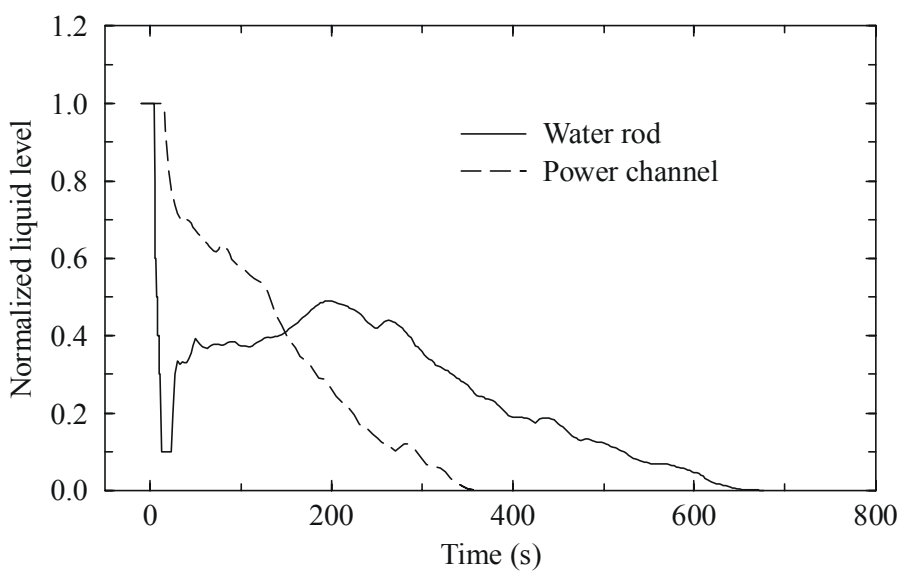

Figure 116. Collapsed liquid levels in the moderator during a $5 \%$ feedwater line break.

The calculated maximum cladding temperatures for the two designs are shown in Figure 117. The maximum cladding temperatures initially increased due to the loss of feedwater flow out the break, and then due to the redistribution of energy within the fuel rod. The initial period of feedwater flow was sufficient to remove most of the stored energy from the fuel rods following the scram, which prevented the fast thermal excursion observed in the large feedwater line break discussed previously. However, the feedwater flow was not sufficient to fill the vessel with liquid. In fact, the core was essentially voided during the accident with both designs. Consequently, the cladding temperatures remained well above the fluid saturation

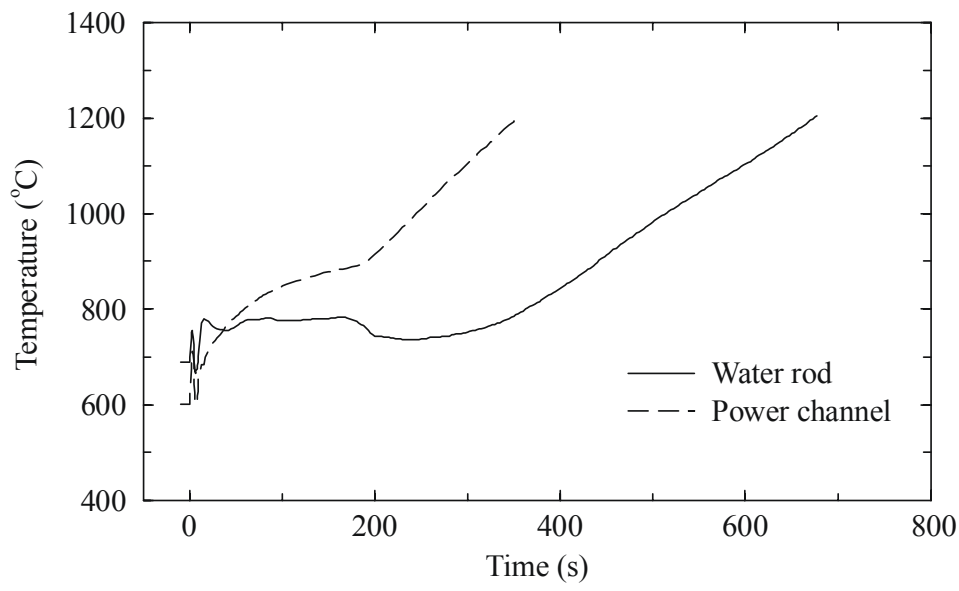

Figure 117. Maximum cladding temperature during a $5 \%$ feedwater line break. temperature throughout the accident. The cladding temperatures remained roughly constant between 25 and $200 \mathrm{~s}$ in the design with water rods. During this time period, the core decay heat was removed by boiling inside the water rods. The maximum cladding temperature increased more rapidly near $340 \mathrm{~s}$ when the mixture level in the water rods dropped below the elevation of the hottest cladding. The insulation in the design with power channels kept more heat inside the coolant channel resulting in higher cladding temperatures between 40 and $190 \mathrm{~s}$. The cladding temperature then increased rapidly, again due to the mixture level in the moderator decreasing below the elevation of the hottest cladding. The rapid temperature increase began earlier in the design with power channels because of the smaller fluid volume in the reactor vessel. The rate of rapid heating was also higher because of the smaller fuel rods in the design with power channels. The calculations were terminated when the maximum cladding temperature reached the $1205^{\circ} \mathrm{C}$ limit for current LWRs, at $357 \mathrm{~s}$ for the design with power channels and at $677 \mathrm{~s}$ for the design with water rods. 
In summary, the safety characteristics of the design with water rods are better than those for the design with power channels for a small feedwater line break as more time is available prior to reaching the accident temperature limit. The safety characteristics of the design with water rods are also better because of the lack of insulation, which allows the water rods to more effectively remove core decay power during the early portion of the accident, and because of the larger reactor vessel, which allows more time before the liquid inventory of the vessel is depleted. However, adequate time should be available to activate the safety systems with both designs.

\subsubsection{Conclusions}

Parametric calculations were performed to characterize the transient response of three SCWR designs so that the required response times and capacities of various safety systems could be determined. The designs used either solid or water moderator. Moderation by water was achieved with either square water rods or hexagonal power channels. Calculations were performed to investigate the relative safety characteristics of the designs with water rods or power channels. Transients initiated by loss-offeedwater, turbine trip, reactivity insertion, and step decrease in MFW temperature were simulated. LOCAs were also simulated.

The parametric calculations showed that the design with solid moderator rods could tolerate a $50 \%$ instantaneous reduction in feedwater flow without a reactor scram and still meet a transient temperature limit of $840{ }^{\circ} \mathrm{C}$. Transients involving total loss of feedwater pose a more serious challenge to the reactor. Calculations indicated that acceptable temperature results could be obtained with a 5-s MFW flow coast down, a reactor scram, and an AFW flow rate that is $15 \%$ or more of the initial feedwater flow. Calculations also showed that a fast opening, 100\%-capacity turbine bypass system could significantly reduce the peak cladding temperatures during this event. An increase in the coolant density feedback coefficient also significantly lowered the peak cladding temperature. Thus, designs with water moderator show potential for increased safety margins. This potential was confirmed by subsequent calculations.

The parametric calculations showed that the SCWR could meet reactor vessel pressure limits following a turbine trip provided that the safety relief valve capacity at normal operating conditions is $90 \%$ or more of the rated steam flow. The power increase following a turbine trip was much smaller than in a comparable BWR.

The parametric calculations showed that the SCWR could easily tolerate reactivity insertion rates between 5 and $100 \mathrm{pcm} / \mathrm{s}$ provided that the reactor was scrammed at $118 \%$ neutron power. The peak cladding temperatures were less than $700{ }^{\circ} \mathrm{C}$ for these transients.

The relative safety performance of the SCWR designs with water moderator is summarized in Tables XXXII and XXXIII. Table XXXII shows the calculated peak cladding temperature for the transients initiated by upsets in the MFW system. The transients include overheating (loss of MFW flow) and overcooling (decrease in MFW temperature) events. Because insulation is one of the principal differences between the designs, Table XXXII also includes results from sensitivity calculations with a 1$\mathrm{mm}$ thick layer of zirconium oxide on the water rod wall.

Table XXXII shows that the base designs described in Table XI (water rods without insulation, power channels with $0.5 \mathrm{~mm}$ insulation) respond similarly during the loss of MFW events. The peak cladding temperature in the design with water rods is slightly higher following the $50 \%$ step decrease in MFW flow and slightly lower following the total loss of MFW. The peak cladding temperature is significantly lower in the design with the power channels in the overcooling event. The effect of insulation is to reduce 
the maximum steady-state cladding temperature by reducing the fluid temperature of the coolant. The insulation retards the flow of heat from the fuel channel to the water rods during an overheating transient, which keeps more of the heat inside the fuel channel and results in a larger increase in cladding temperature. Consequently, insulation actually increases the peak cladding temperature during the overheating transients studied. As discussed in Section 3 of this report, insulation is required to meet the steady-state temperature limit for the design with water rods. The peak cladding temperatures are lower in the design with power channels than in the design with insulated water rods for all three of the transients evaluated. Thus, the overall response to transients initiated by MFW upsets is better in the design with power channels.

Table XXXII. Summary of calculated results for transients initiated by MFW upsets for the designs with solid moderator.

\begin{tabular}{|l|c|c|c|c|}
\hline & $\begin{array}{c}\text { Safety } \\
\text { system } \\
\text { action }\end{array}$ & \multicolumn{3}{|c|}{ Design } \\
\hline & \multicolumn{2}{|c|}{ Water rods } & $\begin{array}{c}\text { Power } \\
\text { channels }\end{array}$ \\
\hline Insulation, mm & & \multicolumn{2}{|c|}{ Peak cladding temperature ${ }^{\circ}$ C) } \\
\hline Event & None & 793 & 820 & 790 \\
\hline $50 \%$ step decrease in MFW flow & $\begin{array}{c}\text { Scram } \\
15 \% \text { AFW }\end{array}$ & 809 & 847 & 821 \\
\hline Total loss of MFW flow & None & 780 & 750 & 694 \\
\hline $\begin{array}{l}30^{\circ} \mathrm{C} \text { step decrease in MFW } \\
\text { temperature }\end{array}$ & & & & \\
\hline
\end{tabular}

Table XXXIII summarizes the response of the two designs during LOCAs by showing the time that the maximum cladding temperature reached $1204{ }^{\circ} \mathrm{C}$, which corresponds to the accident limit for current LWRs with Zircaloy cladding. The response of the design with water rods was better for the LOCAs initiated by a large steam line break and a small feedwater line break because the accident limit was reached later, allowing more time for the safety systems to actuate and mitigate the transient. The larger reactor vessel in this design slowed the depressurization rate and delayed the onset of the nearly adiabatic heatup. The heatup rate was also slower in this design because of its larger fuel rods. The response of the design with power channels was better for the LOCA initiated by a large feedwater line break. In this transient, the heatup was primarily caused by the re-distribution of the initial stored energy in the fuel rod, which was lower in the design with power channels because of the insulation and the higher core mass flux.

Table XXXIII. Summary of calculated LOCA results for the designs with water moderator.

\begin{tabular}{|l|c|c|c|}
\hline & $\begin{array}{c}\text { Safety } \\
\text { system } \\
\text { action }\end{array}$ & \multicolumn{2}{|c|}{ Design } \\
\hline \multicolumn{1}{|c|}{ LOCA } & & Water rods & $\begin{array}{c}\text { Power } \\
\text { channels }\end{array}$ \\
\hline $100 \%$ steam line break & & Time to reach accident limit (s) \\
\hline $100 \%$ feedwater line break & None & 419 & 338 \\
\hline $5 \%$ feedwater line break & Scre & 26 & 57 \\
\hline
\end{tabular}

A comparison of the times presented in the table shows that relatively long times are available for safety systems to mitigate the large steam line break and the small feedwater break. Thus, both designs are 
considered acceptable for these transients. The table shows that the large feedwater line break is the most limiting transient because the temperature limit is reached much earlier. Since the design with power channels has more time available during the most limiting transient, the overall response to LOCAs is judged better for the design with power channels. Designing safety systems to protect the core during a large feedwater line break will be challenging because of the higher operating temperature of the SCWR and the reduced margin to the temperature limit. However, sufficient time appears available to develop a reasonable safety system design.

\subsection{Reactor Vessel Design And Analysis (Larry Conway and John Kielb, Westinghouse)}

\subsubsection{Introduction}

As outlined in Section 2, the SCWR design is focusing on using a direct cycle energy conversion system in order to greatly simplify the overall reactor plant design. With a direct cycle, the reactor coolant from the feedwater system enters the reactor vessel at supercritical pressure $(25.0 \mathrm{MPa}, 3625 \mathrm{psia})$ and at a temperature of $280{ }^{\circ} \mathrm{C}\left(536{ }^{\circ} \mathrm{F}\right)$. The coolant is heated to $\sim 500{ }^{\circ} \mathrm{C}\left(932^{\circ} \mathrm{F}\right)$ and exits the reactor vessel as a supercritical fluid and is delivered directly to the power conversion (turbine-generator) equipment. Inside the reactor vessel, a portion of the inlet water ( $90 \%)$ is to be directed to the upper head of the reactor vessel, where it then flows downward through the fuel via water rods positioned in the fuel assembly. The water in these water rods provides additional neutron moderation, especially at the top of the fuel assemblies, where the exiting supercritical fluid density is very low. This study was performed to establish the feasibility and general layout of the reactor vessel, focusing on identifying issues associated with operating the reactor with an outlet fluid temperature of $500{ }^{\circ} \mathrm{C}\left(932^{\circ} \mathrm{F}\right)$ and at elevated pressures as compared to current PWRs.

The preliminary SCWR vessel design has remained similar to a typical large PWR vessel in many respects, and has used current PWR materials for the vessel pressure boundary. The use of standard PWR vessel design, manufacturing techniques, and materials should prove to be a major economic advantage for the SCWR compared with other Generation IV reactor concepts; the latter will require the use of advanced alloys operating at much higher temperatures. Key considerations in the design of the SCWR vessel design included:

- The reactor coolant flow path should be designed to keep the $280{ }^{\circ} \mathrm{C}\left(536^{\circ} \mathrm{F}\right)$ feedwater fluid in contact with the reactor vessel surface so that currently accepted, state-of-the art, LWR materials such as SA 508 Grade 3 Class 1 carbon steel can be employed in the fabrication of the vessel and head forgings.

- The SCWR should employ the use of control rod drive mechanisms that are mounted in the reactor vessel head versus using bottom mounted control rod drive mechanisms as in current BWRs, so that the reactor core can be located as low in the reactor vessel as possible. This arrangement minimizes the amount of water that needs to be added to the reactor vessel following postulated loss-of-coolant-accidents (LOCAs). It also allows the overall reactor vessel length to be much shorter and represents a significant savings in reactor vessel overall weight, which maximizes the ease of transportation and installation.

- The reactor vessel should have no penetrations in the bottom head in order to facilitate ex-vessel cooling and prevention of core melt-through in the event of severe accidents. This will dictate 
that the SCWR core instrumentation will be inserted through the reactor vessel head, as is currently done in the latest PWR designs.

- The requirement to prevent contact between the core outlet fluid and the pressure vessel will result in the need for the vessel outlet nozzles to have thermal sleeves from the region above the core into the vessel outlet piping.

- The SCWR core design shall utilize a 25x25 fuel assembly that has 36 "square" water moderation rods that will direct feedwater downward through the fuel assembly, in order to achieve a reasonably uniform moderation of the fuel over its entire length.

- The reactor vessel shall be designed to contain $14525 \times 25$ fuel assemblies and shall operate at a nominal thermal power of $3575 \mathrm{MW}$.

- The reactor vessel shall be designed for a core inlet flow rate of $1,843 \mathrm{~kg} / \mathrm{second}(\sim 37,600 \mathrm{gpm})$.

With the above general constraints, the SCWR reactor vessel design study concluded that the SCWR vessel could be designed and manufactured in a manner similar to current PWR reactor vessels. Additional design effort remains to be performed to complete the reactor internals preliminary design, which will require some novel design features, but no unfeasible issues have been identified.

\subsubsection{Reactor Pressure Vessel Design}

The "first-cut" vessel dimensions for the SCWR reactor vessel were established based on the following:

- Provide a sufficient vessel diameter to fit the $145,25 \times 25$ fuel assemblies required to obtain the desired 3545 MWth reactor heat output.

- The vessel diameter shall provide sufficient room for a radial core reflector around the core, inside the core barrel.

- The SCWR core barrel is be $100 \mathrm{~mm}$ ( $\sim$-inches) thick (this thickness assumes that the barrel may need to be a double walled insulated device).

- The water filled vessel downcomer is to be $410 \mathrm{~mm}$ ( 16 -inches) wide in order to provide sufficient shielding and limit the neutron fluence levels in the vessel wall to values similar to or lower than those experienced in existing PWR vessels (PWR vessel downcomer gaps are typically about $225 \mathrm{~mm}$ and this value may to adjusted lower in the final design).

- The vessel height is to be consistent with a "14-foot" core, and shall provide sufficient room for traditional PWR-type reactor core control rods and drive rods.

The above considerations resulted in a vessel with an inside radius of 2.66 meters (104.75"). The inside radius of the reactor vessel head was established to be 2.68 meters (105.34").

Based on using SA-533 (plate) or SA-508 (ring forged) Grade 3, Class 1 material which has a stress $\mathrm{S}_{\mathrm{m}}$ of $26700 \mathrm{psi}(184.14 \mathrm{MPa})$ at temperatures $\leq 371{ }^{\circ} \mathrm{C}\left(700^{\circ} \mathrm{F}\right)$, and a design pressure of $27.5 \mathrm{MPa}(3989$ psia); the following vessel wall thicknesses were established using the minimum thickness calculations based on ASME Code, Section III, Class 1, NB-3324:

- The vessel shell wall thickness - $45.7 \mathrm{~cm}(18.0$ "), minimum required thickness $-43 \mathrm{~cm}$ (16.911”).

- The vessel upper nozzle and closure flange ring-forging wall thickness was established to be $62.9 \mathrm{~cm}(24.75$ ") based on PWR experience.

- The vessel lower head wall thickness $-30.5 \mathrm{~cm}$ (12.0"), minimum required thickness -21.6 cm (8.503").

- The vessel upper head thickness was established to be $30.5 \mathrm{~cm}$ (12") in order to account for the control rod drive and instrument penetrations. 
For this study, two inlet and two outlet nozzles were assumed; and the inlet and outlet nozzle sizes required for the SCWR were selected as 45.7 and 73.7 $\mathrm{cm}$ (18 and 29 inch) inside diameter, respectively. The inlet nozzle, which contains high-pressure water, was sized to limit the fluid velocity to < $\sim 8 \mathrm{~m} / \mathrm{s}(25 \mathrm{ft} / \mathrm{sec})$. To reduce the in-vessel pressure losses and improve the flow distribution capability, the current PWR loop piping velocities approach $16 \mathrm{~m} / \mathrm{sec}(50 \mathrm{ft} / \mathrm{sec})$. The SCWR outlet nozzles were sized to limit the outlet flow velocity to $<\sim 23 \mathrm{~m} / \mathrm{s}(75 \mathrm{ft} / \mathrm{sec})$ to limit pressure losses and forces on the in-vessel upper internals components.

Based on the above sizing and wall thickness bases, the SCWR vessel outline is illustrated in Figure 118 with various dimensions given in Table XXXIV. As shown in the table, the current design is a vessel with an inner diameter of $5.322 \mathrm{~m}$ $(17.46 \mathrm{ft})$, an outer diameter of $6.256 \mathrm{~m}(20.52 \mathrm{ft})$, and a shell thickness of $46 \mathrm{~cm}(\sim 18 \mathrm{in})$. The vessel overall height of $12.40 \mathrm{~m}(40.7 \mathrm{ft})$ with the upper head in place, is based on the AP1000 reactor vessel (Westinghouse's latest PWR design which utilizes 14 feet long fuel assemblies). As shown in Figure 118, the nozzle ring forging course will be thicker than the lower shell courses, and a thickness of 0.629 meters ( 24.75 inches) has been assumed for preliminary calculations. The actual required thickness of the nozzle ring forging will be determined later, based on more detailed evaluations including the closure flange bolting loads.

The weight of the bottom portion of the SCWR reactor vessel shell based on the above dimensions is estimated to be $\sim 730$ metric tons $\left(1.6 \times 10^{6} \mathrm{lbs}\right)$. This vessel weight is comparable to other large PWR components and does not impose any new transportation or installation feasibility issues.
Table XXXIV. SCWR Reactor Vessel Parameters.

\begin{tabular}{|l|l|}
\hline \multicolumn{1}{|c|}{ Parameter } & \multicolumn{1}{c|}{ Value } \\
\hline Type & $\begin{array}{l}\text { PWR with top control } \\
\text { rod drives }\end{array}$ \\
\hline Height & $12.40 \mathrm{~m}$ \\
\hline Material & SA-508 \\
\hline Operating/design press. & $25.0 / 27.5 \mathrm{MPa}$ \\
\hline Operating/design temp. & $280 / 371^{\circ} \mathrm{C}$ \\
\hline \# of inlet/outlet nozzles & $2 / 2$ \\
\hline Inside diameter of shell & $5.322 \mathrm{~m}$ \\
\hline Thickness of shell & $0.457 \mathrm{~m}$ \\
\hline Inside diameter of head & $5.352 \mathrm{~m}$ \\
\hline Thickness of head & $0.305 \mathrm{~m}$ \\
\hline Vessel weight & $780 \mathrm{t}$ \\
\hline Peak fluence $(>1 \mathrm{MeV})$ & $<5 \times 10^{19} \mathrm{n} / \mathrm{cm}^{2}$ \\
\hline
\end{tabular}


The operating pressure of the SCWR reactor vessel is $25 \mathrm{MPa}$ (3626 psia) and the operating temperature will be $280{ }^{\circ} \mathrm{C}$, with a design pressure of $27.5 \mathrm{MPa}$ (3989 psia). The reactor vessel design temperature will be limited to $371{ }^{\circ} \mathrm{C}\left(700{ }^{\circ} \mathrm{F}\right)$ based on the current vessel material (conventional PWR vessels have a design temperature of $\left.343{ }^{\circ} \mathrm{C}\left(650^{\circ} \mathrm{F}\right)\right)$. To ensure the reactor vessel temperature remains below the 371 ${ }^{\circ} \mathrm{C}$ design temperature, the vessel internals will be designed such that only the $280{ }^{\circ} \mathrm{C}$ inlet fluid contacts the vessel and head, and the design will include a feature such as a thermal sleeve, to insulate the vessel outlet nozzle from the outlet coolant temperature of $500{ }^{\circ} \mathrm{C}$.

\subsubsection{Pressure Stress Analysis}

Based on the above reactor vessel dimensions, material, design pressure, and design temperature, a pressure stress analysis was performed. This analysis was based on a quarter-symmetry, threedimensional model of the vessel with the PRO/MECHANICA computer software (See Figures 119 and 120). For this analysis, the reactor vessel was assumed to be supported directly below each of the four main coolant nozzles, which is typical of PWRs. The vessel length, assumed to be similar to the AP1000 reactor vessel, has little impact on this analysis.

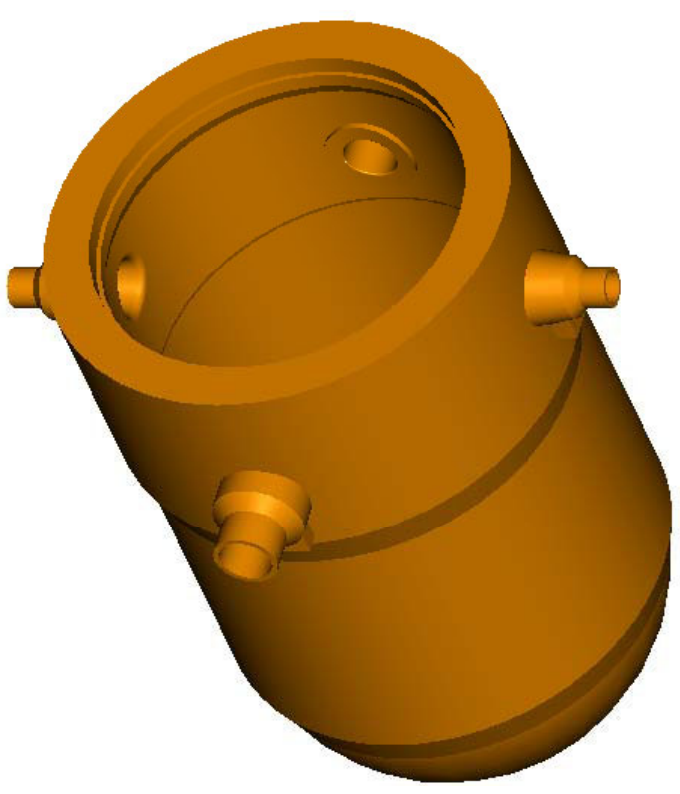

Figure 119. Three-dimensional model of SCWR reactor vessel.

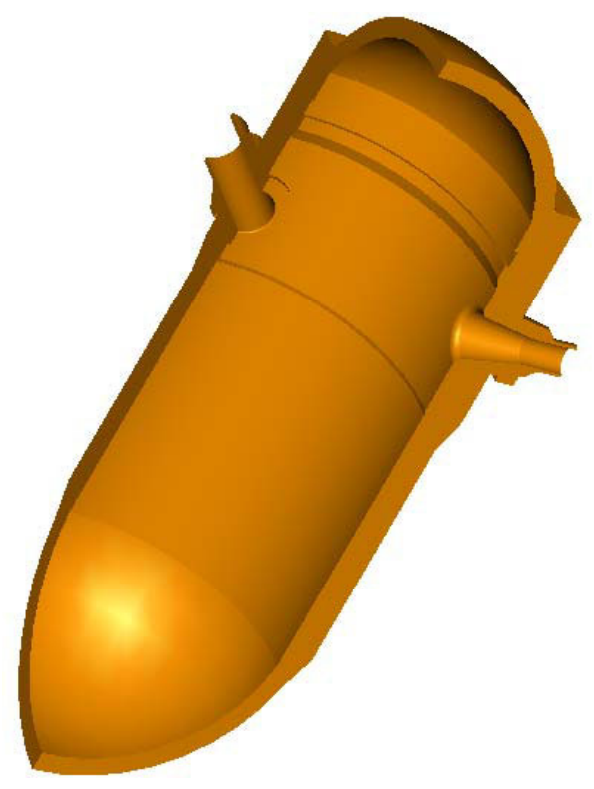

Figure 120. One quarter section model of SCWR reactor vessel and upper head.

The results of this analysis are shown in Figures 121 and 122. Figure 121 shows primary membrane stresses due to pressure at $371{ }^{\circ} \mathrm{C}\left(700^{\circ} \mathrm{F}\right)$, which is the ASME temperature limit for the reactor vessel material. The stresses above the 26,700 psi $\mathrm{S}_{\mathrm{m}}$ stress for SA 508 forgings are shown in red, and it can be seen that the average stress through the wall cross-sections are well below the $\mathrm{S}_{\mathrm{m}}$ stress limit and therefore are within allowables. This conclusion is consistent with the design sizing calculations. Figure 122 shows stresses above the allowable 40,050 psi primary local membrane plus bending stress at the limiting material temperature. This figure shows that the only regions exceeding the allowable are at the nozzle to shell interface at the inside surface of the vessel. The stress contours shown include stress concentration effects caused by the large structural discontinuities that occur at the nozzle inserts. Such stresses are classified as peak stresses and need not be included in the primary stress evaluation. It is 
concluded that all the reactor vessel primary stresses due to pressure are within the allowable limits up to the maximum allowable ASME temperature.

It is again noted that the above analysis assumes that the reactor vessel pressure boundary is not exposed to the $500{ }^{\circ} \mathrm{C}\left(932^{\circ} \mathrm{F}\right)$ outlet fluid temperature, since the vessel material is only ASME Code approved for use at up to $371{ }^{\circ} \mathrm{C}\left(700{ }^{\circ} \mathrm{F}\right)$. This limit applies also to the outlet nozzle and therefore, a thermal sleeve must be included in the design to conduct the outlet fluid from the outlet plenum above the core region, into the outlet piping beyond the vessel nozzle. This thermal sleeve will impact the outlet nozzle design shown above. The design of this thermal sleeve and the resulting impacts on the other reactor vessel components will be accomplished in the next phase of the SCWR design program. This effort will also evaluate the applicability and use of alternative materials more suitable to high temperature operation for the outlet nozzles and those parts of the internals exposed to the elevated SCWR outlet temperature.

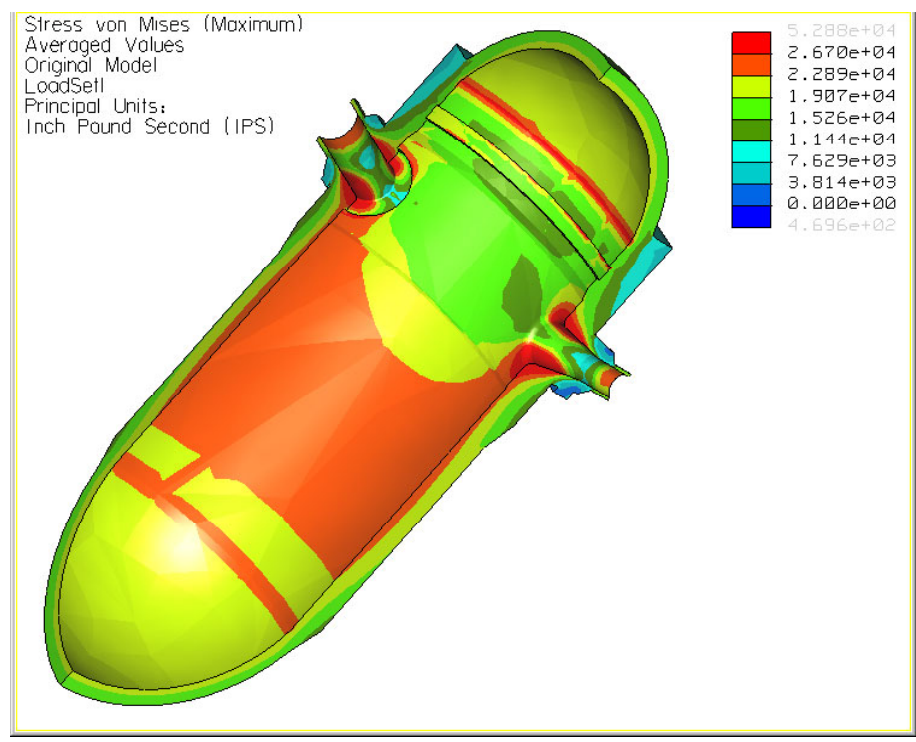

Figure 121. SCWR reactor vessel pressure analysis (membrane and cross-section stresses acceptable).

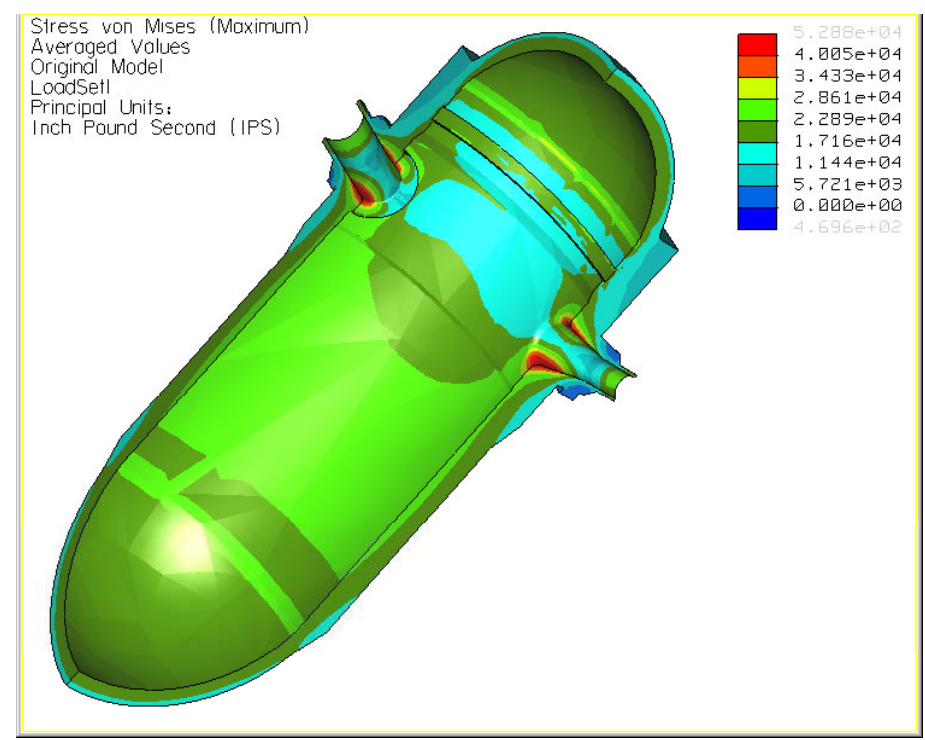

Figure 122. SCWR reactor vessel pressure analysis (local, membrane, and cross-section bending stresses acceptable).

It is also noted that the reactor vessel secondary and peak stress evaluations for fatigue effects due to Level A and Level B service loads are to be evaluated in the next portion of the design effort. These loads are highly dependent on the severity and number of occurrences of transient conditions that will occur during the SCWR operation. These transients have not yet been completely identified, and/or the number of occurrences has not be determined. When these transient evaluations have been completed the SCWR vessel fatigue analysis will be performed.

\subsubsection{SCWR Vessel Manufacturability}

As mentioned, the primary candidate materials for the SCWR reactor vessel and upper head are the same as used in current PWRs; namely, SA 508 Grade 3 Class 1 forging (formerly

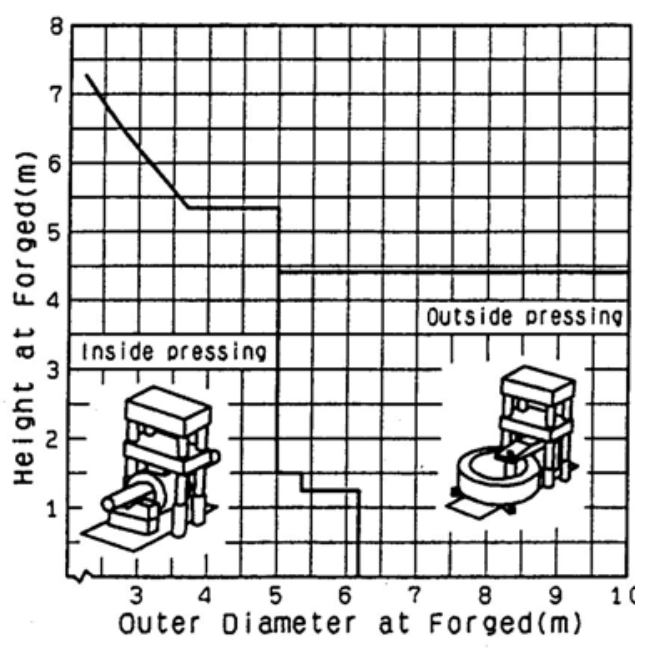

Figure 123. Reactor vessel fabricator ring forging meters capacity exceeds 4 meters. 
designated SA 508 Class 3) or SA 533, Grade 3, Class 1 plate. Of these two materials, which have similar chemical compositions and the same design stress intensities in the ASME Code, the SA 508 forging is preferred to eliminate the need for axial welds in the reactor vessel. It is also highly desirable to be able to fabricate forgings of sufficient length to keep circumferential welds outside the region adjacent to the core (beltline region). Thus the welds between ring forgings are exposed to a much lower fluence level than the forged material, and will not be the limiting factor for evaluating vessel embrittlement, which establishes the reactor vessel usable life time. Based on information from Japan Steel Works (JSW) the current maximum forging lengths that can be provided are similar to the current SCWR "active" core height of $\sim 4.3 \mathrm{~m}(14 \mathrm{ft})$. Thus, it can be concluded that the manufacturing capability exists to fabricate the SCWR reactor vessel with the currently specified material, using ring forgings of the expected thickness and height to meet the SCWR requirements. Examples of JSWs forging capabilities with SA 508 material are illustrated in Figures 123 and 124. There are no new concerns or feasibility issues in making the circumferential welds joining the thick ring forgings and/or the forged heads. Note that the reactor vessel base metal shell will be clad with a weld overlay of a suitable stainless steel as is done in current PWRs to prevent corrosion of the base metal.

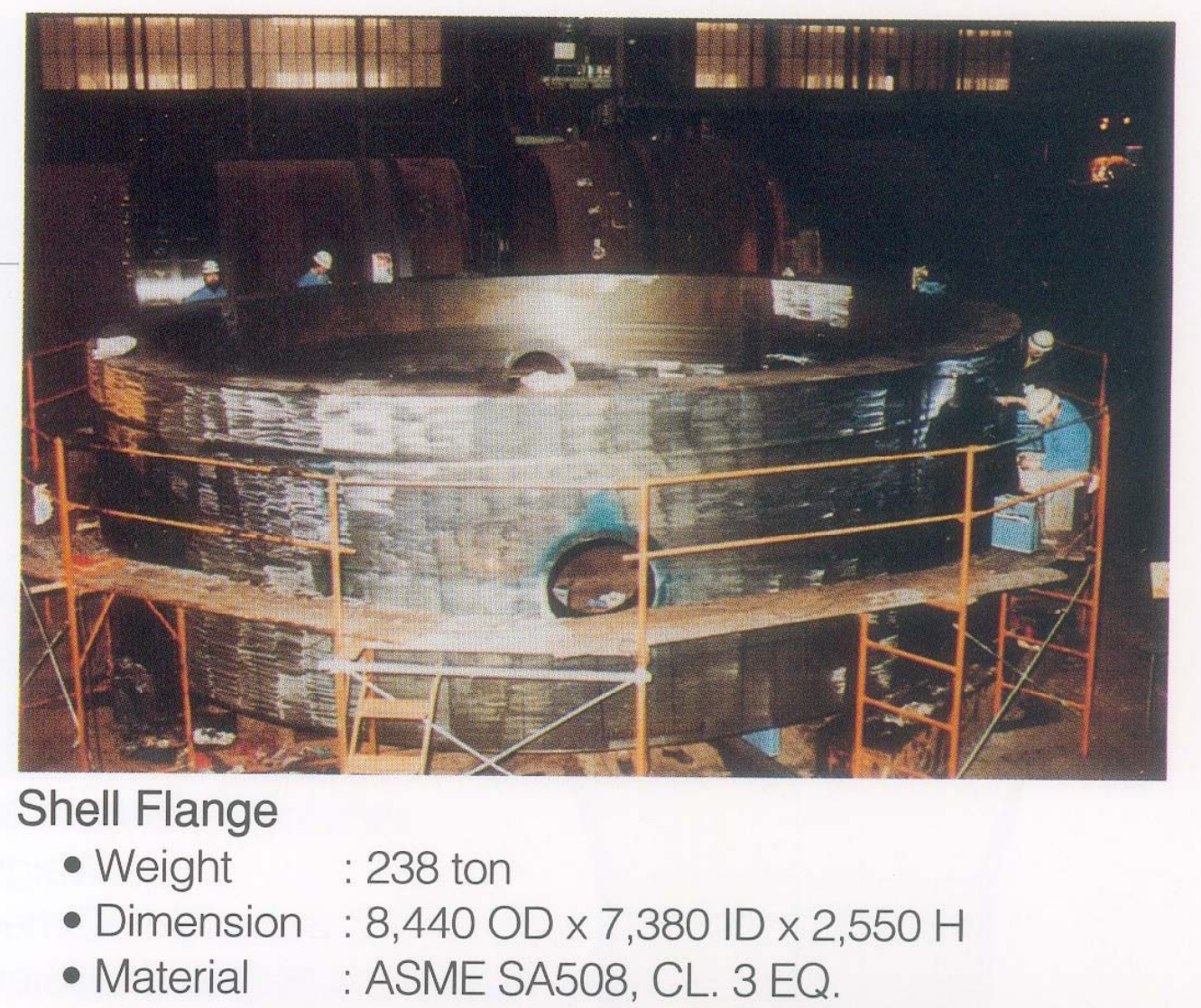

Figure 124. Picture of a reactor vessel nozzle ring forging with a 21 inch wall thickness.

As discussed above, if the reactor vessel internals design cannot include thermal sleeves or other techniques to insulate the outlet nozzles, then more highly alloyed steel must be considered for the nozzle inserts and perhaps for the nozzle ring to accommodate the higher operating temperature of $500{ }^{\circ} \mathrm{C}$. In this case, a Cr-Mo steel, such as an advanced 9Cr-1 Mo-V (Grade 91), would be required. Additionally, given the shell thickness required for the use of SA 508 Grade 3 Class 1 material, consideration will be given to the use of alloys of higher strength such that the thickness of the entire shell can be reduced. This would primarily reduce the weight of the vessel and provide advantages in the transportation of the 
reactor vessel to the plant site and placement of the vessel at the site. Of course, the impact of any new materials on the fabrication of the reactor vessel would have to be assessed.

\subsubsection{The SCWR Reactor Internals}

In addition to the reactor vessel stresses discussed above, the thermal stress that occurs across the reactor vessel internal structures, such as the core barrel and the upper outlet plenum support plate, were given a preliminary review since these structures would be exposed to the full inlet to outlet fluid $\Delta \mathrm{T}$ during plant operation. These preliminary analyses indicate that these "thick" structures will develop high stresses just due to the large $\left(220^{\circ} \mathrm{C} / 400{ }^{\circ} \mathrm{F}\right)$ temperature difference in the fluid contacting the opposite sides of the structures. Therefore it is recognized that these structures need to include specific design features to reduce their $\Delta \mathrm{T}$ and/or thermal stress. In addition, the arrangements for supplying water to the water rods from the reactor vessel upper head while preserving all the anticipated functions of the control rods are also being evaluated.

These preliminary evaluations indicate that the reactor vessel internals that are exposed to the $\mathrm{T}_{\text {cold }}$ fluid on one side and $\mathrm{T}_{\text {hot }}$ fluid on the other side will develop high stresses due to the very high temperature difference across the wall. These components need to be designed with features to minimize these thermally induced stresses. The affected components include the core barrel/neutron reflector structure that surrounds the core and the upper internals barrel extension (these components define the downcomer region and the core exit flow plenum), the core exit plenum top plate that separates the core exit fluid from the cold water in the upper head, and the hot leg thermal sleeve. Features being considered for these components include the use insulating material on the $\mathrm{T}_{\text {hot }}$ side so that the material is maintained near the $\mathrm{T}_{\text {cold }}$ temperature, and the $\Delta \mathrm{T}$ is greatly reduced. A potential solution for components like the hot leg thermal sleeve is to make the sleeve sufficiently thin so that excessive thermal stresses are not possible. Figures 125 and 126 illustrate the deflections and stresses, respectively, that can be induced in thickwalled reactor vessel internals, such as the upper rod guide support plate and barrel, by the large SCWR $\mathrm{T}_{\text {cold }}$ to $\mathrm{T}_{\text {hot }}$ temperature difference.

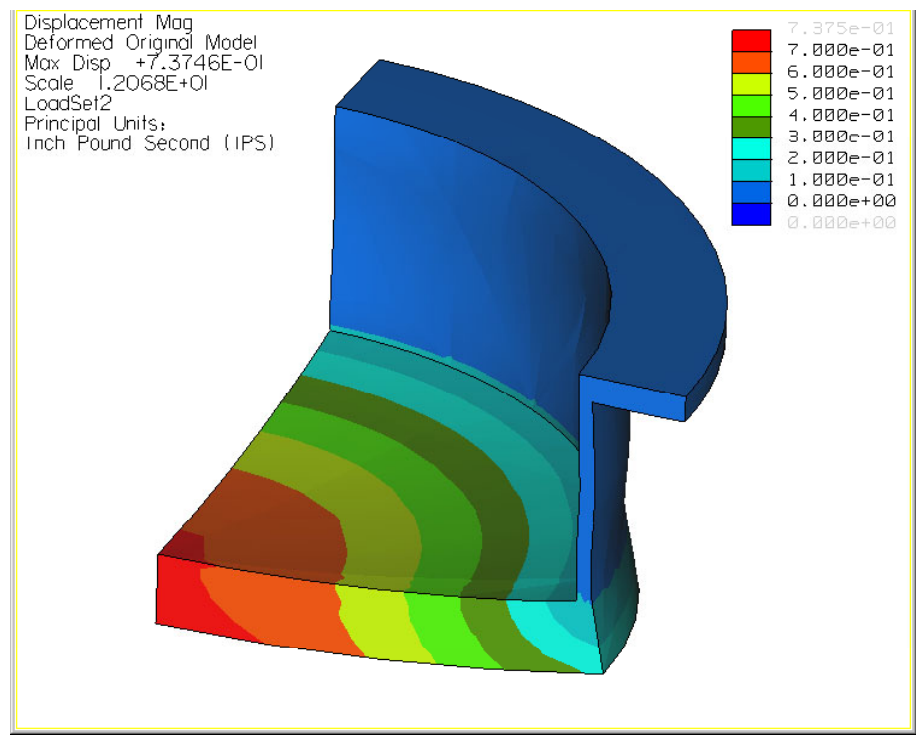

Figure 125. SCWR reactor vessel internals upper guide support plate and barrel thermal deflection due to the temperature difference between the cold and hot sides.

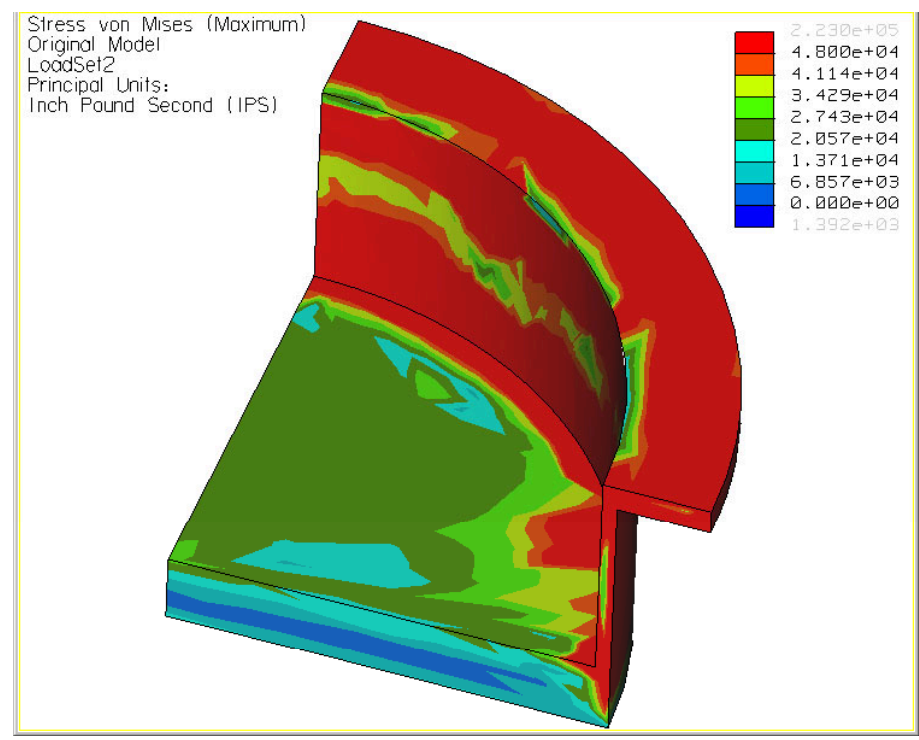

Figure 126. SCWR reactor vessel internals upper guide support plate and barrel Von Mises stress due to the temperature difference between the cold and hot sides. 
Figure 126 shows results that indicate that much of the structure will exceed the 3 Sm primary + secondary ASME Code stress limit of Subsection NG without considering any other stresses due to flow forces or mechanical loadings.

Another important feature of the SCWR reactor vessel internals design effort is to determine the water rod supply and control rod guide design. This design will be part of the on-going reactor design, in that the optimum arrangement has not been selected, but the feasibility of supplying water from the reactor vessel upper head to the water rods while maintaining all control rod functions appears to be mechanically feasible. The most favored arrangement at this time is to use a single water supply tube for each fuel assembly. This supply tube would be large enough to contain a reactor control cluster assembly (RCCA) with 16 rodlets, which can be inserted into the 16 center water rods of the fuel assembly. The supply tube would contain the RCCA guides that would ensure alignment with the rodlet thimbles in each of the appropriate water rods. These guides would be very similar to the RCCA guides used in current PWRs. The water supply tubes would extend through the upper core support plate and mate directly with its associated fuel assembly. Water flow to the 16 innermost and 20 outer water rods would be directed by a water distribution plate that acts as a manifold and which is part of each fuel assembly. The advantages of this single, large water supply tube for each fuel assembly include:

- The number of water supply tubes in the core exit plenum calandria is minimized.

- Each water supply tube would mate directly to a matching nozzle at the top of the fuel assembly, minimizing the number of connections, possible alignment problems, and potential leakage paths.

- By containing all the rodlets of the RCCA and their guides in a single water supply tube, the control rod and guide design becomes very similar to current PWRs.

- The RCCA spider (to which the 16 rodlets are attached) can be inserted inside the single tube to just above the top of the assembly, just as in current PWRs. The withdrawn rod position also is just as in current PWRs, where the rodlets are just above the fuel assembly.

- The ability to move the RCCA spiders inside the large water supply tubes means that the core exit plenum and the water rod supply tubes do not impact the reactor vessel length.

- The RCCA, with all 16 rodlets on the spider, can be inserted into its associated fuel assembly and disconnected from the drive mechanism drive rod. This allows the RCCA to remain in the fuel assembly during refueling operations. This capability, combined with having a control rod in each fuel assembly, makes it possible to consider a "rodded refueling" where no boric acid or other soluble poison needs to be added to the coolant.

- Because the control rods can be inserted into the fuel assemblies and the drive rod disconnected, the drive rod can then be fully raised and removed with the upper head of the vessel. Subsequently, the upper internals (including the core outlet plenum with the water supply tubes, and upper core support plate) can be removed in one piece to expose the rodded assemblies for removal, replacement, and/or shuffling. Thus, the SCWR refueling method is almost identical to current PWRs.

The appropriate material for the water supply tubes and the RCCA guides is not yet finalized. Because these components are exposed to relatively low dose conditions, a recommended candidate alloy is $304 \mathrm{~L}$ austenitic stainless steel, based on experience with currently operating light water reactors. The dose and temperature regime where this alloy is recommended is below the observed threshold for IASCC in current LWRs. The L grade is specified here because of its better corrosion resistance, although 304 has been used in LWR's. However, additional evaluations are required to finalize these selections. For example, in the case of the control rod guide thimbles, located within the water rods, Zircaloy 4 is recommended based upon its proven performance in LWRs at the anticipated low operating temperatures $\left(<300^{\circ} \mathrm{C}\right)$ and for its very low thermal neutron absorption cross section. 


\subsubsection{Conclusions}

The reactor vessel and internals design effort of the past year has provided several major conclusions important to the continued SCWR design progress, including:

- The SCWR can utilize a reactor vessel that is constructed in a similar fashion to existing PWR and BWR reactors. The SCWR reactor vessel can utilize the same materials as current LWRs and can be fabricated using existing vendors.

- The feasibility of designing the reactor vessel internals so that the fluid in contact with the vessel walls is within current PWR operating temperatures was confirmed.

- The feasibility of incorporating water rods in the fuel assembly and supplying these rods with $\mathrm{T}_{\text {cold }}$ fluid has been confirmed on a conceptual design basis.

- The SCWR reactor internals and vessel designs need to incorporate special design features to prevent excessive thermal stresses in structures exposed to both the $T_{\text {hot }}$ and $T_{\text {cold }}$ fluid temperatures.

- The conceptual design of the fuel moderating water rods is consistent with the use of standard PWR type control rods and control rod guides, and can be incorporated with little impact on the vessel overall length.

\subsection{Reactor Vessel Analysis (Prof. Robert Witt, INEEL)}

\subsubsection{Analyses of Reference SCWR Reactor Pressure Vessel}

In preparation for both static and transient structural design and analyses of the reactor pressure vessel and its internals, we performed several static analyses on the reference geometry described in Sections 2 and 5.1 above. The analyses were performed with Structural Dynamics Research Corporation's I-DEAS software. For the preliminary analysis, we used the default properties of "generic, isotropic steel" in the software's material library. The relevant properties of this steel, in English units, are: E (modulus of elasticity $)=30 \mathrm{Mpsi}, v$ (Poisson's ratio) $=0.29, \rho($ density $)=7.317 \times 10^{-4} \mathrm{lb}_{\mathrm{f}} \mathrm{s}^{2} / \mathrm{in}^{4}, \alpha$ (thermal expansion coefficient $)=6.5 \times 10^{-6} /{ }^{\circ} \mathrm{F}$, and $\mathrm{k}$ (thermal conductivity) $=5.62 \mathrm{lb}_{\mathrm{f}} / \mathrm{s} \cdot{ }^{\circ} \mathrm{F}$.

Each model was meshed with approximately 20,000 10-node tetrahedral elements. There were about 33,000 nodes and 100,000 degrees-of-freedom in the structural models and 33,000 nodes and degrees-offreedom in the thermal models. In some details of the analyses shown below, the element boundaries are visible to give a sense of the mesh density.

\subsubsection{Stress Distribution from Internal Pressure}

The design pressure of the SCWR reactor pressure vessel is 3989 psi. The plots in Figure 127 show the pressure-induced Von Mises equivalent stress in the whole vessel (left) and a detail at the outlet nozzle (right). These distributions were obtained by loading all internal surfaces with the design pressure and employing the following boundary conditions: (1) the lateral surfaces of the quarter-vessel model are subjected to symmetry boundary conditions, (2) the outward-facing surfaces of the nozzles are subjected to axial tensile stress of magnitude $\sigma_{\eta}=\mathrm{pR}_{\mathrm{n}} / 2 \mathrm{t}_{\mathrm{n}}$, where $\eta$ is the axial direction along the nozzle, $\mathrm{p}$ is the pressure and $R_{n}$ and $t_{n}$ are the average radius and thickness of each nozzle respectively, and (3) the support pedestals underneath the nozzles are constrained to have no vertical deflection. Peak Von Mises stresses just exceed $50 \mathrm{ksi}$. Because these peak stresses are due to stress concentrations around the nozzles, they are extremely localized. In addition, contributions from temperature-induced stress tend to 
attenuate this peaking, as will be seen in subsequent sections. These peak stresses need not be considered with respect to the limits on primary membrane plus bending stress (limited to $40 \mathrm{ksi}$ ), but they may be of interest with respect to fracture and fatigue. Means of reducing these peak stresses are described in Section 5.6.2.
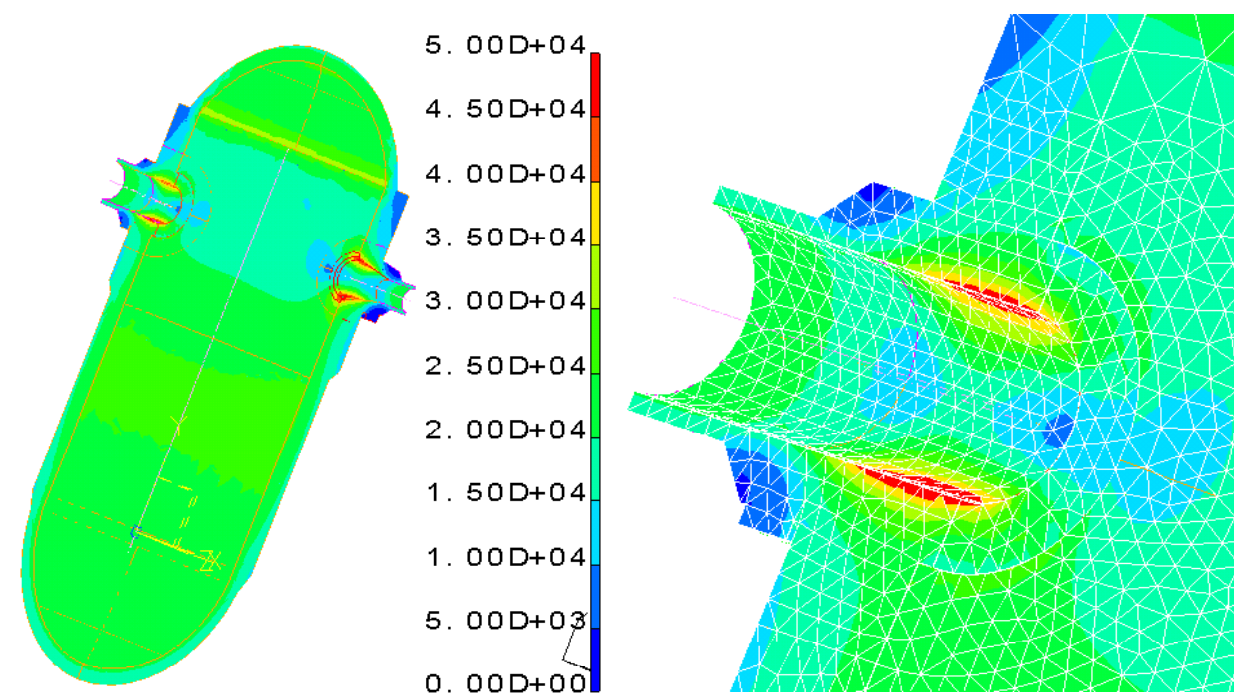

Figure 127. Distribution of Von Mises stress [psi] from pressure load in the whole vessel (left) and around the outlet nozzle (right).

\subsubsection{Stress Distribution from Vessel Weight}

The total weight of the SCWR reactor pressure vessel is on the order of $2 \times 10^{6} \mathrm{lbs}$. This weight is to be supported by four pedestals underneath the two inlet and two outlet nozzles. Each inlet nozzle pedestal is $12 \times 30=360 \mathrm{in}^{2}$, and each outlet nozzle pedestal is $10 \times 40=400 \mathrm{in}^{2}$. The vertical stress from bearing the vessel weight ought to be approximately $2 \times 10^{6} \mathrm{lbs} / 1520 \mathrm{in}^{2}$, or about $1320 \mathrm{psi}$. Figure 128 below illustrates the Von Mises stress from the vessel weight under the same symmetry and vertical support conditions used for the pressure-induced loads.
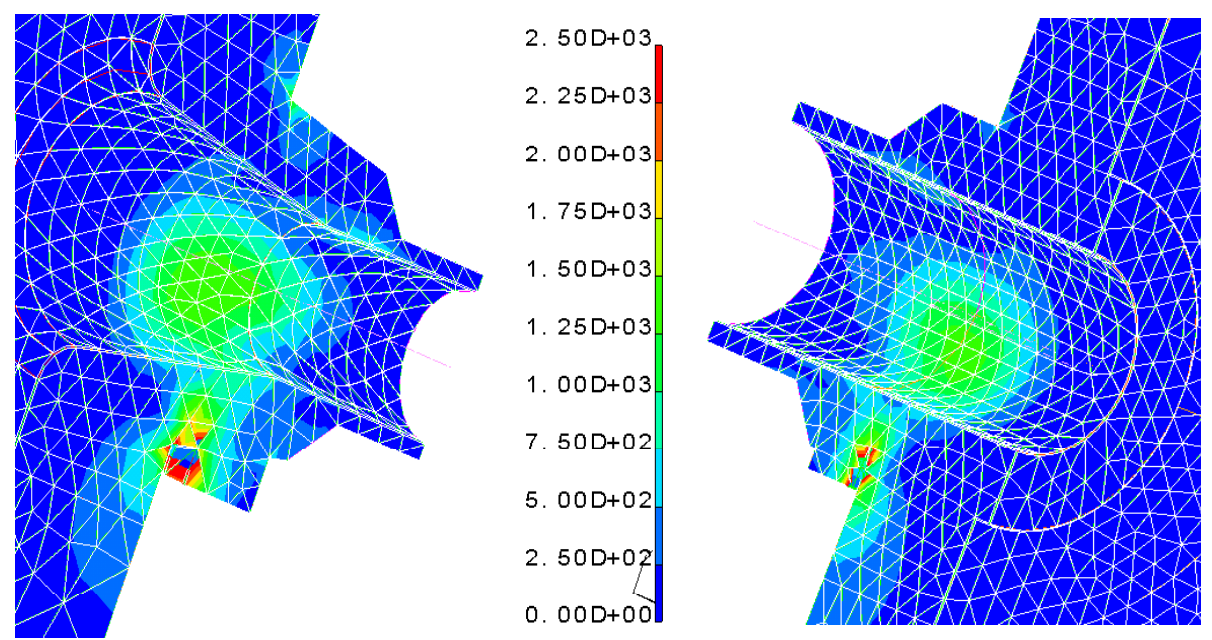

Figure 128. Distribution of Von Mises stress [psi] from vessel weight around the inlet nozzle (left) and around the outlet nozzle (right). 
It is first clear that the bulk of the vessel experiences negligible stress from its own weight, on the order of a few hundred psi. Peak stresses due to the weight include the bearing stress under the nozzle pedestals as well as some bending stress in the inlet and outlet nozzles due to the cantilevered support of the vessel weight from the pedestals. Figure 128 shows stress distribution details around both nozzles. The peak bending stresses around the nozzles do not exceed 1500 psi. The peak Von Mises stress (5290 psi) is under the outlet nozzle, but this peak stress can be reduced by appropriate modification of the geometry. In this initial model, transitions between the pedestals and nozzles were not chamfered (so there were sharp geometric transitions), producing stress concentrations at these locations. In any event, even under these conditions, peak stresses from the vessel's weight are an order of magnitude smaller than the pressure-induced stresses.

\subsubsection{Stress Distribution from Steady-State Vessel Temperature Profile}

In addition to stress induced from pressure loading and the vessel's weight, there are also stresses induced in the vessel from differential thermal expansion. It should be emphasized here that the results presented below are quite crude, because in order to know the appropriate boundary conditions to use in steady-state heat conduction, we have to know the orientation of the internals and the flow path of the water. Absent that, we have assumed that the entire inner surface of the vessel is at $280^{\circ} \mathrm{C}\left(536^{\circ} \mathrm{F}\right)$, with the exception of the outlet nozzle boundary condition described below. This condition on the vessel inner surface is the most optimistic possible in that it assumes perfect isolation of outlet water at $500{ }^{\circ} \mathrm{C}\left(932{ }^{\circ} \mathrm{F}\right)$ from the vessel inner surface.

We also know that a thermal sleeve will be required at the outlet nozzle to prevent the $500{ }^{\circ} \mathrm{C}$ water from degrading the vessel integrity, but again the design of this has not yet been completed. Here we have assumed a reference design that includes an unsophisticated (and poorly functioning) thermal sleeve, then examine cases of increasing outlet water isolation by attenuating the sleeve's thermal conductivity. The reference sleeve is assumed to be one inch thick with a representative steel thermal conductivity of 5 $\mathrm{lb}_{\mathrm{f}} / \mathrm{s} \cdot{ }^{\circ} \mathrm{F}$. Assuming perfect contact with the outlet nozzle and a perfect film coefficient between the flowing water and the inside of the sleeve, the overall heat transfer coefficient $(U=k / t)$ of this poorly designed sleeve would be $5 \mathrm{lb} /$ in $\cdot \mathrm{s} \cdot{ }^{\circ} \mathrm{F}$. The reference boundary condition along the inner surface of the outlet nozzle is therefore a convective condition with a heat transfer coefficient of $5 \mathrm{lb} /$ in $\cdot \mathrm{s}^{\circ} \cdot{ }^{\circ} \mathrm{F}$ coupled to an ambient temperature of $500{ }^{\circ} \mathrm{C}\left(932^{\circ} \mathrm{F}\right)$. Cases considered below include this reference case as well as cases with $\mathrm{k}$ (and therefore $\mathrm{U}$ ) attenuated by factors of 25,50 and 100 .

Finally, we need a heat sink condition along all the outer surfaces linking the vessel to the ambient containment air. In the BWR6 reactors, the larger sections of the vessel are surrounded by about three inches of reflective insulation. This insulation consists of metallic reflector sheets sandwiched between stainless steel sheets and is designed to trap an air volume between the insulation and reactor vessel to prevent convection [Perry 1986]. Heat fluxes from the surface of the insulation are about $65 \mathrm{Btu} / \mathrm{hr} \cdot \mathrm{ft}^{2}$ and exterior insulation surface temperature is about $150^{\circ} \mathrm{F}$. Assuming BWR water at $550{ }^{\circ} \mathrm{F}$, a BWR vessel thickness of 6.5 inches, and containment air at $85^{\circ} \mathrm{F}$, we can use this information to find a heat transfer coefficient between containment air and the exterior of the insulation, an effective thermal conductivity for the insulation, and an effective overall heat transfer coefficient between containment air and the vessel exterior. Even though there may be differences between SCWR insulation and BWR6 insulation, we have used the BWR6 values in our calculations as a first approximation.

The results of these calculations are as follows: a representative heat transfer coefficient between vessel insulation and containment air is about $5.7 \mathrm{~W} / \mathrm{m}^{2} \cdot \mathrm{K}\left(0.018 \mathrm{lb} /\right.$ in $\left.\cdot \mathrm{s} \cdot{ }^{\circ} \mathrm{F}\right)$; a representative thermal conductivity for the insulation is $0.0088 \mathrm{lb} / \cdot \cdot \mathrm{s} \cdot{ }^{\circ} \mathrm{F}$; and a representative overall heat transfer coefficient between containment air and vessel exterior (including the effect of the insulation) is $0.0025 \mathrm{lb} / \mathrm{in} \cdot \mathrm{s} \cdot{ }^{\circ} \mathrm{F}$. 
Around the insulated surface of the SCWR, these values produce a $\Delta \mathrm{T}$ across the vessel of a few ${ }^{\circ} \mathrm{F}$. Given the nature of this insulation (metal sheets sandwiched between other metal sheets), it is assumed that insulation of the nozzles is problematic, so the exterior surfaces of the nozzles are assumed to be coupled to containment air through a heat transfer coefficient of $5.7 \mathrm{~W} / \mathrm{m}^{2} \cdot \mathrm{K}\left(0.018 \mathrm{lb}_{\mathrm{f}} / \mathrm{in} \cdot \mathrm{s} \cdot{ }^{\circ} \mathrm{F}\right)$.

Figure 129 shows a detail of the temperature distribution around the outlet nozzle for the reference case of $\mathrm{k}=5 \mathrm{lb} f / \mathrm{s} \cdot{ }^{\circ} \mathrm{F}$. Because the reference case does not isolate the outlet water effectively, we see a rapid rise in nozzle temperature; the end of the outlet nozzle is within a few ${ }^{\circ} \mathrm{F}$ of the outlet water temperature of $932^{\circ} \mathrm{F}$. Because such a nozzle temperature is considered unacceptable, we do not pursue the resulting stress distribution of this case here. Instead, three cases are considered with the thermal conductivity attenuated by factors of 25,50 and 100 from this reference value $\left(\mathrm{k}=0.2,0.1\right.$ and $\left.0.05 \mathrm{lb}_{\mathrm{f}} / \mathrm{s} \cdot{ }^{\circ} \mathrm{F}\right)$. Figures 130, 131, and 132 show the nozzle outlet temperatures with the thermal conductivity of the sleeve attenuated by factors of 25, 50 and 100 .

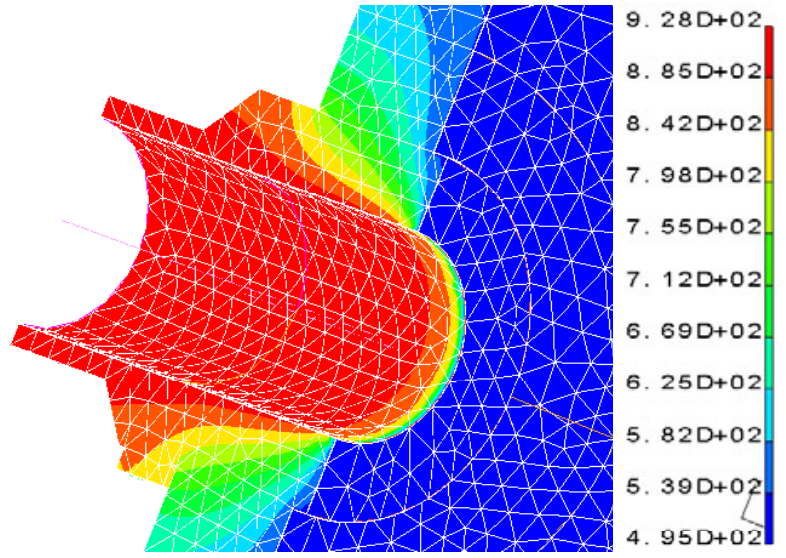

Figure 129. Temperature distribution around the outlet nozzle for the reference case: no attenuation in sleeve thermal conductivity $\left(k=5 \mathrm{lb}_{\mathrm{f}} / \mathbf{s}^{\circ} \mathbf{F}\right)$.
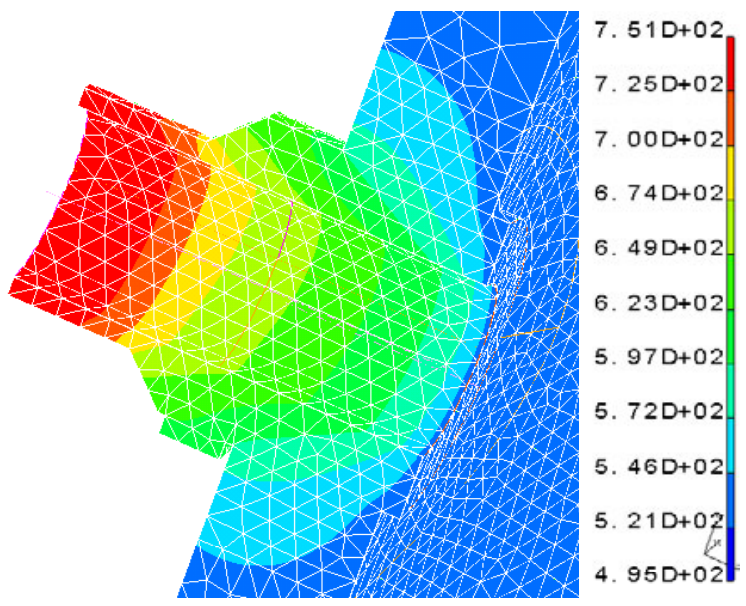

Figure 131. Temperature distribution around the outlet nozzle $\left[{ }^{\circ} \mathbf{F}\right.$ ] assuming a factor of 50 attenuation in thermal sleeve conductivity $(k=0.1$ $\left.\mathbf{l} \mathbf{b}_{\mathbf{f}} / \mathbf{s} \cdot{ }^{\circ} \mathbf{F}\right)$.
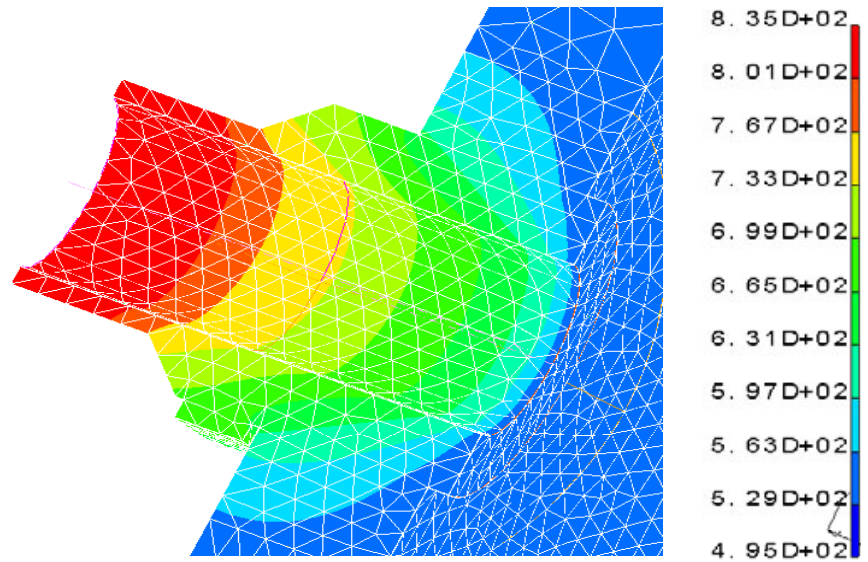

Figure 130. Temperature distribution around the outlet nozzle $\left[{ }^{\circ} \mathrm{F}\right]$ assuming a factor of 25 attenuation in thermal sleeve conductivity $\left(k=0.2 \mathrm{lb} / \mathrm{f} / \mathrm{s} \cdot{ }^{\circ} \mathbf{F}\right)$.

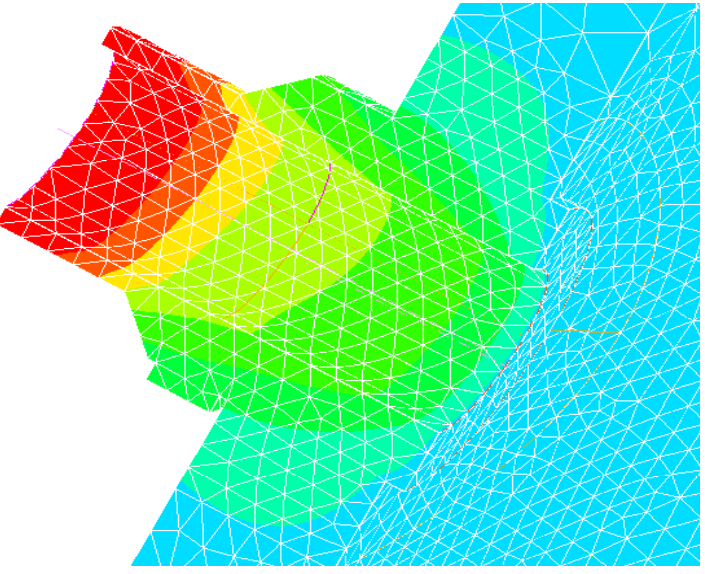

6. $41 \mathrm{D}+02$
6. $26 \mathrm{D}+02$
6. $12 \mathrm{D}+02$
5. $97 \mathrm{D}+02$
5. $83 \mathrm{D}+02$
5. $68 \mathrm{D}+02$
5. $54 \mathrm{D}+02$
5. $39 \mathrm{D}+02$
5. $24 \mathrm{D}+02$
5. $10 \mathrm{D}+02$
4. $95 \mathrm{D}+02$

Figure 132. Temperature Distribution Around the Outlet Nozzle $\left[{ }^{\circ} \mathrm{F}\right]$ assuming a factor of 100 attenuation in thermal sleeve conductivity $(k=0.05$ $\left.\mathbf{l b _ { \mathbf { f } }} / \mathbf{s} \cdot{ }^{\circ} \mathbf{F}\right)$. 
Figures 133, 134, and 135 show the Von Mises stress resulting from the temperature distribution, and the net Von Mises stress distribution from pressure, weight and temperature distribution together. The outlet nozzles are assumed to be part of a freely expanding piping system, so no axial constraint is imposed at the end of the nozzles. The portion of the outlet nozzle within the vessel thickness is constrained by its surrounding structure, however, so compressive stress is induced at this location. This location also coincides with the portion of the outlet nozzle experiencing peak tensile stress under the pressure loads, so the net result is a reduction of the peak Von Mises stresses relative to those in Figure 127. (For each figure, compare the right plot of net Von Mises stress distribution to the right hand plot of Figure 127.) Since the inlet nozzle is nearly isothermal, its net Von Mises stress distribution is essentially unchanged from what is shown in Figure 127.
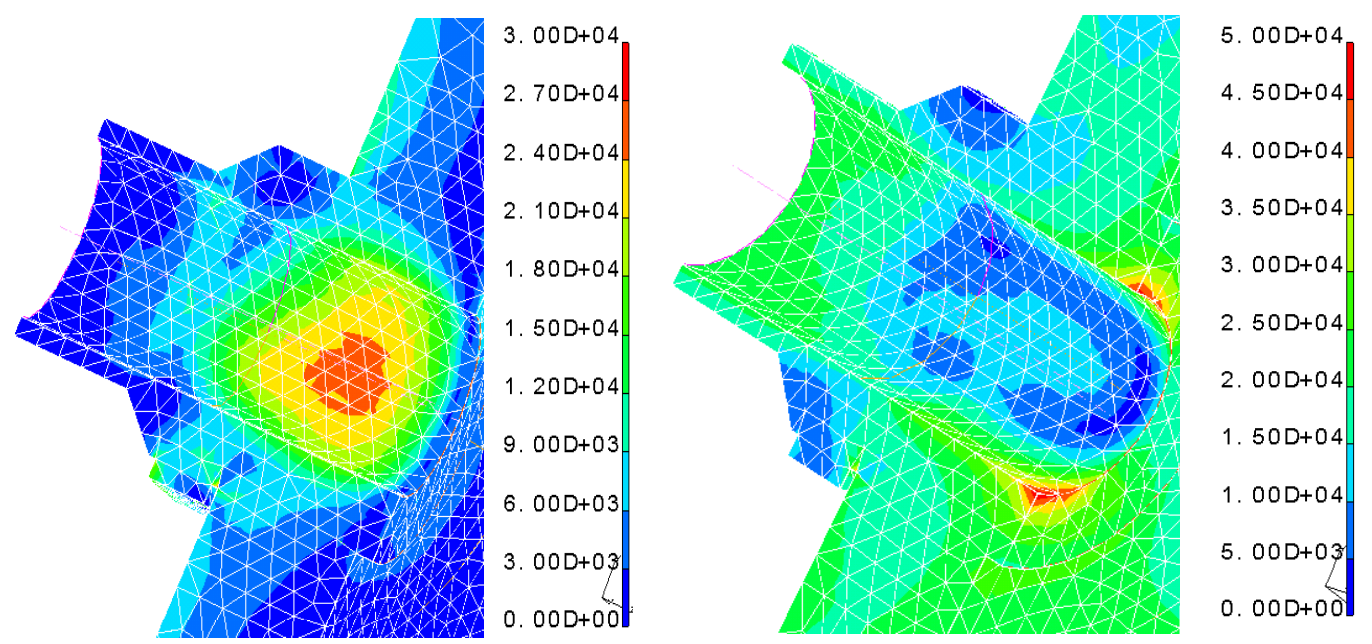

Figure 133. Von Mises stress [psi] due to temperature distribution alone (left) and to the combined effects of pressure, weight and temperature distribution (right) assuming a factor of 25 attenuation in thermal sleeve conductivity $\left(\mathrm{k}=0.2 \mathrm{lb}_{\mathrm{f}} / \mathbf{s} \cdot{ }^{\circ} \mathbf{F}\right)$.
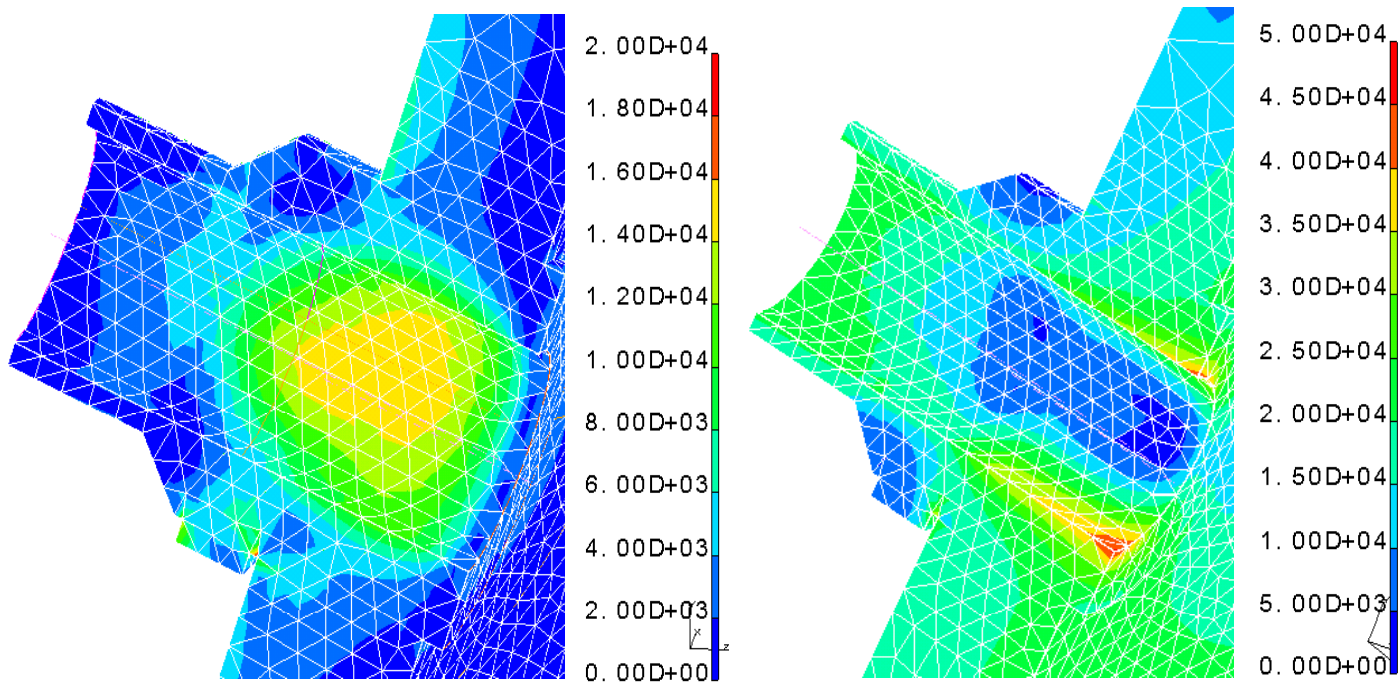

Figure 134. Von Mises stress [psi] due to temperature distribution alone (left) and to the combined effects of pressure, weight and temperature distribution (right) assuming a factor of 50 attenuation in thermal sleeve conductivity $\left(k=0.1 \mathrm{lb} / \mathrm{f} \cdot{ }^{\circ} \mathbf{F}\right)$. 

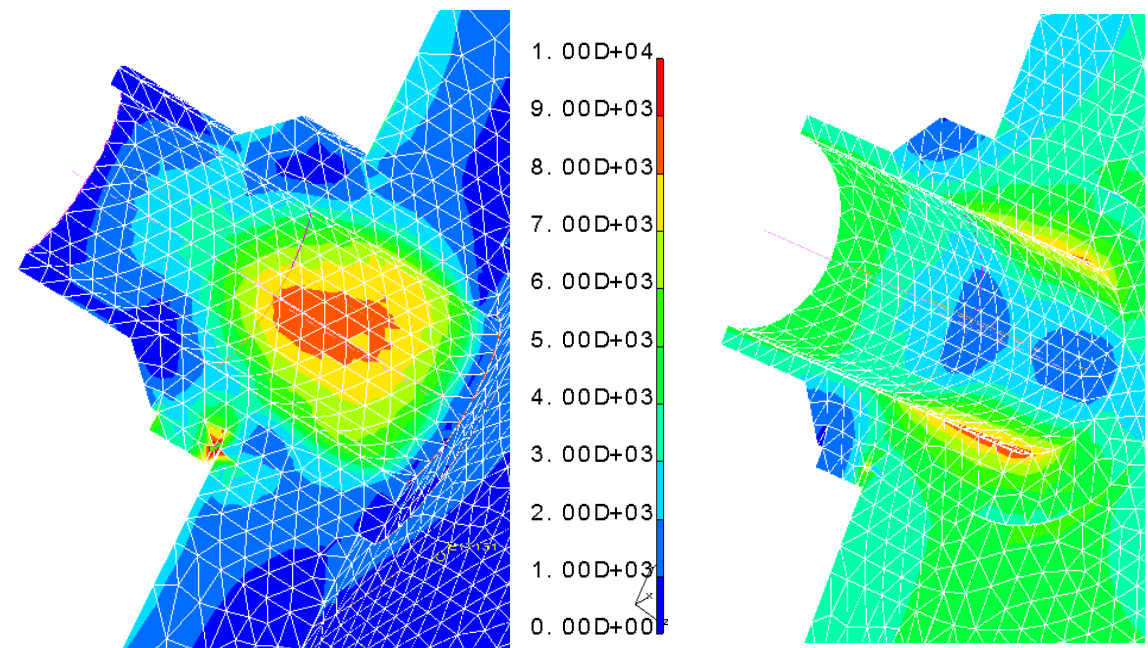

5. $00 \mathrm{D}+04$
4. $50 \mathrm{D}+04$
4. $00 \mathrm{D}+04$
3. $50 \mathrm{D}+04$
3. $00 \mathrm{D}+04$
2. $50 \mathrm{D}+04$
2. $00 \mathrm{D}+04$
1. $50 \mathrm{D}+04$
1. $00 \mathrm{D}+04$
5. $00 \mathrm{D}+03$
0. $00 \mathrm{D}+00 \mathrm{P}$

Figure 135. Von Mises stress [psi] due to temperature distribution alone (left) and to the combined effects of pressure, weight and temperature distribution (right) assuming a factor of 100 attenuation in thermal sleeve conductivity $\left(k=0.05 \mathrm{lb}_{\mathrm{f}} / \mathbf{s} \cdot{ }^{\circ} \mathbf{F}\right)$

\subsubsection{Conclusions from Steady Temperature/Stress Analysis of Preliminary SCWR Reactor Pressure Vessel}

The design temperature for LWR reactor pressure vessels, fabricated from SA508, is $343{ }^{\circ} \mathrm{C}\left(650{ }^{\circ} \mathrm{F}\right)$ [Buongiorno et al. 2003]. On this basis, the results from Figures 130 through 135 demonstrate that, if the SCWR is to be fabricated from this steel, the thermal sleeve in the outlet nozzle must provide a degree of isolation equivalent to an overall heat transfer coefficient of about $0.05 \mathrm{lb} / \mathrm{in} \cdot \mathrm{s} \cdot{ }^{\circ} \mathrm{F}$. If the vessel is to be fabricated from a more advanced alloy capable of tolerating a higher temperature, the sleeve does not need to be as effective.

An additional issue may be the axial temperature gradient experienced by the outlet nozzle and its adjoining steam piping. Even if an effective thermal sleeve is designed to isolate the outlet nozzle, it is undesirable to make a sudden transition from low to high temperature between the outlet nozzle and this piping because of the thermal stress induced at the transition. Although the circumstances are different, this has been an issue in fast breeder reactor development [Takakura 1995], where the temperatures involved are slightly higher than those in the SCWR $\left(550{ }^{\circ} \mathrm{C}\right.$ in the FBR vs $500{ }^{\circ} \mathrm{C}$ in the SCWR) but the net Von Mises stresses are much lower.

\subsubsection{Modifications of Reference SCWR Reactor Pressure Vessel - An Examination of Inlet and Outlet Nozzles}

The analyses of the reference design discussed above indicated that the peak stresses around the inlet and outlet nozzles exceed $50 \mathrm{ksi}$. It is worthwhile to examine the source of this peak stress because, as is shown below, relatively minor modifications to the existing design can not only reduce this peak stress, it can also permit the thickness of the nozzle course section to be reduced. In spite of the fact that the vessel is three-dimensional, the source of the peaking can be easily described as a two-dimensional phenomenon. Figure 136 shows a schematic of a common two-dimensional stress concentration problem - a hole in an infinite plate subjected to biaxial stress. In the limit of uniaxial stress, $\sigma_{2}=0$, the stress concentration factor is $K=3$. In the limit of biaxial stress with $\sigma_{2}=\sigma_{1}, K=2$. The nozzle opening in a 
reactor pressure vessel is represented by an intermediate state with $\sigma_{2}=\sigma_{1} / 2$. Assuming a stress concentration factor $K=2.5$, the peak stress expected at the top of the nozzle is estimated as:

$$
\sigma_{A}=K \sigma_{1} \cong 2.5 \times p \frac{\bar{R}}{t}=2.5 \times 3989 \mathrm{psi} \times \frac{104.75+24.75 / 2 \mathrm{in}}{24.75 \mathrm{in}}=47.2 \mathrm{ksi}
$$

This is consistent with our finite element analyses producing peak Von Mises stresses just exceeding 50 ksi.

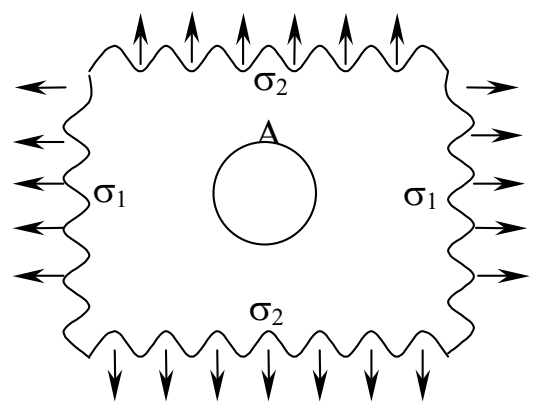

$$
\begin{aligned}
& \sigma_{\mathrm{A}}=K \sigma_{1} \\
& \text { Uniaxial Stress: } \sigma_{2}=0 \\
& K=3 \\
& \text { Biaxial Stress: } \sigma_{2}=\sigma_{1} \\
& K=2
\end{aligned}
$$

Figure 136. Stress concentration factors for a circular hole in an infinite plate [Young 1989].

To reduce this peak stress, we either have to reduce the nominal stress $\sigma_{1}$ or the stress concentration factor $K$. Reducing $\sigma_{1}$ requires an increase in thickness, but the reference design nozzle course thickness is already $0.63 \mathrm{~m}$ ( 24.75 inches) thick and in fact it would be desirable to reduce this thickness. This requires a reduction in $K$. Reducing $K$ requires an increase in the local radius of curvature around the top of the inlet nozzle. This can be achieved by making a gradual transition in the inlet nozzle between circular and elliptical cross-sections.

The reference design inlet nozzle is a conical expansion nozzle with a $10^{\circ}$ angle of expansion along its axis. In the alternative design below, we begin with the same circular cross-section where the nozzle begins to expand, then gradually shift from circular to elliptical cross-sections at 5 inch intervals moving towards the center of the vessel. The area of each elliptical section is the same as the corresponding circular section in the reference design. At the junction with the inner part of the vessel $(2.66 \mathrm{~m}$ or 104.75 inches from the centerline), the ratio of the major to minor axes of the elliptical cross-section is about 5 to 3. There is nothing special about this aspect ratio; it is shown for illustration and it may be possible to optimize the shape further.

Figure 137 shows the reference and alternative inlet nozzles side-by-side for comparison. The thickness of the nozzle course section in the alternative design has been reduced to 22 inches. An additional modification in the alternative design is a 10-inch chamfer radius at the junction of the inlet nozzle with the outside of the pressure vessel. This is included in part to compensate for a local reduction in thickness
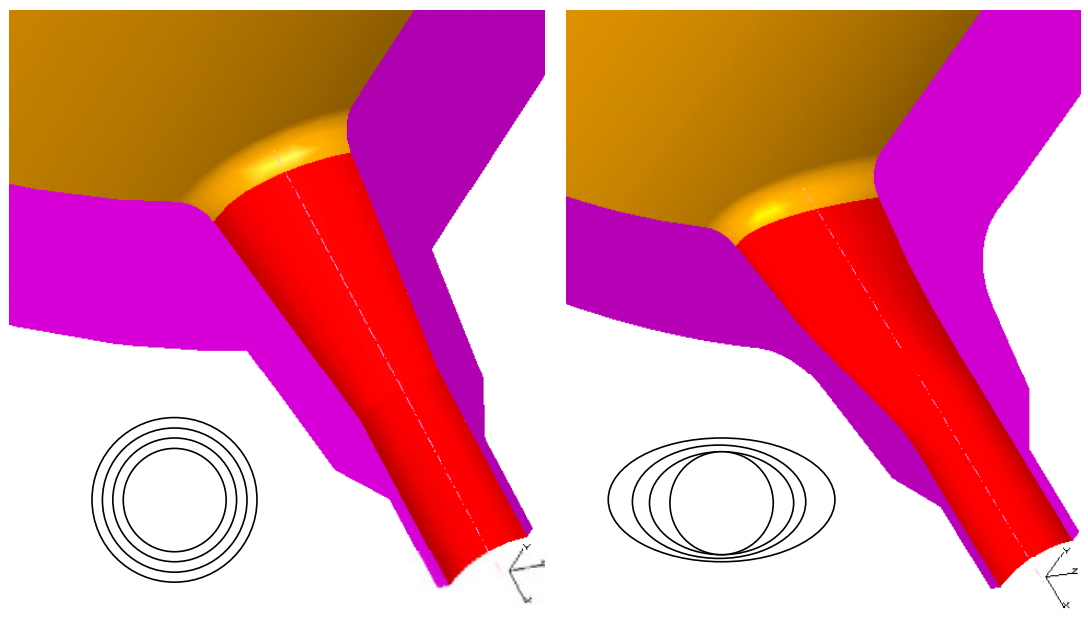

Figure 137. Inlet nozzle shape for the reference design (left) and alternative design (right). 
where the wider elliptical cross-sections eliminate structural material. In both cases, there is a 5-inch chamfer radius where the inlet nozzle penetrates the inside of the vessel.

\subsubsection{Finite Element Models of Reference and Alternative Inlet Nozzles}

In order to focus attention on just the nozzles, the physical domain was reduced from the models in Section 5.6.1. With reference to the left side of Figure 127, imagine cutting the vessel through the nozzle sections, eliminating one of the nozzles (in the present case, the outlet nozzle) and employing symmetry conditions along the new cut plane. This reduces the physical representation to a quarter of a nozzle and enables a higher mesh density in the nozzle region without substantially increasing the number of degrees-of-freedom for the whole model. Figure 138 shows a side-by-side comparison of the reference design and the alternative design in the region of the inlet nozzles for the pressure loading. Peak Von Mises stresses for the reference case are the same as those shown in Figure 127, while peak Von Mises stresses for the alternative case do not exceed $40 \mathrm{ksi}$. This is despite the reduction of the nozzle course thickness about $11 \%$, from $0.63 \mathrm{~m}$ (24.75) inches in the reference design to $0.56 \mathrm{~m}$ (22 inches) in the alternative design. The decision to remain with a conical expansion nozzle or one that transitions as shown in the bottom right of Figure 137 will depend on relative ease of fabrication, which we have not yet ascertained.
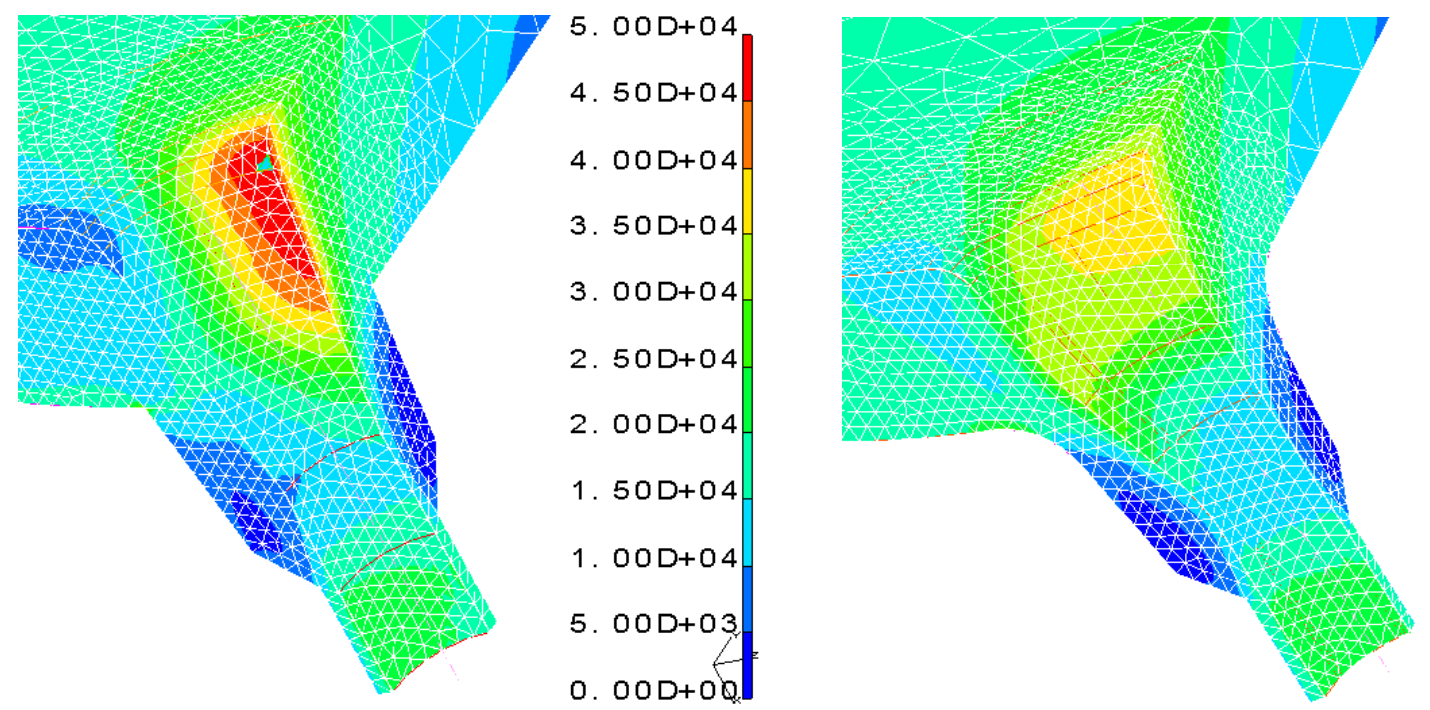

Figure 138. Von Mises stress distributions [psi] under internal pressure for inlet nozzle reference design (left) and alternative design (right).

\subsubsection{Alternative Designs for Outlet Nozzle}

We can presumably achieve the same reduction in stress for the outlet nozzle by adopting the circular-toelliptical transition for the nozzle's inner shape. In addition, we are faced with the issue of incorporating a thermal sleeve. Isolating hot leg water in the SCWR from the bulk of the reactor vessel takes on far more importance than in the case of a conventional PWR because of the difference between hot and cold leg water temperatures. In a conventional PWR, the difference between hot and cold leg water temperatures is on the order of $30^{\circ} \mathrm{C}$. In the SCWR, it is on the order of $220^{\circ} \mathrm{C}$. In a conventional PWR, the thermal sleeve is a relatively thin cylindrical shell that is open on its outside to cold leg water. The annular gap between hot leg and thermal sleeve is quite small and the convection patterns that develop within this annular gap are complicated [Kussmaul and Mayinger 1999]. Local stagnation regions seem likely in the narrowest of passages furthest down the hot leg, suggesting that isolation around these local 
regions is compromised. We need to examine convection patterns and temperature distributions under conditions appropriate for the SCWR to determine if the isolation provided by such a traditional thermal sleeve is appropriate. In the meantime, we are exploring some unconventional ideas for the sleeve.

Figure 139 shows a side-by-side comparison of the outlet nozzle in the reference design and that for a proposed design that incorporates a new kind of thermal sleeve. In the alternative design, the inner surface of the outlet nozzle again has the circular-to-elliptical transition that reduces peak stress in the bulk of the pressure vessel.

The inward-facing surface of the outlet nozzle has a 3-inch thick ellipticallyshaped cavity to mate with the first section of the steam line. The first section of the steam line consists of a cylindrical pipe with an elliptical faceplate that fits into the cavity machined into the outlet nozzle's inward-facing surface. Not shown here is an appropriate seal between the elliptical plate and bulk vessel. A metallic,
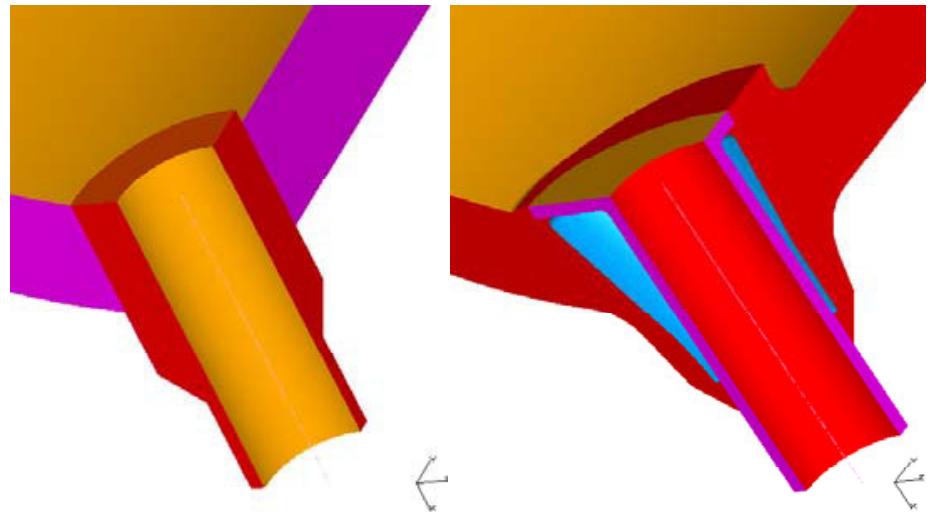

Figure 139. Outlet nozzle shape for the reference design (left) and alternative design (right). elliptical O-ring between the plate and bulk vessel might provide such a seal. It is anticipated that such an assembly would be pressed until flush and then welded at two locations: the elliptical boundary between plate and bulk vessel (gold/red boundary in the above right figure) and around the steam line pipe where the reinforced nozzle meets the steam line. Such an assembly would isolate the cavity between steam line and bulk vessel (blue) and ensure that water would not be able to fill the cavity. From the outside of the reinforced nozzle, a hole could be drilled through to the cavity which could then be evacuated or filled with a low conductivity noble gas and monitored during operation. It would not be necessary to understand the gas convection pattern within the cavity and heat transfer between steam line and the bulk vessel would take place through radial conduction and thermal radiation. This level of isolation is necessary to maintain bulk vessel temperatures at or below the levels shown in Figure 132.

To facilitate discussion of the important issues needing to be resolved, we have performed a thermal/structural analysis on the alternative nozzle shown in Figure 139. The results are presently not acceptable, but should provide direction for additional modification. For the thermal analysis, we assumed a temperature of $500{ }^{\circ} \mathrm{C}\left(932^{\circ} \mathrm{F}\right)$ on the inward facing surface and inside of the steam line. The rest of the vessel's internal surface is assumed to be at a temperature of $280{ }^{\circ} \mathrm{C}\left(536{ }^{\circ} \mathrm{F}\right)$. External boundaries are subjected to the same convective heat transfer used in the analyses of Figures 130 through 132. No heat transfer was assumed between cavity surfaces bordering the steam line and the bulk vessel. This corresponds to perfect cavity isolation and allows us to see how the temperature distribution develops from vessel conduction only.

The results of the thermal analyses are shown in Figure 140. In spite of the lack of heat transfer across the cavity, the bulk vessel adjacent to the cavity still manages to achieve temperatures in the range of 650 $\sim 690^{\circ} \mathrm{F}$. This is due to conduction through contact surfaces on either side of the cavity. We can get a sense of the effective heat transfer coefficient associated with thermal radiation by taking the outer steam line surface to be at $500{ }^{\circ} \mathrm{C}\left(932{ }^{\circ} \mathrm{F}\right)$, the inner bulk vessel surface to be at $343{ }^{\circ} \mathrm{C}\left(650{ }^{\circ} \mathrm{F}\right)$, and using representative emissivities for ordinary steel surfaces [Chapman 1974] (no coatings, $\varepsilon \sim 0.5$ ). Then: 
$q^{\prime \prime} \cong \sigma \frac{T_{H}^{4}-T_{C}^{4}}{1 / \varepsilon_{H}+1 / \varepsilon_{C}-1}=\frac{0.1714}{3}\left(13.91^{4}-11.09^{4}\right)=1275 \mathrm{Btu} / \mathrm{hr} \cdot \mathrm{ft}^{2}=23 \mathrm{lb}_{\mathrm{f}} / \mathrm{in} \cdot \mathrm{s}$

$h \cong \frac{q^{\prime \prime}}{T_{H}-T_{C}}=\frac{23}{282}=0.08 \mathrm{lb}_{\mathrm{f}} /$ in $\cdot \mathrm{s} \cdot{ }^{\circ} \mathrm{F}$

This corresponds to a case between Figures 131 and 132. With coatings on the inner surfaces to lower emissivities, this could presumably be reduced to an even lower level. Even with successful attenuation of heat transfer by thermal radiation, however, heat conduction around the cavity still produces bulk vessel temperatures exceeding $343{ }^{\circ} \mathrm{C}\left(650^{\circ} \mathrm{F}\right)$.

The Von Mises stresses resulting from this temperature distribution and the resultant Von Mises stresses from both thermal and pressure loads are shown in Figures 141 and 142. Identical properties are used for steam line and

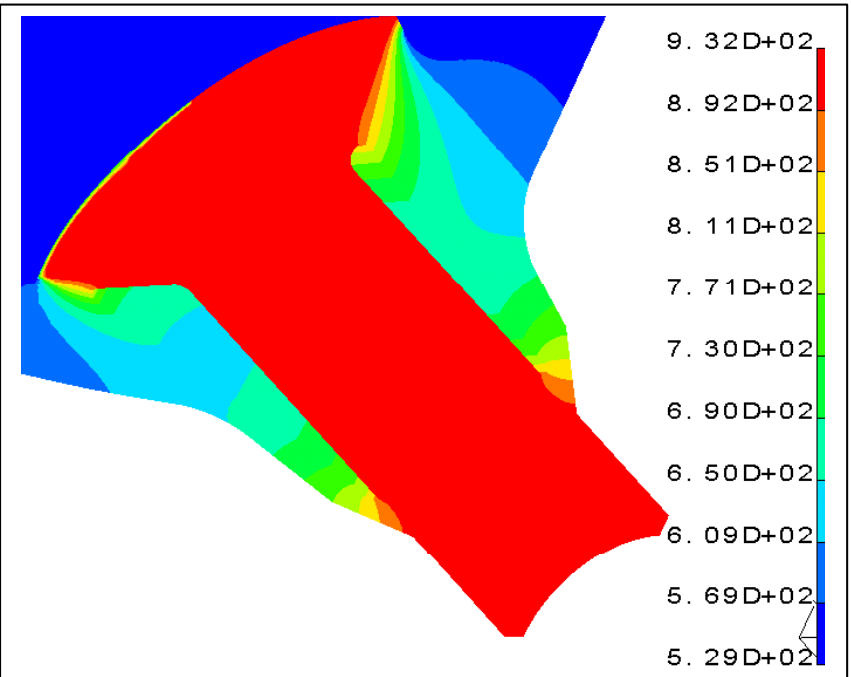

Figure 140. Temperature distribution $\left[{ }^{\circ} \mathrm{F}\right]$ around the alternative outlet nozzle. bulk vessel, so there is no difference in thermal expansion coefficient between the two. Note that the scale has been re-defined in this figure so that the range is between 0 and $88 \mathrm{ksi}$. In this plot, the transition from green to yellow contours signifies crossing the 40-ksi level.

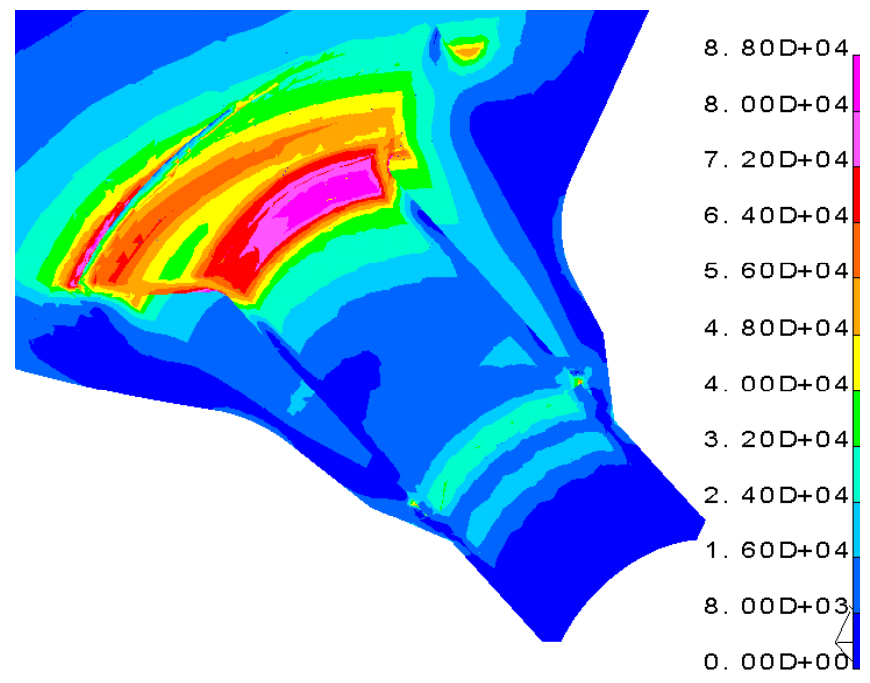

Figure 141. Results from Stress Analysis of Alternative Outlet Nozzle - Von Mises stresses [psi] due to temperature distribution only.

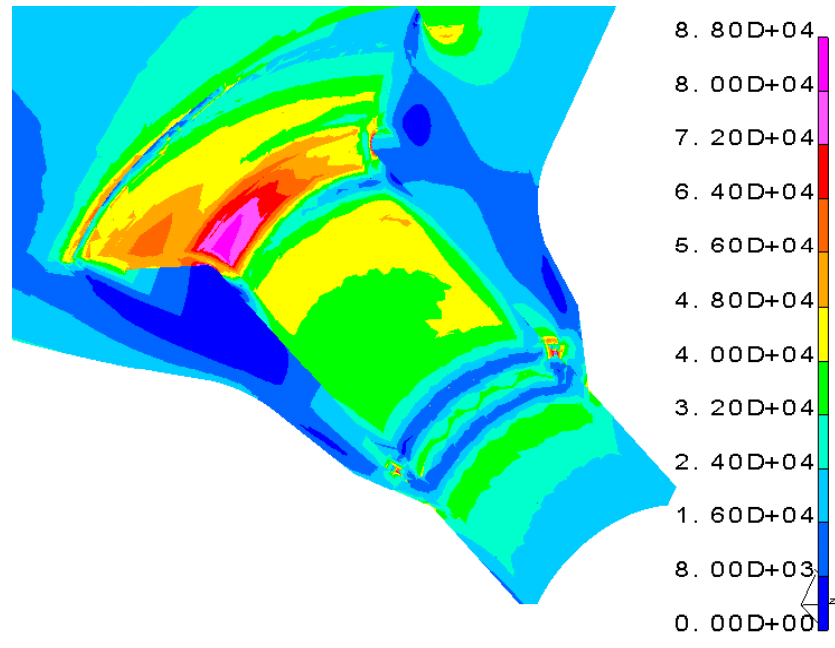

Figure 142. Results from stress analysis of alternative outlet nozzle - Von Mises stresses [psi] due to temperature distribution and internal pressure.

The expansion of the steam line produces huge compressive stress at its inner surface near the inside of the vessel. Large compressive stresses are also evident in local regions of the vessel's inner surface. 
Despite the isolation afforded by the cavity, the enhanced conduction provided by metal-to-metal contact on either side of the cavity leads to unacceptable results of this design.

Several points come to mind. First, the finite element model assumes perfect contact between the steam line's elliptical plate and the bulk vessel's cavity for that plate. (Contact is also perfect at the junction between the steam line and the outlet nozzle.) In reality there will be contact resistance everywhere except welds and other locations where the transition from one material to another is essentially continuous. Plausible joining technologies must be modeled appropriately so that we have a better sense of how heat flows from the steam line into the vessel.

Along similar lines, we do not yet have realistic thermal boundary conditions along the vessel inner surface. The transition from hot leg to cold leg temperatures must be indicative of how the core barrel mates with the steam line. Under the present analysis, there is nearly a step change from hot to cold leg temperatures that exacerbates peak stresses. We also need to include the effect of thermal radiation across the cavity.

It is also possible that, given the relatively extreme nature of the difference between hot and cold leg temperatures in the SCWR, we need multiple isolation mechanisms to ensure the integrity of the bulk vessel. Some combination of traditional isolation (by diverting cold leg water around the steam line) and incorporation of high thermal resistance materials may be necessary to arrive at an acceptable design. 


\section{References}

- Aerospace Structural Metals Handbook, December 1992.

- Bailly H., et al., Le combustible nucléaire de réacteurs à eau sous pression et des réacteurs à neutrons rapides, EYROLLES, publisher, 1996.

- Bailly, H, Ménessier, D, Prunier, C, The Nuclear Fuel of Presssurized Water Reactors and Fast Reactors, Design And Behavior, Intercept Ltd, 1999.

- Bayless, P. D. and J. M. Divine, Experiment Data Report for LOFT Large Break Loss-of-Coolant Experiment L2-5, NUREG/CR-2826, EGG-2210, August, 1982.

- Berna, G. A., C. E. Beyer, K. L. Davis, and D. D. Lanning, FRAPCON-3: A Computer Code for the Calculation of Steady-State Thermo-Mechanical Behavior of Oxide Fuel Rods for High Burnup, PNNL-11513, NUREG/CR-6534, 1997.

- Bhadeshia, H. K. D. H, "Directional Recryistallisation \& its Exploitation in Mechanically Alloyed Metals", Proceedings of the $21^{\text {st }}$ Riso International Symposium on Materials Science, Denmark, 2000, pp. 15-28.

- Bishop, A. A., R. O. Sandberg, and L. S. Tong, Forced Convection Heat Transfer to Water near Critical Temperature and Supercritical Pressures, WCAP-2056-P, Part-III-B, February 1964.

- Bottcher, J., S. Ukai, and M. Inoue, "ODS Steel Clad MOX Fuel-Pin Fabrication and Irradiation Performance in EBR-II", Nuclear Technology, Vol. 138, June 2002

- Briggs, S., "Practical Surface Analysis", In auger and X ray photo electron spectroscopy, Vol 1, Wiley, Chichester, 1990, p 509.

- Buongiorno, J., W. Corwin, P. E. MacDonald, L. Mansur, R. Nanstad, R. Swindeman, A. Rowcliffe, G. Was, D. Wilson, and I. Wright, "SCWR Survey of Materials Experience and R\&D Needs to Assess Feasibility", INEEL/EXT-03-00693, Rev. 1, 2003.

- Buongiorno, J., and P. E. MacDonald, "Study of Solid Moderators for the Thermal-Spectrum Supercritical Water-Cooled Reactor (Neutronics)", Proceedings of the $11^{\text {th }}$ International Conference on Nuclear Engineering (ICONE-11), Paper 36571, Tokyo, April 20-23, 2003 a.

- Buongiorno, J., and P. E. MacDonald, "Study of Solid Moderators for the Thermal-Spectrum Supercritical Water-Cooled Reactor (Thermo-mechanics and Cost)", Proceedings of the $11^{\text {th }}$ International Conference on Nuclear Engineering (ICONE-11), Paper 36572, Tokyo, April 2023, 2003b.

- Burns \& Roe Enterprises Inc., Supercritical Water Reactor (SCWR), Study of Power Conversion Cycle, Control Strategy and Start-up Procedures, September 2003.

- Bushby, S. J., et al. "Conceptual Designs for Advanced, High-Temperature CANDU Reactors", Proceedings of the $8^{\text {th }}$ International Conference on Nuclear Engineering (ICONE-8), Paper 8470, Baltimore, April 2-6, 2000.

- Chapman, Alan J., Heat Transfer, Macmillan Publishing Co., $3^{\text {rd }}$ Edition, 1974

- Cheng, S. K., and N. E. Todreas, "Hydrodynamic Models and Correlations for Bare and WireWrapped Hexagonal Rod Bundles", Nuclear Engineering and Design, Vol. 92, pp. 227-251, 1986.

- Cheng, X., and T. Schulenberg, "Thermal-Hydraulic Analysis of Supercritical Light Water Reactors", Proceedings of the 2002 International Congress on Advanced Nuclear Power Plants (ICAPP-2002), Hollywood, Florida, June 9-13, 2002.

- Cheng, X. and T. Schulenberg, 2001, Heat Transfer at Supercritical Pressures - Literature Review and Application to an HPLWR, Forshungszentrum Karlsruhe, FZKA 6609, May.

- Da Cunha Belo, M., M. Walls, N.E. Hakiki, J. Corset, E. Picquenard, G. Sagon and D. Noel "Composition structure and proprieties of the oxides films formed on the stainless steel 316L in primary type PWR envirionments," Corrosion Science, Vol. 40, No. 2/3,(1998) 447-463. 
- Davis, C. B., Personal Communication, October, 2003.

- Davis, C. B. and A. S. Shieh, 2000, "Overview of the Use of ATHENA for Thermal-Hydraulic Analysis of Systems with Lead-Bismuth Coolant," Proceedings. of the $8^{\text {th }}$ International Conference on Nuclear Engineering, Baltimore, MD USA, April 2-6, ICONE-8220.

- Dittus, F. W. and L. M. K. Boelter, 1930, "Heat Transfer in Automobile Radiators of the Tubular Type," Publications in Engineering, 2, University of California, Berkeley, pp. 443-461.

- Duderstadt, J. J., and L. J. Hamilton, Nuclear Reactor Analysis, p.563, John Wiley \& Sons, Inc., 1976.

- Dupin. P. Gosser, M. G. Walls, B. Rondot, J. L. Pastol, S. Faty, M. G. S. Fereira, M. Da Cunha Belo "Influence du $\mathrm{pH}$ sur les proprietes chimiques et structurales des films d'oxyde formes sur l'acier 316L et les alliages 600 et 690 dans les milieux aqueux a haute temperature," Ann Chim Sci Mat, 27 (2002) 19-32.

- European Utility Requirements for LWR Nuclear Power Plants, Revision C, April 2001

- Fournier, L., D. Delafosse, and T. Magnin, "Oxidation induced intergranular cracking and Portevin-Le Chatelier effect in nickel base superalloy 718", Materials Science and Engineering, A316 (2001) 166-173.

- General Physics Corporation, 1979, "BWR Simulator Training," Second Edition, Volume 3.

- Hamilton, M. L., et al. Fabrication Technological Development of the Oxide Dispersion Strengthened Alloy MA957 for Fast Reactor Applications, PNNL-13168, February 2000.

- Harper, M. A., "Improved ODS Alloy for Heat Exchanger Tubing", Proceedings of the $16^{\text {th }}$ Annual Conference on Fossil Energy Materials, Baltimore, April 22-24, 2002.

- Haymard, T., Svishchev, R. Makhija "Stainless steel flow reactor for supercritical water oxidation: corrosion test" J of Supercritical Fluid, 27 (2003) 275-281.

- Howell, J. R. and S. H. Lee, 1999, "Convective Heat Transfer in the Entrance Region of a Vertical Tube for Water near the Thermodynamic Critical Point," International Journal of Heat and Mass Transfer, 42, pp. 1177-1187.

- INEEL, 2002, RELAP5-3D Code Manual, INEEL-EXT-98-00834, Revision 2.0, July.

- Ishiwatari, Y., Y. Oka, and S. Koshizuka, 2002, "Safety analysis of a high temperature supercritical pressure light water cooled and moderated reactor," Proceedings of the International congress on Advanced Nuclear Power Plants (ICAPP), Hollywood, FL USA, June 9-13.

- Jackson, J. D., 1979, "Mixed Forced and Free Convection - The Influence of Buoyancy on Turbulent Forced Flow in Vertical Pipes," The Euromech Meeting on Boundary Layers and Turbulence in Internal Flows, Session 5, University of Salford, England.

- Jackson, J. D., "Consideration of the Heat Transfer Properties of Supercritical Pressure Water in Connection with the Cooling of Advanced Nuclear Reactors," Proceedings of the $13^{\text {th }}$ Pacific Basin Nuclear Conference, Shenzhen, China, 21-25 October 2002.

- Jonsson, N. O., U. Bredolt, T. A. Dolck, A. Johanson, T. Ohlin, L. Oriani, L. Conway, SCWR Design Review and Design of Safety Systems and Containment - Status, September 2003, SE-03044 (Rev. 0), September 2003.

- Klopp, W. D., MA 956, Aerospace Structural Metals Handbook, Code 1451, December 1992.

- Koshizuka, S., and Y. Oka, "Computational Analysis of Deterioration Phenomena and Thermal Hydraulic Design of SCR", Proceedings of the $1^{\text {st }}$ International Symposium on Supercritical Water-Cooled Reactors Design and Technology (SCR-2000), The University of Tokyo, November 6-9, 2000.

- Koshizuka, S. and Y. Oka, "Computational Analysis of Deterioration Phenomena and Thermalhydraulic Design of SCR," Proceedings of the First International Symposium on Supercritical Water-cooled Reactors, Design and Technology, November 6-9, University of Tokyo, SCR-2000, pp. 169-179, 2000. 
- Krasnoshchekov, E. A. and V. S. Protopopov, "Experimental Study of Heat Exchange in Carbon Dioxide in the Supercritical Range at Higher Temperature Drops," Teplofizika Vysokikh Temperatur, Vol 4. No. 3, pp. 389-398, May 1966.

- Kussmaul, K. and Mayinger, W., "Numerical and Experimental Analyses of the Behaviour of a Nozzle with Thermal Sleeve under Stratified Flow," Nucl Engr and Design, 190 (1999), 127-140

- MacDonald, P., J. Buongiorno, C. Davis, and K. Weaver, 2002a, "Feasibility Study of Supercritical Light Water Cooled Fast Reactors for Actinide Burning and Electric Power Production," Nuclear Energy Research Initiative Project 2001-001, Progress Report for Work Through September 2002, $3^{\text {rd }}$ Quarterly Report, INEEL/EXT-02-00925.

- MacDonald, P., J. Buongiorno, C. Davis, and K. Weaver, 2002b, "Feasibility Study of Supercritical Light Water Cooled Fast Reactors for Actinide Burning and Electric Power Production," Nuclear Energy Research Initiative Project 2001-001, Progress Report for Work Through September 2002, $4^{\text {th }}$ Quarterly Report, INEEL/EXT-02-01330.

- Marchaterre, J. F., and M. Petrick, Review of the Status of Supercritical Water Reactor Technology, Atomic Energy Commission Research and Development report, ANL-6202, Argonne National Laboratory, 1960.Middle South Utilities, Updated Final Safety Analysis Report, Grand Gulf Nuclear Station, Chapter 15.

- Materials Science And Technology, Nuclear Materials Volume A \& B, VCH publisher, 1994.

- Middle South Utilities, Updated Final Safety Analysis Report, Grand Gulf Nuclear Station, Chapter 15.

- Mitton, D. B., J. C. Orzakki and R. M. Latanision, "Corrosion phenomena associated with SCWO systems", Proc. 3rd Int. Symp. on Supercritical Fluids, 3, p. 43, Strasbourg, France, Oct. 17-19 (1994).

- Mitton, D. B., P. A. Marrone and R. M. Latanision, "Interpretation of the Rationale for Feed Modification in SCWO Systems”, J. Electrochem. Soc., p. L59, 1996.

- Montenor, M Ferreira, N Hakiki, M. Da Cunha Belo "Chemical composition and electronic structure of the oxide film formed on 316L stainless steel and nickel based alloys in high temperature aquous environments," Corrosion Science, 42 (2000) 1635-1650.

- NUREG-0800, Standard Review Plan, 4.2 Fuel System Design, U. S. Nuclear Regulatory Commission.

- Oka, Y., "Review of High Temperature Water and Steam Cooled Reactor Concepts", Proceedings of the $1^{\text {st }}$ International Symposium on Supercritical Water-Cooled Reactors Design and Technology (SCR-2000), The University of Tokyo, November 6-9, 2000.

- Oka, Y., and S. Koshizuka, "Design Concept of Once-Through Cycle Supercritical-Pressure Light Water Cooled Reactors", Proceedings of the $1^{\text {st }}$ International Symposium on Supercritical Water-Cooled Reactors Design and Technology (SCR-2000), The University of Tokyo, November 6-9, 2000.

- Perry BWR System Description Manual, Section B13, 1986.

- Petrov, N. E. and V. N. Popov, "Heat Transfer and Hydraulic Resistance with Turbulent Flow in a Tube of Water at Supercritical Parameters of State," Thermal Engineering, 35, (10), 1988.

- Riemke, R. A., C. B. Davis, and R. R. Schultz, "RELAP5-3D Code for Supercritical-Pressure, Light-water-Cooled Reactors," Proceedings of the $11^{\text {th }}$ International Conference on Nuclear Engineering, Tokyo, Japan, April 20-23, ICONE11-36125, 2003.

- Strasser A., et al., An evaluation of stainless steel cladding for use in current design LWRs, EPRI NP-2642, 1982.

- Special Metals, http://www.specialmetals.com/products/index.html, 2003.

- Special Metals Corporation, Technical Bulletin INCONEL 625, pub \# SMC-063, November 2002.

- Special Metals Corporation, Publication Number SMC-008, 1999 
- Spinks N. J., et al. "Thermo-economic Assessment of Advanced, High-Temperature CANDU Reactors", Proceedings of the $10^{\text {th }}$ International Conference on Nuclear Engineering (ICONE10), Paper 22433, Arlington, Virginia, April 14-18, 2002.

- Takakura, K., "Development of Elevated Temperature Structural Design Guide for Japanese Demonstration Breeder Reactor", Nucl Engr and Design, 155 (1995) 559-570.

- Tsuchiya, Y., et al., "SCC and Irradiation Properties of Metals under Supercritical-water Cooled Power Reactor Conditions", Proceedings of GENES4/ANP2003, (September 2003), Kyoto, JAPAN.

- Ukai, S., T. Nishida, T. Okuda, T. Yoshitake, "Development of Oxide Dispersion Strengthened Steels for FBR Core Application, (II) Morphology Improvement by Martensite Transformation", Journal of Nuclear Science and Technology, Vol.35, No.4, pp.294-300, 1998.

- Wright, I. G., C. G. McKamey, and B. A. Pint, "Oxide Dispersion Strengthened Alloy Development", Oak Ridge National Laboratory, 2000.

- $\mathrm{Wu}$, T. H., Z. Xu, and J. D. Jackson, "Mixed Convection Heat Transfer to Water Flowing Through a Vertical Passage of Annular Cross Section", Transactions of the Institution of Chemical Engineers, Chemical Engineering Research and Design, 80, Part A, pp. 239-245, 2002.

- Yamagata, K., K. Nishiwawa, S. Hasegawa, T. Fujii, and S. Yoshida, "Forced Convective Heat Transfer to Supercritical Water Flowing in Tubes," International Journal of Heat and Mass Transfer, Vol. 15, pp. 2575-2593, 1972.

- Young, Warren, C., "Roark's Formula's for Stress and Strain," McGraw-Hill, $6^{\text {th }}$ Edition, 1989

- Zielinsky and Kurzylowski, "TEM study of the oxide scales formed on type 316 ss during annealing at 600C in a vacuum and air." Scripta Mat. 43 (2000) 33-37.

- Zigrang, D. J. and N. D. Sylvester, "A Review of Explicit Friction Factor Equations," Transactions of ASME, Journal of Energy Resources Technology, 107, pp. 280-283, 1985. 


\section{Project Schedule}

\begin{tabular}{lll}
\hline Task & Activity & Description \\
\hline Task 1 & $\begin{array}{l}\text { Fuel-cycle Neutronic Analysis and Reactor Core Design } \\
\text { (INEEL) }\end{array}$ \\
& 1.1 & Reactivity Swing Analysis \\
1.2 & Actinide Discharge and Isotopic Evaluation \\
1.3 & Reactivity Coefficient Calculations \\
1.4 & Peaking Factors and Reactor Control
\end{tabular}

Task 2 Fuel Cladding and Structural Material Corrosion and Stress Corrosion Cracking Studies (University of Michigan, MIT)

2.1 Identification of Most Promising Materials (MIT)

2.2 Design and Construction of an Out-of-pile Supercritical Water Test Facility (U-Mich)

2.3 Corrosion and Stress Corrosion Cracking Behavior of Candidate Materials (U-Mich, MIT)

2.4 Radiation Stability of Candidate Alloys (U-Mich)

2.5 Modeling of Corrosion and stress Corrosion Cracking in Supercritical Water (U-Mich, MIT)

Task 3 Plant Engineering and Reactor Safety Analysis (Westinghouse and INEEL)

3.1 Conceptual Design of the Reactor Coolant

3.2 Definition of the Thermal/Mechanical Design

3.3

3.4 Limits

Core Thermal-hydraulic Design (Westinghous

hydraulic/Neutronic Oscillations (INEEL)

3.5 Plant Configuration and Operation (Westinghouse)

3.6 Establish the Conceptual Design of Required Safety Systems and Define their Performance Parameters (Westinghouse)

3.7 Analysis of Anticipated Transients and Potential Accidents (INEEL)

3.8 Conceptual Layout of Reactor Containment, Fuel Handling, and Auxiliary Buildings (Westinghouse)

3.9 Economic Analysis (Westinghouse)

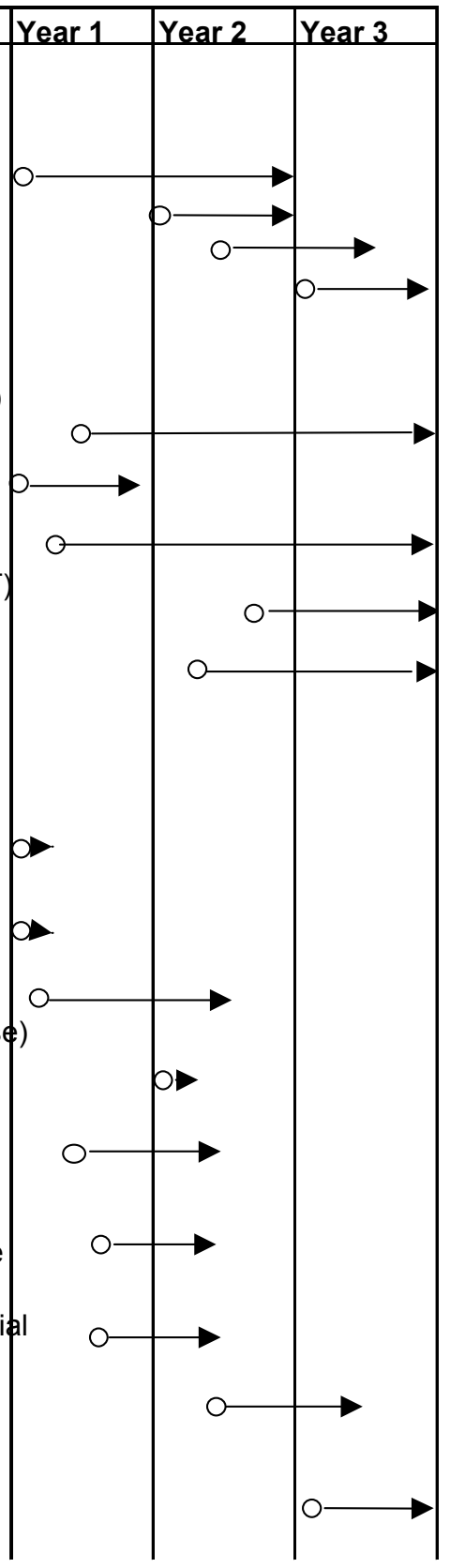




\section{Budget and Actual Costs for Year 2 \\ INEEL}

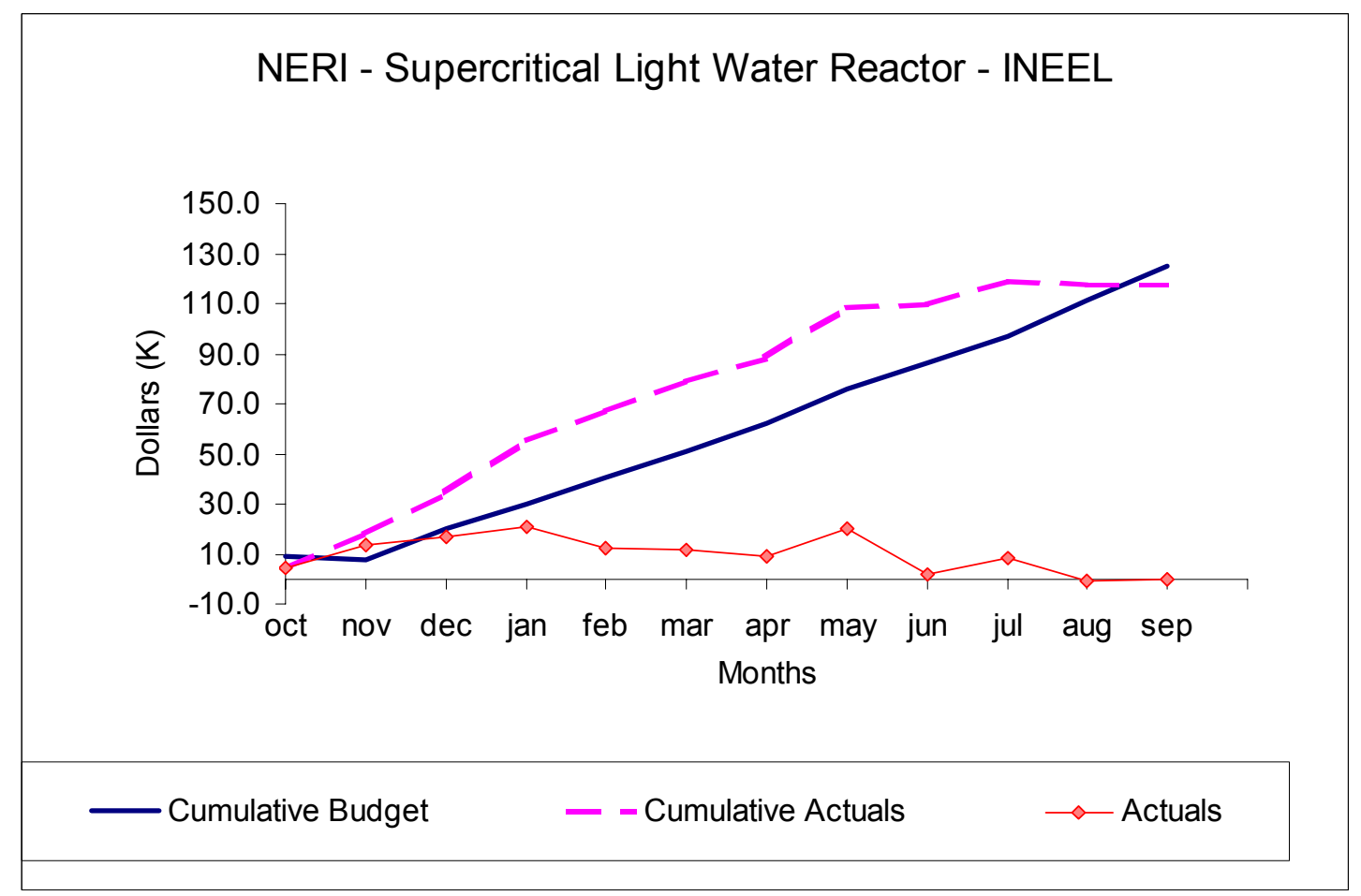

\section{MIT}

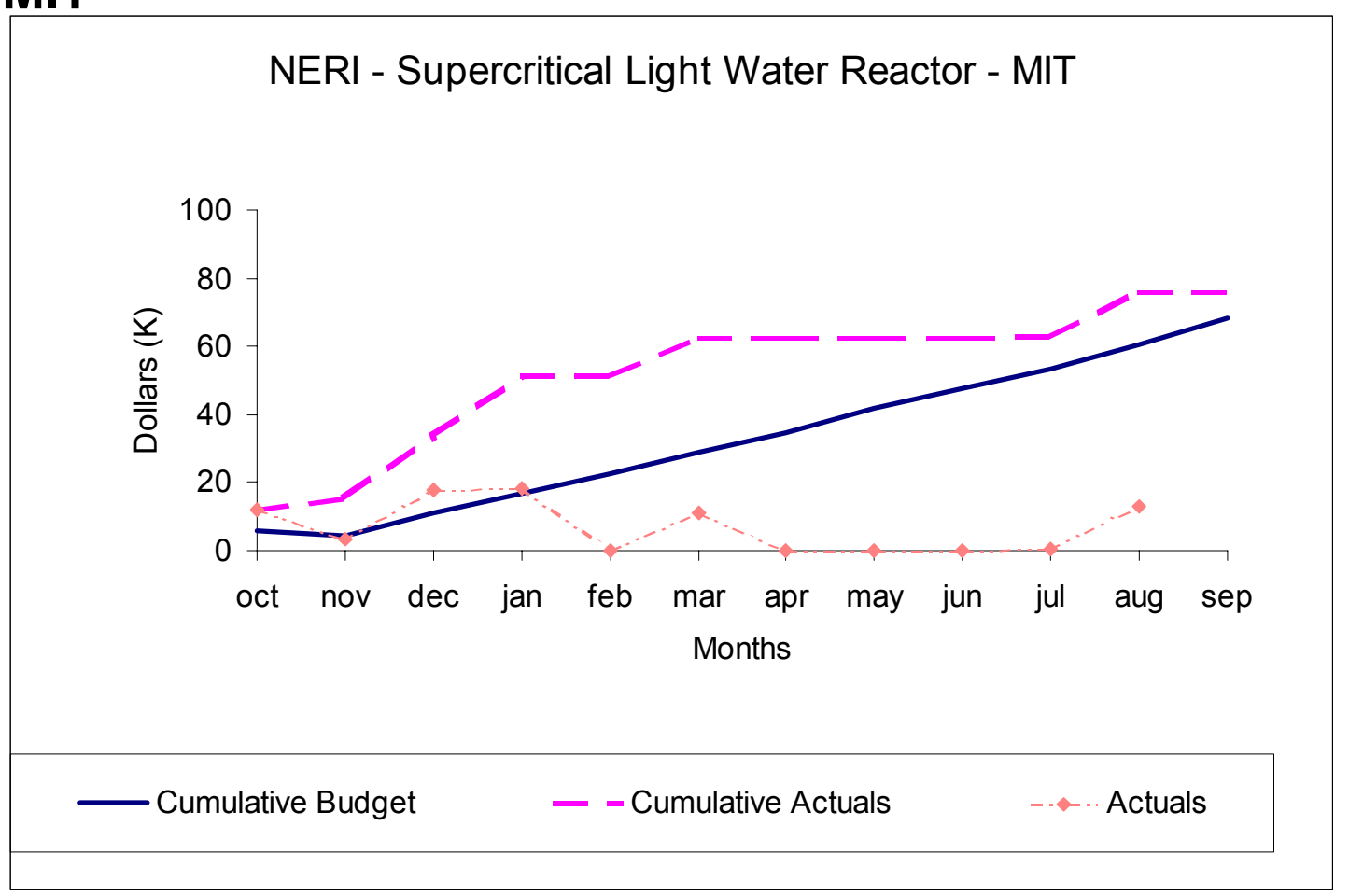




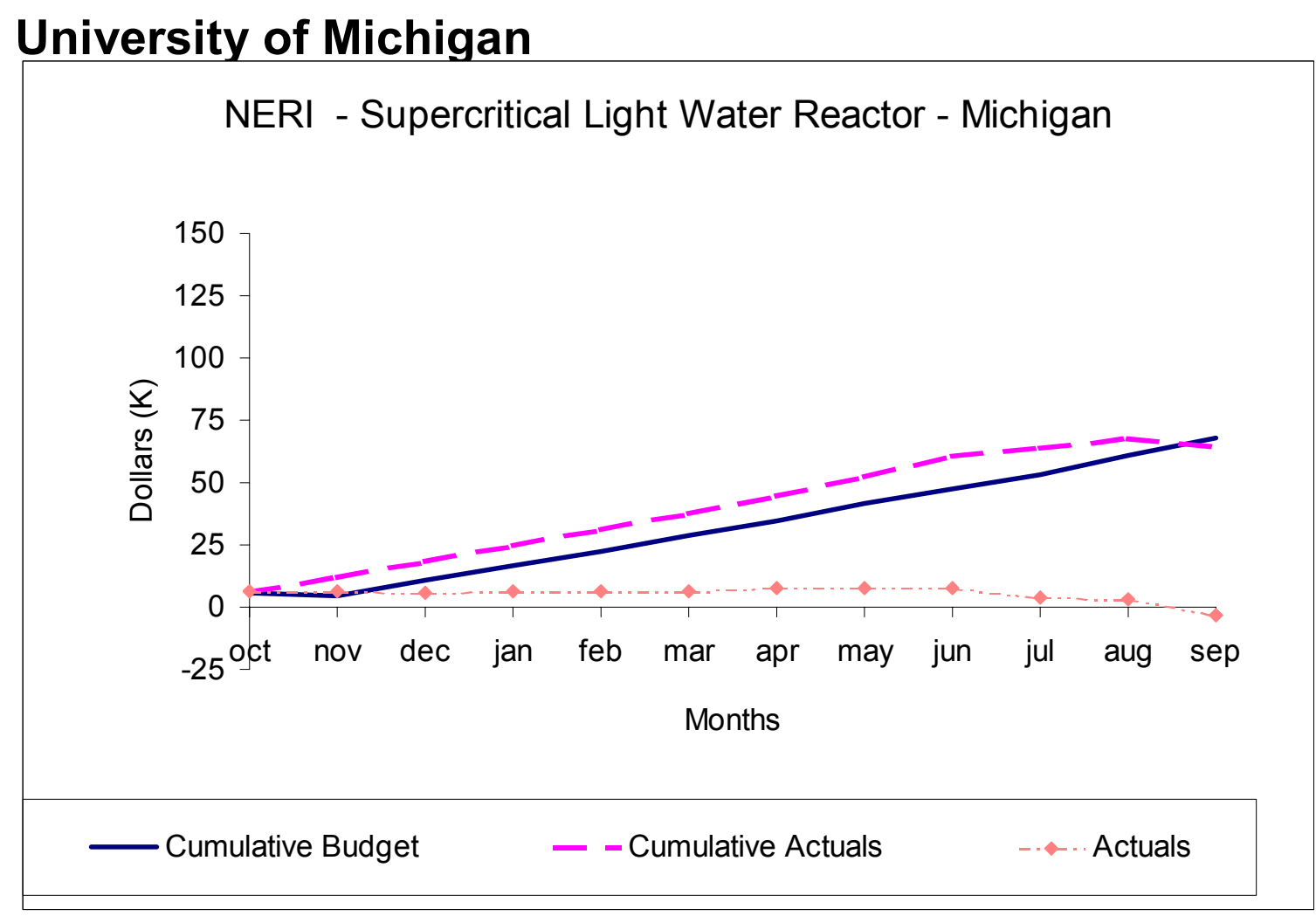

\section{Westinghouse Electric Co.}

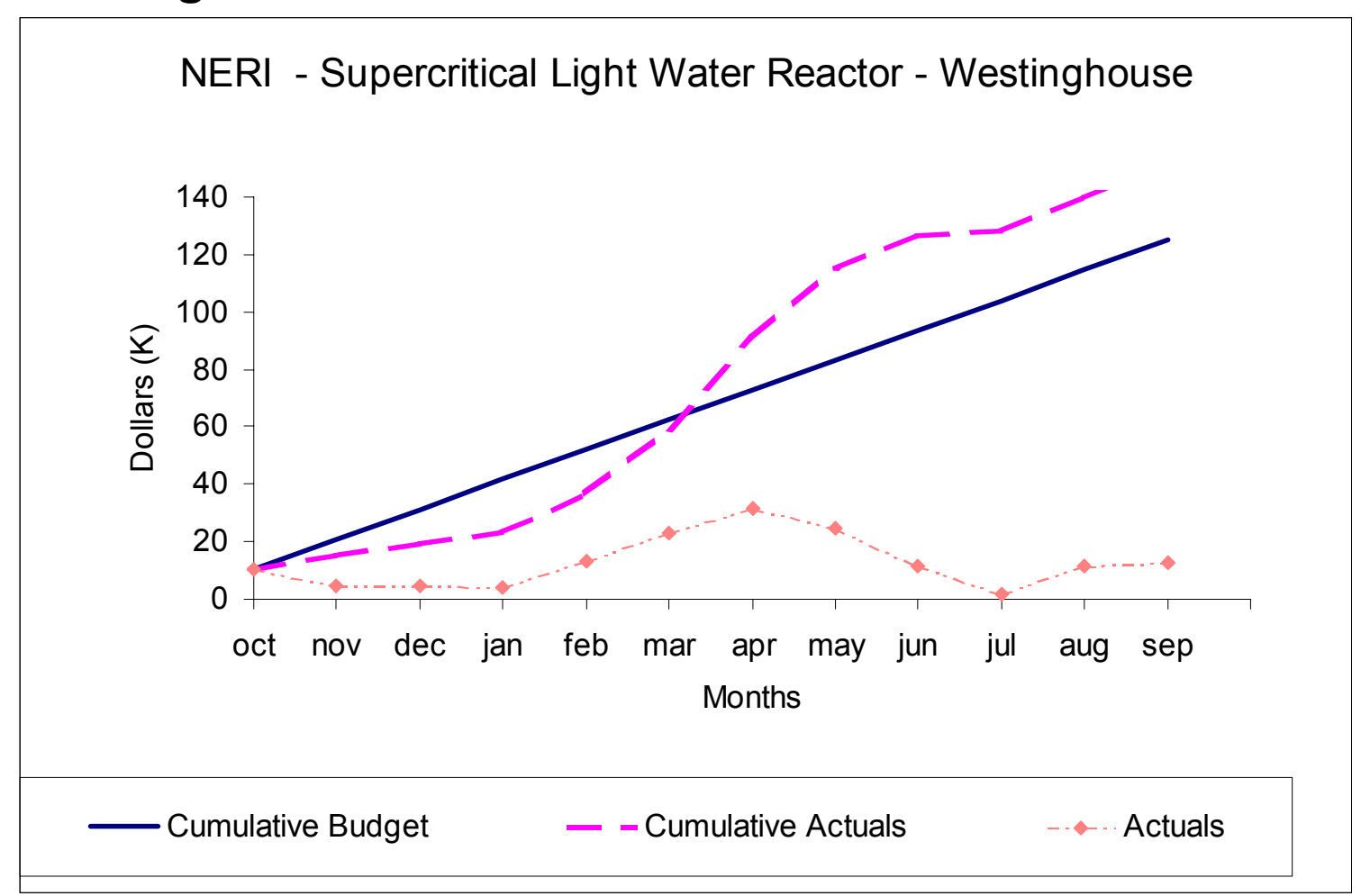




\section{Publications}

S. Teysseyre, J. McKinley, and G. S. Was, D. B. Mitton, H. Kim, J-K Kim and R. M. Latanision, "Corrosion and Stress Corrosion Cracking of Austenitic Alloys in Supercritical Water," Proc. 11 ${ }^{\text {th }}$ Int'l Conf. Environmental Degradation of Materials in Nuclear Power Systems - Water Reactors, American Nuclear Society, La Grange Park, IL, in press.

R. A. Riemke, C. B. Davis, and R. R. Schultz, "RELAP5-3D Code for Supercritical-Pressure, Lightwater-Cooled Reactors," Proceedings of the $11^{\text {th }}$ International Conference on Nuclear Engineering, Tokyo, Japan, April 20-23, ICONE11-36125, 2003.

J. Buongiorno and P. E. MacDonald, "Study of Solid Moderators for the Thermal-Spectrum Supercritical Water-Cooled Reactor (Neutronics)", Proceedings of the $11^{\text {th }}$ International Conference on Nuclear Engineering (ICONE-11), Paper 36571, Tokyo, April 20-23, 2003.

J. Buongiorno and P. E. MacDonald, "Study of Solid Moderators for the Thermal-Spectrum Supercritical Water-Cooled Reactor (Thermo-mechanics and Cost)", Proceedings of the $11^{\text {th }}$ International Conference on Nuclear Engineering (ICONE-11), Paper 36572, Tokyo, April 20-23, 2003.

C. B. Davis, J. Boungiorno, and P. E. MacDonald, "A Parametric Study of the Thermal-Hydraulic Response of Supercritical Light Water Reactors During Loss-of-Feedwater and Turbine-Trip Events," Paper 1009, Proceedings of GENES4/ANP2003, September 15-19, Kyoto, Japan, 2003.

J. McKinley, G. S. Was, D. B. Mitton, H. Kim, J-K Kim and R. M. Latanision, "Corrosion and Stress Corrosion Cracking of Austenitic Alloys in Supercritical Water," Proc. Int'l Conf. Global Environment and Advanced Nuclear Power Reactors, GENES4/ANP2003, Atomic Energy Society of Japan, Tokyo, September 2003.

G. S. Was, "Stress Corrosion Cracking of Austenitic Alloys in Supercritical Water," Workshop on Radiation Effects on Water Chemistry of Supercritical Water-Cooled Reactor, SCR-2003, University of Tokyo, September, 2003.

B. Fischer, M. Przywojski, J. Buongiorno, "Nitrogen-16 Generation, Transport and Associated Shielding Requirements in the Supercritical-Water-Cooled Reactor", submitted to Nuclear Technology, September 2003.

J. Buongiorno, “An Alternative SCWR Design Based on Vertical Power Channels and Hexagonal Fuel Assemblies", Paper 87696, Proceedings of Global 2003, New Orleans, November 16-20, 2003. 


\section{Appendix A - RELAP5 Code Improvements}

The RELAP5 computer code (INEEL 2002) was used in the thermal-hydraulic analysis of several supercritical water reactor (SCWR) designs. The code was originally developed for thermal-hydraulic analysis of light water reactors (LWRs) and related experimental systems during loss-of-coolant accidents and operational transients. The code is being improved to support the analysis of potential Generation IV reactors, including those cooled by lead-bismuth (Davis and Shieh 2000) and supercritical light water (Riemke et al. 2003). Additional correlations have been added to the code for the analysis of supercritical water reactors. These additions include the correlations of Bishop et al. (1964), Koshizuka-Oka (2000), and Jackson (2002) for forced convection heat transfer to supercritical water; the correlation of Jackson (1979) for representing the effects of mixed convection heat transfer; and the correlation of Petrov and Popov (1988) for determining the effect of wall temperature on the friction factor at supercritical conditions.

The code's primary correlation for forced convection heat transfer is based on the correlation of DittusBoelter (1930). The correlation is

$$
\mathrm{Nu}=0.023 \operatorname{Re}^{0.8} \operatorname{Pr}^{0.4}
$$

where $\mathrm{Nu}$ is the Nusselt number, Re is the Reynolds number, and Pr is the Prandtl number. The DittusBoelter correlation is widely used, but was not developed specifically for supercritical applications. As described by Cheng and Schulenberg (2001), the correlation of Bishop et al. (1964) was developed specifically for heat transfer in supercritical water. The Bishop correlation has a similar form to the Dittus-Boelter correlation but accounts for the variation in properties between the wall and the fluid and entrance effects. The correlation is

$$
\mathrm{Nu}_{\mathrm{b}}=0.0069 \mathrm{Re}_{\mathrm{b}}{ }^{0.90} \operatorname{Pr}_{\mathrm{b}}{ }^{0.66}\left(\frac{\rho_{\mathrm{w}}}{\rho_{\mathrm{b}}}\right)^{0.43}\left(1+\frac{2.4 \mathrm{D}_{\mathrm{h}}}{\mathrm{L}}\right)
$$

where $\rho$ is the fluid density, $\mathrm{D}_{\mathrm{h}}$ is the hydraulic diameter, L is the heated length, and the subscripts $\mathrm{b}$ and $\mathrm{w}$ refer conditions in the bulk fluid and at the wall, respectively. The Prandtl number is calculated from a combination of bulk and wall properties

$$
\operatorname{Pr}_{\mathrm{b}}=\overline{\mathrm{C}}_{\mathrm{p}} \frac{\mu_{\mathrm{b}}}{\mathrm{k}_{\mathrm{b}}}
$$

where $\mu$ is the viscosity, $\mathrm{k}$ is the thermal conductivity, and the specific heat capacity at constant pressure, $\overline{\mathrm{C}}_{\mathrm{p}}$, represents an average value that is calculated from the difference in enthalpy, $\mathrm{h}$, and temperature, $\mathrm{T}$, of the wall and the bulk

$$
\overline{C_{p}}=\frac{h_{w}-h_{b}}{T_{w}-T_{b}}
$$

According to Cheng and Schulenberg (2001), the Bishop correlation applies for pressure between 22.6 and $27.5 \mathrm{MPa}$, mass flux between 680 and $3600 \mathrm{~kg} / \mathrm{s}-\mathrm{m}^{2}$, heat flux between 310 and $3500 \mathrm{~kW} / \mathrm{m}^{2}$, 
hydraulic diameter between 2.5 and $5.1 \mathrm{~mm}$, length-to-diameter ratio between 30 and 565, bulk fluid temperature between 294 and $525{ }^{\circ} \mathrm{C}$, and temperature difference between the wall and the bulk fluid between 16 and $216{ }^{\circ} \mathrm{C}$.

Figures A1 and A2 present a comparison of the Bishop heat transfer coefficient as calculated by RELAP5 with those presented in a previous quarterly report (MacDonald et al. 2002a). Figures A1 and A2 represent cases with and without deterioration in the heat flux. In both cases, the results calculated by RELAP5 are within a few percent of those presented previously.

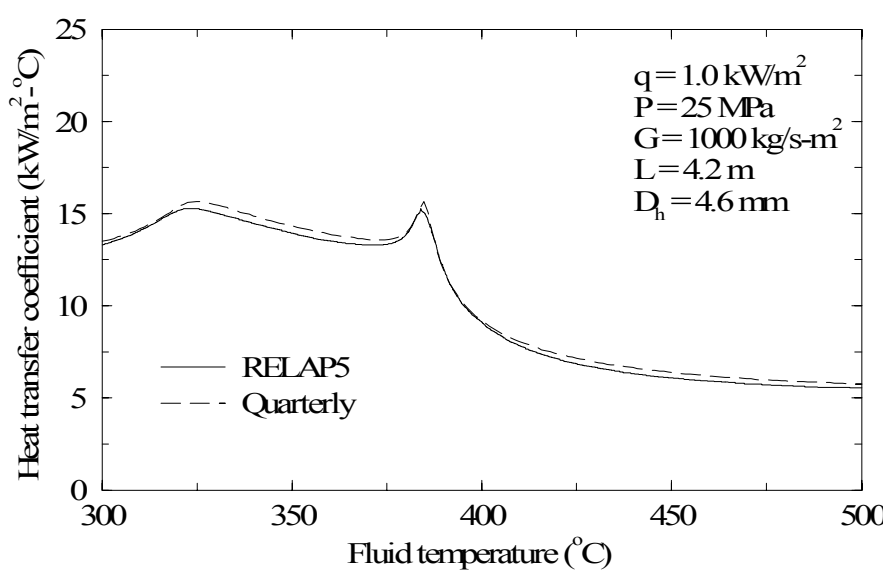

Figure A1. Heat transfer coefficients from the Bishop correlation at supercritical conditions with deterioration in the heat flux.

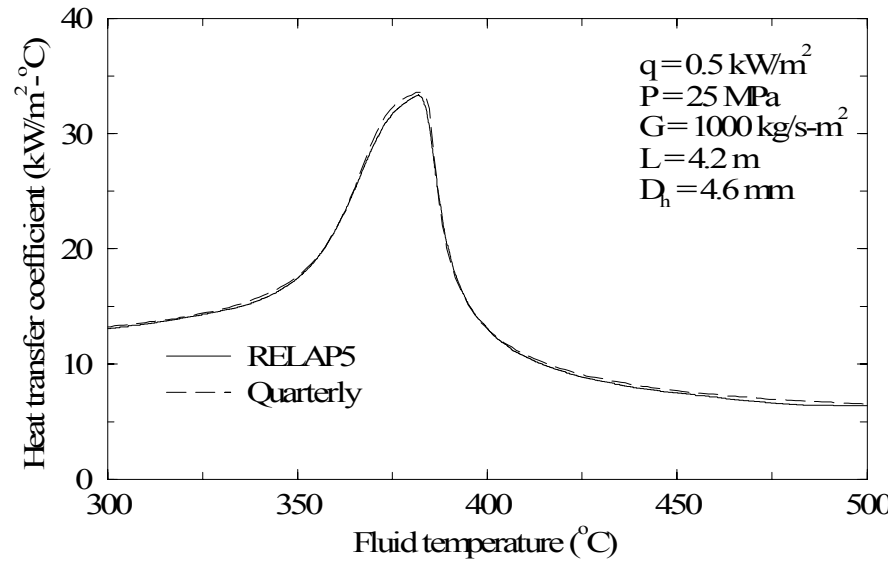

Figure A2. Heat transfer coefficients from the Bishop correlation at supercritical conditions without deterioration in the heat flux.

The correlation of Koshizuka and Oka (2000) was based on numerical analysis of heat transfer to supercritical water in a $10-\mathrm{mm}$ diameter pipe. The correlation is

$$
\begin{aligned}
& \mathrm{Nu}=0.015 \cdot \mathrm{Re}^{0.85} \cdot \mathrm{Pr}^{\mathrm{C}} \\
& \mathrm{C}=0.69-\frac{81000}{\mathrm{q}_{\text {det }}^{\prime \prime}}+\mathrm{f}_{\mathrm{c}} \cdot \mathrm{q}^{\prime \prime} \\
& \mathrm{f}_{\mathrm{c}}= \begin{cases}2.9 \cdot 10^{-8}+\frac{0.11}{\mathrm{q}_{\text {det }}^{\prime \prime}} & 0 \leq \mathrm{h} \leq 1500 \mathrm{~kJ} / \mathrm{kg} \\
-8.7 \cdot 10^{-8}-\frac{0.65}{\mathrm{q}_{\text {det }}^{\prime \prime}} & 1500 \mathrm{~kJ} / \mathrm{kg} \leq \mathrm{h} \leq 3300 \mathrm{~kJ} / \mathrm{kg} \\
-9.7 \cdot 10^{-7}+\frac{1.30}{\mathrm{q}_{\text {det }}^{\prime \prime}} & 3300 \mathrm{~kJ} / \mathrm{kg} \leq \mathrm{h} \leq 4000 \mathrm{~kJ} / \mathrm{kg}\end{cases}
\end{aligned}
$$

where $\mathrm{q}^{\prime \prime}$ is the heat flux in $\mathrm{W} / \mathrm{m}^{2}$ and $\mathrm{q}_{\text {det }}^{\prime \prime}$ is the deterioration heat flux based on the correlation of Yamagata et al. (1972)

$$
\mathrm{q}_{\text {det }}^{\prime \prime}=200 \mathrm{G}^{1.2}
$$

where $\mathrm{G}$ is the mass flux in $\mathrm{kg} / \mathrm{s}-\mathrm{m}^{2}$. The correlation applies for mass flux between 1000 and $1750 \mathrm{~kg} / \mathrm{s}-$ $\mathrm{m}^{2}$, enthalpy between 0.1 and $3300 \mathrm{~kJ} / \mathrm{kg}$, and heat flux between 0 and $1800 \mathrm{~kW} / \mathrm{m}^{2}$. 
Figures A3 and A4 present a comparison of the heat transfer coefficient from the Koshizuka-Oka correlation as calculated by RELAP5 with those presented in a previous quarterly report (MacDonald et al. 2002a). The figures represent cases with and without deterioration in the heat flux and are consistent with those shown previously. The results calculated by RELAP5 agree closely with those presented previously.

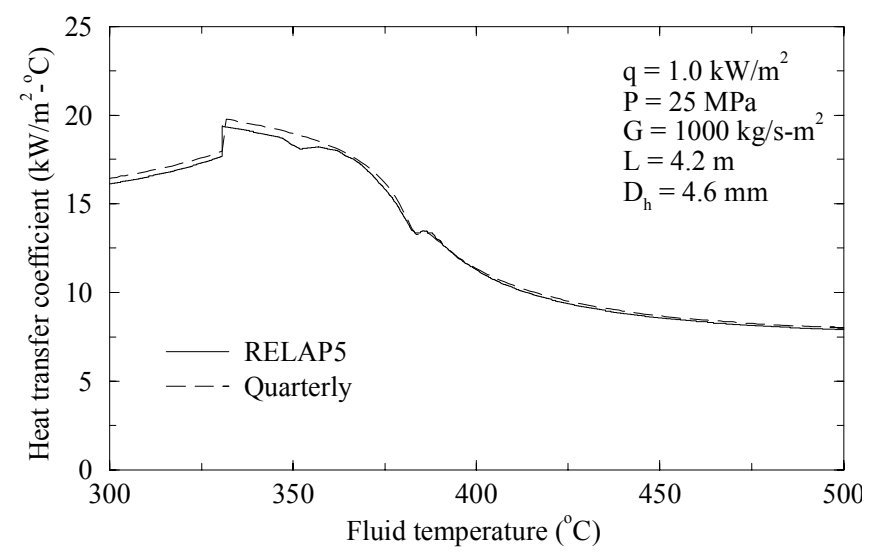

Figure A3. Heat transfer coefficients from the Koshizuka-Oka correlation at supercritical conditions with deterioration in the heat flux.

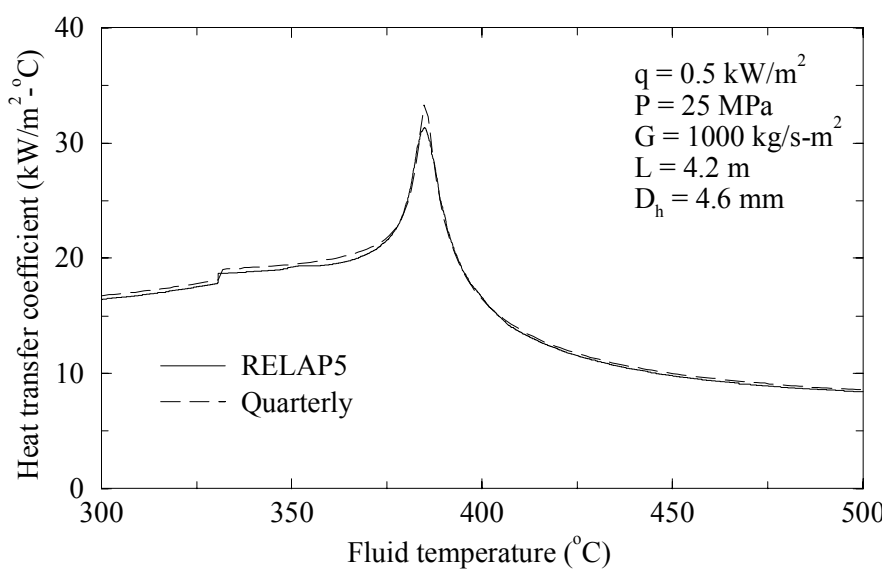

Figure A4. Heat transfer coefficients from the Koshizuka-Oka correlation at supercritical conditions without deterioration in the heat flux.

The correlation of Jackson (2002) was developed for forced convection heat transfer from tubes to supercritical water and supercritical carbon dioxide. The correlation is

$$
\mathrm{Nu}_{\mathrm{b}}=0.0183 \operatorname{Re}_{\mathrm{b}}^{0.82} \operatorname{Pr}_{\mathrm{b}}^{0.5}\left(\frac{\rho_{\mathrm{w}}}{\rho_{\mathrm{b}}}\right)^{0.3}\left(\frac{\overline{\mathrm{C}}_{\mathrm{p}}}{\mathrm{C}_{\mathrm{pb}}}\right)^{\mathrm{n}}
$$

where $\overline{\mathrm{C}}_{\mathrm{p}}$ is defined in Equation (A4) and the exponent $\mathrm{n}$ is defined as

$$
\mathrm{n}=\left\{\begin{array}{l}
0.4 \text { for } \mathrm{T}_{\mathrm{b}}<\mathrm{T}_{\mathrm{w}}<\mathrm{T}_{\mathrm{pc}} \\
0.4+0.2\left(\left(\mathrm{~T}_{\mathrm{w}} / \mathrm{T}_{\mathrm{pc}}\right)-1\right) \text { for } \mathrm{T}_{\mathrm{b}}<\mathrm{T}_{\mathrm{pc}}<\mathrm{T}_{\mathrm{w}} \\
0.4+0.2\left(\left(\mathrm{~T}_{\mathrm{w}} / \mathrm{T}_{\mathrm{pc}}\right)-1\right)\left(1-5\left(\left(\mathrm{~T}_{\mathrm{b}} / \mathrm{T}_{\mathrm{pc}}\right)-1\right) \text { for } \mathrm{T}_{\mathrm{pc}}<\mathrm{T}_{\mathrm{b}}<1.2 \mathrm{~T}_{\mathrm{pc}} \text { and } \mathrm{T}_{\mathrm{b}}<\mathrm{T}_{\mathrm{w}}\right. \\
0.4 \text { for } 1.2 \mathrm{~T}_{\mathrm{pc}}<\mathrm{T}_{\mathrm{b}}<\mathrm{T}_{\mathrm{w}}
\end{array}\right.
$$

where $T_{p c}$ is the pseudocritical temperature. The pseudocritical temperature is defined as the temperature at which the specific heat capacity at constant pressure is maximized. RELAP5 obtains the pseudocritical temperature of water from the correlation of Howell and Lee (1999)

$$
\mathrm{T}_{\mathrm{pc}}=547.27+114.97 \mathrm{P}_{\mathrm{r}}-15.216 \mathrm{P}_{\mathrm{r}}^{2}
$$

where $T_{p c}$ is in degrees $K$ and $P_{r}$ is the reduced pressure, which is calculated as 


$$
\mathrm{P}_{\mathrm{r}}=\frac{\mathrm{P}}{\mathrm{P}_{\text {crit }}}
$$

where $\mathrm{P}$ is the pressure and $\mathrm{P}_{\text {crit }}$ is the critical pressure. The Jackson correlation was based on the correlation of Krasnoschekov and Protopopov (1966), which according to Cheng and Schulenberg (2001) has been verified in water for pressure between 22.5 and $26.5 \mathrm{MPa}$, mass flux between 700 and 3600 $\mathrm{kg} / \mathrm{s}-\mathrm{m}^{2}$, and hydraulic diameter between 1.6 and $20 \mathrm{~mm}$. The implementation of the Jackson correlation into RELAP5 was verified by comparing the results of hand calculations with those from the code.

RELAP5 normally calculates the heat transfer coefficient as the maximum of the forced convection, natural convection, and laminar correlations. Selecting the maximum of the forced and natural convection correlations is a simple attempt to represent the effects of mixed convection at low flow rates. A more mechanistic model was implemented into the code for analysis of supercritical water reactors because of the potential importance of mixed convection heat transfer in designs utilizing water rods. The mixed convection model was based on the semi-empirical correlation of Jackson (1979) as described by Wu et al. (2002) for a tube

$$
\frac{\mathrm{Nu}}{\mathrm{Nu}_{\mathrm{f}}}=\left[\left|1 \pm 2.5 \times 10^{5} \mathrm{Bo}\left(\frac{\mathrm{Nu}}{\mathrm{Nu}_{\mathrm{f}}}\right)\right|^{-2}\right]^{0.46}
$$

where $\mathrm{Nu}$ is the actual Nusselt number, $\mathrm{Nu}_{\mathrm{f}}$ is the Nusselt number due to forced convection, and $\mathrm{Bo}$ is the buoyancy number. The buoyancy number is calculated as

$$
\mathrm{Bo}=\frac{\mathrm{Gr}^{*}}{\operatorname{Re}^{3.425} \operatorname{Pr}^{0.8}}
$$

where the Grashoff number, Gr*, is

$$
\mathrm{Gr}^{*}=\frac{\beta \mathrm{gD}_{\mathrm{h}}{ }^{4} \mathrm{q}_{\mathrm{w}}^{\prime \prime} \rho^{2}}{\mathrm{k} \mu^{2}}
$$

where $\beta$ is the coefficient of volumetric expansion, $\mathrm{g}$ is the acceleration due to gravity, and the other parameters were defined previously. The plus sign in Equation (A11) applies to the buoyancy-opposed (downward flow) case while the minus sign applies to the buoyancy-aided (upward flow) case. The solutions of Equation (A11) are shown in Figure A5 as a function of the buoyancy number. For Bo $<10^{-7}$, buoyancy effects are negligible and the Nusselt number is essentially determined by forced convection. For downward flow, the heat transfer is enhanced as Bo increases. At Bo $=10^{-4}$, the Nusselt number is more than two times that from forced convection. For upward flow, the heat transfer is initially impaired until reaching a minimum of 0.47 times the forced convection value at $\mathrm{Bo}=1.05 \times 10^{-6}$. Further increases in Bo result in enhanced heat transfer until values for both flow directions are similar at Bo $=10^{-4}$. In the RELAP5 model, the results for the upward flow case are linearly interpolated for $1.0 \times 10^{-6}<$ Bo $<$ $1.10 \times 10^{-6}$ to smooth the results and eliminate a discontinuity obtained from the exact solution to Equation (11). This discontinuity is caused by a change in the number of roots of Equation (A11) from three to one near $\mathrm{Bo}=1.05 \times 10^{-6}$. 


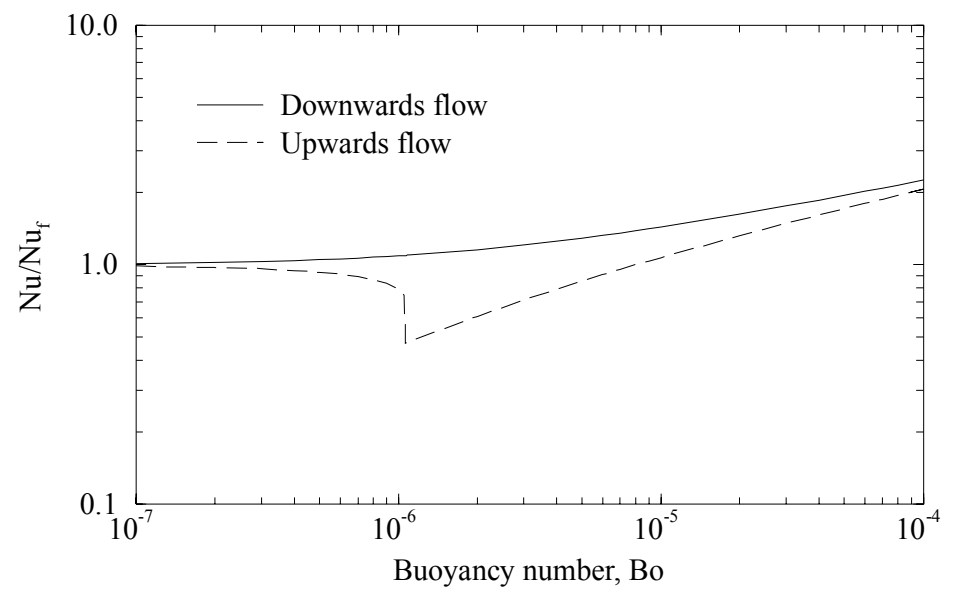

Figure A5. The semi-empirical model of Jackson (1979) for mixed convection in a heated tube.

Petrov and Popov (1988) present a correlation for the effect of the heated wall on the friction factor at supercritical conditions in water. The heated friction factor, $\mathrm{f}$, is calculated as

$\mathrm{f}=\mathrm{f}_{0}\left(\frac{\rho_{\mathrm{w}}}{\rho_{\mathrm{b}}}\right)^{0.4}=\left[1.82 \log _{10}(\mathrm{Re} / 8)\right]^{-2.0}\left(\frac{\rho_{\mathrm{w}}}{\rho_{\mathrm{b}}}\right)^{0.4}$

where $\mathrm{f}_{0}$ is the unheated friction factor. Figure A6 shows that the unheated friction factor, $\mathrm{f}_{0}$, presented above agrees closely with the Zigrang-Sylvester (1985) correlation used by RELAP5 for smooth tubes. The maximum deviation between correlations is about 5\% and occurs at low Reynolds numbers. At a Reynolds number of $5 \times 10^{4}$, which is representative of the SCWR core during normal operation, the difference between correlations is imperceptible. The Zigrang-Sylvester correlation accounts for surface roughness while the correlation for $\mathrm{f}_{0}$ does not. Consequently, the effect of the heated wall is simulated in RELAP5 using the density ratio term from Petrov and Popov and the Zigrang-Sylvester correlation. The user can select whether or not the heated wall effect is to be calculated and the value of the exponent on the density ratio term.

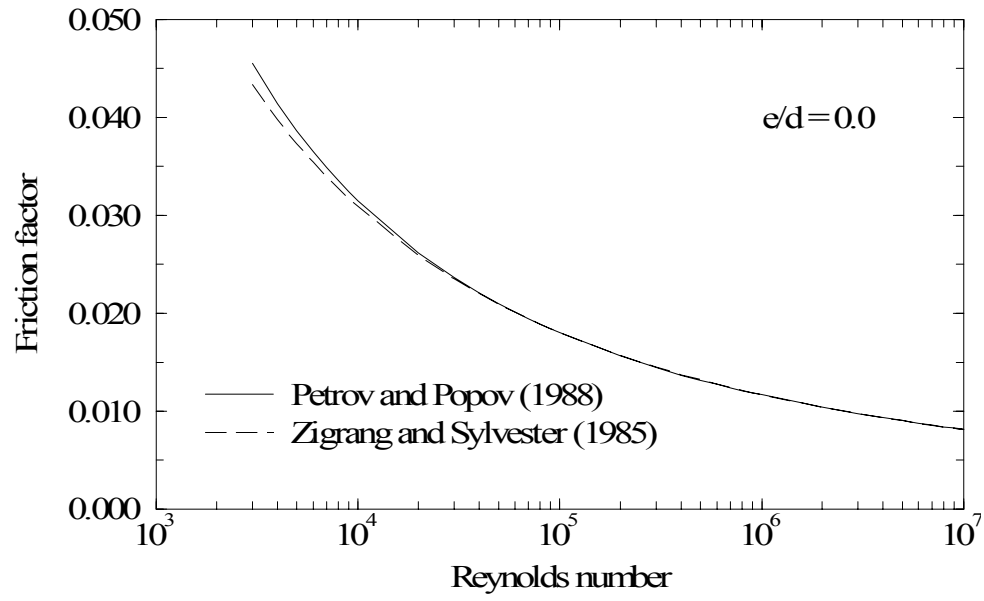

Figure A6. Unheated friction factors from the Petrov and Popov (1988) and Zigrang-Sylvester (1985) correlations. 


\title{
Feasibility Study of Supercritical Light Water Cooled Reactors for Electric Power Production
}

Nuclear Energy Research Initiative Project 2001001, Westinghouse Electric Co. Award Number: DE-FG07-02SF22533

\section{Progress Report for Work Through September 2003}

\author{
$2^{\text {nd }}$ Annual Report \\ $8^{\text {th }}$ Quarterly Report
}

Principal Investigators:

Philip MacDonald, Dr. Jacopo Buongiorno, Cliff Davis, and Prof. Robert Witt

Telephone: 208-526-9634

Fax: 208-526-2930

Email: pem@inel.gov

Collaborating Organizations:

Massachusetts Institute of Technology

Principal Investigators: Prof. Ron Latanision and Dr. Bryce Mitton

University of Michigan

Principal Investigator: Prof. Gary Was, J. McKinley, and S. Teysseyre

Westinghouse Electric Company

Principal Investigators: Dr. Luca Oriani, Dr. Vefa Kucukboyaci, Hans Garkish, Lawrence Conway, and John Kielb 